\title{
Strukturelle Untersuchungen zum Velvet-Komplex aus Aspergillus nidulans
}

\author{
Dissertation \\ zur Erlangung des mathematisch-naturwissenschaftlichen Doktorgrades \\ "Doctor rerum naturalium" \\ an der Georg-August-Universität Göttingen
}

vorgelegt von

Yasar Luqman Ahmed

aus Rabwah, Pakistan

Göttingen 2012 

Mitglieder des Betreuungsausschusses:

Referent: Prof. Dr. Ralf Ficner Georg-August-Universität Göttingen Institut für Mikrobiologie und Genetik Abteilung für Molekulare Strukturbiologie

Korreferent: Prof. Dr. Gerhard Braus Georg-August-Universität Göttingen Institut für Mikrobiologie und Genetik

Abteilung für Molekulare Mikrobiologie und Genetik

Tag der mündlichen Prüfung: 
Er ist es. Der euch aus Erde erschuf, dann aus einem Samentropfen, dann aus einem Blutklumpen; dann lässt Er euch als ein Kindlein hervorgehen; dann (lässt Er euch wachsen) auf dass ihr eure Vollkraft erreichet; dann (lässt Er) euch alt werdenwenngleich einige unter euch vorher zum Sterben berufen werden -, und (Er lässt euch leben) damit ihr eine bestimmte Frist erreichet und damit ihr Weisheit lernet.

Der Heilige Koran (Sure 40, Vers 68) 


\section{Vorwort}

Die vorliegende Arbeit ist eine Zusammenfassung meiner Arbeit am VelvetKomplex, angefertigt in der Abteilung für Molekulare Strukturbiologie unter der Anleitung von Herrn Prof. Dr. Ralf Ficner im Zeitraum von 2008-2011. Teile dieser Arbeit sind bereits veröffentlicht worden, bzw. sind im Prozess der Veröffentlichung.

\section{Publikationen}

Yasar Luqman Ahmed ${ }^{1}$, Jennifer Gerke ${ }^{2}$, Özgür Bayram ${ }^{2}$, Piotr Neumann ${ }^{1}$, Hee Soo Park ${ }^{3}$, Min $\mathrm{Ni}^{3}$, Achim Dickmanns ${ }^{1}$, Sun Chang Kim ${ }^{4}$, Jae-Hyuk Yu ${ }^{3}$, Gerhard H. Braus ${ }^{2}$, Ralf Ficner ${ }^{1}$. Fungal Velvet domain proteins and mammalian NFkB share a similar DNA binding domain.

(Manuskript in Vorbereitung)

Özgür Bayram², Özlem Sarikaya Bayram², Yasar Luqman Ahmed ${ }^{1}$, Jun-ichi Maruyama $^{2,5}$, Oliver Valerius ${ }^{2}$, Ralf Ficner ${ }^{1}$, Stefan Irniger ${ }^{2}$, Gerhard H. Braus ${ }^{2}$. Shuttling of entire MAPK module from membrane to nuclear envelope links fungal development to secondary metabolism.

(Eingereicht zur Publikation)

\section{Tagungsbeiträge}

Yasar Luqman Ahmed ${ }^{1}$, Piotr Neumann¹, Özgür Bayram², Jennifer Gerke², Gerhard H. Braus ${ }^{2}$, Ralf Ficner ${ }^{1}$. Crystal structures of Velvet transcription factors reveal an unexpected fold.

DGK-Meeting, September 2011, Salzburg/Österreich

\footnotetext{
${ }^{1}$ Abteilung für Molekulare Strukturbiologie, Institut für Mikrobiologie und Genetik, Georg-August Universität Göttingen, Deutschland

${ }^{2}$ Abteilung für Molekulare Mikrobiologie und Genetik, Institut für Mikrobiologie und Genetik, Georg-August Universität Göttingen, Deutschland

${ }^{3}$ Departments of Bacteriology and Genetics, University of Wisconsin-Madison, Madison, Wisconsin, USA

${ }^{4}$ Department of Biological Sciences, Korea Advanced Institute of Science and Technology, Dae-Jon, Republic of Korea

${ }^{5}$ Aktuelle Adresse; Department of Biotechnology, The University of Tokyo, Tokyo, Japan
} 



\section{Inhaltsverzeichnis}

1 Einleitung 1

1.1 Pilze . . . . . . . . . . . . . . . . . . 1

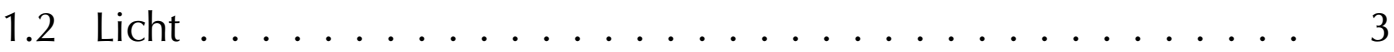

1.2.1 Phycomyces blakesleeanus ............... 3

1.2.2 Neurospora crassa . . . . . . . . . . . . . . . . 4

1.2.3 Lichtwahrnehmung in Pilzen . . . . . . . . . . 5

1.2.4 Warum machen Pilze ihre Entwicklung von Licht abhängig? . 6

1.3 Aspergillus nidulans . . . . . . . . . . . . . . . 7

1.3.1 Entwicklung von Aspergillus nidulans . . . . . . . . . . . . . 7

1.3.1.1 Asexuelle Fortpflanzung . . . . . . . . . . . . . 9

1.3.1.2 Sexuelle Entwicklung . . . . . . . . . . . . 9 9

1.3.2 Sekundärmetabolismus .............. . 10

1.4 Der Velvet-Komplex . . . . . . . . . . . . . . . . . . 11

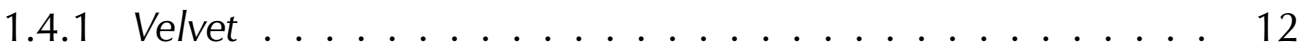

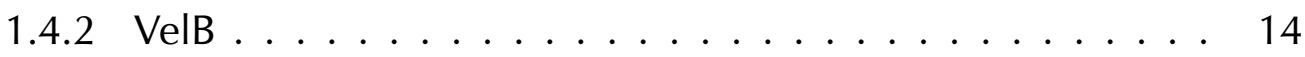

1.4.3 LaeA - eine putative Methyltransferase . . . . . . . . . 16

1.4.4 Velvet-ähnliche Komplexe in anderen Organismen . . . . . . 18

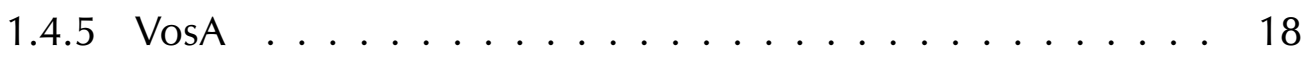

1.5 Ziel dieser Arbeit . . . . . . . . . . . . . . . . . . . 19

2 Ergebnisse 21

2.1 LaeA . . . . . . . . . . . . . . . . . . . . . . 21

2.1 .1 Volllängen-LaeA . . . . . . . . . . . . . . . . 21

2.1.2 GST-LaeA91 und GST-LaeA101 . . . . . . . . . . . . . 24

2.1.2.1 Präparation von LaeA91 und LaeA101 . . . . . . 24

2.1.2.2 Kristallisation von LaeA91 und LaeA101 . . . . . 25

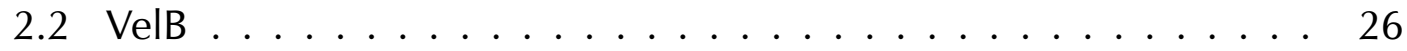

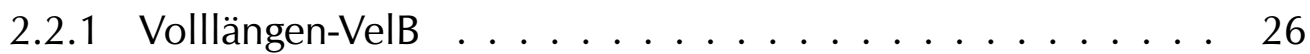

2.2.1.1 Präparation von Volllängen-VelB . . . . . . . . . 26

2.2.1.2 Kristallisation von Volllängen-VelB . . . . . . . . 29

2.2 .2 VelB-mini . . . . . . . . . . . . . . . 30

2.2.2.1 Präparation von VelB-mini . . . . . . . 30 
INHALTSVERZEICHNIS

2.2.2.2 Kristallisation von VelB-mini . . . . . . . . 31

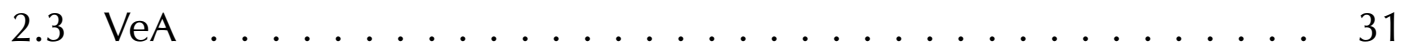

2.3.1 Präparation von VeA224S . . . . . . . . . . . . . 31

2.3.2 Kristallisation von VeA224S . . . . . . . . . . . . . . . 32

2.3.3 Datensammlung von VeA224S . . . . . . . . . . . 32

2.3.4 Strukturbestimmung von VeA224S . . . . . . . . . . . . . 33

2.4 Importin $\alpha \Delta$ IBB-VeA-Komplex . . . . . . . . . . . . . . . . . . . . . . . . . . 33

2.5 LaeA-VeA-VelB-Komplex . . . . . . . . . . . . . . . 35

2.5.1 Rekonstituierung des LaeA-VeA-VelB-Komplex . . . . . . . 35

2.5.2 Kristallisation des LaeA-VeA-VelB-Komplex . . . . . . . . . 38

2.6 VeA-VelB-Komplex . . . . . . . . . . . . . . . . . . . 38

2.6.1 Volllängen-VeA-VelB-Komplex ............. . . 38

2.6.1.1 Rekonstituierung des VeA-VelB-Komplexes . . . . . 38

2.6.1.2 Kristallisation des VeA-VelB-Komplex . . . . . . . 40

2.6.2 Minimal VeA-VelB-Komplex . . . . . . . . . . . . . . . 40

2.6.2.1 Präparation des minimalen VeA-VelB-Komplex . . . 40

2.6.2.2 Kristallisation des minimalen VeA/VelB-Komplex . . 41

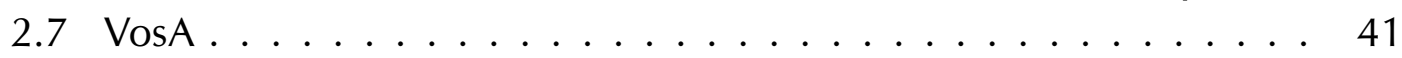

2.7.1 Präparation von VosA190S . . . . . . . . . . . . 42

2.7.2 Kristallisation von VosA190S . . . . . . . . . . . . 43

2.7.3 Strukturbestimmung von VosA190S . . . . . . . . . . . . . . . . . 44

2.7.4 Struktur von VosA190S . . . . . . . . . . . . . . 48

2.7.5 Strukturvergleich von VosA190S und NFkB-p50 . . . . . . . 51

2.7.6 Essentielle Reste für die DNA-Bindung in VosA190S . . . . . 54

2.7.7 Bindungsstudien zu den VosA190S-Mutanten mit VelB-mini . 54

2.7.8 DNA-Bindung der VosA190S-Mutanten . . . . . . . . . . . 55

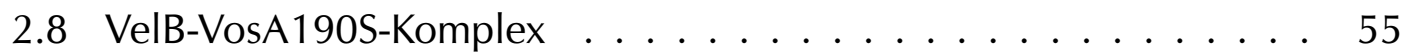

2.8.1 Präparation des VelB-VosA190S-Komplex . . . . . . . . . . 55

2.8.2 Kristallisation des VelB-VosA190S-Komplex . . . . . . . . . . 57

2.8.3 Strukturbestimmung des VelB-VosA190S-Komplex . . . . . . 58

2.8.4 Struktur des VelB-VosA190S-Komplex . . . . . . . . . . . . . 60

2.8.5 Strukturvergleich mit NFKB-p50 . . . . . . . . . . . 65

2.8.6 Minimal-VosA-VelB-Komplex . . . . . . . . . . . 66

2.8.6.1 Präparation des minimal-VelB-VosA190S-Komplex . 66

2.8.6.2 Kristallisation des minimal-VosA-VelB-Komplex . . 67

3 Diskussion $\quad 69$

3.1 LaeA . . . . . . . . . . . . . . . . . . . . . . . . 69

3.2 LaeA-VeA-VelB-Komplex . . . . . . . . . . . . . . . 71

3.3 Velvet-Proteine . . . . . . . . . . . . . . . . . 72

3.3 .1 VeA ........................ 72

3.3 .2 VeA-VelB-Komplex ................ 72 
3.3.3 Velvet-Proteine interagieren mit DNA . . . . . . . . 73

3.3 .4 VosA190s ....................... 73

3.3.5 VelB-VosA190S-Komplex . . . . . . . . . . . . 75

3.3.6 VelB - eine Ausnahme? . . . . . . . . . . . . . 76

3.3.7 Vergleich Velvet- und NFkB-Proteine . . . . . . . . . . 77

3.3.8 Ursprung der Velvet-Proteine . . . . . . . . . . . 79

4 Zusammenfassung $\quad 83$

5 Summary $\quad 85$

6 Material und Methoden 87

6.1 Material ...................... 87

6.1.1 Chromatographiesysteme, -säulen und Zubehör . . . . . . . . . 87

6.1.2 Computerprogramme und Datenbanken . . . . . . . . . . . 87

6.1 .3 DNA-Oligonukleotide . . . . . . . . . . . . 88

6.1 .4 Feinchemikalien . . . . . . . . . . . . . . . 88

6.1.5 Größenstandards für DNA und Proteine . . . . . . . . . . . . . 88

6.1 .6 Geräte . . . . . . . . . . . . . . . . . . . 89

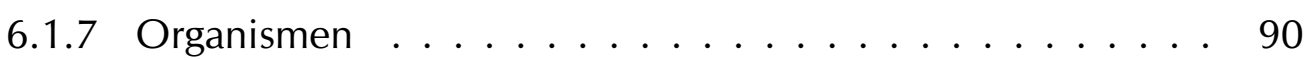

6.1 .8 Plasmide . . . . . . . . . . . . . . . . . . . . . . . . . . . . 90

6.1 .9 Proteasen und Inhibitoren . . . . . . . . . . . . . . 90

6.1.10 Sammlungen von Kristallisationslösungen . . . . . . . . . . . 90

6.1.10.1 Lösungen im $8 \times 12$-Format . . . . . . . . . . 90

6.1.10.2 Lösungen im $4 \times 6$-Format . . . . . . . . . . . 92

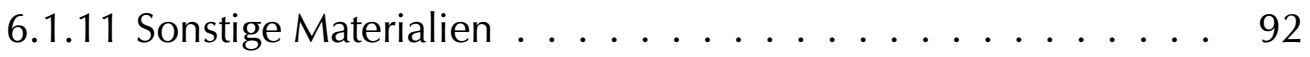

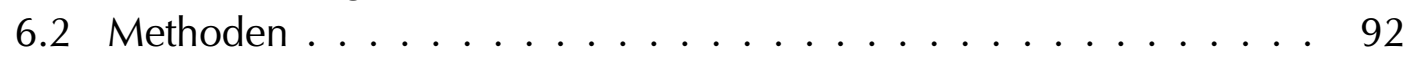

6.2.1 Molekularbiologische Methoden . . . . . . . . . . . . 92

6.2.1.1 Polymerase-Kettenreaktion . . . . . . . . . . 92

6.2.1.2 Konzentrationsbestimmung von DNA mit einen Photometer.................. 93

6.2.1.3 Trennung von DNA-Fragmenten durch Agarosegelelektrophorese . . . . . . . . . . . . 94

6.2.1.4 Gelretardation . . . . . . . . . . . . . . 94

6.2.1.5 Visualisierung von Nukleinsäuren mit Ethidiumbromid oder GelRed . . . . . . . . . . . . . . . . . . 95

6.2.2 Mikrobiologische Methoden . . . . . . . . . . . . 95

6.2.2.1 Herstellung von Flüssig- und Festmedien . . . . . . 95

6.2.2.2 Herstellung chemisch kompetenter Escherichia coliZellen . . . . . . . . . . . . 97

6.2.2.3 Transformation chemisch kompetenter E. coli-Zellen 97

6.2.2.4 Herstellung von Glyzerin-Dauerkulturen . . . . . . 98

6.2.2.5 Präparation von Plasmid-DNA . . . . . . . . . . 98

6.2.2.6 Expression rekombinanter Proteine in E. coli . . . . 98 
INHALTSVERZEICHNIS

6.2.2.7 Zellernte und Aufschluss . . . . . . . . . . . 100

6.2.3 Proteinbiochemische Methoden . . . . . . . . . . . . . 100

6.2.3.1 Konzentrationsbestimmung von Proteinlösungen . . 100

6.2.3.2 SDS-Polyacrylamidgelelektrophorese . . . . . . . 100

6.2.3.3 Einengen von Proteinlösung durch Zentrifugation . 101

6.2.3.4 Spaltung von Proteinen durch Proteasen . . . . . . 102

6.2.3.5 Nachweis von Protein-Protein-Interaktionen . . . . 102

6.2.4 Chromatographische Methoden . . . . . . . . . . . . 102

6.2.4.1 Präparation von GST-Fusionsproteinen . . . . . . 103

6.2.4.2 Präparation von $\mathrm{His}_{6}$-Fusionsproteinen . . . . . . 103

6.2.4.3 Präparation von MBP-Fusionsproteinen . . . . . . . 103

6.2.4.4 Präparation von Strep II-markierten Proteinen . . . . 103

6.2.4.5 Größenausschlusschromatographie . . . . . . . . 104

6.2.4.6 Umpuffern von Proteinlösungen . . . . . . . . . . 104

6.2.5 Expressions- und Reinigungsprotokolle . . . . . . . . . . . . 104

6.2.5.1 MBP-LaeA . . . . . . . . . . . . . . . . . . . . . . . 104

6.2.5.2 GST-LaeA91 und $-101 \ldots . . \ldots 104$

6.2 .5 .3 VelB . . . . . . . . . . . . . . 105

6.2.5.4 VelB-mini . . . . . . . . . . . . 105

6.2.5.5 VeA224S ................... 105

6.2.5.6 Importin $\alpha \Delta$ IBB-VeA-Komplex $\ldots \ldots \ldots \ldots . . \ldots 105$

6.2.5.7 LaeA-VeA-VelB-Komplex . . . . . . . . . . . . . . . 106

6.2.5.8 VeA-VelB-Komplex . . . . . . . . . . . . . . 106

6.2.5.9 VeA224S-VelB-mini-Komplex . . . . . . . . . 106

6.2 .5 .10 VosA190S . . . . . . . . . . . . . . . . 107

6.2 .5 .11 VosA $190 \mathrm{H} \ldots \ldots \ldots$. . . . . . . . . . . 107

6.2.5.12 VelB-VosA190S-Komplex . . . . . . . . . . . . 107

6.2.5.13 VelB-mini-VosA190S-Komplex . . . . . . . . . . 107

6.2.6 Kristallographische Methoden . . . . . . . . . . . . . 108

6.2.6.1 Hochdurchsatzkristallisation . . . . . . . . . . . 108

6.2.6.2 Optimierung von Kristallen . . . . . . . . . . . . . . 108

6.2.6.3 Kryo-Kristallographie . . . . . . . . . . . . . . . 108

6.2.6.4 Datensammlung . . . . . . . . . . . . . . . 109

6.2.6.5 Phasenbestimmung und Berechnung der Elektronen-

dichtekarte . . . . . . . . . . . . . 109

6.2.6.6 Modellbau und Verfeinerung . . . . . . . . . . . . 110

6.2.6.7 Strukturaufklärung von VosA190S . . . . . . . . 111

6.2.6.8 Strukturaufklärung des VelB-VosA-Komplex . . . . . 111

6.2.6.9 Visualisierung und Oberflächenberechnungen . . . 111

$\begin{array}{ll}\text { Literaturverzeichnis } & 113\end{array}$

$\begin{array}{ll}\text { A Abkürzungsverzeichnis } & 125\end{array}$ 
KAPITEL 1

\section{Einleitung}

\subsection{Pilze}

Mit einer konservativ geschätzten Mitgliederzahl von 1,5 Millionen (Hawksworth, 1991) gehören die Pilze zu einem der wichtigsten Reiche in der Domäne der Eukaryoten. Lange Zeit wurden sie zu den Pflanzen oder einfachen Organismen mit nicht-sexueller Reproduktion (Haeckel's ,Protista') gezählt. Erst 1959 erklärte der Biologe Robert Whittaker sie zu einem eigenständigen Reich außerhalb der Pflanzen und Tiere (Übersicht in Scamardella, 1999). Zahlreiche biotechnische Prozesse und Produkte werden direkt oder indirekt durch Pilze realisiert, sie sind daher für den Menschen und die Umwelt unverzichtbar.

\section{Rolle in der Umwelt}

In der Umwelt sorgen Pilze und Bakterien für den Abbau von organischem Material und tragen somit zur Wiederverwertung von Nährstoffen bei. Thre Nahrung nehmen sie durch Absorption auf. Hierfür scheiden sie eine Reihe von Enzymen aus, die in der Lage sind, verschiedene Polymere in ihre Untereinheiten abzubauen, u.a. Proteine, Cellulose, Chitin, aber auch Lipide. Einige Pilze der Abteilung Basidiomycota sind sogar in der Lage Lignin zu zersetzen.

Eine weitere wichtige Rolle von Pilzen ist ihre Symbiose mit Pflanzen (Mykorrhiza). Etwa 6000 Pilze und 240000 Pflanzen stehen in einer solchen symbiotischen Beziehung (Bonfante, 2003). Einige Pilze nehmen jedoch eine andere Art von Beziehung zu Pflanzen und Tieren auf, sie sind parasitär. Zu den bekanntesten Beispielen zählen Ustilago maydis (Maisbeulenbrand), Magnaporthe grisea (Reisbrand) und Claviceps pupurea (viele Getreidesorten, Mutterkorn). C. purpurea produziert giftige Alkaloide (Ergoline), die im Mittelalter Ursache für den Ergotismus (Vergiftung durch Ergoline) nach dem Verzehr von kontaminierten Nahrungsmitteln war.

Abgesehen von pathogenen Pilzen, die Pflanzen befallen, stellen viele Pilze auch eine Gefahr für den Menschen dar. Sie sind in diesem Zusammenhang u.a. 


\section{Kapitel 1 | EINLEITUNG}

die Auslöser einer schwerer Lungenentzündung (Pneumocystis spp., Cryptococcous spp. und Histoplasma capsulatum), Meningitis (Cryptococcous spp.) und verschiedener Hautkrankheiten (Malassezia spp.) um nur einige zu nennen (Übersicht in Reedy et al., 2007). Vor allem für immunsupprimierte Patienten ist das Risiko einer Pilzinfektion sehr hoch, so liegt die Sterberate bei einer invasiven Aspergillosis bei 90\% (De Lucca, 2007). Die Behandlung von Pilzinfektionen gestaltet sich schwierig, da Pilze auch Eukaryoten sind.

\section{Pilze als Nahrung und ihre Rolle in der Nahrungsmittelindustrie}

Seit Tausenden von Jahren werden Hefen für die Herstellung von Brot, Bier und Wein eingesetzt. Einige Pilze wie z.B. Champignons (Agaricus), Steinpilze oder die seltenen und sehr begehrten Trüffel sind gängige Nahrungsmittel. Thre Rolle in der Herstellung von Nahrungsmitteln ist jedoch viel größer. Geschätzte 40\% der kommerziell verfügbaren Enzyme (Archer et al., 2008) kommen aus Pilzen oder haben ihren Ursprung über Pilzen (bei rekombinanten Prozessen). Einige organische Säuren entstehen in Fermentationsprozessen mit Pilzen, z.B. Zitronensäure (Aspergillus niger) und Äpfelsäure (Schizophyllum commune und Paecilomyces varioti) (Übersicht in Archer et al., 2008). Die für die Herstellung von Käse benötigte Protease Chymosin stammt i.d.R. auch aus Pilzen.

\section{Medizinische Bedeutung}

In der Medizin werden viele von Pilzen hergestellte Sekundärmetabolite aufgrund ihrer biologischen Wirkung geschätzt. Während die Revolution der Medizin durch Penicillin allseits bekannt ist, gibt es noch sehr viele weitere Sekundärmetabolite aus Pilzen, die eine ähnliche Veränderung in diesem Gebiet herbeigeführt haben, z.B. Cyclosporin A. Dieses zyklische Peptid besteht aus 11 Aminosäuren und wurde aus Cylindrocarpon lucidum (und Tolypocladium inflatum) isoliert (Borel et al., 1976). Es ist wegen seiner immunsupprimierenden Wirkung in der Transplantationsmedizin unverzichtbar geworden.

Auch in Hinsicht auf Sekundärmetabolite bilden Pilze nicht nur nützliche, sondern für Mensch und Umwelt auch hochgefährliche Substanzen. So wirken die Aflatoxine (Aspergillus flavus Toxine) allein schon reproduktionstoxisch, mutagen und cancerogen. Aflatoxine stellen vor allem in der Nahrungsmittelindustrie ein großes Problem dar, da sie bereits bei geringer Kontamination zur Unbekömmlichkeit führen. Weitere Sekundärmetabolite aus Pilzen sind u.a. als Nerven-, Nieren- und Lebergifte klassifiziert (Übersicht in Bhatnagar et al., 2002). 


\subsection{Licht}

Eine wichtige Eigenschaft aller Organismen ist die Wahrnehmung und Umsetzung von extrazellulären Signalen. Licht spielt dabei eine besonders große Rolle sowohl für phototrophe Lebewesen, dessen Fortbestehen von Licht abhängig ist (Photosynthese), als auch für solche, die ihre Entwicklung von Licht abhängig machen. Zur zweiten Gruppe zählen auch die Pilze mit zahlreichen Beispielen von unterschiedlicher Entwicklung und Morphologie bei Wachstum bei Licht oder im Dunkeln. Einige bekannte Fälle zu der veränderten Entwicklung aufgrund von Licht (Photomorphogenese) werden in den folgenden Abschnitten näher erläutert.

\subsubsection{Phycomyces blakesleeanus}

Phycomyces blakesleeanus ist ein filamentöser Pilz, der zu den Zygomycota (Jochpilze) zählt und dessen Hyphen nicht durch Querwände (Septa) getrennt sind. So gilt das Myzel als eine kollektive Zelle (Coenocyt) mit Millionen von Kernen. Der Nobelpreisträger Max Delbrück begann mit der Forschung an P. blakesleeanus, in der Hoffnung, darin ein Modellsystem für die Erforschung von Sinneswahrnehmung gefunden zu haben. Abgesehen vom Hörsinn weist P. blakesleeanus alle Sinne auf, die auch dem Menschen zugeschrieben werden (Cerdá-Olmedo, 2001).

P. blakesleeanus bildet in Abhängigkeit von Licht zwei Typen von asexuellen Strukturen aus, die Mikro- oder Makrosporangien. Erstere enthalten etwa 1000, letztere bis zu 100000 Sporen. Durch Licht wird die Bildung von Mikrosporangien inhibiert, während die der Makrosporangien induziert wird. Die Makrosporen befinden sich am Ende von mehreren Zentimeter langen Hyphen, die in die Luft ragen und eine sehr ausgeprägte Hinwendung zum Licht (Phototropismus) aufweisen (Abb. 1.1). Eine asexuelle Fortpflanzung von P. blakesleeanus findet beim Zusammentreffen von zwei Kolonien mit unterschiedlichen Paarungstypen statt.

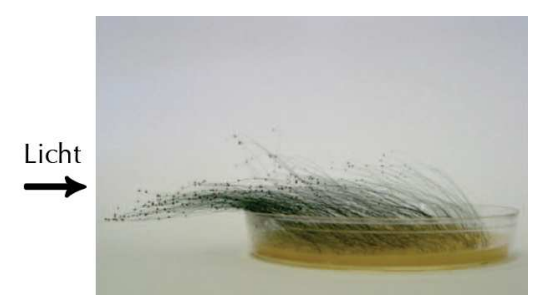

Abbildung 1.1: Phototropismus bei Phycomyces blakesleeanus: Makrosporangien wachsen in Richtung des Lichts, adaptiert aus Idnurm et al. (2006).

Ein weiterer ausschließlich im Licht stattfindender Prozess ist die Synthese des Pigments $\beta$-Carotin (Übersicht in Cerdá-Olmedo, 2001). Dieses führt zu einer Gelbfärbung von P. blakesleeanus-Kolonien, die in Licht anwachsen, während 


\section{Kapitel 1 | EINLEITUNG}

Kolonien, die im Dunkeln anwachsen, farblos (weiß) bleiben. In diesem Zusammenhang werden die Carotinoide generell als Sekundärmetabolite akzeptiert, da ihre Synthese nur im späten Wachstum beginnt (Bramley und Davies, 1975).

\subsubsection{Neurospora crassa}

Auch in Neurospora crassa wird die Synthese von $\beta$-Carotin unter Einfluss von Licht beobachtet (Photocarotinogenese). Ein weiterer lichtgesteuerter Prozess, der extensiv in den letzten Jahrzenten in N. crassa erforscht wurde, ist die zirkadiane Uhr. Lichtexpositon von N. crassa führt zur Einstellung der zirkadianen Uhr. Anschließend ist N. crassa in der Lage, auch bei konstanter Dunkelheit den Zeitverlauf zu bestimmen. So kann die abwechselnde Bildung von Konidien (in Antizipation von Tageslicht) und feinem Myzel (Antizipation von Nacht) in einen sogenannten "race tube Experiment (engl. Rennrohr) beobachtet werden (Brandt, 1953; Pittendrigh et al., 1959). Dabei wird ein Glasrohr, das Nährmedium enthält, auf der einen Seite mit N. crassa angeimpft, mit Licht bestrahlt und anschließend in vollständiger Dunkelheit inkubiert. N. crassa wächst entlang des Rohrs abwechselnd mit feinen Myzelien oder in die Luft ragenden Konidien (Abb 1.2). Dabei ist eine Rhytmik von etwa 22 Stunden zu erkennen.

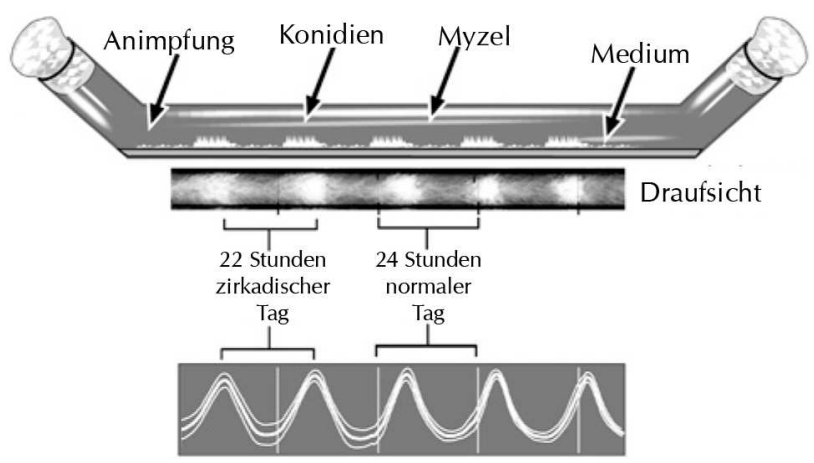

Abbildung 1.2: Wachstum von N. crassa entlang eines mit Nährmedium gefüllten Glasrohrs. N. crassa bildet mit einem Rhythmus von etwa 22 Stunden abwechselnd Konidien und Myzel aus, adaptiert aus Price-Lloyd et al. (2005).

Die molekulare Grundlage dieses Mechanismus ist sehr gut erforscht - ein komplexes Netzwerk an Protein-Protein, Protein-DNA-Interaktionen und posttranslationalen Modifikationen führt zu einer geregelten Antwort bei Licht. So wurde beobachtet, dass die Menge an Transkripten des frequency-Gens ( $f r q$ ) nach Lichtexposition innerhalb von 15-30 Minuten um das vier bis 25-fache ansteigt (Crosthwaite et al., 1995). Durch dieses Ereignis wird die innere Uhr von N. cras$s a$ eingestellt. Die erhöhte Menge an frq-Produkt (FRQ) reguliert negativ die Transkription von frequency und so oszilliert die Menge an FRQ.

Auslöser dieser erhöhten Transkription von frq ist ein Komplex bestehend aus den Proteinen White-collar 1 und 2 (White collar complex, WCC) (Übersicht in Hogenesch und Ueda, 2011). WC-1 und -2 enthalten beide eine PAS-Domäne 
(Per-Arnt-Sim) und ein Zinkfingermotiv für DNA-Bindung (Ballario et al., 1996). WC-1 wurde 2002 von zwei Gruppen als der Blaulichtrezeptor von N. crassa identifiziert, es benötigt für seine Funktion das Coenzym Flavin-Adenin-Dinukleotid (FAD) (He et al., 2002; Froehlich et al., 2002). FAD befindet sich in der LOVDomäne (engl. Light, Oxygen, Voltage), eine Sensordomäne, die je nach Ko-Faktor Licht, Sauerstoff oder Elektrizität wahrnehmen kann. Somit ist WC-1 Lichtrezeptor und gleichzeitig Wandler dieses externen Signals in eine genetische Antwort. In Neurospora crassa sind etwa 180 Gene identifiziert worden, die durch die zirkadische Uhr reguliert werden, sog. ccgs (engl. ccgs, circadian controlled genes, Übersicht in Liu und Bell-Pedersen, 2006).

Die genannten Beispiele verdeutlichen die bedeutende Wirkung von Licht auf Pilze. Da diese Organismen nicht phototrop sind, stellen sich die Fragen nach der Ursache und den Gründen hierfür.

\subsubsection{Lichtwahrnehmung in Pilzen}

In Pilzen wurden Lichtrezeptoren für unterschiedliche Wellenlängen gefunden. Sie haben ähnlich zu den Pflanzen und phototrophen Bakterien, Phytochrome, Cryptochrome und Phototropin-ähnliche Proteine.

Im Bereich von 320 bis $500 \mathrm{~nm}$ (UV-A/Blaulicht) wird die Lichtwahrnehmung in Pilzen u.a. durch Cryptochrome oder WC1-Homologe realisiert. WC-1 wurde ursprünglich in N. crassa entdeckt und enthält eine LOV-Domäne, die anders als in Pflanzen nicht FMN, sondern FAD als Chromophor gebunden hat. Inzwischen wurden Homologe zu WC-1 in vielen Pilzen identifiziert, darunter auch LreA (engl. light response $A$ ) in $A$. nidulans. Die Struktur des Blaulichtrezeptor VVD (engl. vivid) aus N. crassa konnte sowohl in der Licht- als auch in der Dunkelform gelöst werden und gibt Hinweise darüber, wie Licht zu einer Konformationsänderung und Dimerisierung von Proteinen mit einer LOV-Domäne führt (Zoltowski et al., 2007; Vaidya et al., 2011).

Cryptochrome sind Blaulichtrezeptoren, die mit den Photolyasen verwandt sind. Sie haben eine Sequenz-Identität von etwa 25-40\% zu ihnen (Sancar, 2003). Anders als Photolyasen wurde bei Cryptochromen bisher angenommen, sie seien nicht in der Lage DNA-Reparaturen mit Hilfe von Licht durchzuführen (Photoreparatur). Vor kurzem konnte jedoch das Cryptochrom CryA in Aspergillus nidulans charakterisiert werde, CryA, welches sowohl regulatorische Funktionen als auch DNA-Reparaturaktivität aufweist (Bayram et al., 2008a). Der $\triangle c r y A-$ Stamm zeigte verringerte Überlebensraten nach UV-Bestrahlung und produzierte sehr große Mengen an sog. Hüllezellen. CryA ist daher in der Repression der sexuellen Entwicklung bei Blaulicht verwickelt. Bei der Expression von CryA in einem DNA-Reparatur-defizienten E. coli-Stamm konnte eine erhöhte Überlebensrate nach UV-Bestrahlung beobachtet werden, was möglicherweise auf einen teilweise wiederhergestellten Photoreparaturmeachnismus zurückzufüh- 


\section{Kapitel 1 | EINLEITUNG}

ren ist. Außer CryA gibt es eine weitere Klasse an Cryptochromen, die auch DNA-Reparaturaktivität aufweisen, die Cry-DASH-Proteine (Selby und Sancar, 2006).

Phytochrome aus Pilzen enthalten wie bakterielle Phytochrome Biliverdin IX $\alpha$ als Chromophor. Sowohl pflanzliche, bakterielle als auch Pilz-Phytochrome werden in eine Photosensor-Domäne und eine Ausgabe-Domäne unterteilt. In der Photosensor-Domäne ist der Chromophor gebunden und kann je nach Licht in zwei Konformationen vorliegen. Bei Rotlicht $(660 \mathrm{~nm})$ liegt diese in der Pr-Form (engl. Phytochrome red) und bei Dunkelrotlicht $(730 \mathrm{~nm}$ ) in der Pfr-Form (engl. Phytochrome far red) vor. Diese Z/E-Isomerie wird durch die Ausgabe-Domäne in Form von Phosphorylierung weitergeleitet (Übersicht in Rockwell et al., 2006, Abb. 1.3). Alle Phytochrome enthalten am C-Terminus eine Histidin-Kinaseverwandte Domäne (HKRD), die jedoch bei Pflanzen aufgrund des fehlenden kritischen Histidins inaktiv ist (Übersicht in Rodriguez-Romero et al., 2010). Bei FphA (engl. fungal phytochrome A) aus A. nidulans ist eine Interaktion mit den Regulator VeA (1.4.1) gezeigt worden (Purschwitz et al., 2008).
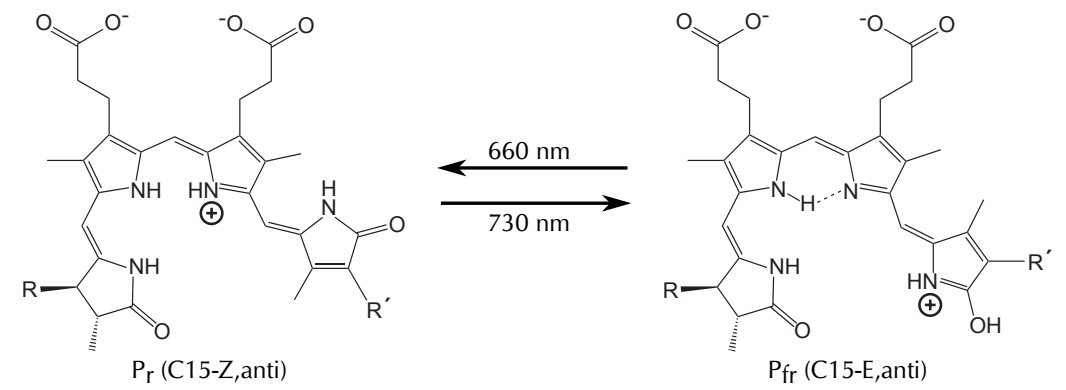

Abbildung 1.3: Z/E-Isomerie des Phytochrom-Chromophors. Bei $660 \mathrm{~nm}$ liegt die $\mathrm{P}_{\mathrm{r}}$ - und bei $680 \mathrm{~nm}$ die $P_{\text {fr }}$-Form vor. Adaptiert aus Rockwell et al. (2006).

\subsubsection{Warum machen Pilze ihre Entwicklung von Licht abhängig?}

Pilze leben bevorzugt in feuchten und dunklen Habitaten, in denen sie vor Austrocknung und UV-Strahlung geschützt sind. Für ihre Verbreitung verwenden Pilze Sporen und für deren Freisetzung benötigen sie ein verlässliches Signal für ihre eigene ober- oder unterirdische Positionsbestimmung - das Licht. In der Natur garantiert das Licht, dass sich der Organismus an einer durch Wasser oder Luft zugänglichen Oberfläche befindet und daher die Verbreitung durch Sporen optimal ist. Bei der Synthese von Sekundärmetaboliten wird angenommen, dass diese hauptsächlich für die Bekämpfung von Bakterien oder anderen Gegnern in der jeweiligen ökologischen Nische notwendig sind. Dies beinhaltet jedoch nicht viele andere Sekundärmetabolite, die lediglich die Erscheinung des Pilzes verändern (Pigmente). 
Die vorliegende Arbeit befasst sich mit Komponenten aus einem Pilz, der auch Photomorphogenese aufweist, Aspergillus nidulans. Dort sind Sekundärmetabolismus und Entwicklung an Licht gekoppelte Prozesse (Abb. 1.4).
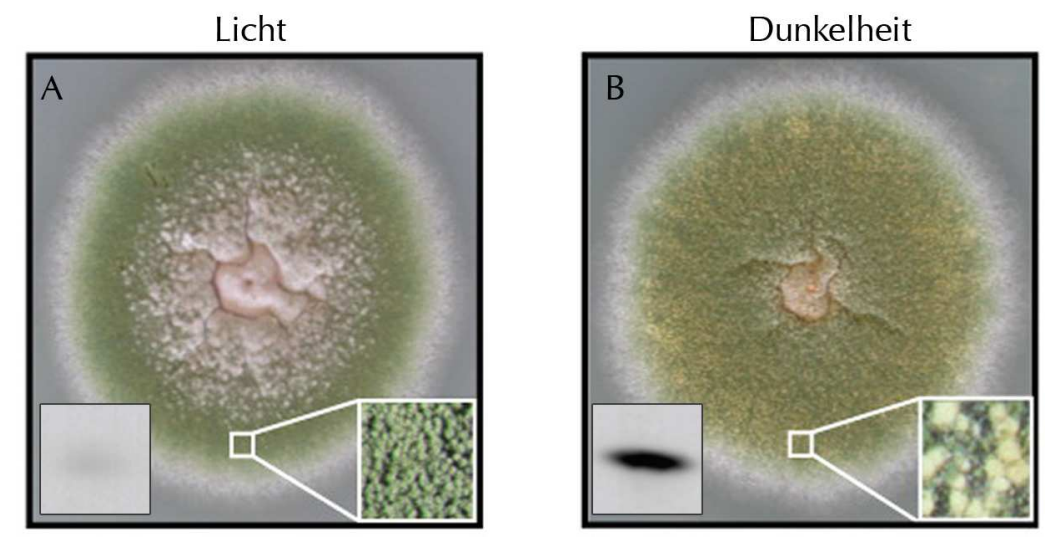

Abbildung 1.4: Erscheinung und Sekundärmetabolismus von A. nidulans bei Dunkelheit und Licht. Im Licht (A) werden grün-pigmentierte Konidien und kein Sterigmatocystin (fehlende Bande in Dünnschichtchromatographie) gebildet. In Dunkelheit (B) werden vermehrt sexuelle Fruchtkörper (gelbe Punkte) und Sterigmatocystin (Bande in Dünnschichtchromatographie) gebildet, adaptiert aus Rodriguez-Romero et al. (2010).

\subsection{Aspergillus nidulans}

Die Gattung Aspergillus wurde erstmals 1729 von dem italienischen Priester Pier Antonia Micheli beschrieben. Eine Betrachtung des Sporenträgers unter dem Mikroskop erinnerte ihn an die Form eines Weihwasserwedels (Aspergill) und so nannte er den Pilz Aspergillus. Als Modelorganismus wurde Aspergillus nidulans durch Guido Pontecorvo in den 50er Jahren des vergangenen Jahrhunderts an der Universität von Glasgow etabliert. Einfache Kultivierbarkeit, schnelles Wachstum, sexuelle und asexulle Entwicklung und viele Mutanten, die auf dem ,Glasgow'-Wildtypen basieren, machen A. nidulans auch heute noch zu einem hervorragenden Forschungsobjekt. Für die sexuelle Entwicklung von $A$. nidulans ist ein Kreuzungspartner nicht zwingend erforderlich, da A. nidulans ein homothallischer Pilz ist. Die Sequenzierung des 30 Megabasen großen haploiden Genoms, das auf acht Chromosomen verteilt ist, wurde 2005 abgeschlossen (Galagan et al., 2005). Mehr als 9500 offene Leserahmen (engl. Open Reading Frame, ORF) konnten durch automatische Sequenzanalysen detektiert werden. 


\section{Kapitel 1 | EINLEITUNG}

\subsubsection{Entwicklung von Aspergillus nidulans}

Die vegetative Wachstumsphase von A. nidulans beginnt mit der Keimung einer Spore. Von A. nidulans werden zwei Arten von Sporen gebildet, die Konidiospore (Produkt der asexuellen Entwicklung) und die Ascospore (Produkt der sexuellen Entwicklung). Aus der keimenden Spore wächst durch apikale Extension und Querverzweigung das Myzel, das bereits unterschiedliche Zelltypen enthält. Erst etwa 20 Stunden nach der Keimung sind die Hyphen kompetent für weitere Differenzierung (Axelrod et al., 1973). Eine weitere Bedingung für eine Differenzierung ist das Vorhandensein einer Luft-Medium-Interphase, denn in Flüssigmedium liegende Kolonien sind nicht in der Lage, weitere Strukturen zu bilden.

Im Folgenden durchläuft $A$. nidulans hauptsächlich zwei unterschiedliche reproduktive Zyklen. Der asexuelle Zyklus wird im Licht, bei begrenztem Angebot an Nährstoffen oder starkem osmotischen Stress eingeschlagen (Mooney und Yager, 1990; Skromne et al., 1995; Han et al., 2003). Licht mit einer Wellenlänge von $680 \mathrm{~nm}$ induziert die Konidiation, während Licht mit $740 \mathrm{~nm}$ und Dunkelheit die Fruchtkörperbildung aktiviert (Mooney und Yager, 1990) (Abb. 1.4). Die von Etta Käfer beschriebene Velvet-Mutante (1965) macht die Erforschung dieses Pilzes im Labor einfach, da für die Induktion der asexuellen Fortpflanzung und Sporulation keine konstante Beleuchtung notwendig ist. Die Konidiation erfolgt auch im Dunkeln. Ein weiterer Auslöser für die Entwicklung sind Derivate der Hydroxylinolen- und Hydroxyoleinsäure, die psi-Faktoren (engl. precocious sexual inducer). psiB und $C$ lösen die sexuelle Entwicklung aus und reprimieren die Konidiation. psiA hingegen zeigt eine antagonistische Wirkung zu B und C (Champe und El-Zayat, 1989; Champe et al., 1987).

\subsubsection{Asexuelle Fortpflanzung}

Die asexuelle Entwicklung beginnt mit der Bildung der Konidophoren, den Trägern der Konidien. Hierfür wachsen Hyphenzellen zu einem Stil der bis zu $100 \mu \mathrm{m}$ in die Luft ragt und ein bis zwei $\mu \mathrm{m}$ größer (im Durchschnitt) ist als das übliche Myzel (Luftmyzel). An diesen sepziellen Hyphenzellen (Fuß) wird außerdem eine zweite Zellwandschicht gebildet, die beim übrigen Myzel nicht vorhanden ist. Am oberen Ende des Stiels entsteht durch Schwellung ein Vesikel, in dem durch Kernteilung etwa 60 bis 70 Zellkerne gebildet werden. Durch längliche Zellteilung entstehen am oberen Ende des Vesikels die Metulae, die jeweils mit einen Zellkern befüllt werden und wiederum zwei Auswüchse (Phialiden) bilden. Die Phialiden bilden lange Ketten von Konidiosporen (Übersicht in Etxebeste et al., 2010). Die grün pigmentierten Konidiosporen sind so am oberen Ende des Myzels exponiert und werden leicht durch Wind verbreitet (Abb. 1.5). Reife Konidiophoren sind bereits 15 Stunden nach Differenzierung zu erkennen, der gesamte asexuelle Zyklus benötigt lediglich zwei bis drei Tage. 


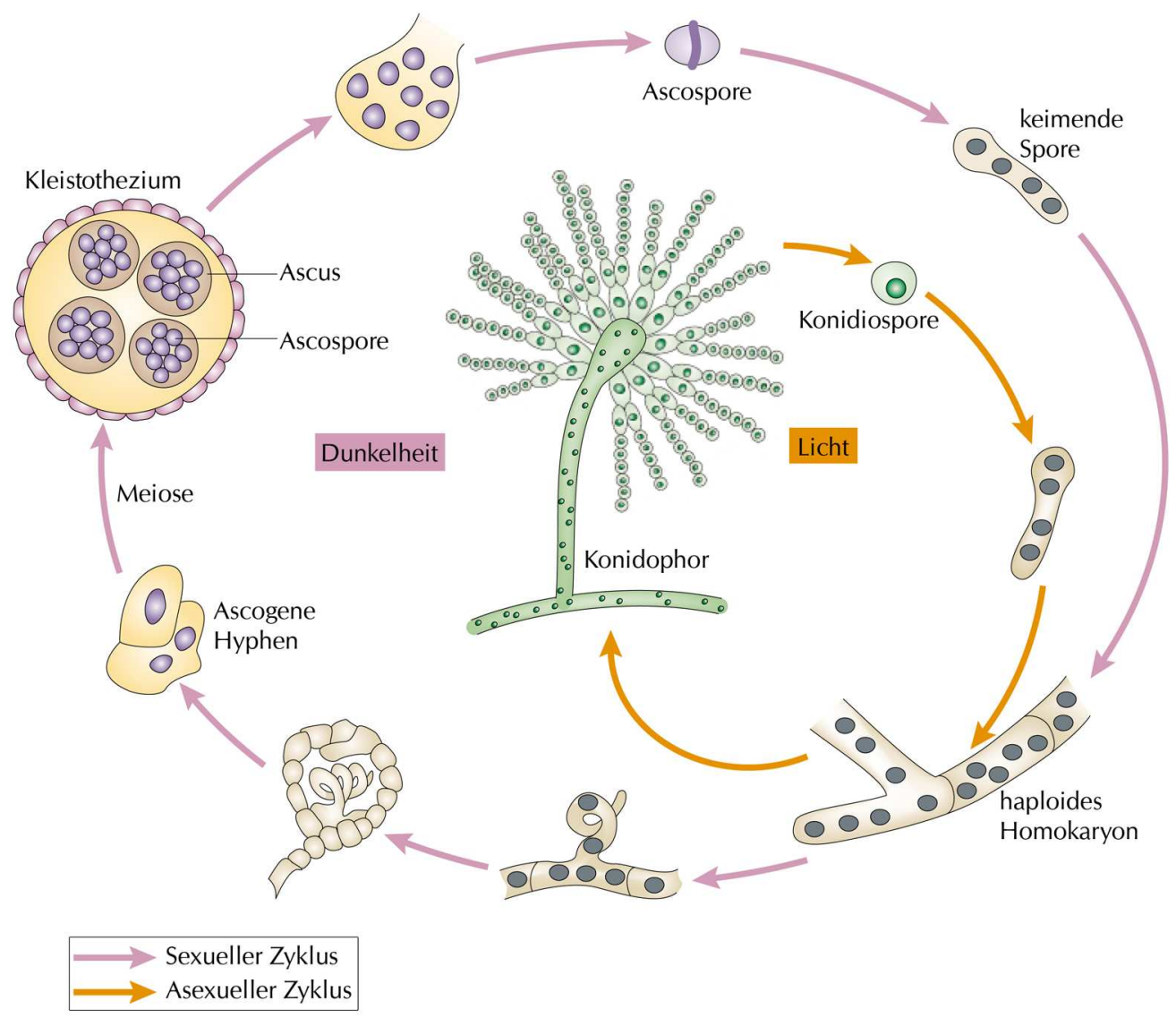

Abbildung 1.5: Schematische Darstellung des Lebenszyklus von Aspergillus nidulans. Der in Licht ablaufende asexuelle Zyklus benötigt zwei bis drei Tage, der sexuelle Entwicklungsweg hingegen bis zu sieben Tage, adaptiert aus Casselton und Zolan (2002).

\subsubsection{Sexuelle Entwicklung}

Im Vergleich zur asexuellen Fortpflanzung ist die sexuelle Entwicklung von A. nidulans ein weitaus komplexerer und zeitintensiverer Prozess. So benötigt der komplette Zyklus ausgehend von differenzierendem Myzel bis zur Bildung des Fruchtkörpers etwa sieben Tage. In Aspergillus spp. gibt es zwei Gene für Paarungstypen, die $\alpha$ - und HMG-Gene (engl. high-mobility group), beide sind in A. nidulans vorhanden.

Die sexuelle Entwicklung beginnt mit der Annäherung zweier Hyphen, die anschließend fusionieren und eine dikaryotische Hyphe bilden. Diese wird von einem weiter wachsenden Myzel umgeben, das eine Art „Nest" bildet und zu Hüllezellen differenzieren (Braus et al., 2002). Das umgebende Myzel und die Hüllezellen bilden die Hülle des Kleistotheziums aus. Diese Hüllezellen versorgen den heranwachsenden Fruchtkörper mit Nährstoffen. Das Kleistothezium wächst aus dem Nest heraus, während die dikaryotischen Zellen der ascogenen Hyphen eine hakenähnliche Form annehmen, Crozier genannt. 


\section{Kapitel 1 | EINLEITUNG}

Die Karyogamie zweier haploider Kerne läuft im terminalen Bereich der Crozier ab. Aus dieser Zygote gehen durch meiotische Teilung vier Zellkerne hervor, die dann durch mitotische Teilung in acht haploiden Kernen resultieren. Diese acht haploiden Kernen werden durch Membranen getrennt. Im weiteren Verlauf wird eine zusätzliche Mitose durchgeführt, so dass jeder Ascus 8 binukleäre Ascosporen enthält. Reife Kleistothezien sind bis zu $200 \mu \mathrm{m}$ groß und enthalten für gewöhnlich 80000 Ascosporen (Braus et al., 2002). Anders als die Konidiosporen sind die Ascosporen aufgrund einer Ansammlung von Asperthicin rot pigmentiert.

\subsubsection{Sekundärmetabolismus}

Der primäre Metabolismus ist für die Aufrechterhaltung aller lebensnotwendigen Prozesse innerhalb eines Organismus notwendig. Der Sekundärmetabolismus hingegen wird nur unter bestimmten Umständen aktiviert. Es wird angenommen, dass die Synthese von Sekundärmetaboliten u.a. der Eroberung von ökologischen Nischen dient. In den Jahren 1993 bis 2001 wurden allein mehr als 1500 Sekundärmetabolite entdeckt, von denen mehr als die Hälft eine antibakterielle, -pilzliche oder -Tumor-Wirkung zeigte (Keller et al., 2005). Die Entdeckung und Anwendung von Sekundärmetaboliten bleibt daher weiterhin ein wichtiges Forschungsgebiet.

Sekundärmetabolite werden abhängig von ihren Synthesewegen in vier Gruppen unterteilt: nicht-ribosomale Peptide (NRPS), Polyketide (PK), Indolalkaloide und Terpene. Nach der Sequenzierung des A. nidulans Genoms wurden 50 Gene durch bioinformatische Methoden identifiziert, die für Proteine kodieren, die in der Synthese von Sekundärmetaboliten involviert sind (Keller et al., 2005), darunter 27 Polyketidsynthasen und 14 NRP-Synthetasen. Anders als die verstreuten Gene für den primären Metabolismus sind die Gene für den Sekundärmetabolismus meist in Gruppen zusammengefasst und liegen nah beieinander. Nicht alle natürliche Produkte von A. nidulans sind bekannt, da viele Gene still sind und nur unter spezifischen Bedingungen aktiviert werden. So wird z.B. die Synthese von zwei Kathepsin K (Protease) Inhibitoren nur in Anwesenheit von Streptomyces rapamycinus durchgeführt (Nützmann et al., 2011).

$\mathrm{Zu}$ den am Besten in A. nidulans charakterisierten Sekundärmetaboliten zählt der Aflatoxinvorgänger Sterigmatocystin (Polyketid). A. nidulans synthetisiert auch Penicillin (NRPS-Produkt). Sterigmatocystin ist ein Vorläufer der Aflatoxine, einer Gruppe an Toxinen, die zuerst in Aspergillus flavus entdeckt wurden. Sie gelten als hochgradig toxisch, cancerogen und teratogen.

Die Synthese von Sterigmatocystin (ST) ist abhängig von verfügbaren Nährstoffen und Licht. Die ST-Biosynthese ist verringert, wenn der Pilz dem Licht ausgesetzt ist und wird erhöht, sofern er im Dunkeln ist (Kato et al., 2003). Bei übermäßigem Angebot an Nährstoffen kann eine erhöhte ST-Biosynthese auch in Licht beobachtet werden. Vor kurzem wurde außerdem gezeigt, dass die Indukti- 

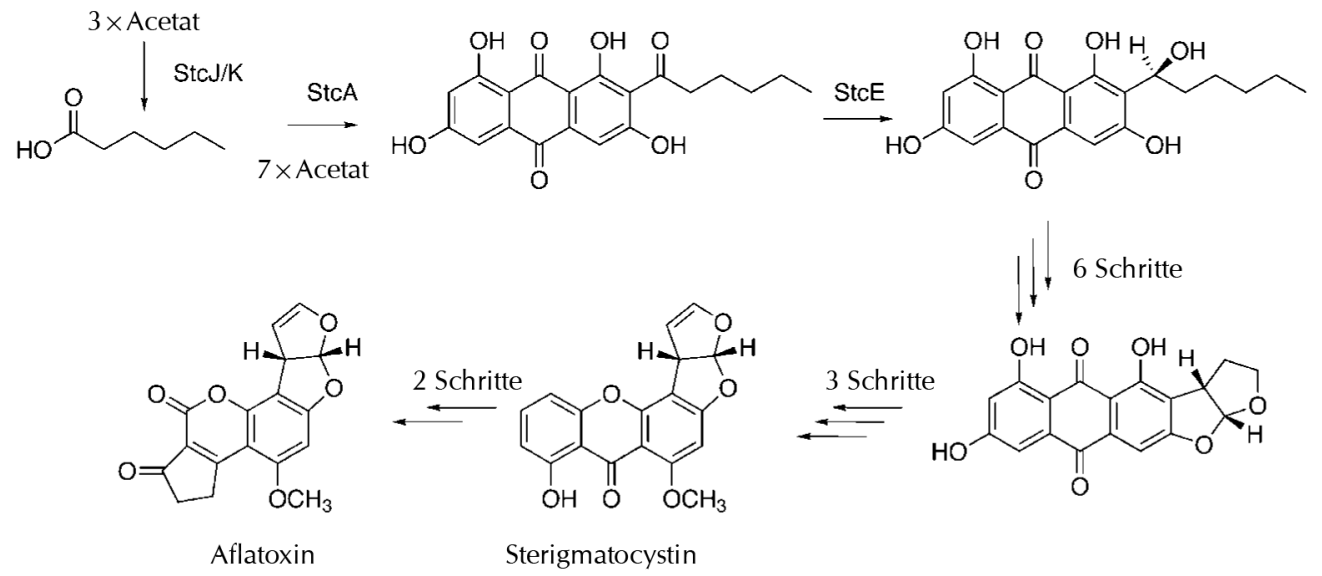

Abbildung 1.6: Biosynthese von Sterigmatocystin (Aspergillus nidulans) und Aflatoxin (Aspergillus flavus) in Pilzen, nach Sanchez et al. (2008), verändert.

on der ST-Biosynthese nicht nur bei absoluter Dunkelheit, sondern bereits durch Licht mit einer Wellenlänge von 680 bis $740 \mathrm{~nm}$ stattfindet (Purschwitz et al., 2008). Ähnlich wie die Entwicklung unterliegt auch der Sekundärmetabolism dem Einfluss der psi-Faktoren, so stimuliert psiB die ST-Produktion (Tsitsigiannis und Keller, 2006). Die Synthese von ST in A. nidulans ist ein sehr komplexer Prozess. In 16 Schritten, die durch Enzyme katalysiert werden, entsteht aus Acetyl-CoA Sterigmatocystin. In A. nidulans geschieht die Umwandlung in ein Aflatoxin nicht, da hierfür zwei Enzyme fehlen. Beide sind in A. flavus und A. parasiticus vorhanden (Sanchez et al., 2008) (Abb. 1.6).

\subsection{Der Velvet-Komplex}

Die Verbindung zwischen der Regulation von Sekundärmetabolismus und Entwicklung in Aspergillus nidulans und auch die beteiligten Proteine sind seit langer Zeit bekannt. Eine Verbindung zwischen dem Aktivator für die sexuelle Entwicklung und dem Aktivator für Sekundärmetabolitsynthese war jedoch bisher nicht bekannt. Erst kürzlich wurde gezeigt, dass die Regulation dieser beiden Prozesse durch einen trimeren Komplex (Velvet-Komplex) koordiniert wird (Bayram et al., 2008b). Dieser Komplex besteht aus der putativen Methyltransferase LaeA und den beiden Velvet-Proteinen VeA und VelB. Die molekulare Funktion dieser Proteine, die keinerlei Ähnlichkeit zu bekannten Proteinen zeigen, ist bisher unbekannt. Alle Proteine konnten zu bestimmten Zeiten im Zellkern nachgewiesen werden, obwohl nur VeA eine eindeutige Kernlokalisationssequenz trägt. Basierend auf verfügbaren Daten zum Velvet-Komplex sowie assoziierten Proteinen, ist bekannt, dass der Import von VeA über das Importin $\alpha$-Ortholog KapA realisiert wird. VelB gelangt durch seinen Interaktionspartner VeA in den Zellkern. Dieser Importprozess wird nur im Dunkeln beobachtet, und so bildet 


\section{Kapitel 1 | EINLEITUNG}

sich im Zellkern der trimere Komplex bestehend aus LaeA-VeA-VelB (VelvetKomplex). Der Velvet-Komplex aktiviert den Sekundärmetabolismus und die sexuelle Entwicklung. Desweiteren ist das Zusammenkommen des VelB-VosAKomplexes im Zellkern abhängig von Licht (Abb. 1.7). Dieser Komplex reguliert die Sporogenese und Biosynthese von Trehalose.

Die Entfernung einer Komponente führt sowohl zur gestörter Entwicklung als auch veränderter Produktion von Sekundärmetaboliten. Durch die Analyse von verschiedenen Überexpressions-Mutanten konnte das $r s m A$-Gen (engl. remediator of secondary metabolism) identifiziert werden, das den Sekundärmetabolismus auch bei $\triangle l a e A$ - und $\triangle v e A$-Hintergrund aktivieren kann. Die Defekte bei der Entwicklung konnten durch die Überexpression von $r s m A$ nicht aufgehoben werden (Shaaban et al., 2010). Die jeweilige Rolle dieser Proteine sowie ihre Beziehung zueinander ist Gegenstand der folgenden Abschnitte.

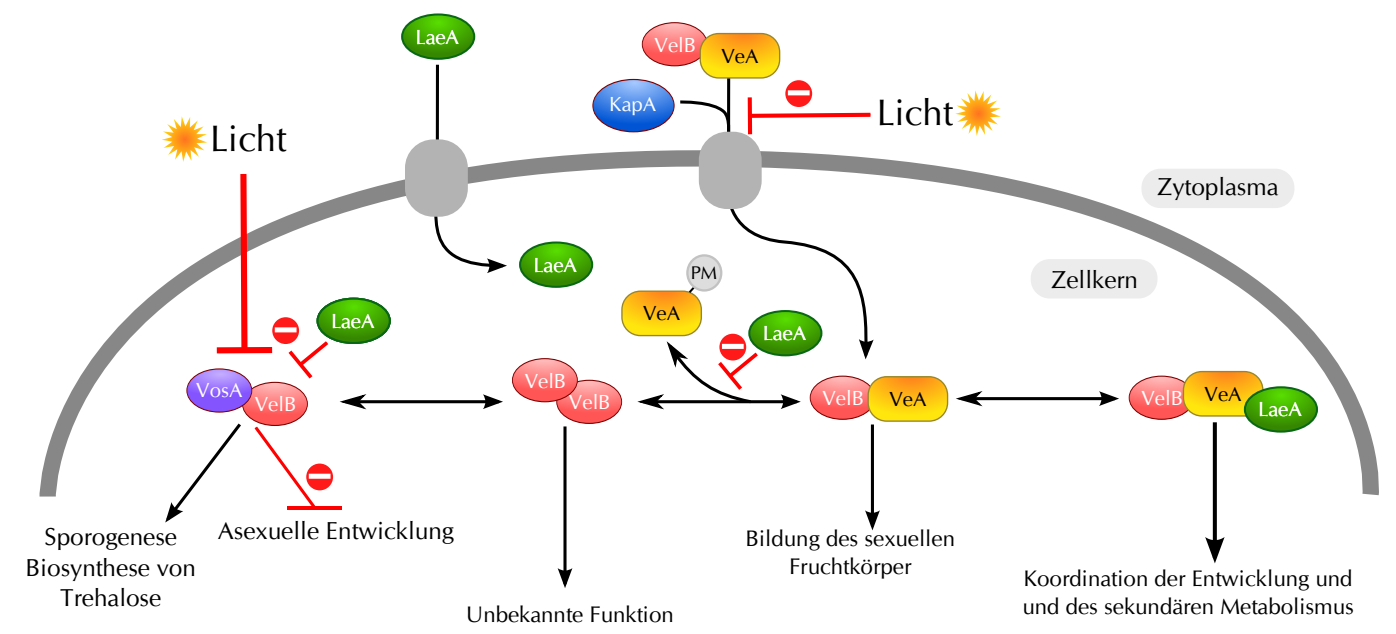

Abbildung 1.7: Schematische Darstellung der bekannten Interaktionen, Lokalisation sowie Funktion der Proteine. VeA interagiert mit VelB und wird über KapA im Dunkeln in den Zellkern transportiert. Im Zellkern kann VelB Teil von drei verschiedenen Komplexen sein, die unterschiedliche Funktionen haben. Der LaeA-VeA-VelB-Komplex bildet sich im Zellkern und aktiviert den sekundären Metabolismus und die sexuelle Entwicklung. Der VelB-VosA-Komplex reguliert die Biosynthese von Trehalose und reprimiert die asexuelle Entwicklung. VeA wird im Zellkern posttranslational modifiziert (PM), dies wird durch LaeA verhindert, basierend auf Bayram und Braus (2011).

\subsubsection{Velvet}

Der Velvet-Phänotyp

In den 60er Jahren des vergangen Jahrhunderts wurden viele Mutanten von Pilzen für die Forschung mittels Exposition an Röntgenstrahlen generiert. Dabei trat ein Phänotyp von Aspergillus nidulans hervor, der sehr häufig selektiert wurde. Dieser Phänotyp äußerte sich durch eine samtartige Oberfläche (Abb. 1.8C) und neigte zu einer höheren asexuellen Vermehrung über Sporen (Konidiation) - der Velvet-Phänotyp (Käfer, 1965). Diese Eigenschaft machte diese Mutante geeignet 
für die Verwendung im Labor, da die Ausbildung von Konidien nicht mehr abhängig vom Licht war.
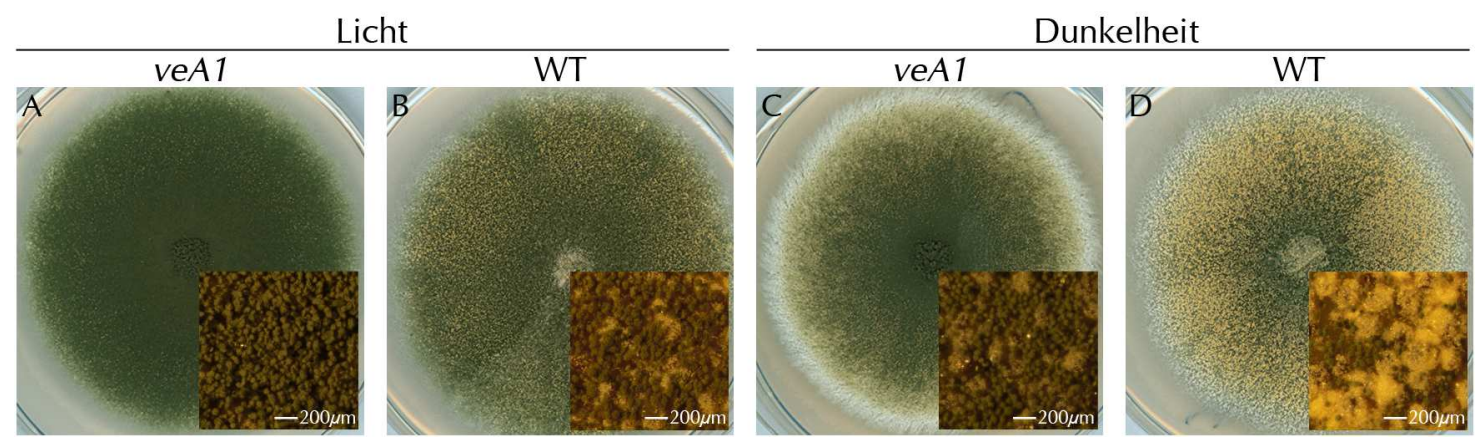

Abbildung 1.8: Phänotyp von WT und veA1-A. nidulans bei Licht und Dunkelheit. Der veA1-Stamm produziert im Licht (A) und auch Dunkelheit $(C)$ vermehrt Konidien und nur wenige Kleistothezien (gelb). Der Wildtyp hingegen produziert in Licht (B) wenige aber im Dunkelheit (D) vermehrt Kleistothezien. Die Bilder wurden freundlicherweise von Özgür Bayram zur Verfügung gestellt.

Velvet - der zentrale Regulator

Erst vor einigen Jahren wurde die molekulare Basis für dieses Phänomen aufgeklärt. Diese Mutante enthält ein mutiertes veA-Gen (Velvet A), dessen Starttriplet ATG zu ATT mutiert ist. Durch das Fehlen des korrekten ATG-Triplets beginnt die Translation des Proteins erst bei Methionin 37 (Kim et al., 2002). Die ersten 36 Aminosäuren beinhalten jedoch einen Teil einer zweiteiligen Kernlokalisationssequenz (Stinnett et al., 2007, Abb. 1.9). Diese verkürzte Form von VeA (VeA1), enthält noch das pat7-Motiv (ein Kernlokalisationsmotiv) und wird nur sehr ineffizient durch das Importin $\alpha$ Ortholog KapA in den Zellkern transportiert (Stinnett et al., 2007; Araújo-Bazán et al., 2009).

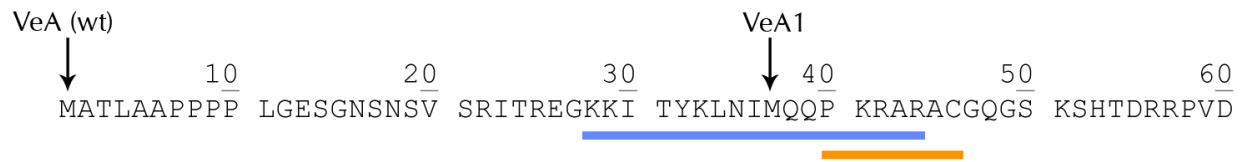

Abbildung 1.9: $\mathrm{N}$-Terminus von Wildtyp-VeA und VeA1. Der Beginn der beiden Varianten ist mit einem Pfeil markiert. In VeA(wt) sind beide Teile der zweiteiligen Kernlokalisationssequenz (gelb unterlegt) vollständig, in VeA1 hingegen nicht. Das pat7-Motiv (orangene Linie) ist in beiden Formen vorhanden, basierend auf Stinnett et al., 2007.

Die Konidiation von $A$. nidulans ist abhängig von Licht, diese Abhängigkeit ist jedoch in einem veA1-Stamm aufgehoben. Desweiteren ist ein ähnliches Verhalten wie bei pflanzlichen Phytochromen zu beobachten. Konidiation kann mit rotem Licht $(680 \mathrm{~nm})$ herbeigeführt werden, eine zeitnahe Bestrahlung mit dunkelrotem Licht $(730 \mathrm{~nm})$ hebt jedoch dessen Wirkung wieder auf (Mooney und Yager, 1990). Dieses Phänomen ist auf das inzwischen identifizierte Phytochrom FphA (engl. Fungal phytochrome A) zurückzuführen (Blumenstein et al., 2005). FphA 


\section{Kapitel 1 EINLEITUNG}

interagiert mit LreA und LreB (WC-1 und 2 Homologe) und auch mit VeA im Zellkern (Purschwitz et al., 2008).

Die sexuelle Entwicklung wird durch VeA aktiviert (Kim et al., 2002), während die asexuelle Entwicklung reprimiert wird. Die Repression wirkt über brlA (engl. bristle A), einen Transkriptionsfaktor, der als aktivierender Hauptregulator der asexuellen Entwicklung gilt (Kato et al., 2003). In der gleichen Arbeit wurde VeA auch als Aktivator der Sterigmatocystin-Biosynthese identifiziert. Die Entfernung von veA führte zur Repression von aflR (engl. aflatoxin Regulator) und entsprechend zu nahezu keinem Sterigmatocystin.

Die Unterdrückung der sexuellen Entwicklung bei ungünstigen Bedingungen wie Nährstoffmangel oder hoher Salzkonzentrationen wird durch RosA (engl. repressor of sexual development $A$ ), einem putativen $\mathrm{Zn}(\mathrm{II})_{2} \mathrm{Cys}_{6}-$ Transkriptionsfaktor über die Repression von VeA realisiert (Vienken et al., 2005).

Ein weiterer Faktor, von dem postuliert wird, eine repressive Wirkung auf veA auszuüben, ist der Blaulichtrezeptor CryA. Ein $\triangle c r y A-S t a m m$ weist nämlich erhöhte Mengen an veA-Transkripten auf (Bayram et al., 2008a).

Das VeA-Protein

Die Sequenzierung des Velvet-Gens enthüllte ein Protein aus 573 Aminosäuren mit einer N-terminal gelegenen Kernlokalisationssequenz und einer C-terminal liegenden PEST-Region (Kim et al., 2002). PEST-Regionen sind reich an Prolinen, Glutaminsäure, Serin und Threonin, sie kommen in Proteinen mit hoher Synthese- und Abbaurate vor (Rogers et al., 1986). Auch ist bekannt, dass VeA posttranslational modifiziert wird. Hierbei handelt es sich sowohl um Phosphorylierung als auch um eine bisher unbekannte Modifikation (Purschwitz et al., 2009; Sarikaya Bayram et al., 2010). Diese Modifikation an VeA ist abhängig vom intakten N-Terminus und scheint im Zellkern durchgeführt zu werden, da dies nicht für VeA1 beobachtet wurde. LaeA wirkt dieser Modifikation entgegen (Abb. 1.7).

VeA-Homologe oder allgemein Velvet-Proteine sind in den Asco- und Basidiomyceten stark konserviert, in Saccharomyces cerevisae und Candida albicans jedoch nicht. Die Velvet-Proteine sind charakterisiert durch eine i.d.R. N-terminal gelegene Region die unter den Mitgliedern dieser Proteinfamilie große Ähnlichkeit aufweisen. Diese Region ist etwa 150 Aminosäuren lang und wird als Velvet-Faktor oder Velvet-Domäne bezeichnet (Übersicht in Bayram und Braus, 2011). Die Sequenz dieses Bereiches weist keinerlei Ähnlichkeit zu bereits charakterisierten Proteinen auf, wird jedoch für die Interaktion zwischen den einzelnen Velvet-Proteinen benötigt (Bayram et al., 2008b). Es wird daher vermutet, dass es sich hierbei um eine Protein-Protein-Interaktionsdomäne handelt. 


\subsubsection{VelB}

Bei der Päparation von TAP ${ }^{1}$-markierten VeA aus $A$. nidulans-Kolonien, die im Dunkeln kultiviert wurden, konnte ein $40 \mathrm{kDa}$ Protein isoliert werden, VelB (Velvet-like protein B). Im $\Delta$ velB-Stamm erfolgt im Dunkeln keine Fruchtkörperbildung und die ST-Biosynthese entspricht nur etwa 50\% der des Wildtyps. VelB ist sowohl bei Licht als auch bei Dunkelheit im Cytoplasma und im Zellkern $\mathrm{zu}$ finden, der Import in den Zellkern ist jedoch abhängig von VeA (Bayram et al., 2008b). Ein weiterer Interaktionspartner von VelB ist VosA, die Funktion dieser Interaktion war jedoch bisher unbekannt. Ursprünglich wurde VosA allein als Aktivator von tps $A$ und orl $A$ angesehen. Inzwischen ist jedoch VelB als essenzieller Interaktionspartner von VosA identifiziert worden. Ähnlich zu $\triangle v o s A$ enthalten Sporen von $\triangle v e l B$ keine Trehalose und weisen entsprechend sehr geringe Überlebensraten auf (Sarikaya Bayram et al., 2010).

Domänenaufbau von VelB

VelB ist auch ein Mitglied der Velvet-Protein-Familie, weist aber eine ungewöhnliche Anordnung der Velvet-,,Domäne“ auf. Da keine strukturellen Informationen zu dem Bereich, der als Velvet-Domäne definiert ist, vorliegen, sind mehrere strukturelle Anordnungen denkbar. Es könnte sich bei der aktuell definierten Velvet-Region um zwei Domänen handeln, die meist hintereinander kodiert vorliegen, jedoch in VelB durch eine weitere Domäne getrennt sind. Die zweite Möglichkeit besteht darin, dass es sich bei der Velvet-Region tatsächlich nur um eine Domäne handelt, die im Falle von VelB durch eine Sequenz unterbrochen ist (Abb. 1.10). Bei dieser Anordnung handelt es sich nicht um eine A. nidulansEigenheit, denn in VelB-Homologen ist auch eine solche Abfolge zu finden (Abb. 1.10). Grundsätzlich sind daher beide strukturellen Konstellationen denkbar.

\footnotetext{
${ }^{1}$ Fusionsprotein bestehend aus Calmodulinbindeprotein und Protein A aus Staphylococcus aureus
} 


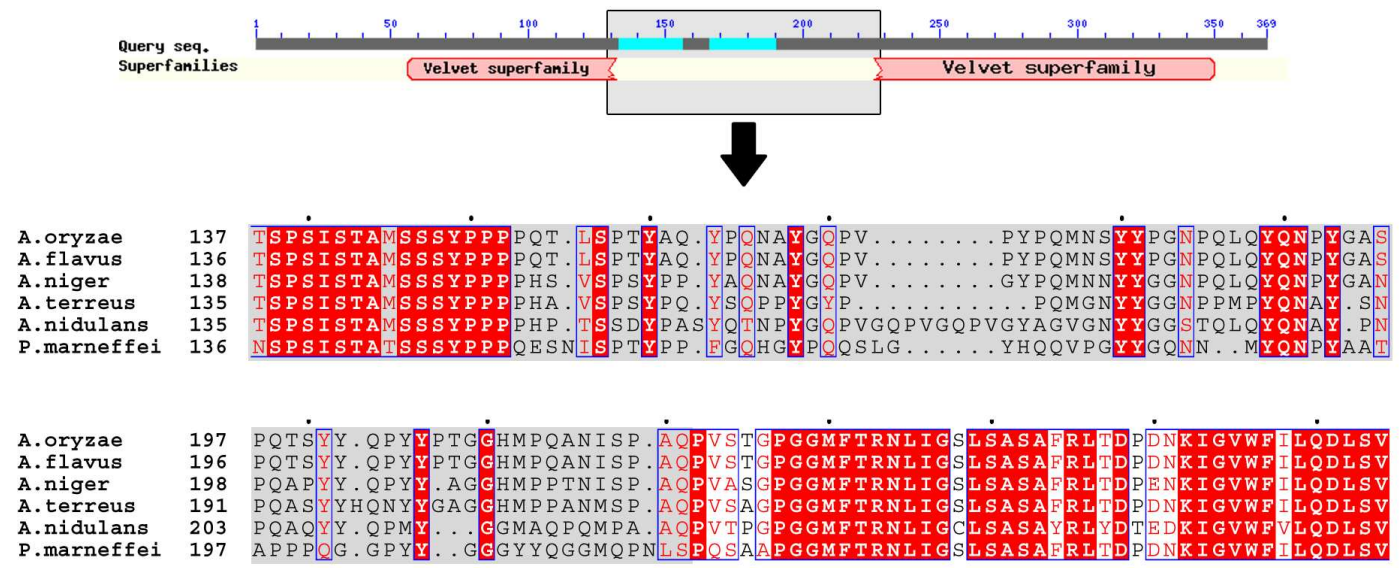

Abbildung 1.10: Domänenvorhersage und Sequenzvergleich von VelB bzw. Homologen. Oben: Vorherhersage über die Domänenanordnung von VelB, beide Velvet-definierenden-Regionen sind hellrot, generiert mit CDD (Marchler-Bauer et al., 2011). Unten: Sequenzvergleich von VelB-Homologen aus A. oryzae, A. flavus, A. niger, A. terreus, A. nidulans und Penicillium marneffei. Stark konservierte Reste sind rot unterlegt, gezeigt ist nur der Bereich der zwischen der Velvet-Region liegt (grau unterlegt). Sequenzvergleich generiert mit ClustalW (Larkin et al., 2007) und visualisiert mit ESPript (Gouet et al., 1999).

\subsubsection{LaeA - eine putative Methyltransferase}

Die Aktivierung des sekundären Metabolismus ist nicht nur von VeA oder VelB abhängig. Bei späteren Arbeiten wurde ein Faktor identifiziert, der bei Entfernung zu einer vollständigen Herunterregulierung der Gene für den sekundären Metabolismus führte. Aufgrund der fehlenden AflR-Expression bei diesem Stamm, wurde dieser Faktor LaeA genannt (engl. loss of aflR expression). In der Sequenz von LaeA wurde keine Kernlokalisationssequenz identifiziert, trotzdem ist es überwiegend im Zellkern lokalisiert (Bok und Keller, 2004). LaeA ist ein $42 \mathrm{kDa}$ Protein mit einem typischen Motif für S-Adenosyl-Methionin (SAM)abhängige Methyltransferasen. Dass es sich bei LaeA tatsächlich um ein Enzym mit der Fähigkeit, SAM zu binden und die Methylgruppe zu transferieren, handelt, ist sehr wahrscheinlich. Eine bekannte Methode für die Inaktivierung von Methyltransferasen ist der Austausch von zwei konservierten Glycinen im aktiven Zentrum, die für die Bindung von SAM essenziell sind (Hamahata et al., 1996). Die Anwendung dieser Methode auf laeA führt bei Aspergillus nidulans zum gleichen Phänotyp wie ein $\triangle$ laeA-Stamm (Bok et al., 2006). 


\section{Unbekanntes Substrat}

$\mathrm{Ob}$ es sich bei bei LaeA um eine Histonmethyltransferase handelt, ist hingegen unklar. Bisher bekannte Lysin-Histonmethyltransferasen lassen sich in zwei Gruppen einteilen, die SET-Domäne-enthaltenden und Dot1-ähnlichen (Übersicht in Cheng et al., 2005). Die SET-Proteine enthalten mehrere konservierte Sequenzmotive, die in LaeA nicht zu finden sind. Darunter das SET Motiv I (GxG), II (YXG), III (RFINHxCxPN) und IV (ELxFDY) (Übersicht in Qian und Zhou, 2006) (Abb. 1.11). Das Motiv I ist für die Bindung von SAM notwendig, ist nicht spezifisch für SET-Domänen und kommt auch in anderen Methyltransferasen vor. Die andere Klasse an Histon-Lysinmethyltransferasen ist die Dot1Familie zu der LaeA jedoch auch keine Ähnlichkeit zeigt. Auch hier ist keines der Dot1-spezifischen Motive in LaeA zu finden.

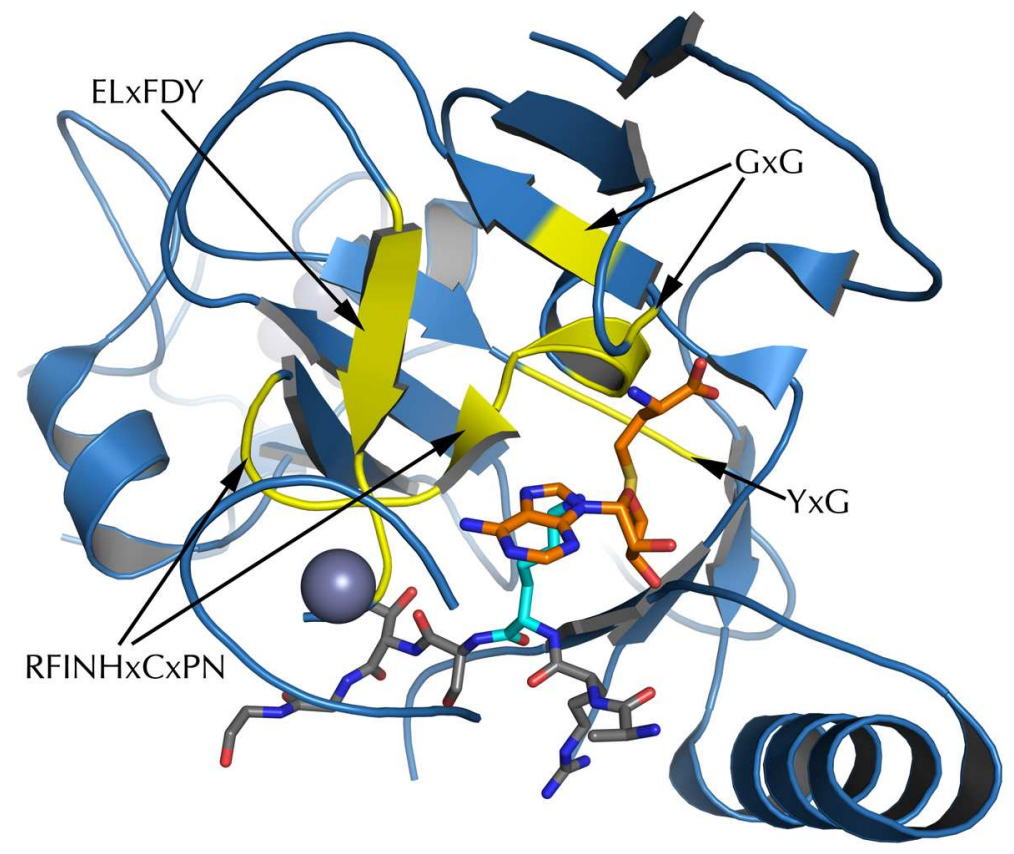

Abbildung 1.11: Kristallstruktur von Dim-5 aus Neurospora crassa. Gezeigt ist Dim-5 (blau) mit gebundenen Histon 3-Peptid (grau) und S-Adenosil-Homocystein (SAH, orange) gebunden hat. Die SET-Motive (gelb) und das Ziel-Lysin (cyan) des Peptids sind farblich hervorgehoben, ein Zink-Ion ist als Kugel dargestellt (grau). PDB-Eintrag: 1PEG, Zhang et al. (2003).

Was die Modifikation von Histonen betrifft, so ist eine Methylierung von Argininen denkbar. Diese Modifikation wird von PRMTs (engl. protein arginine methyltransferase) durchgeführt. Bekannte Motive der PRMTs wie der "double E-loop", eine Schleife mit zwei konservierten Glutaminsäure-Resten oder der "THW-loop", eine Schleife mit konservierter Abfolge von Threonin-Histidin- und Tryptophan-Resten kommen aber in LaeA nicht vor.

Es ist jedoch nicht ausgeschlossen, dass es sich bei LaeA um eine neue Pilzspezifische Histonmethyltransferase handelt, die ein unbekanntes Motif für die 


\section{Kapitel 1 | EINLEITUNG}

spezifische Erkennng von Histonen verwendet. Es ist auch möglich, dass LaeA nicht Histone, sondern andere Proteine methyliert und so in die Regulation eingreift.

Rolle in der Entwicklung

Die Identifizierung von LaeA als Hauptregulator des Sekundärmetabolismus geschah in einen Stamm mit veA1-Hintergrund und daher galt LaeA lange Zeit nur als Regulator des sekundären Metabolismus. Vor kurzem wurde die Rolle von LaeA bei der Entwicklung mit einem $v e A^{+}$-Hintergrund analysiert. In $\triangle l a e A-$ Mutanten sind mehrere Defekte zu erkennen. So ist die Zahl der Hüllezellen stark reduziert, gleichzeitig die der Fruchtkörper jedoch erhöht. Die Fruchtkörper weisen aber eine verringerte Größe auf und enthalten entsprechend nur 20\% der Ascosporen im Vergleich zum Wildtyp (Sarikaya Bayram et al., 2010). Eine weitaus interessantere Beobachtung ist jedoch, dass der $\Delta l a e A-S t a m m$ keinerlei Inhibierung bei der Formierung von Kleistothezien durch Licht aufweist. Dies ist ein Hinweis darauf, dass LaeA für die Licht-abhängige Reprimierung der Kleistothezienbildung notwendig ist.

\subsubsection{Velvet-ähnliche Komplexe in anderen Organismen}

Die Komponenten des Velvet-Komplexes wurden inzwischen auch in den Genomen anderer Pilze gefunden. Ähnlich wie in A. nidulans wird auch in Fusarium fujikuroi der Sekundärmetabolismus und die Entwicklung durch diesen Komplex gesteuert. Durch die Deletion des veA-sowie laeA-Homologs Ffvel1 und Fflae1 wurde ein positiver (Gibberelline, Fumonisin und Fusarin C) und negativer (Bikaverin) Einfluss von velvet auf den Sekundärmetabolismus beobachtet (Wiemann et al., 2010). Ein ähnlicher Einfluss auf die Konidiation und Virulenz von F. fujikuroi hatte das VelB-Homolog FfVel2. Einer der Erreger für Lungenentzündungen, Histoplasma capsulatum wächst bei Raumtemperatur mit Hyphen und wechselt zur Hefenform nach Aufnahme durch den Wirt. Anders als bei A. nidulans ist nicht Licht, sondern Temperatur der Auslöser der Morphogenese. Bei $37^{\circ} \mathrm{C}$ wechselt $H$. capsulatum in die Hefeform. Die Regulation dieser Morphogenese findet über Ryp1, Ryp2 (VosA-Ortholog) und Ryp3 (VelB-Ortholog) statt. Ähnlich zu A. nidulans werden Ryp2 und Ryp3 auch für die Inhibierung der verfrühten asexuellen Sporulation sowie Bildung von überlebensfähigen asexuellen Sporen benötigt (Webster und Sil, 2008).

Die Möglichkeit, einzelne Komponenten dieses Komplexes unter den verschiedenen Pilzen auszutauschen, bestärkt das Argument, dass es sich hier um einen sehr konservierten regulatorischen Komplex handelt. Der $\Delta l a e A$-Phänotyp von $A$. nidulans kann mit den F. fujikuroi lae1 komplementiert werden (Wiemann et al., 2010). Desweiteren kann der Verlust von veA in A. nidulans durch das N. crassa Homolog ve-1 komplementiert werden (Bayram et al., 2008c). 


\subsubsection{VosA}

VosA (Viability of Spores) ist ein $47 \mathrm{kDa}$ Protein, das die Biosynthese von Trehalose die Sporogenese reguliert. Für ersteres ist die Transkription von $t p s A$, tps $C$ und orl $A$ notwendig. Die Degradation von Trehalose geschieht durch das Produkt zweier Gene, die Trehalasen kodieren, tre $A$ und treB. Für die Synthese von Trehalose sind die tpsA/C- und orlA-Gene verantwortlich. Die Menge an tpsA/C- und orlA-Transkripten ist aber in einem $\Delta$ vosA-Stamm verringert, während diejenige von tre $A$ erhöht ist. Die gebildeten Sporen enthalten keine Trehalose und weisen sehr geringe Überlebensraten auf (Ni und $\mathrm{Yu}$, 2007) (Abb. 1.12). In Hinsicht auf die Sporogenese wirkt VosA auf $b r l A$ reprimierend und verhindert so eine verfrühte Konidiation.

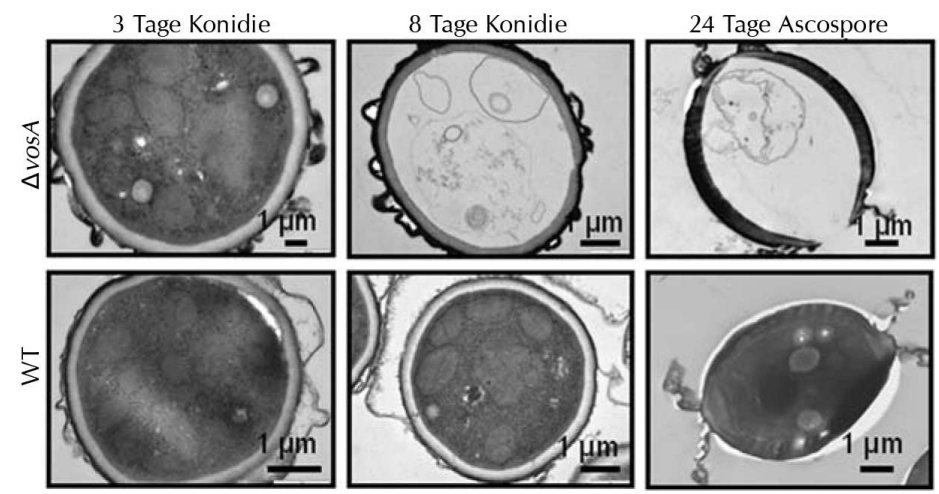

Abbildung 1.12: TEM-Bilder von A. nidulans Sporen aus WT- und $\triangle$ vosA-Stämmen. Organellen, Zellkern und andere Strukturen sind in den Sporen aus $\triangle$ vOSA nach acht Tagen nicht mehr erkennbar. adaptiert aus $\mathrm{Ni}$ und $\mathrm{Yu}$ (2007).

Weiterhin konnte gezeigt werden, dass eine Fusion der C-terminalen Hälfte (AS 214-C) von VosA an die DNA-Bindedomäne von Gal4 zur Expression von $\beta$-Galaktosidase in S. cerevisae führt. Eine Fusionierung der N-terminalen Hälfte (AS 1-214) oder des gesamten Proteins zeigten keine solche Aktivität.

Eine Interaktion von VosA mit LaeA und VelB konnte mittels der "Yeast2-Hybrid"-Methode gezeigt werden (Bayram et al., 2008b). Bei VosA handelt es sich auch um ein Velvet-Protein, die Velvet-Region umfasst die ersten 190 Aminosäuren. 


\section{Kapitel 1 | EINLEITUNG}

\subsection{Ziel dieser Arbeit}

Die Erforschung von Velvet begann mit einen Mutanten der durch Exposition mit Röntgenstrahlen generiert wurde. In der vorliegenden Arbeit sollte eine röntgenkristallographische Analyse der Velvet-Proteine VeA, VelB und VosA sowie des nicht-Velvet-Proteins LaeA durchgeführt werden.

$\mathrm{Zu}$ Beginn der Arbeit existierten relativ wenig biochemische Daten zu den einzelnen Proteinen des Velvet-Komplexes und zu VosA. Die veränderten Phänotypen lassen keinen eindeutigen Rückschluss auf die Funktion dieser Proteine auf molekularer Ebene zu. Ein Großteil der bekannten Interaktionen ist lediglich in vivo durch Fluoreszenz-markierte Proteine oder mittels Yeast-2-HybridVerfahren gezeigt worden. Viele Arbeiten haben Teile der generellen Signalkaskade, in der diese Proteine involviert rekonstruiert. Auch sind die meisten Gene, die von diesen Proteinen reguliert werden, bekannt. In Bezug auf Struktur und molekulare Funktionsweise herrscht jedoch ein Mangel an experimentellen Daten. Eine Funktionszuweisung anhand von Sequenzanalysen ist nicht möglich, da sie keinen bisher bekannten Proteinen ähneln.

$\mathrm{Ni}$ und $\mathrm{Yu}$ vermuteten aufgrund ihrer Arbeit an VosA, dass Velvet-Proteine Transkriptionsfaktoren sind (Ni und Yu, 2007). Eine Sequenzanalyse der VelvetProteine lässt jedoch kein bekanntes DNA-Bindemotiv erkennen. Es könnte sich hier um eine neue Klasse von DNA-Bindeproteinen handeln, oder die Vermutung ist falsch und Velvet-Proteine erfüllen ihre Funktion auf andere Weise. Eine Möglichkeit wäre, dass diese Proteine lediglich Gerüstproteine sind, die andere Proteine zusammenführen und dadurch zur Regulation beitragen. Die zweite Möglichkeit ist aufgrund der bekannten Interaktionen zwischen Velvet- und nicht-Velvet-Proteinen sehr wahrscheinlich. Es wurde erhofft, dass eine strukturelle Analyse neue Erkenntnisse über die molekulare Funktionsweise dieser Protein-Familie gibt.

Bei der putativen Methyltransferase LaeA ist nicht bekannt auf welches Molekül LaeA die Methylgruppe überträgt. Eine biochemische Analyse sollte dabei helfen das Ziel-Molekül von LaeA zu identifizieren.

Grundlage für die Strukturaufklärung mittels Röntgenkristallographie ist die Kristallisation der Proteine. Da sehr große Mengen an hochreinem Protein für die Kristallisation benötigt werden ist die erfolgreiche rekombinante Expression und Präparation aller Proteine und Proteinkomplexe notwendig. Hierfür ist die Etablierung von robusten Expressions- und Reinigungsprotokollen erforderlich. Bei Proteinen mit vollkommen unbekannter Struktur ist jedoch die Strukturbestimmung auch im Falle einer erfolgreichen Kristallisation nicht zwingend gegeben. Dies liegt daran das für die Bestimmung der Struktur das kristallographische Phasenproblem gelöst werden muss. Ausschlaggebend ist hier die Auswahl einer geeigneten Methode für die de novo-Phasierung der gesammelten Daten im Beugungsexperiment. 


\section{KAPITEL 2}

\section{Ergebnisse}

Der Ergebnisteil gliedert sich in acht Abschnitte, die sich jeweils mit der Präparation, Kristallisation und Strukturbestimmung der putativen Methyltransferase LaeA, der Velvet-Proteine VeA, VelB und VosA sowie die verschiedenen Komplexe dieser befassen.

\subsection{LaeA}

Es wurde versucht, Volllängen-LaeA als MBP- , GST- und $\mathrm{His}_{6}$-Fusionsprotein zu präparieren. Ein grundsätzliches Problem hierbei war die geringe Löslichkeit von LaeA in den verwendeten Puffern. Die Löslichkeit von LaeA konnte auch durch Komplexierung mit VeA bzw. VeA-VelB nicht erhöht werden. Nterminale Verkürzungen wiesen eine verbesserte Löslichkeit auf und konnten zur Homogenität in größeren Mengen präpariert werden.

\subsubsection{Volllängen-LaeA}

Volllängen-LaeA wurde, wie in 6.2.5.1 beschrieben, exprimiert und präpariert. MBP-LaeA wurde eindeutig überexprimiert (Abb. 2.1, Spur V und N). Der Großteil des Fusionsproteins befand sich nach Aufschluss im löslichen Überstand (Abb. 2.1, Spur Ü). Es konnte viel Ziel-Protein im Durchfluss- und in den Waschfraktionen detektiert werden konnte (Abb. 2.1, Spur W). Die Gesamtproteinmenge im Eluat (Spur E) betrug $45 \mathrm{mg}$.

Die Spaltung von MBP-LaeA durch die Zugabe von TEV-Protease (6.2.3.4) verlief vollständig (Abb. 2.3, Spur $-\mathrm{T}$ und $+\mathrm{T}$ ), es kam jedoch zu starker Präzipitatbildung. Der Überstand wurde über eine Superdex 75 26/60 Säule weiter gereinigt. Drei lokale UV-Maxima wurde detektiert, die laut Kalibrierung der Säule dem Ausschlussvolumen (Abb. 2.2 [1]), einen globulären Protein mit einer Größe von 80 - 90 kDa [2] und einem Protein mit etwa 40 - 50 kDa [3] entsprechen.

Es wurde vermutet, dass das zweite lokale UV-Maximum LaeA und das dritte MBP entspricht, da LaeA möglicherweise als Dimer vorliegen kann (Bayram et al., 2008b). Eine Dimerisierung von MBP ist zwar bekannt, aber diese wird 


\section{Kapitel 2 | ERGEBNISSE}

Abbildung 2.1: SDS-PA-Gel der Reinigung von MBP-LaeA mit Amylose. Aufgetragen sind Proteingrößenstandard $(\mathrm{M})$, Proben vor $(\mathrm{V})$ und nach (N) der Induktion mit IPTG, von unlöslicher (P) und löslicher (Ü) Fraktion, Durchfluss (D), Waschschritt (W) und Elution (E). MBP-LaeA (86 kDa) ist mit einem Pfeil markiert.

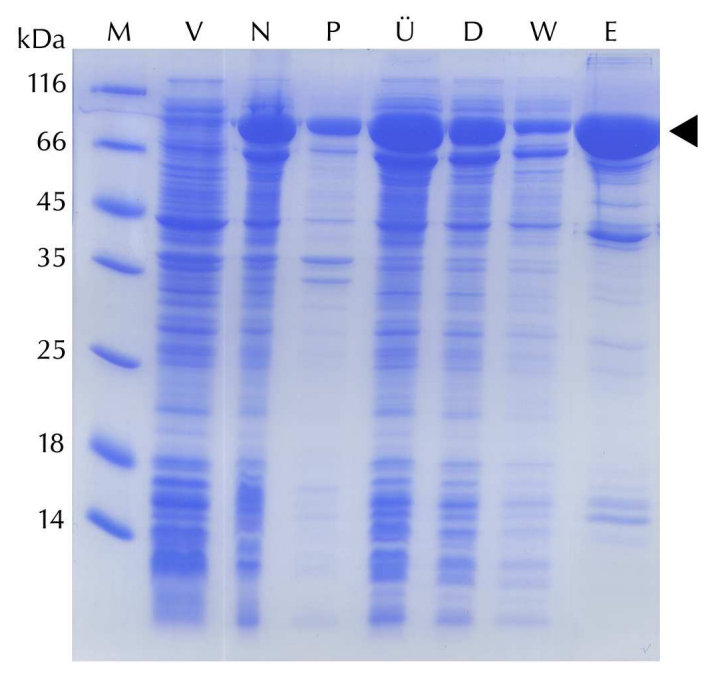

durch die Bindung des Liganden (Maltose) wieder aufgehoben (Richarme, 1982). Maltose wird durch eine Größenausschlusschromatographie oder Dialyse nur sehr ineffizient von MBP getrennt (Angabe vom Amylose-Hersteller, NEB).

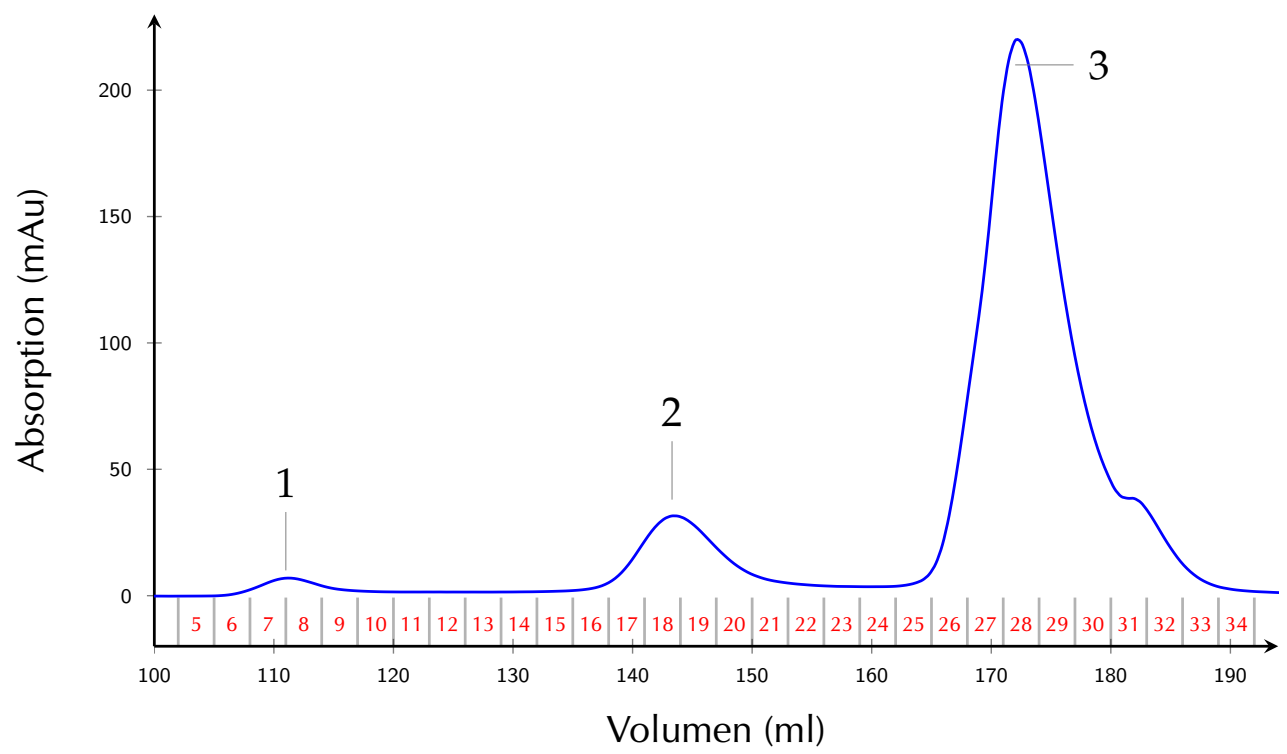

Abbildung 2.2: Chromatogramm der Größenausschlusschromatographie von geschnittenem Fusionsprotein (MBP + LaeA) über eine Superdex 75 26/60 Säule. Das erste UV-Maximum (1) entspricht dem Ausschlussvolumen der Säule, die anderen zwei denen von LaeA (2) und MBP (3). Blau: UVAbsorption bei $280 \mathrm{~nm}$ in gerätespezifischer Einheit (Y-Achse, $\mathrm{mAu}$ ) entlang des Elutionsvolumens (X-Achse, $\mathrm{ml}$ ). Gesammelte Fraktionen sind entlang der X-Achse nummeriert. 


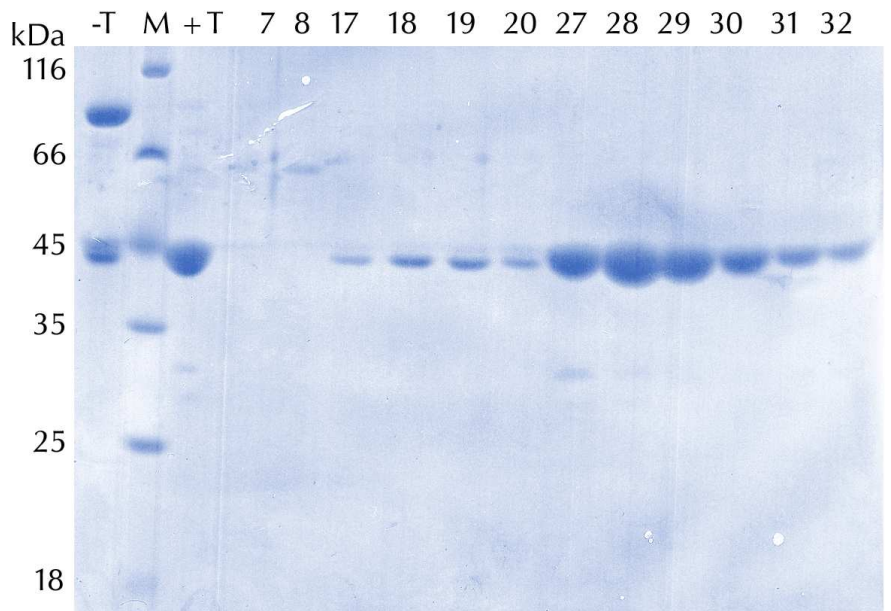

\begin{abstract}
Abbildung 2.3: SDS-PA-Gel der Größenausschlusschromatographie von geschnittenem Fusionsprotein (MBP + LaeA). Aufgetragen ist die verwendete Probe für die Gelfiltration (VG), Proteingrößenstandard (M), Eluat von der Amylose-Matrix vor (-T) und nach Verdau mit TEV-Protease $(+\mathrm{T})$ sowie Fraktionen aus der Gelfiltration (732). Die Fraktionsnummern beziehen sich auf die Fraktionen aus dem Chromatogramm in Abb. 2.2.
\end{abstract}

Trotzdem wurde für die Unterscheidung von MBP (42,9 kDa) und LaeA (43 kDa) eine massenspektrometrische Analyse von Dr. Oliver Valerius (Universität Göttingen) durchgeführt. Bei der oberen Bande (UV-Maximum 3) handelt es ich um MBP und bei der unteren um LaeA (UV-Maximum 2). Die Fraktionen 17 bis 29 enthielten insgesamt $1 \mathrm{mg}$ LaeA, konnten aber nicht höher als $0,65 \mathrm{mg} / \mathrm{ml}$ ankonzentriert werden.

Um die Ausbeute zu erhöhen, wurde versucht, die Löslichkeit von VolllängenLaeA zu verbessern. Eine signifikante Verbesserung der Löslichkeit von VolllängenLaeA konnte jedoch auch nach extensiver Variation der Expressions- und Reinigungsparameter nicht erzielt werden (nicht gezeigt). Zunächst wurde eine systematische Variation der Salz- und Glyzerinkonzentration beim Verdau mit der TEV-Protease getestet. Später wurde auch die Zugabe von SAM bei diesen Schritt evaluiert. Des weiteren wurden verschiedene Zelllinien [SoluBL21 (DE3) und ArcticExpress] und Expressionstemperaturen (12 bis $\left.20^{\circ} \mathrm{C}\right)$ getestet. Auch die Koexpression von unterschiedlichen Chaperonen oder Induktion dieser durch einen Hitze- und/oder Salzschock wurde durchgeführt. Schließlich wurde die Thermoflour-Methode angewendet um ein geeignetes Puffersystem / $\mathrm{pH}$-Wert zu finden, jedoch konnte hier keine Verschiebung in der Schmelztemperatur beobachtet werden (nicht gezeigt). Trotz all dieser Versuche konnte keine Verbesserung in der Löslichkeit erzielt werden.

Es wurde versucht die Löslichkeit durch zwei weitere Ansätze zu verbessern. Im ersten Ansatz wurde eine Komplexierung mit den natürlichen Interaktionspartner VeA oder VeA-VelB versucht, da diese Proteine relativ gut löslich waren. Die Ergebnisse dieser Komplexierung sind in 2.5.1 beschrieben. Im zweiten Ansatz wurden N-terminale Verkürzungen von LaeA generiert (2.1.2). Wegen der geringen Ausbeuten an Volllängen-LaeA konnten mit dem Volllängen-Protein keine Kristallisationsversuche durchgeführt werden. 


\section{Kapitel 2 | ERGEBNISSE}

\subsubsection{GST-LaeA91 und GST-LaeA101}

Die Generierung der LaeA-Verkürzungen basierte auf eine Sekundärstrukturvorhersage, die mit dem Programm PSI-PRED (Bryson et al., 2005) durchgeführt wurde. In dieser Vorhersage wurde mit einer hohen Sicherheit den ersten 80 Aminosäuren keine Sekundärstruktur zugeschrieben. Daher wurden zwei Konstrukte generiert denen jeweils die ersten 91 bzw. 101 Aminosäuren fehlten (GST-LaeA91 und 101). Als Affinitätssequenz wurde GST mit einer Schnittstelle für PreScission-Protease gewählt.

\subsubsection{Präparation von LaeA91 und LaeA101}

GST-LaeA91 und GST-LaeA101 wurden, wie in 6.2.5.2 beschrieben, exprimiert und präpariert. Da die Ergebnisse zu beiden Proteinen keine gravierenden Unterschiede aufweisen, ist hier nur die von GST-LaeA101 genauer beschrieben. GST-LaeA101 lag nach dem Zellaufschluß überwiegend im Pellet vor (Abb. 2.4A, Spur P). Die Elution enthielt nur noch wenige Verunreinigungen (Spur E). Anders als bei der Spaltung von GST- oder MBP-Volllängen-LaeA wurde kein Präzipitat beobachtet.
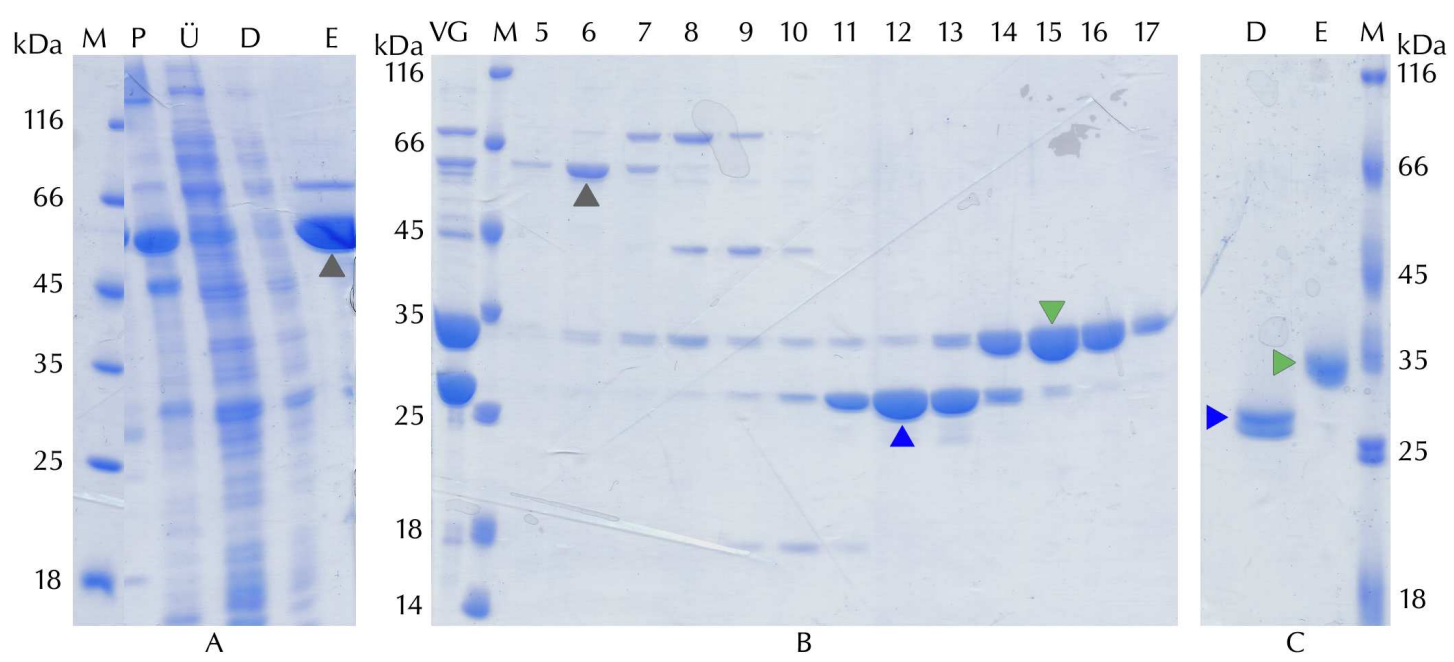

Abbildung 2.4: A: SDS-PA-Gel der affinitätschromatographischen Reinigung von GST-LaeA101 mit einer GSTrap $5 \mathrm{ml}$. Aufgetragen ist Proteingrößenstandard (M), Proben aus unlöslicher (P) und löslicher (Ü) Fraktion, Durchfluss (D) und Eluat (E) der GSH-Sepharose. B: SDS-PA-Gel der Größenausschlusschromatographie von GST + LaeA101. Aufgetragen ist die verwendete Probe vor Gelfiltration (VG), Proteingrößenstandard (M) und Fraktionen aus der Gelfiltration (5-17). Die Nummern beziehen sich auf die Fraktionen aus dem Chromatogramm in Abb. 2.5. C: SDS-PA-Gel Entfernung von GST aus LaeA101-Fraktionen über GSH-Sepharose. LaeA101 liegt im Durchfluss (D) und GST nur in der Elution $(E)$ vor. Ungeschnittenes GST-LaeA101 $(\approx 58 \mathrm{kDa})$ ist jeweils mit einem grauen Pfeil, GST $(\approx 27 \mathrm{kDa})$ mit einem blauen Pfeil und LaeA101 $(\approx 32 \mathrm{kDa})$ mit einem hellgrünen Pfeil markiert.

In der Gelfiltration wurden drei lokale UV-Maxima detektiert, mit nur geringen Mengen im Ausschluss (2.5). Es war möglich, LaeA101 von GST und aggregiertem Proteinen zu trennen (Abb. 2.4B). Restmengen an GST wurden durch 
erneutes Auftragen auf eine GSH-Sepharose entfernt (Abb. 2.4C, Spur ). Die Ausbeute an reinem LaeA101 aus $330 \mathrm{ml}$ ZYM5052-Expressionskultur lag bei 2,56 mg. Bei LaeA91 konnten mit der gleichen Strategie aus 21 2YT-Expressionskultur $28 \mathrm{mg}$ LaeA91 präpariert werden.

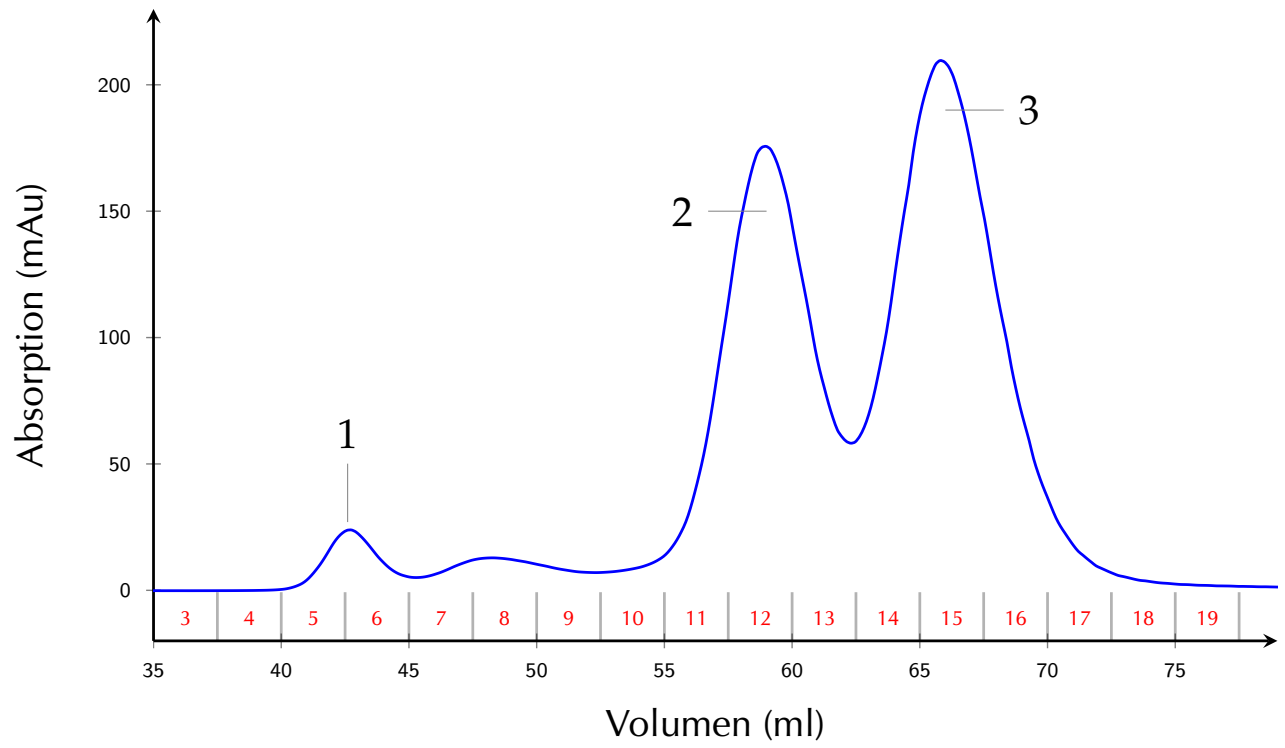

Abbildung 2.5: Chromatogramm der Größenausschlusschromatographie von geschnittenem Fusionsprotein (GST + LaeA101) über eine Superdex 75 16/60 Säule. Blau: UV-Absorption bei $280 \mathrm{~nm}$ in gerätespezifischer Einheit (Y-Achse, $\mathrm{mAu}$ ) entlang des Elutionsvolumens (X-Achse, $\mathrm{ml}$ ). Das erste UV-Maximum (1) entspricht dem Ausschlussvolumen der Säule, die anderen zwei denen von GST (2) und LaeA101 (3). Gesammelte Fraktionen sind entlang der X-Achse nummeriert.

\subsubsection{Kristallisation von LaeA91 und LaeA101}

Die Verkürzungen LaeA91 und LaeA101 konnten in ausreichenden Mengen gewonnen werden. Vor den Kristallisationsversuchen wurde S-Adenosyl-Methionin (SAM) in einem 5-fach molaren Überschuss zum Protein gegeben. Dabei wurde die Proteinlösung für wenige Sekunden trüb und anschließend wieder klar.

LaeA91 wurde mit einer Konzentration von $4,3 \mathrm{mg} / \mathrm{ml}$ bei 4 und $20{ }^{\circ} \mathrm{C}$ wie in 6.2.6.1 beschrieben pippettiert. Dabei wurden die Sammlungen JBscreens, JCSG, $\mathrm{AmSO}_{4}$ Suite und ProPlex verwendet.

LaeA101 wurde mit einer Konzentration von $8 \mathrm{mg} / \mathrm{ml}$ bei $20^{\circ} \mathrm{C}$ wie in 6.2.6.1 beschrieben pipettiert. Zum Einsatz kamen die Sammlungen JBScreens, JCSG, ProPlex und PGA.

Auch nach 6 Monaten konnte keine Kristallbildung in den Ansätzen von LaeA91 und -101 beobachtet werden. 


\section{Kapitel 2 | ERGEBNISSE}

\subsection{VelB}

VelB wurde im Vorfeld von Annette Berndt und Dr. Achim Dickmanns mit einer $\mathrm{N}-\mathrm{His}_{6}$-Sequenz gereinigt und versucht zu kristallisieren, was jedoch nicht erfolgreich war. Daher wurde versucht, Volllängen-VelB mit einer C-terminalen Affinitätssequenz ( $\mathrm{His}_{6}$ und Strep II) zu exprimieren und reinigen. Dabei war es nicht möglich, VelB in absolut reiner Form zu präparieren. Auch nach Verwendung von Proteaseinhibitoren waren immer Fragmente und Degradationsprodukte vorhanden, die nicht entfernt werden konnten. Erst die Komplexierung mit VeA erlaubte eine sehr reine Präparation (2.6.1). Im Verlauf der Arbeit wurde außerdem festgestellt, dass die VelB-Präparationen teilweise nach der Affinitätschromatographie mit DNA kontamiert waren. Nach Kristallisation und Strukturbestimmung des VosA-VelB-Komplex wurde eine spezielle Verkürzung von VelB generiert (VelB-mini), die in reiner Form präpariert werden konnte (2.2.2).

\subsubsection{Volllängen-VelB}

\subsubsection{Präparation von Volllängen-VelB}

C-His ${ }_{6}$-VelB (VelB) wurde, wie in 6.2.5.3 beschrieben, exprimiert und präpariert. VelB wurde gut überexprimiert und zeigte eine hohe Löslichkeit (nicht gezeigt). Die Elution der HisTrap $5 \mathrm{ml}$ Säule enthiehlt noch sehr viele Verunreinigungen (Abb. 2.6A).
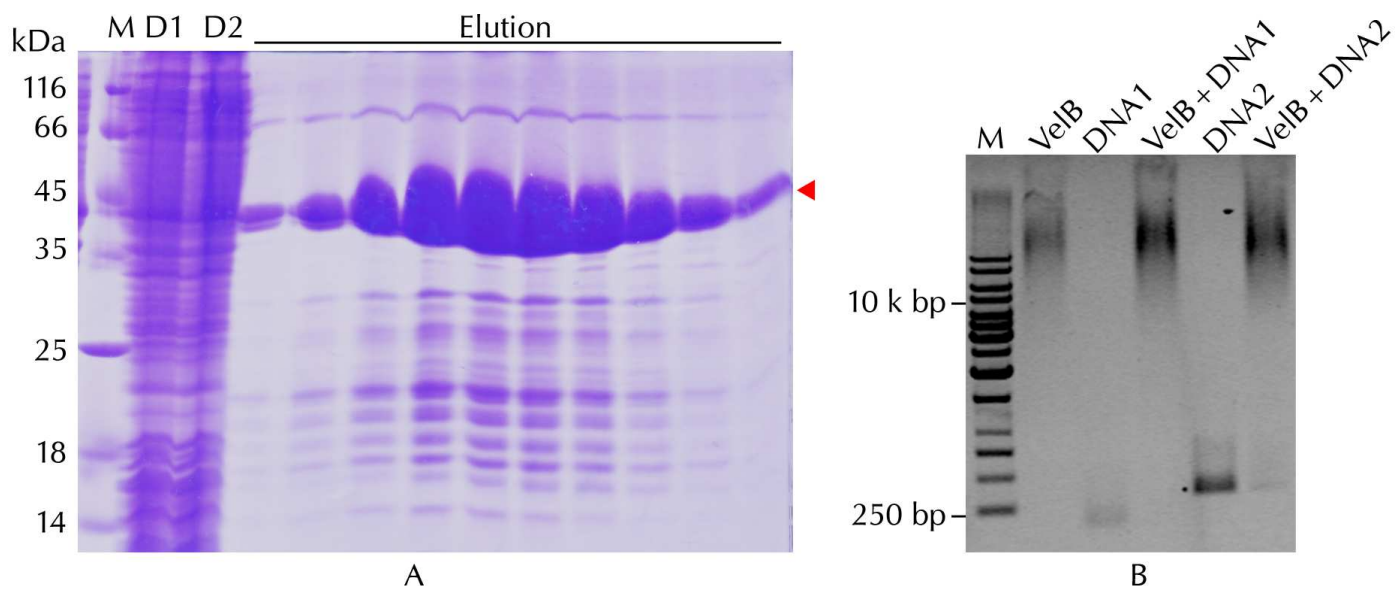

Abbildung 2.6: Reinigung von VelB und DNA-Bindungstest. A: SDS-PA-Gel der affinitätschromatographischen Reinigung von VelB mit einer HisTrap $5 \mathrm{ml}$ Säule. Aufgetragen sind Proteingrößenstandard (M), Proben vom Durchfluss (D1 - 2) und Eluat (Elution). C-His ${ }_{6}$-VelB $(41 \mathrm{kDa})$ ist markiert mit einen roten Pfeil. B: Agarosegel für die Detektion von DNA in VelB-Präparation und einfache DNA-Bindung durch diese (Gel-Retardation). Aufgetragen sind DNA-Größenstandard (M), VelB allein (VelB), 110 bp DNA (DNA1), VelB + DNA1, $\approx 300$ bp DNA (DNA2) und VelB + DNA2.

Es wurde vermutet, dass das sehr schmierige Laufverhalten von C-His $6^{-}$ VelB in der Elution durch DNA-Kontamination verursacht wird. Für den DNA- 
Nachweis wurden daher $150 \mu \mathrm{g}$ VelB auf einen Agarosegel geladen (Abb. 2.6B, Spur VelB). Zusätzlich wurde geprüft ob das präparierte VelB in der Lage ist weitere DNA zu binden, dafür wurden jeweils $150 \mu \mathrm{g}$ VelB mit etwa $2 \mu \mathrm{g}$ doppelsträngiger DNA $\left(\approx 110\right.$ und $300 \mathrm{bp}$ ) für eine Stunde bei $4{ }^{\circ} \mathrm{C}$ inkubiert über Agarosegel-Elektrophorese getrennt und mit Ethidiumbromid gefärbt. In der vorliegenden Protein-Präparation konnte DNA detektiert werden (Abb. 2.6B, Spur VelB). Auch konnte eine Bindung und daraus resultierende Veränderung im Laufverhalten der beiden DNA-Fragmente (Spur DNA1 und DNA2) durch die Proteinlösung (Spur VelB+DNA1 und VelB+DNA2) beobachtet werden.

Anschließend wurde VelB erneut präpariert, jedoch wurden $2 \mathrm{M} \mathrm{LiCl} \mathrm{zum}$ Zellaufschluss gegeben um Nukleinsäuren zu fällen. Die Löslichkeit von VelB wurde dadurch nicht beinträchtigt (Abb.2.7A, Spur P und Ü). Auf einem SDSPA-Gel war die Reinheit in etwa gleich wie die Präparation ohne $2 \mathrm{M} \mathrm{LiCl}$.
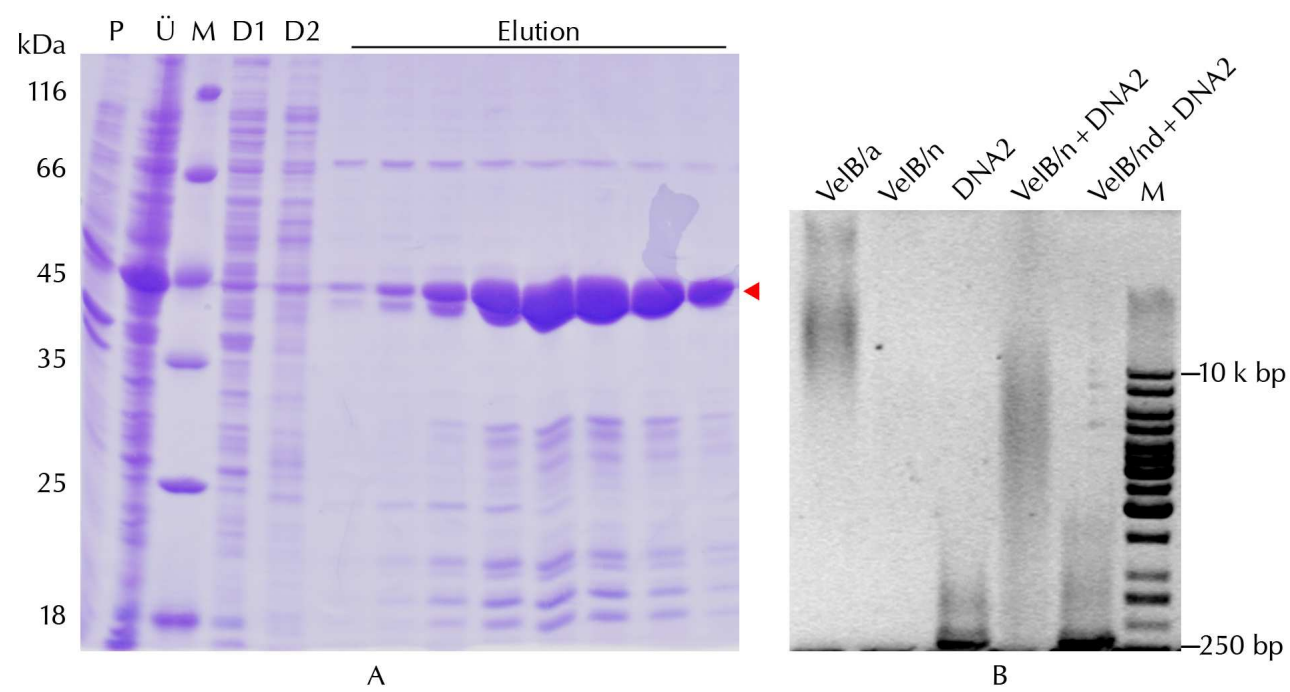

Abbildung 2.7: VelB-Präparation mit $2 \mathrm{M} \mathrm{LiCl}$ im Lysepuffer und DNA-Bindungstest. A: SDS-PA-Gel der affinitätschromatographischen Reinigung von C-His ${ }_{6}-$ VelB mit einer HisTrap $5 \mathrm{ml}$. Aufgetragen sind Proben vor $(\mathrm{V})$ und nach $(\mathrm{N})$ Induktion mit IPTG, unlösliche $(\mathrm{P})$ und lösliche (Ü) Fraktion, Proteingrößenstandard (M), Durchfluss (D1 - 2) und Eluat (Elution). C-His ${ }_{6}-\mathrm{VelB}(41 \mathrm{kDa})$ ist mit einem roten Pfeil markiert. B: Agarosegel für die Detektion von DNA in C-His $s_{6}-$ VelB-Präparation und einfache DNA-Bindung durch diese. Aufgetragen sind alte C-His $s_{6}-$ VelB-Präparation (VelB/a), neue C-His ${ }_{6}$-VelB-Präparation $(\mathrm{VelB} / \mathrm{n}), \approx 300$ bp D-DNA Fragment (DNA2), neues C-His ${ }_{6}$-VelB inkubiert mit DNA2 (VelB/n + DNA2), neues hitze-denaturiertes VelB inkubiert mit DNA2 (VelB/nd + DNA2) und DNA-Größenstandard (M).

Im Gegensatz zu der Reinigung ohne Lithiumchlorid $(\mathrm{LiCl})$ war die Reinigung mit 2M LiCl nicht mit DNA kontaminiert (Abb. 2.7B, Spur VelB/a und $/ \mathrm{n})$. DNA-Bindeaktivität konnte auch in dieser Präparation beobachtet werden (Spur VelB/n+DNA2). Diese Aktivität wurde stark reduziert, wenn vor Zugabe der DNA die Proteinlösung für 3 Minuten bei $80^{\circ} \mathrm{C}$ inkubiert wurde (Spur $\mathrm{VelB} / \mathrm{nd}+\mathrm{DNA} 2)$. 


\section{Kapitel 2 | ERGEBNISSE}

In der Größenauschlusschromatographie eluierte VelB in zwei lokalen UVMaxima. Das Elutionsvolumen der UV-Maxima entspricht etwa 80-90 kDa (UVMaximum 1) und 40-50 kDa (UV-Maximum 2). VelB aus UV-Maximum 1 enthielt weniger Verunreinigungen als VelB aus UV-Maximum 2 (Abb. 2.9A, Spuren 6-7 und 8-10). Diese Verunreinigungen konnten auch in weiteren Experimenten und mit einem Anionentauscher (Source 30Q) nicht entfernt werden (Abb. 2.9B).

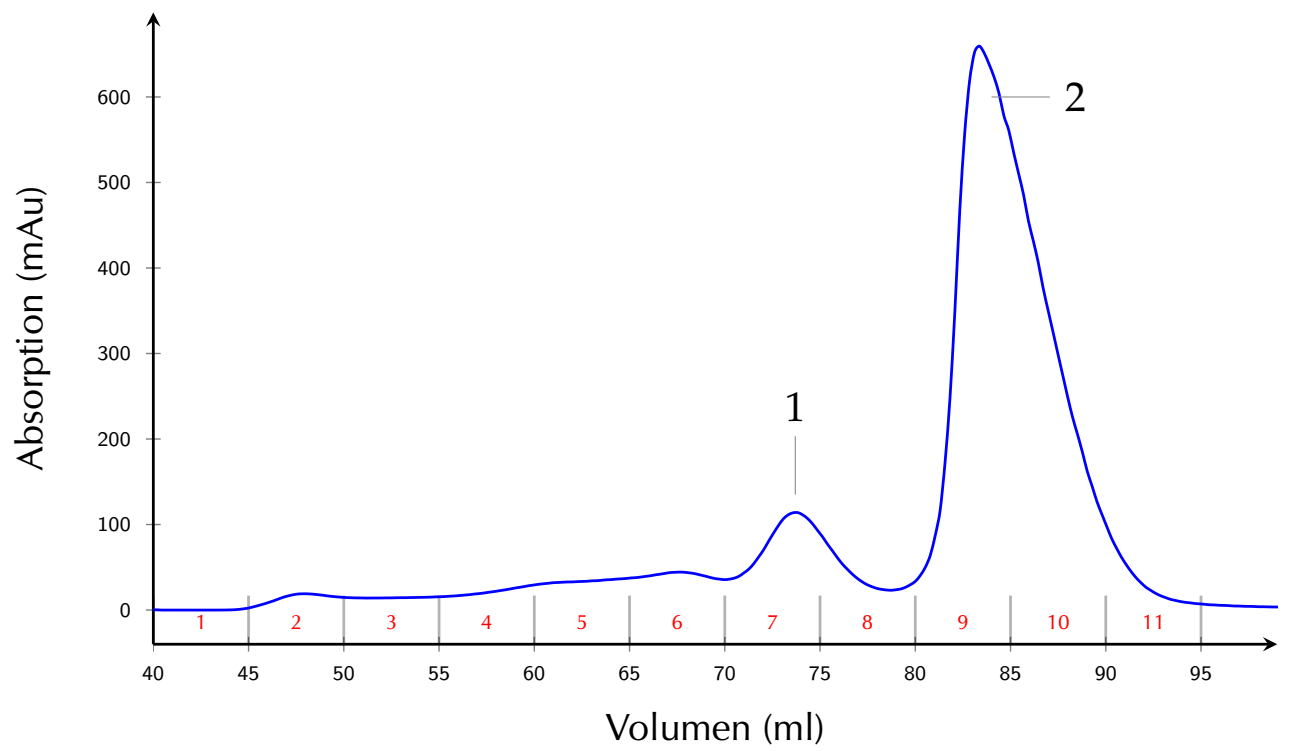

Abbildung 2.8: Chromatogramm der Größenausschlusschromatographie von VelB über eine Superdex 200 16/60 Säule. Das erste UV-Maximum (1) entspricht dimerem VelB, das zweite (2) monomerem. Blau: UV-Absorption bei $280 \mathrm{~nm}$ in gerätespezifischer Einheit (Y-Achse, $\mathrm{mAu}$ ) entlang des Elutionsvolumens (X-Achse, $\mathrm{ml}$ ). Gesammelte Fraktionen sind entlang der X-Achse nummeriert.

Die Ausbeute lag mit dieser Methode bei $7 \mathrm{mg}$ dimerem und $\approx 80 \mathrm{mg}$ monomerem VelB aus 11 2YT-Expressionskultur. Protein aus Fraktion 7 und 9 wurde auf DNA-Bindeaktivität geprüft. Lediglich bei Fraktion 7 konnte eine Verschiebung der DNA auf den Agarosegel beobachtet werden (Abb. 2.9C, Spur F7+D). In keiner der beiden Proteinlösungen konnte eine DNA-Kontamination detektiert werden (Spur F7 und F9). In späteren Experimenten wurde festgestellt das $2 \mathrm{M}$ $\mathrm{LiCl}$ für den Aufschluss nicht notwendig ist, da das Eluat der Gelfiltration i.d.R. frei von DNA-Kontamination war (nicht gezeigt). Weiterhin wurde beobachtet das monomeres VelB eingefroren, bei $-80^{\circ} \mathrm{C}$ gelagert und ohne Probleme wieder aufgetaut werden konnte, dimeres VelB hingegen beim Auftauen größtenteils ausfiel. 

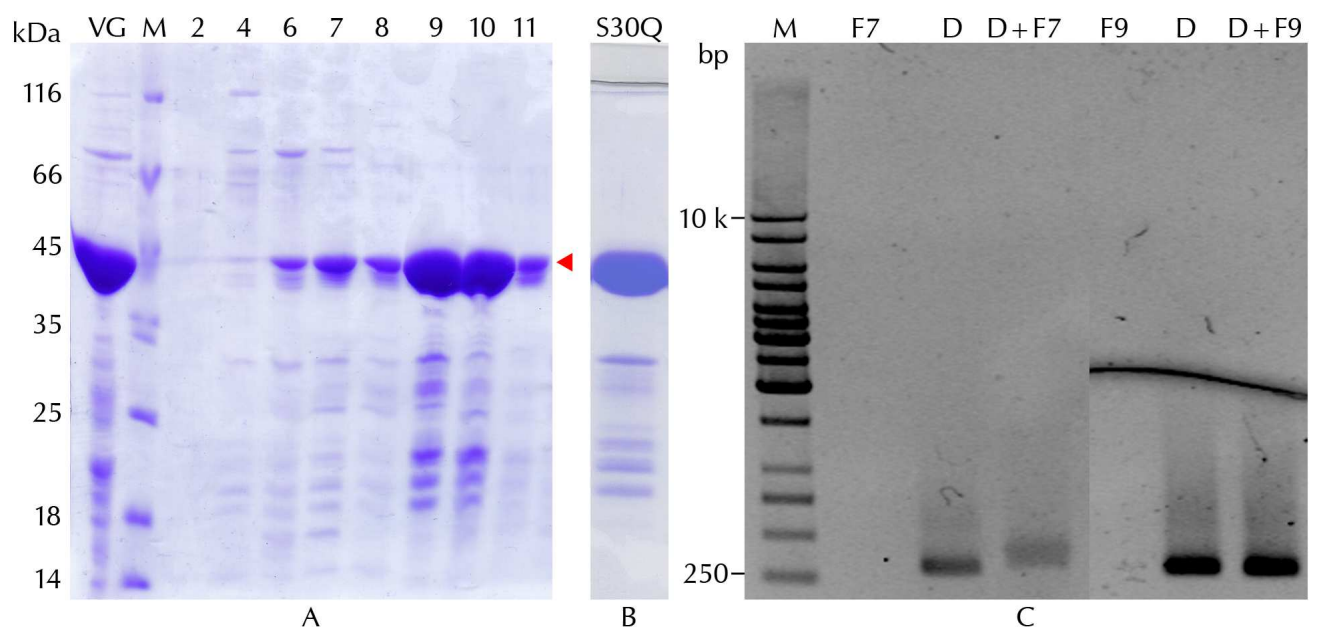

Abbildung 2.9: Gereinigtes VelB und DNA-Bindungstest mit VelB. A: SDS-PA-Gel der Größenausschlusschromatographie von VelB. Aufgetragen ist die Probe vor Gelfiltration (VG), Proteingrößenstandard $(M)$ und Fraktionen aus der Gelfiltration (2-11). Die Nummern beziehen sich auf die Fraktionen aus dem Chromatogramm in Abb. 2.8. VelB (41 kDa) ist mit einem roten Pfeil markiert. B: VelB-Eluat des Source 30Q Anionentauschers (S30Q). C: Agarosegel für die Detektion von DNA in Fraktion 7 und 9 aus Gelfiltration (2.8) von VelB und qualitative Überprüfung der DNA-Bindeaktivität. Aufgetragen sind DNA-Größenstandard, Fraktion 7 und 9 aus Gelfiltration (Spur F7 und F9), $\approx 300$ bp DNA2 Fragment (D) sowie Fraktion 7 und 9 inkubiert mit D-DNA (F7 + D und F9+D).

\subsubsection{Kristallisation von Volllängen-VelB}

Eine extensive Suche nach geeigneten Kristallisationsbedingungen für monomeres VelB wurde bereits in Vorarbeiten von Annette Berndt und Dr. Achim Dickmanns durchgeführt. Es konnten dabei keine Proteinkristalle gefunden werden, daher wurde im folgenden nur dimeres VelB für die Kristallisation verwendet. Zum Einsatz kamen die in 6.1.10.2 aufgeführten Kristallisationslösungen. Kristallisationsansätze wurden sowohl bei 4 als auch $20^{\circ} \mathrm{C}$ inkubiert. Die getesten Proteinkonzentration variierten zwischen 2,5 und $40 \mathrm{mg} / \mathrm{ml}$. Es wurden auch Spuren von Proteasen (Trypsin und Chymotrypsin, 1:100) zur Kristallisationsbedingung gegeben um flexible Teile des Proteins zu entfernen und so die Kristallisation zu fördern (Dong et al., 2007). Aber auch durch diesen Ansatz war es nicht möglich, Kristalle von VelB zu erhalten. Der Schwerpunkt wurde daher auf die Rekonstituierung eines Komplexes mit LaeA-VeA, VeA oder VosA gelegt. Zu einem späteren Zeit wurde aufgrund neuer Erkenntnisse eine spezielle Verkürzung von VelB generiert, diese ist Gegenstand des nächsten Abschnitts. 


\section{Kapitel 2 | ERGEBNISSE}

\subsubsection{VelB-mini}

VelB konnte zusammen in einem Komplex mit verkürzten VosA (VosA190S) kristallisiert werden. Lediglich die Reste, die als (Teil der) Velvet-Region gelten, konnten in der Elektronendichte lokalisiert werden (s. Abb. 1.10, S. 15). Die Verkürzung, die generiert wurde, enthielt die Aminosäuren 44-126 und 240-343. Die Aminosäuren 127-239 wurden durch eine Schleife ersetzt, die aus dem strukturell ähnlichen Bereich von VosA übernommen wurden. Es handelt sich hier um eine Abfolge von acht Aminosäure (ASIPPSTA). Als Affinitätssequenz wurde eine C-terminale His $_{6}$-Markierung gewählt. Mit dieser speziellen Verkürzung sollte geklärt werden, ob VelB-mini in Lösung als Monomer oder Dimer vorliegt und ob es korrekt gefaltet ist. Letzeres wurde durch die Komplexierung mit VeA224S (2.6.2) und VosA190S (2.8.6) überprüft.

\subsubsection{Präparation von VelB-mini}

VelB-mini wurde wie in 6.2.5.4 beschrieben exprimiert und präpariert. Nach dem ersten Reinigungsschritt mit einer HisTrap Säule lag VelB-mini (22,5 kDa) bereits in sehr reiner Form vor (Abb. 2.10A).
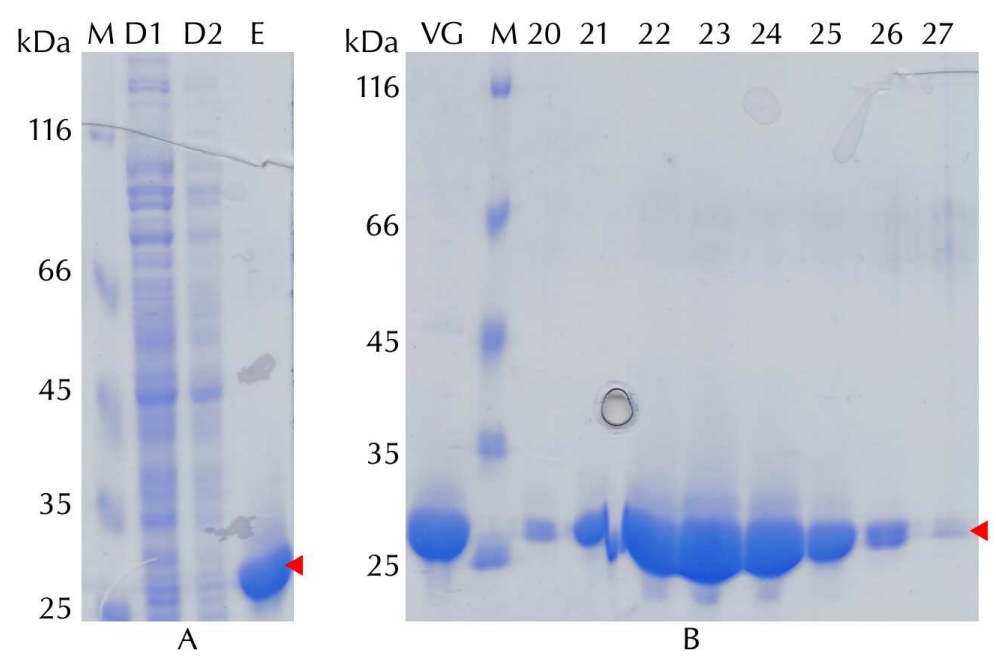

Abbildung 2.10: A: SDS-PA-Gel der affinitätschromatographischen Reinigung von VelB-mini mit
einer HisTrap $5 \mathrm{ml}$ Säule. Aufgetragen sind Proteingrößenstandard (M), Proben vom Durchfluss
(D1-2) und Elution (E). B: SDS-PA-Gel der Gelfiltration von VelB-mini mit einer Superdex $20016 / 60$
Säule. Aufgetragen sind Probe vor Gelfiltration (VG), Proteingrößenstandard (M) und Fraktionen der
Gelfiltration (nicht gezeigt). VelB-mini ( $(22,5 \mathrm{kDa})$ ist in beiden Gelen mit einem roten Pfeil markiert.

Die weitere Reinigung erfolgte mit einer Superdex 200 16/60 Säule. VelB-mini eluierte in einem UV-Maximum, das auch etwa der Größe von monomerem VelBmini entsprach (nicht gezeigt). Nach der Gelfiltration waren nur noch wenige Verunreinigungen zu erkennen (2.10B). Es wurde nicht versucht, diese durch weitere Reinigungsschritte zu entfernen. Durch diese Reinigungsprozedur war es möglich, $35 \mathrm{mg}$ hochreines VelB-mini aus $500 \mathrm{ml}$ ZYM5052-Autoinduktionskultur $\mathrm{zu}$ isolieren. 


\subsubsection{Kristallisation von VelB-mini}

Kristallisationsversuche wurden mit dem Pipettier-Roboter (6.2.6.1) angesetzt. Es wurden alle in 6.1.10.1 aufgeführten Sammlungen mit einer Konzentration von 11,5 sowie $6,5 \mathrm{mg} / \mathrm{ml}$ pipettiert. Die Kristallisationsplatten wurden bei $20^{\circ} \mathrm{C}$ inkubiert. Es konnten auch nach längerer Zeit keine Kristalle von VelB-mini in den Ansätzen beobachtet werden.

\section{$2.3 \mathrm{VeA}$}

Volllängen-VeA allein konnte nicht zur Homogenität gereinigt werden, wies aber auch eine DNA-Bindung auf (nicht gezeigt). Es wurde daher eine Verkürzung von VeA generiert, die die ersten 224 Aminosäuren enthält. Dieser Bereich beinhaltet die N-terminale Kernlokalisationssequenz und die Velvet-Domäne von VeA. Als Affinitätssequenz wurde eine C-terminale Strep II-Markierung gewählt. Die Expression und Reinigung ist in 6.2.5.5 beschrieben.

\subsubsection{Präparation von VeA224S}

Bei der Präparation von VeA224S wurde beobachtet das ein großer Teil von VeA224S im Durchfluss der StrepTactin HP-Säule (Spur D1 und 2) vorlag. Das Eluat enthielt 6,3 mg VeA224S (25,8 kDa) in hochreiner Form. Es wurde direkt für die Kristallisation verwendet. In späteren Experimenten wurde die Monodispersität von VeA224S durch Gelfiltration untersucht, VeA224S eluierte in einem UV-Maximum (nicht gezeigt). Das Elutionsvolumen entsprach laut Kalibrierung der Säule etwa einem globulären Protein mit einer Größe von etwa 40-50 kDa.

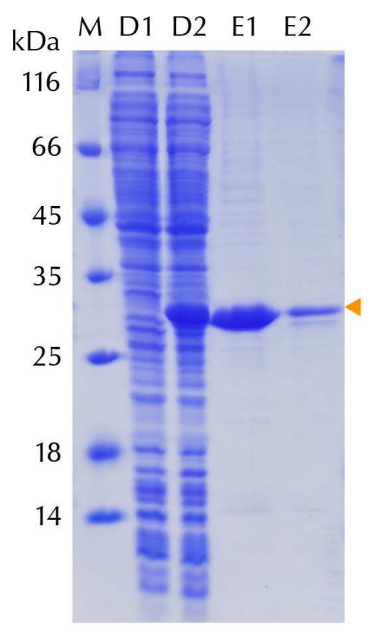

Abbildung 2.11: SDS-PA-Gel der affinitätschromatographischen Reinigung von VeA224S mit einer StrepTactin HP $5 \mathrm{ml}$ Säule. Aufgetragen sind Proben Proteingrößenstandard (M), Proben vom Durchfluss (D1 - 2) und Eluat (E1 - 2). VeA224S (25,8 kDa) ist mit einem orangenen Pfeil markiert. 


\section{Kapitel 2 | ERGEBNISSE}

\subsubsection{Kristallisation von VeA224S}

VeA224S wurde einer systematischen Suche nach Kristallisationsbedingungen unterzogen. Es wurden die Lösungen JBScreens, ProPlex und JCSG (6.2.6.1) mit je zwei Konzentrationen $(5,2$ und $13,5 \mathrm{mg} / \mathrm{ml})$ pipettiert. Die Inkubation der Ansätze erfolgte bei $20^{\circ} \mathrm{C}$. Nach ein bis zwei Tagen konnten in zahlreichen Bedingungen Kristalle beobachtet werden (Abb. 2.12), die eine ähnliche Form wie die VosA190S-Kristalle hatten (Abb. 2.25, S. 43). Die meisten Bedingungen waren PEG-basiert, wenige enthielten als Präzipitanz eine Sulfat-Verbindung.
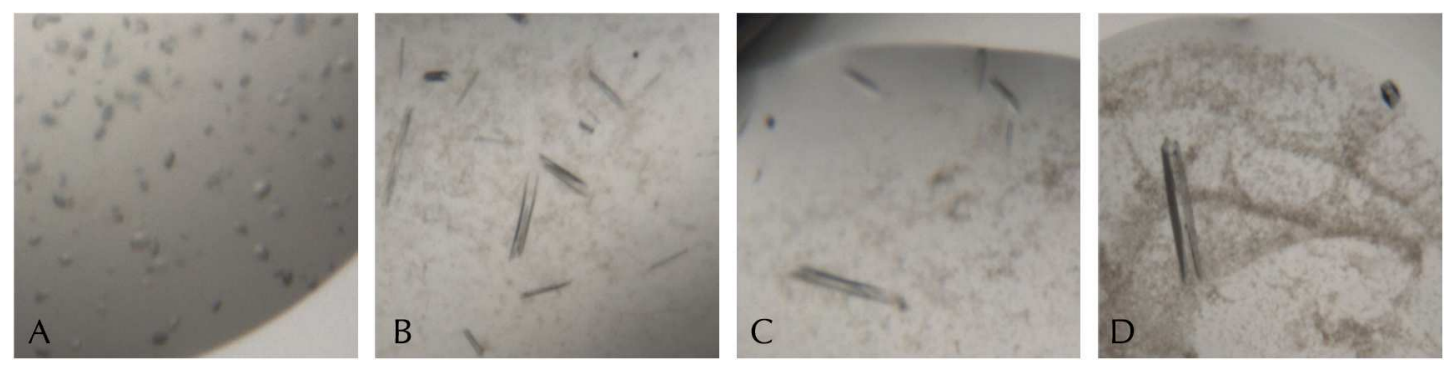

Abbildung 2.12: Kristalle von VeA224S. Die Bedingungen enthalten $100 \mathrm{mM} \mathrm{MES} \mathrm{pH} \mathrm{6,5} \mathrm{und}$ 1,6 $\mathrm{M} \mathrm{MgSO}_{4}$ (A), $200 \mathrm{mM}\left(\mathrm{NH}_{4}\right)_{2} \mathrm{SO}_{4}, 100 \mathrm{mM}$ Bis-Tris pH 5,5 und 25\% (w/v) PEG 3350 (B), $200 \mathrm{mM} \mathrm{MgCl} 2,100 \mathrm{mM}$ Bis-Tris pH 5,5 und 25\% (w/v) PEG 3350 (C) und 8\% PEG 8000 und $100 \mathrm{mM}$ Tris/ $\mathrm{HCl} \mathrm{pH} \mathrm{8,5} \mathrm{(D).} \mathrm{Die} \mathrm{Kristalle} \mathrm{sind} \mathrm{nach} \mathrm{ein} \mathrm{bis} \mathrm{drei} \mathrm{Tagen} \mathrm{bei} 20^{\circ} \mathrm{C}$ gewachsen. Die Proteinkonzentration beträgt 5,2 (A-C) bzw. $13,5 \mathrm{mg} / \mathrm{ml}$ (D).

\subsubsection{Datensammlung von VeA224S}

Es wurden zwei VeA224S-Kristalle gemessen, die aus den folgenden Bedingungen stammten:

- $8 \%$ PEG 8000, $100 \mathrm{mM}$ Tris/ $\mathrm{HCl} \mathrm{pH} \mathrm{8,5}$

- $25 \%$ PEG 3350, $200 \mathrm{mM}\left(\mathrm{NH}_{4}\right)_{2} \mathrm{SO}_{4}, 100 \mathrm{mM}$ BisTris/HCl pH 5,5

Beide Kristalle wurden mit 12 \% (v/v) 1,4-Butandiol eingefroren und am Synchrotron Swiss Light Source (SLS, Villigen, Schweiz) gemessen. Es konnte jeweils ein Datensatz aufgenommen werden. Die Datenstatistiken hierzu sind in Tabelle 2.1 aufgeführt. 
Tabelle 2.1: Statistik zur Datensammlung der VeA224S-Kristalle

\begin{tabular}{|c|c|c|}
\hline & VeA224S-Kristall 1 & VeA224S-Kristall 2 \\
\hline Messstation & \multicolumn{2}{|c|}{ SLS, X06SA (Villigen, Schweiz) } \\
\hline Wellenlänge [Å] & \multicolumn{2}{|c|}{0,80000} \\
\hline Raumgruppe & \multicolumn{2}{|c|}{$\mathrm{P} 2{ }_{1} 2{ }_{1} 2$} \\
\hline Zellkonstanten $[\AA]$ & \multicolumn{2}{|c|}{$a=52.86, b=106.17, c=156.26$} \\
\hline Winkel $\left[{ }^{\circ}\right]$ & \multicolumn{2}{|c|}{$\alpha=\beta=\gamma=90$} \\
\hline Auflösung [Å] & $\begin{array}{l}50,00-2,97 \\
(3,07-2,97)^{*}\end{array}$ & $\begin{array}{l}50,00-2,82 \\
(2,89-2,82)^{*}\end{array}$ \\
\hline $\mathrm{R}_{\text {merge }}[\%]$ & $4,4(51,0)^{*}$ & $3,4(50,6)^{*}$ \\
\hline Signal/Rauschen $(I / \sigma)$ & $23,1(2,9)^{*}$ & $26,6(2.9)^{*}$ \\
\hline Vollständigkeit [\%] & $99,5(99,6)^{*}$ & $99,3(99,8)^{*}$ \\
\hline Redundanz & $4,0(4,1)^{*}$ & $3,6(3,8)^{*}$ \\
\hline
\end{tabular}

* Werte in Klammern sind jeweils für die höchstaufgelöste Schale.

\subsubsection{Strukturbestimmung von VeA224S}

Die gesammelten Daten konnten erfolgreich mit molekularem Ersatz phasiert werden. Als Suchmodell wurden Fragmenten von VosA190S verwendet. Die Strukturbestimmung von VeA224S ist noch nicht abgeschlossen. Ausgehend von den vorhandenen Daten ist VeA224S wie VosA auch ein Dimer, die Anordnung der VeA224S-Moleküle ist jedoch anders als beim VosA-VosA-Homo bzw. VelBVosA-Heterodimer. Der Modellbau und die detaillierte Strukturanalyse steht noch aus.

\subsection{Importin $\alpha \Delta \mathrm{IBB}-\mathrm{VeA}-K o m p l e x$}

Da VeA weder alleine noch im Komplex mit VelB kristallisiert werden konnte wurde versucht VeA mit Importin $\alpha$ zu komplexieren. Humanes Importin $\alpha$ ist ein Ortholog zu Aspergillus nidulans KapA, das für den Import von VeA in den Zellkern verantwortlich ist. Statt Volllängen-Importin $\alpha$ wurde eine Verkürzung verwendet, der die autoinhibierende Importin $\beta$ Bindedomäne (IBB) fehlt (Imp $\alpha$ $\triangle \mathrm{IBB})$. Das Plasmid hierfür wurde von Dr. Achim Dickmanns zur Verfügung gestellt. Der Komplex wurde wie in 6.2.5.6 beschrieben rekonstituiert.

Beide Proteine konnten in der Elution der HisTrap-Säule beobachtet werden (Abb. 2.13, Elution H). Außerdem waren noch sehr viele Verunreinigungen vorhanden. Durch die Verwendung einer GSH-Sepharose konnten die meisten dieser Verunreinigungen entfernt werden. Hier konnten im Durchfluss beide Proteine detektiert werden, wobei VeA im Überschuss vorlag (Abb. 2.13, Spur DG). In der Elution der GSH-Sepharose lagen beide Protein in etwa gleichen Mengen und relativ rein vor (Abb. 2.13, Spur Elution G). Die Abspaltung der 


\section{Kapitel 2 | ERGEBNISSE}

\begin{abstract}
Abbildung 2.13: SDS-PA-Gel der affinitätschromatographischen Reinigung von des $\mathrm{C}-\mathrm{His}_{6}-\mathrm{VeA}$ und GST-Importin $\alpha \triangle \mathrm{IBB}$ mit einer HisTrap und GSH-Sepharose. Aufgetragen sind Durchfluss (DH und DG) und Eluat (Elution) beider Schritte sowie ein Proteingrößenstandard (M). $\mathrm{C}-\mathrm{His}_{6}-\mathrm{VeA}(\approx 64 \mathrm{kDa})$ ist mit einem orangenen, GST-Importin $\alpha \Delta \mathrm{IBB}(\approx 78 \mathrm{kDa})$ mit einem schwarzen, Importin $\alpha \Delta \mathrm{IBB}(\approx 51 \mathrm{kDa})$ mit einem violetten und GST mit einem blauen Pfeil markiert.
\end{abstract}

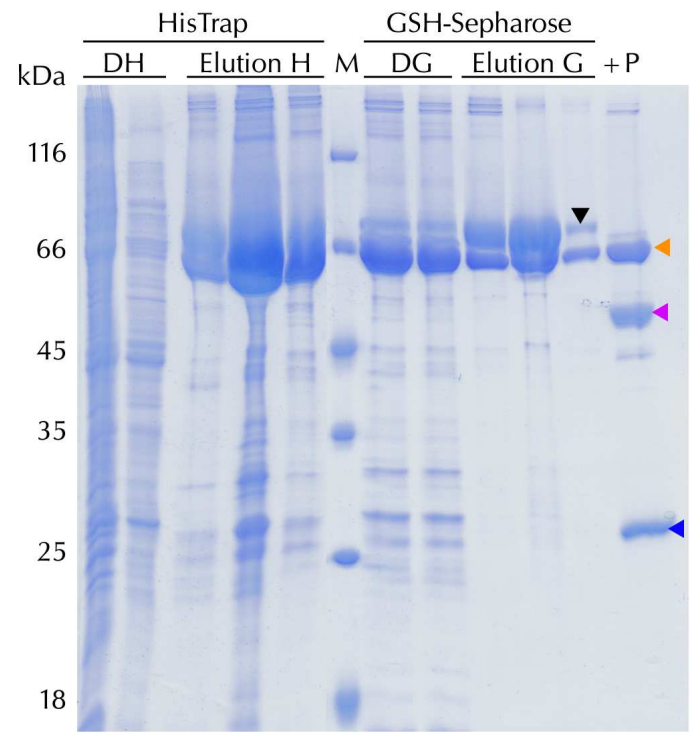

GST-Affinitätssequenz von GST-Importin $\alpha \Delta \mathrm{IBB}$ durch Zugabe von PreScissionProtease war vollständig (Abb. 2.13, Spur $+\mathrm{P}$ ).

Die Entfernung von GST durch Gelfiltration war erfolgreich, GST eluierte in einem zweiten lokalen UV-Maximum. Eine Verunreinigung bei etwa $45 \mathrm{kDa}$ konnte somit auch teilweise vom Ziel-Komplex getrennt werden (Abb. 2.15, Spur 11-17).

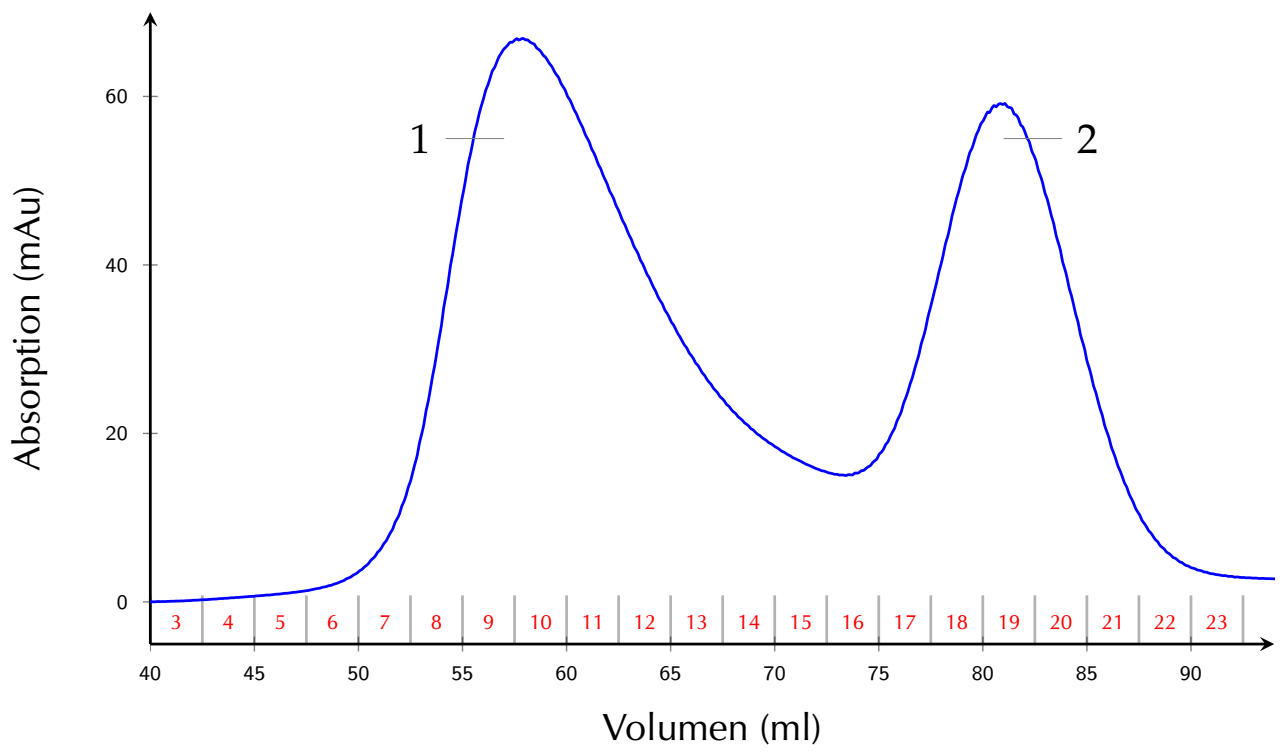

Abbildung 2.14: Chromatogramm der Größenausschlusschromatographie des Imp $\alpha \Delta$ IBB-VeAKomplexes mit einer Superdex 200 16/60 Säule. Das erste UV-Maximum (1) entspricht den Imp $\alpha$ $\triangle$ IBB-VeA-Komplex und das zweite (2) GST. Blau: UV-Absorption bei $280 \mathrm{~nm}$ in gerätespezifischer Einheit (Y-Achse, $\mathrm{mAu}$ ) entlang des Elutionsvolumens (X-Achse, $\mathrm{ml}$ ). Gesammelte Fraktionen sind entlang der X-Achse nummeriert. 


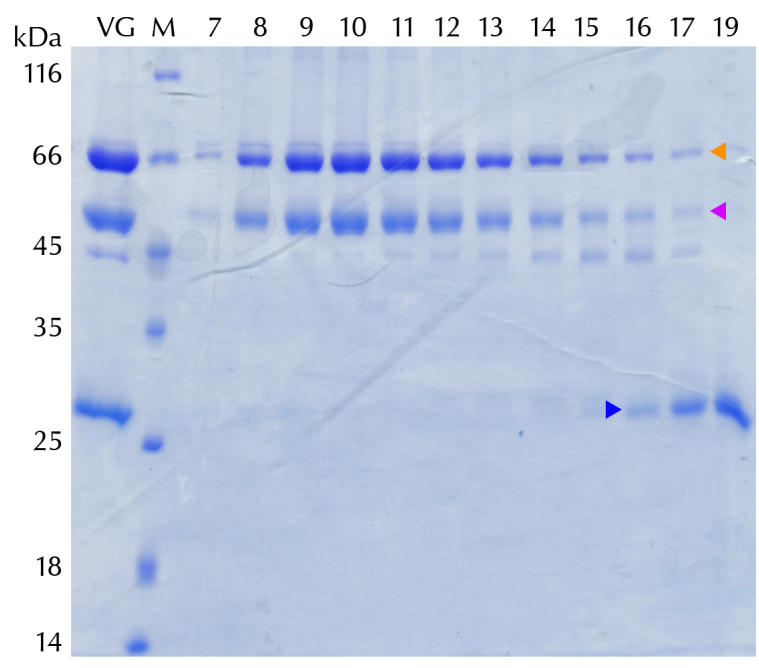

Abbildung 2.15: SDS-PA-Gel der Größenausschlusschromatographie des GST + Imp $\alpha$ $\triangle \mathrm{IBB}-\mathrm{VeA}-\mathrm{Komplexes}$. Aufgetragen sind Probe vor der Gelfiltration (VG), Proteingrößenstandard $(M)$ und Fraktionen aus der Gelfiltration (7-19). Die Nummern beziehen sich auf die Fraktionen aus dem Chromatogramm in 2.14. $\mathrm{VeA}(\approx 64 \mathrm{kDa})$ ist einem orangenen, Importin $\alpha \Delta \mathrm{IBB}(\approx 51 \mathrm{kDa})$ mit einem violetten und GST $(\approx 27 \mathrm{kDa})$ mit einem blauen Pfeil markiert.

Ausgehend von $500 \mathrm{ml}$ ZYM5052- (GST-Imp $\alpha \Delta \mathrm{IBB})$ und 212 YT-Expressionskultur (C-His 6 -VeA) konnten $2 \mathrm{mg}$ Importin $\alpha \Delta \mathrm{IBB}-\mathrm{VeA}-K o m p l e x$ in hochreiner Form gewonnen. Da beim Einengen der Proteinlösung der Großteil präzipitierte, konnten nur wenige Kristallisationsversuche angesetzt werden. Im Rahmen dieser Arbeit konnte keine Kristallbildung beobachtet werden.

\subsection{LaeA-VeA-VelB-Komplex}

Aufgrund zahlreicher Schwierigkeiten bei der Präparation und Kristallisationsversuchen der einzelnen Volllängen-Proteine wurde versucht den gesamten Komplex bestehend aus LaeA, VeA und VelB zu rekonstituieren. Hiermit sollte auch qualitativ die korrekte Faltung aller verwendeten Proteine festgestellt werden.

\subsubsection{Rekonstituierung des LaeA-VeA-VelB-Komplex}

Der Komplex wurde wie in 6.2.5.7 beschrieben rekonstituiert. In der Elution der Amylose-Säule konnten große Mengen an MBP-LaeA sowie zwei Proteine, deren Größe der von VeA und VelB entsprachen, detektiert werden (Abb. 2.16). Die Abspaltung der MBP-Sequenz von LaeA und der N-terminalen $\mathrm{His}_{6}$-Sequenz von VelB durch die TEV-Protease war fast vollständig. Nur sehr wenig MBP-LaeA wurde nicht verdaut (Abb. 2.16, Spur Ü) und im Falle von VelB ist eine kleine Verschiebung im Vergleich zum ungeschnitten VelB (mit N-His 6 ) auf dem Gel sichtbar. Doch auch hier war zu beobachten, dass viel Protein ausfiel, vermutlich LaeA. Aufgrund der sehr ähnlichen Größen von VelB, LaeA und MBP konnten diese auf den Gel nicht getrennt aufgelöst werden.

Für die Entfernung von MBP wurde der Überstand im nächsten Schritt auf eine HisTrap $5 \mathrm{ml}$ Säule geladen, an der VeA, das eine C-His 6 -Sequenz enthielt, binden sollte. Im Durchfluss konnte hier nur ein etwa $45 \mathrm{kDa}$ großes Protein, vermutlich MBP, detektiert werden (Abb. 2.17, Spur D1-3). Dagegen lag in 
Abbildung 2.16: SDS-PA-Gel der affinitätschromatographischen Reinigung von MBPLaeA, N-His 6 -VelB und C-His ${ }_{6}-\mathrm{VeA}$ mit Amylose. Aufgetragen sind Proteingrößenstandard (M), Durchflussfraktionen (D), Eluat (Elution), Eluat vor (-T) und nach (+T) TEV-Verdau sowie Überstand (Ü) nach Zentrifugation des TEV-Verdaus. MBP-LaeA $(86 \mathrm{kDa})$ ist mit einem schwarzen Pfeil markiert, $\mathrm{N}-\mathrm{His}_{6}$-VelB $(\approx 43 \mathrm{kDa})$ mit einem roten, $\mathrm{C}-\mathrm{His}_{6}-\mathrm{VeA}(\approx 64 \mathrm{kDa})$ mit einem orangenen und TEV-Protease mit einem violetten.

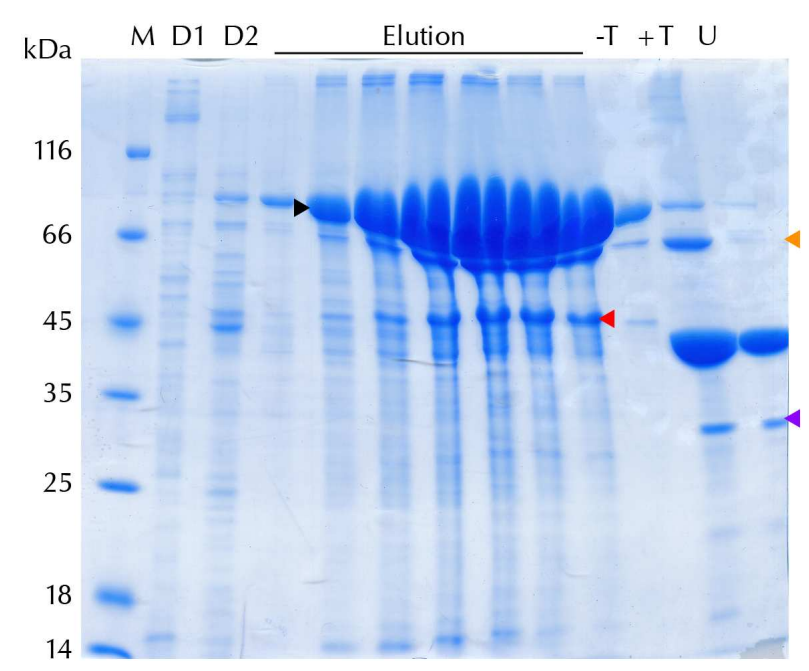

der Elution sowohl das vermeintliche C-His ${ }_{6}$-VeA (Abb. 2.17, orangener Pfeil) als auch möglicherweise VelB und LaeA vor (Elution, grauer Pfeil). Eine massenspektrometrische Analyse (durchgeführt von Dr. Oliver Valerius) einer der Banden der Elution (grauer Pfeil) bestätigte diese Annahme. Sowohl LaeA als auch VelB wurden nachgewiesen. Spuren von MBP waren auch vorhanden. Die TEV-Protease (His ${ }_{6}$-markiert) wurde auch in der Elution beobachtet (violetter Pfeil). Ungeschnittenes MBP-LaeA lag in geringen Mengen im Durchfluss und auch in der Elution vor. Abbaufragmente wie von VeA oder VelB, wie sie bei der einzelnen Präparation immer vorkamen, konnten hier nicht beobachtet werden.

Abbildung 2.17: SDS-PA-Gel der affinitätschromatographischen Reinigung von C-His 6 -VeA, LaeA und VelB mit einer HisTrap $5 \mathrm{ml}$ Säule. Aufgetragen sind verwendete Proben für HisTrap (VH), Durchflussfraktionen (D1-3), Eluat (Elution) und Proteingrößenstandard (M). MBP-LaeA (86 kDa) ist mit einem schwarzen Pfeil markiert, N-His ${ }_{6}$-VelB $(\approx 43 \mathrm{kDa})$ mit einem roten, $\mathrm{C}-\mathrm{His}_{6}-\mathrm{VeA}(\approx 64 \mathrm{kDa})$ mit einem orangenen und TEV-Protease mit einem violetten.

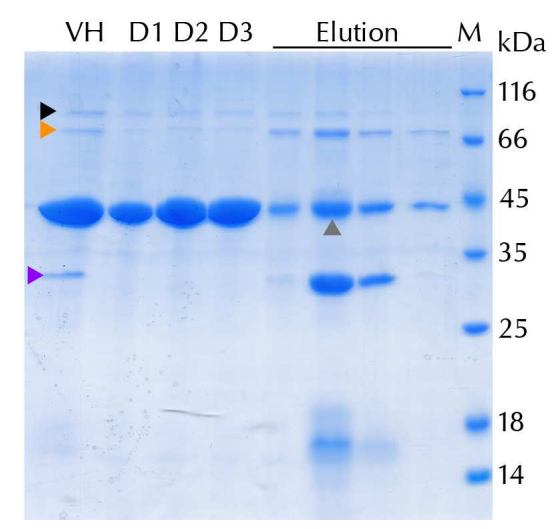

In der Größenausschlusschromatographie wurden mehrere lokale UV-Maxima detektiert, u.a. eins, in dem alle drei Protein nachgewiesen werden konnten (Abb. 2.19, Spur 15). Des weiteren konnte ein zweiter Komplex, der lediglich die VelvetProteine VeA und VelB enthielt, beobachtet werden (Abb. 2.19, Spuren 19-23 und Vergrößerung).

Mit dieser Strategie konnten etwa 200 bis $800 \mu \mathrm{g}$ Velvet-Komplex aus insgesamt 51 ZYM5052-Expressionskultur präpariert werden. Die Verwendung von GST-LaeA statt MBP-LaeA, oder spätere Zugabe von LaeA zu VeA-VelB zeigten keine verbesserte Löslichkeit des Komplexes (nicht gezeigt). 


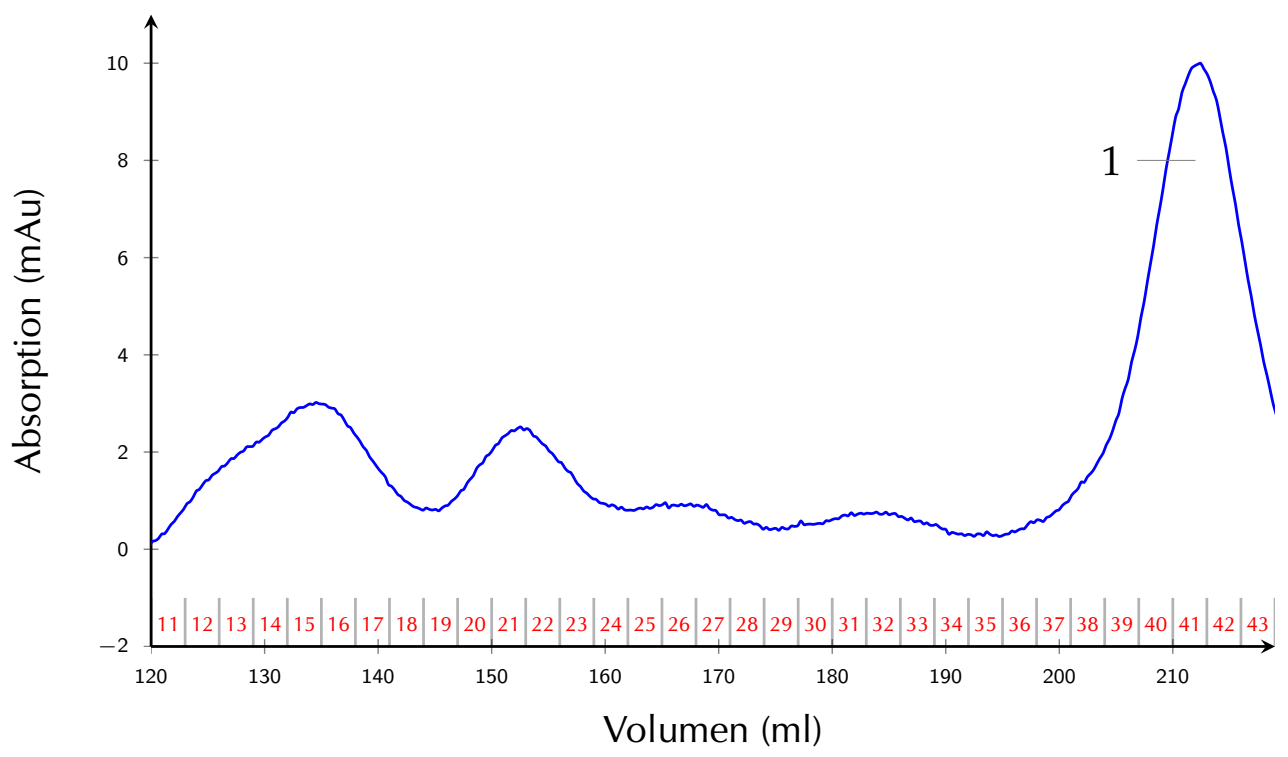

Abbildung 2.18: Chromatogramm der Größenausschlusschromatographie des LaeA-VeA-VelBKomplexes über eine Superdex 200 26/60 Säule. Das letzte UV-Maximum (1) entspricht dem der TEV-Protease. Blau: UV-Absorption bei $280 \mathrm{~nm}$ in gerätespezifischer Einheit (Y-Achse, mAu) entlang des Elutionsvolumens (X-Achse, ml). Gesammelte Fraktionen sind entlang der X-Achse nummeriert.

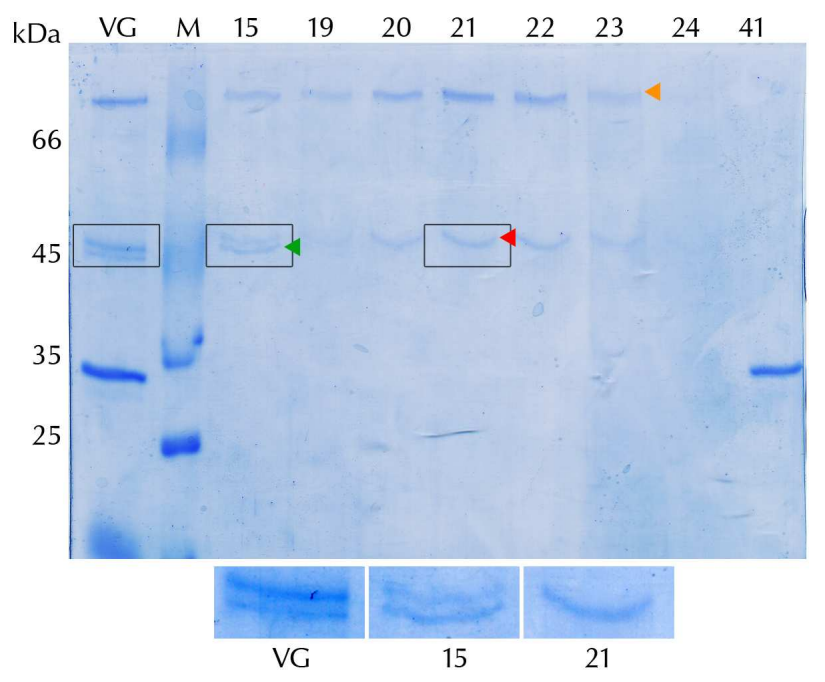

Abbildung 2.19: Oben: SDS-PA-Gel der Größenausschlusschromatographie des LaeA/C-His ${ }_{6}-V_{e A}-$ VelB-Komplexes. Aufgetragen sind Proben vor der Gelfiltration (VG), Proteingrößenstandard (M) und Fraktionen aus der Gelfiltration (15-41). Die Nummern beziehen sich auf die Fraktionen aus dem Chromatogramm in Abb. 2.18. LaeA $(\approx 43 \mathrm{kDa})$ ist mit einem grünen Pfeil markiert, VelB $(\approx 40 \mathrm{kDa})$ mit einem roten und $\mathrm{C}-\mathrm{His}_{6}-\mathrm{VeA}(\approx 64 \mathrm{kDa})$ mit einem orangenen. Unten: Vergrößerte Bereiche aus dem Gel, die jeweils LaeA + VelB (VG und 15) oder nur VelB (21) zeigen, der Kontrast wurde erhöht. 


\section{Kapitel 2 | ERGEBNISSE}

\subsubsection{Kristallisation des LaeA-VeA-VelB-Komplex}

Die Kristallisationslösungen JBScreens $(1 / 2 / 4 / 5)$ wurden mit einer Proteinkonzentration von $5,4 \mathrm{mg} / \mathrm{ml}$ und zwei Tropfenverhältnissen (Protein:Kristallisationslösung 1:1 und 2:1) mit einem Roboter bei $20^{\circ} \mathrm{C}$ pipettiert (6.2.6.1). Im Rahmen dieser Arbeit konnte keine Kristallbildung beobachtet werden.

\subsection{VeA-VelB-Komplex}

\subsubsection{Volllängen-VeA-VelB-Komplex}

Während der Arbeiten an der Rekonstituierung des LaeA-VeA-VelB-Komplexes wurde klar, dass die Ausbeute lediglich aufgrund der sehr geringen Löslichkeit von LaeA nicht verbessert werden konnte. Eine weitere Erkenntnis war, dass von der Gelfiltration ein stabiler VeA-VelB-Komplex eluierte. Es wurde daher versucht, diesen Komplex zu rekonstituieren und zu kristallisieren. Da dies jedoch nicht erfolgreich war, wurde ein Minimal-VeA-VelB-Komplex generiert (2.6.2). Dieser konnte in höheren Mengen und größerer Reinheit gewonnen werden, konnte aber auch nicht kristallisiert werden.

\subsubsection{Rekonstituierung des VeA-VelB-Komplexes}

Der VeA-VelB wurde wie in 6.2.5.8 beschrieben rekonstituiert und präpariert. Beide Proteine konnten im Eluat des ersten Reinigungsschritts (HisTrap) beobachtet werden, VeA lag jedoch im Überschuss vor (Abb. 2.20, linke Seite, Elution). Auch waren noch viele Verunreinigungen vorhanden. Diese Verunreinigungen konnten durch eine StrepTactin HP Säule größtenteils entfernt werden. Auch der Überschuss an VeA wurde auf diese Weise entfernt (Abb. 2.20, rechte Seite, Spur D). Die Elution der StrepTactin HP Säule enthielt auch beide Proteine mit noch einigen Verunreinigungen (rechte Seite, Elution).

Abbildung 2.20: SDS-PA-Gel der affinitätschromatographischen Reinigung von $\mathrm{C}-\mathrm{His}_{6}-\mathrm{VeA}$ und C-Strep II-VelB mit einer HisTrap und StrepTactin HP Säule. Aufgetragen sind Durchfluss (D) und Eluat (Elution) beider Schritte sowie ein Proteingrößenstandard (M). C-Strep II-VelB $(\approx 41 \mathrm{kDa})$ ist mit einem roten und $\mathrm{C}-\mathrm{His}_{6}-\mathrm{VeA}$ $(\approx 64 \mathrm{kDa})$ mit einem orangenen Pfeil markiert.

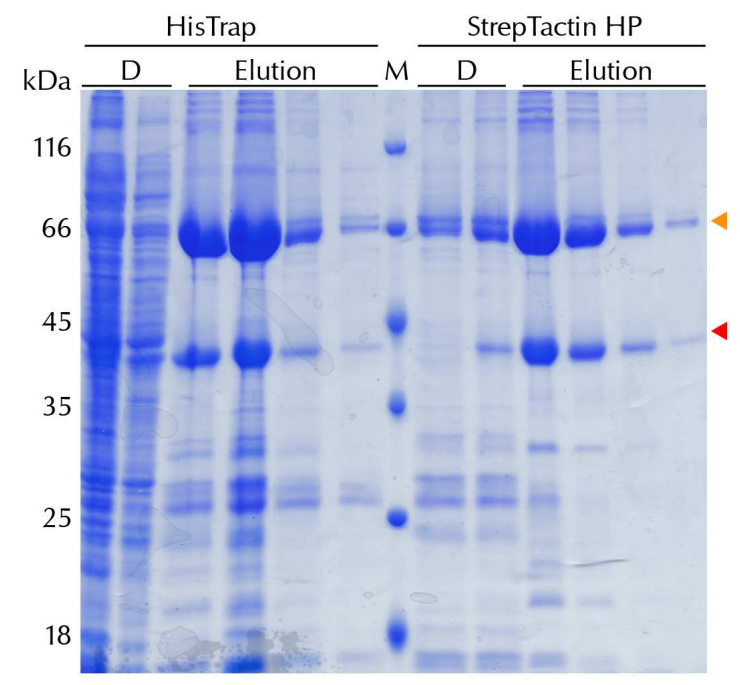


In der Gelfiltration eluierte der Komplex in einem UV-Maximum mit leichter Schulter. Eine Verunreinigung über VeA war noch erkennbar. Diese Bande (Abb. 2.22, Spur 6-10 und Vergrößerung) konnte durch MS-Analyse (durchgeführt von Bernhard Schmidt) als das E. coli Chaperon DnaK identifiziert werden. In weiteren Experimenten wurde oft eine Doppelbande von VelB beobachtet (Abb. 2.22, Vergrößerung). Es war mittels MS nicht möglich, zu bestimmen, ob es sich hier um eine N- oder C-terminale Verkürzung handelt. Die Ausbeute mit dieser Reinigungsstrategie lag i.d.R. bei etwa 2,5 mg VeA-VelB-Komplex aus 21 2YT-Expressionskultur. Der Komplex konnte nicht höher als 5 bis $6 \mathrm{mg} / \mathrm{ml}$ ankonzentriert werden.

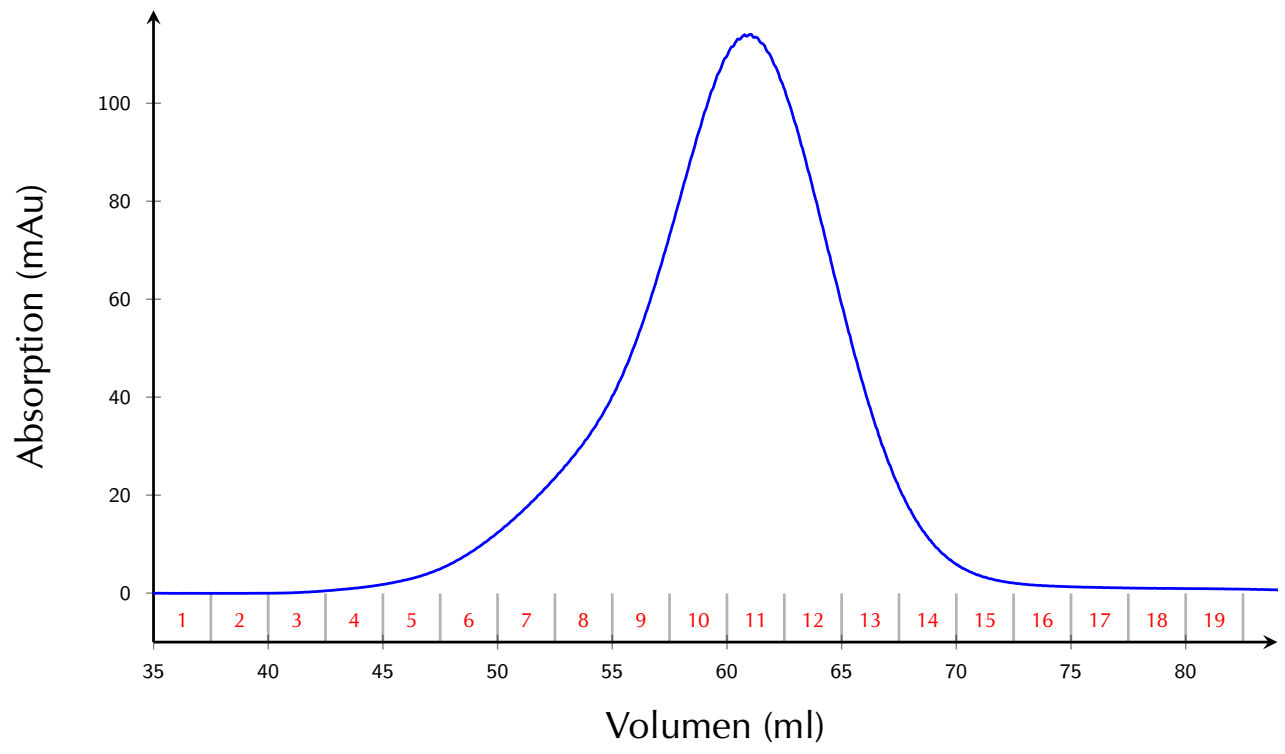

Abbildung 2.21: Chromatogramm der Größenausschlusschromatographie des VeA-VelB-Komplexes über eine Superdex 200 16/60 Säule. Blau: UV-Absorption bei $280 \mathrm{~nm}$ in gerätespezifischer Einheit (Y-Achse, $\mathrm{mAu}$ ) entlang des Elutionsvolumens (X-Achse, $\mathrm{ml}$ ). Gesammelte Fraktionen sind entlang der X-Achse nummeriert.

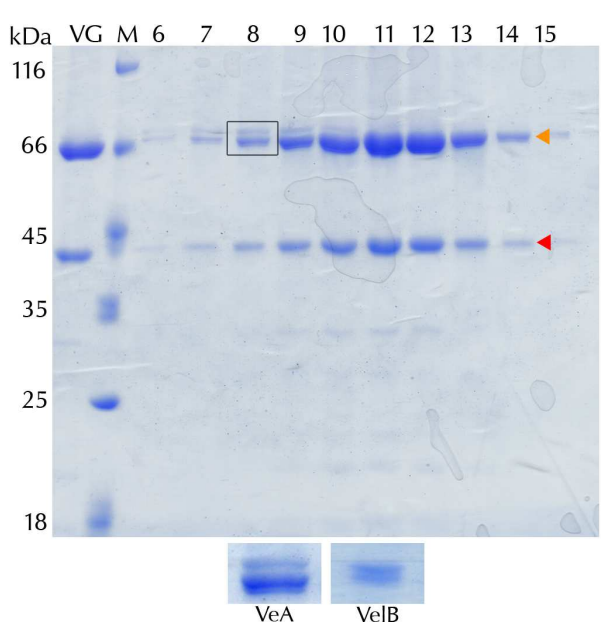

Abbildung 2.22: Oben: SDS-PA-Gel der Größenausschlusschromatographie des VeA-VelB-Komplexes. Aufgetragen sind Proben vor der Gelfiltration (VG), Proteingrößenstandard $(M)$ und Fraktionen aus der Gelfiltration (6-15). Die Nummern beziehen sich auf die Fraktionen aus dem Chromatogramm in Abb. 2.21. VelB $(\approx 41 \mathrm{kDa})$ ist mit einen roten und $\mathrm{C}-\mathrm{His}_{6}-$ $\mathrm{VeA}(\approx 64 \mathrm{kDa})$ mit einen orangenen Pfeil markiert. Unten: Vergrößerter Bereich aus diesen Gel das die Verunreinigung über VeA zeigt und VelB-Doppelbande (aus anderem Gel), der Kontrast wurde erhöht. 


\section{Kapitel 2 | ERGEBNISSE}

\subsubsection{Kristallisation des VeA-VelB-Komplex}

Kristallisationsansätze wurden mit einer Konzentration von $5 \mathrm{mg} / \mathrm{ml}$ bei 4 und $20^{\circ} \mathrm{C}$ mit einen Roboter angesetzt (6.2.6.1). Dabei wurden die folgenden Sammlungen verwendet: PGA, JBScreens, JCSG und ProPlex. Es konnte bis zum Abschluss dieser Arbeite keine Kristallbildung festgestellt werden. Die meisten Tropfen waren auch nach sehr langer Zeit bei beiden Temperaturen noch klar.

\subsubsection{Minimal VeA-VelB-Komplex}

Im weiteren Verlauf wurde nicht mehr versucht einen Komplex aus VolllängenVeA und -VelB zu reinigen. Stattdessen wurde versucht einen minimalen VeAVelB-Komplex (mini-VeA-VelB) zu rekonstituieren. Dieser Komplex sollte sich aus zwei separat bereits kristallisierten Komponenten zusammensetzen: VeA224S (2.3.1) und VelB-mini (2.2.2). Letzteres basiert auf einer vermutlich proteolytisch verkürzten Form von VelB im VelB-VosA190S-Komplex (2.8). Mit diesem Komplex sollte auch überprüft werden, ob VelB-mini korrekt gefaltet und somit in der Lage ist VeA224S zu binden.

\subsubsection{Präparation des minimalen VeA-VelB-Komplex}

Der minimale-VeA-VelB-Komplex, bestehend aus VeA224S (2.3.1) und VelB-mini (2.2.2) wurde wie in 6.2.5.9 beschrieben präpariert. Beide Proteine waren gut löslich und lagen im Überstand vor (Abb. 2.23A, Spur Ü). Im ersten Schritt wurde eine HisTrap Säule verwendet, im Durchfluss konnte kein VeA224S oder VelB-mini detektiert werden (Abb. 2.23A, Spur D1-2). Die Elution enthielt bereits beide Proteine mit nur wenigen Verunreinigungen, wobei ein leichter Überschuss an VelB-mini beobachtet wurde (Spur EH). Durch die Verwendung der StrepTactin HP Säule konnte überschüssiges VelB-mini sowie eine Verunreinigung unter VeA224S entfernt werden (Spur U1-2). In späteren Durchflussfraktionen waren auch größere Mengen an VeA224S zu erkennen, ein Zeichen dafür das die Kapazität der Säule erreicht wurde (Spur U2).

Nach der StrepTactin HP Säule lag der mini-VeA-VelB-Komplex in sehr reiner Form vor (2.23A, Spur ES). Es wurde trotzdem eine Gelfiltration durchgeführt, u.a. auch um die Monodispersität des Komplexes zu prüfen. Der mini-VeAVelB-Komplex eluierte in einem UV-Maximum bei der Gelfiltration (nicht gezeigt), enthielt nahezu keine Verunreinigungen (Abb. 2.23B) und lies sich sehr leicht einengen. Die Ausbeute betrug mit dieser Reinigungsstrategie $21 \mathrm{mg}$ aus $2 \times 500$ ml ZYM5052-Expressionskultur. Der minimale VeA-VelB-Komplex wurde so für Kristallisationsversuche verwendet. 

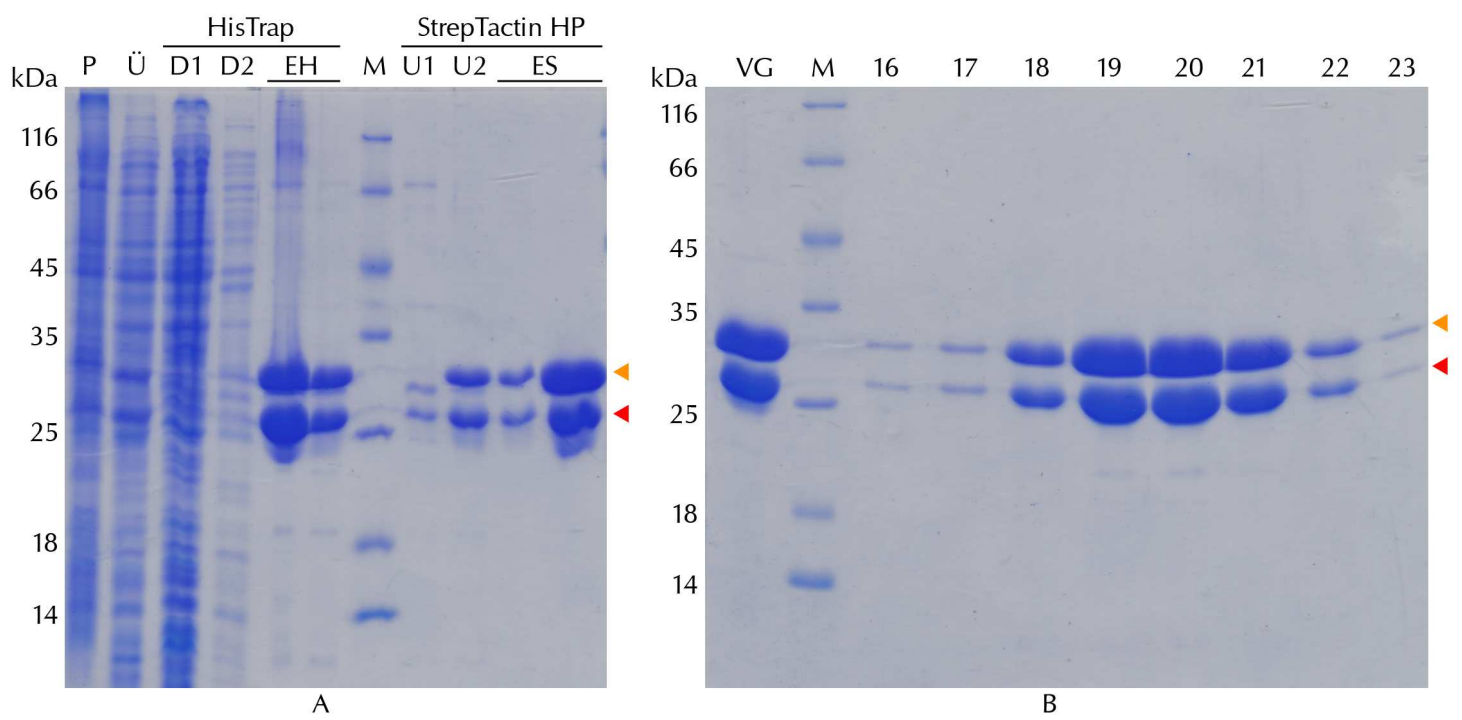

Abbildung 2.23: A: SDS-PA-Gel der affinitätschromatographischen Reinigung von des VeA224SVelB-mini Komplexes (mini-VeA-VelB) mit einer HisTrap und StrepTactin HP Säule. Aufgetragen sind Durchfluss (D1-2) und Eluat (EH und ES) beider Schritte sowie ein Proteingrößenstandard (M). B: SDS-PA-Gel der Größenausschlusschromatographie des mini-VeA-VelB-Komplexes. Aufgetragen sind Probe vor der Gelfiltration (VG), Proteingrößenstandard (M) und Fraktionen aus der Gelfiltration (16-23). Die Nummern beziehen sich auf die Fraktionen aus der Gelfiltration (nicht gezeigt). In beiden Gelen ist VelB-mini $(\approx 22 \mathrm{kDa})$ mit einem roten und VeA224S $(\approx 25 \mathrm{kDa})$ mit einem orangenen Pfeil markiert.

\subsubsection{Kristallisation des minimalen VeA/VelB-Komplex}

Für die Kristallisation des mini-VeA/VelB-Komplexes wurde eine Proteinkonzentration von $12 \mathrm{mg} / \mathrm{ml}$ gewählt. Pipettiert wurden die Sammlungen $\mathrm{AmSO}_{4}$ Suite, JB NucPro, JBScreens, JCSG, Morpheus, NatrixHT, PGA, und ProPlex (6.2.6.1). Die Ansätze wurden bei $20^{\circ} \mathrm{C}$ inkubiert, aber auch nach sechs Monaten wurde keine Kristallbildung beobachtet.

\subsection{VosA}

VosA konnte sowohl in voller Länge (nicht gezeigt) als auch in verkürzter Form exprimiert und gereinigt werden. Lediglich die verkürzte Form wurde kristallisiert (2.7.2) und die Struktur konnte erfolgreich bestimmt werden (6.2.6.7, 2.7.4). Eine Ko-Kristallisation mit DNA war nicht erfolgreich (nicht gezeigt). Von VosA-Mutanten wurde die DNA-Bindung analysiert (2.7.6, S. 54). 


\title{
Kapitel 2 | ERGEBNISSE
}

\subsubsection{Präparation von VosA190S}

VosA190 umfasst die Aminosäuren 1-190 und wurde entweder mit einer Cterminalen Strep II- (VosA190S, 6.2.5.10) oder His $_{6}$-Markierung (VosA190H, 6.2.5.11) exprimiert. Da die Ergebnisse zu beiden Präparationen keine markanten Unterschiede aufweisen, ist nur die Präparation von VosA190S beschrieben.

VosA190S war größtenteils im Überstand (Abb. 2.24A, Spur Ü) und lag bereits im ersten Reinigungsschritt mit sehr hoher Reinheit vor (Abb. 2.24A, Spur E). Lediglich einige Banden bei etwa 50 und $116 \mathrm{kDa}$ waren zu erkennen.

In der Gelfiltration konnte nur ein UV-Maximum detektiert werden (nicht gezeigt), dieses enthielt überwiegend VosA190S (Abb. 2.24B). Die Verunreinigung mit einer Größe von etwa $50 \mathrm{kDa}$ war noch vorhanden (Spuren 20-22). Durch eine MS-Analyse (Dr. Oliver Valerius) konnte diese vermeintliche Verunreinigung als VosA190S identifiziert werden. Mit dieser Reinigungsstrategie konnten aus $250 \mathrm{ml}$ ZYM5052-Expressionskultur etwa $5 \mathrm{mg}$ VosA190S bzw. $10 \mathrm{mg}$ VosA190H isoliert werden. In einem Gelretardationsexperiment wurde das gereinigte VosA190S auch auf DNA-Bindung überprüft. Dabei wurden zwei Beobachtungen gemacht: VosA190S war in der Lage, das eingesetzte 300 bp DNA-Fragment zu binden (Abb. 2.24C, Spur b und Vb), und in der Protein-Präparation konnte keine DNA detektiert werden (Spur V).
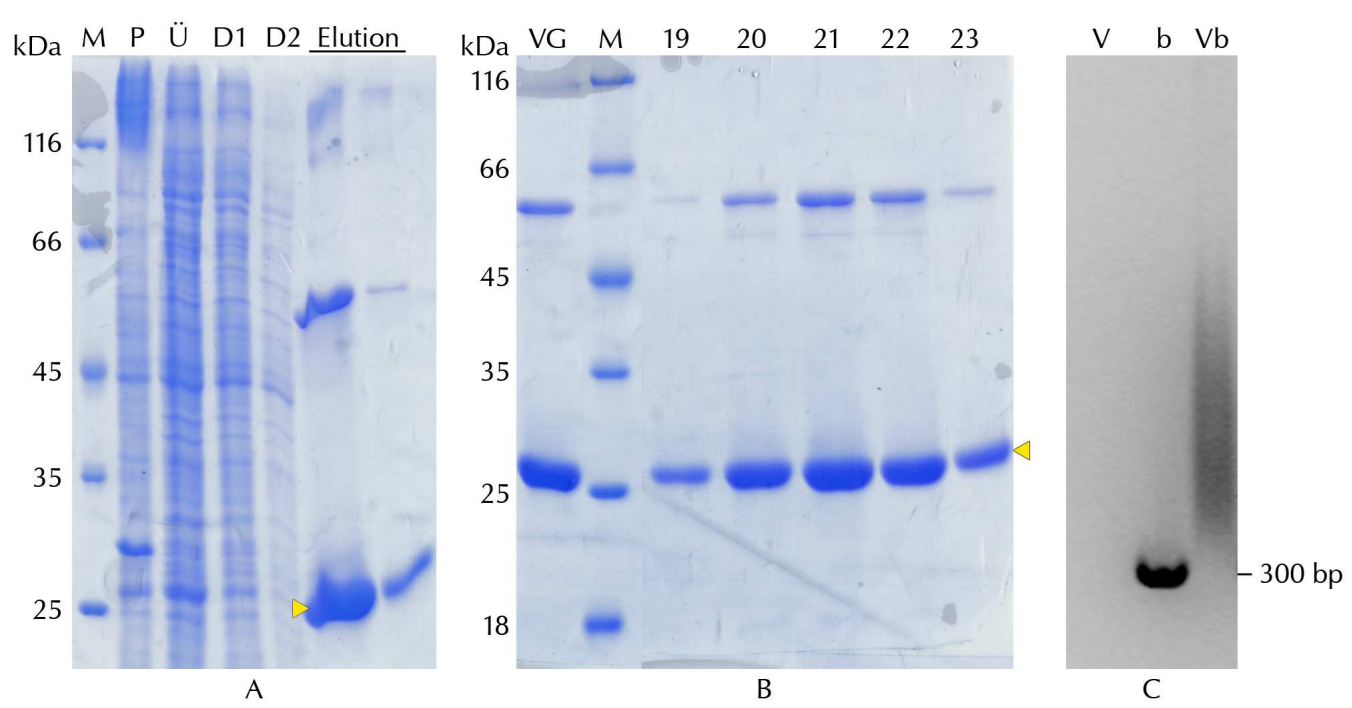

\begin{abstract}
Abbildung 2.24: A: SDS-PA-Gel der affinitätschromatographischen Reinigung von VosA190S mit einer StrepTactin HP Säule. Aufgetragen sind Proteingrößenstandard (M), unlösliche (P) und lösliche (Ü) Fraktion, Durchfluss (D1 und 2) sowie Eluat (Elution). B: SDS-PA-Gel der Größenausschlusschromatographie von VosA190S. Aufgetragen sind verwendete Probe vor Gelfiltration (VG), Proteingrößenstandard (M) und Fraktionen aus der Gelfiltration (3-23). Die Nummern beziehen sich auf die Fraktionen aus der Gelfiltration (nicht gezeigt). VosA190S $(\approx 22 \mathrm{kDa})$ ist in beiden SDS-PA-Gelen mit einem gelben Pfeil markiert. C: Agarosegel des Gelretardationsexperimentes mit VosA190S und DNA-Fragment aus dem Promoterbereich des brlA-Gens. Aufgetragen ist VosA190S aus Gelfiltration (V), brlA-Fragment (b) und beides zusammen ( $\mathrm{Vb}$ ).
\end{abstract}




\subsubsection{Kristallisation von VosA190S}

Kristallisationsversuche wurden nur von VosA190S (C-Strep II) und VosA190H $\left(\mathrm{C}-\mathrm{His}_{6}\right)$ durchgeführt. Bei VosA190S wurde eine Konzentration von 10,4 mg/ml und bei VosA190H 15,1 mg/ml verwendet. Es wurden die Sammlungen ProPlex, JBScreens, $\mathrm{AmSO}_{4}$ Suite und JCSG bei $20^{\circ} \mathrm{C}$ pipettiert. Bei beiden Varianten konnten Kristalle in mehreren Bedingungen gefunden werden (Abb. 2.25). Die meisten Kristallisationsbedingungen waren PEG-basiert.
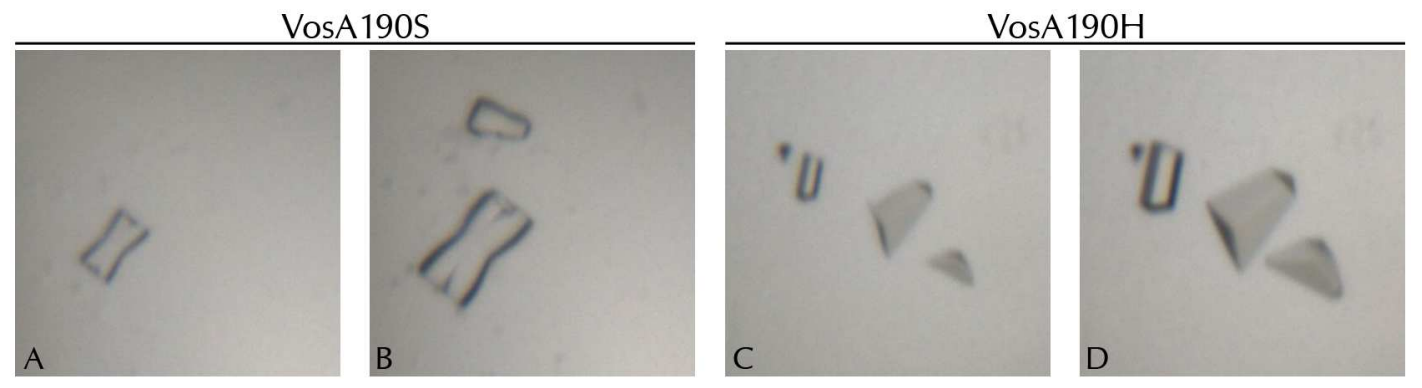

Abbildung 2.25: Kristalle von VosA190S und VosA190H. X-Förmige Kristalle von VosA190S nach einen (A) und sechs Tagen (B), die Bedingung enthielt 30\% PEG 4000 und $100 \mathrm{mM} \mathrm{MES} \mathrm{pH}$ 6,5. Kristalle von VosA190H nach zwei (A) und 29 Tagen (D), die Bedingung enthielt 30\% PEG 2000 MME und $150 \mathrm{mM} \mathrm{KBr}$. Die Bilder wurden von einem automatisierten System aufgenommen (6.2.6.1).

Die Kristalle waren reproduzierbar und für eine potentielle Phasierung von Daten nach dem MAD-Verfahren kam das KBr in der VosA190H-Bedingung in Frage. Beim MAD-Verfahren müssen mehrere Datensätze bei unterschiedlichen Wellenlängen gemessen werden, die ein Kristalle u.U. nicht übersteht. Bei der Reproduktion der Kristalle wurden die Bedingungen beider VosA190-Varianten kombiniert und weiter optimiert. $\mathrm{KBr}$ wurde durch $\mathrm{KI}$ ersetzt und schließlich war es möglich VosA190S in einer Bedingung mit 32\% PEG 2000 MME und $150 \mathrm{mM}$ KI zu kristallisieren (Abb. 2.26). Diese wurden für die Strukturbestimmung verwendet. CuK $\alpha$-Drehanoden mit einer Wellenlänge von $\lambda=1,5418 \AA$ sind besonders für die Phasenbestimmung mittels $S A D$ von Iodid-derivatisierten Kristallen geeignet. Dies liegt am starken anomalen Signal von Iodid $\left(f^{\prime \prime}=6,8\right.$ Elektronen) bei dieser Wellenlänge. 

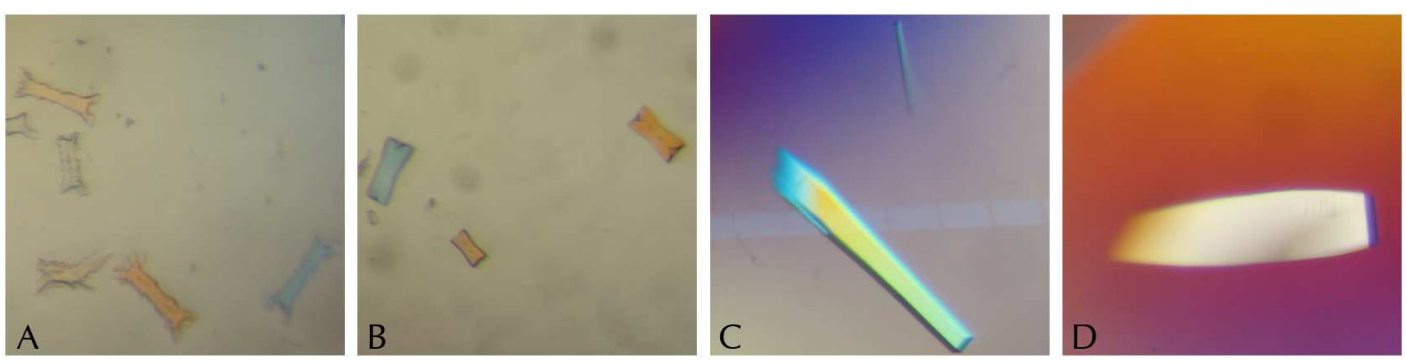

Abbildung 2.26: Optimierung der VosA190S-Kristalle. Die Bedingungen enthalten 24\% PEG8000 (A), 24\% PEG 4000 (B) oder 32\% PEG 2000 MME und 150 mM KI (C und D). Einige Kristalle waren in der längsten Dimension $\approx 250 \mu \mathrm{m}(\mathrm{C})$. Die Färbung ist durch die Verwendung eines Polarisationsfilters entstanden.

\subsubsection{Strukturbestimmung von VosA190S}

Einer der in Abb. 2.26 dargestellten VosA190S-Kristalle wurde mit 12\% (v/v) Butandiol als Zusatz in der Kristallisationsbedingung eingefroren und mit einen Röntgendiffraktometer (MicroMax 007, Rigaku, Japan) in der Abteilung für Molekulare Strukturbiologie gemessen (6.2.6.4). Der Datensatz wurde mit dem XDS-Paket (Kabsch, 2010) prozessiert. Dabei wurde das Programm angewiesen, dass Friedel-Paare aufgrund anomaler Streuung (durch die Iodid-Ionen) unterschiedliche Intensitäten aufweisen können (Option: FRIEDEL'S_LAW=FALSE). Die Kristalle konnten der Raumgruppe $\mathrm{P}_{1} 22$ zugeordnet werden. Die Statistiken zur Datensammlung sind in Tabelle 2.2 zusammengefasst.

Tabelle 2.2: Statistik zur Datensammlung des VosA190S-Kristalls

\begin{tabular}{|c|c|}
\hline \multicolumn{2}{|c|}{ VosA190S-KI-Datensatz } \\
\hline Messstation & MicroMax 007, MSB, Göttingen \\
\hline Wellenlänge [Å] & 1,5418 \\
\hline Raumgruppe & $P 4_{1} 22$ \\
\hline Zellkonstanten $[\AA ̊]$ & $a=b=45,350 ; c=189,320$ \\
\hline Winkel $\left[{ }^{\circ}\right]$ & $\alpha=\beta=\gamma=90$ \\
\hline Auflösung [Å] & $47,35-1,79(1,90-1,79)^{*}$ \\
\hline$R_{\text {merge }}[\%]$ & $3,6(24,7)^{*}$ \\
\hline Signal/Rauschen $(\mathrm{I} / \sigma)$ & $22,17(5,01)^{*}$ \\
\hline Vollständigkeit [\%] & $99,1(95,4)^{*}$ \\
\hline Redundanz & $4,01(3,57)^{*}$ \\
\hline
\end{tabular}

* Werte in Klammern beziehen sich jeweils auf die höchstaufgelöste Schale.

Die Phasierung der Daten erfolgte mit SHELXC/D/E (Sheldrick, 2008), die jeweils über das Programm HKL2MAP (Pape und Schneider, 2004) gesteuert wurden (6.2.6.7). Die beste Lösung nach 100 Zyklen in SHELXD hatte KorrelationsKoeffizienten $\mathrm{CC}_{\text {all }} / \mathrm{CC}_{\text {weak }}$ von $43,12 \%$ und $25,4 \%$ und enthielt 10 Iodid-Ionen. 
Eine Lösung sollte mindestens 30\% und 15\% haben. Für die weitere Prozessierung wurden jedoch nur Iodid-Ionen mit einer Besetzung $>0,2$ verwendet, so dass drei Positionen mit einer Besetzung von jeweils 1,0 0,36 und 0,24 übrigblieben. Nach Phasierung mit SHELXE lag der FOM ${ }^{1}$-Wert bei 0,7. Die Struktur wurde wie in 6.2.6.7 beschrieben gebaut und verfeinert. Die initiale Elektronendichtekarte war gut interpretierbar, nach Verfeinerung waren einige Seitenketten und Aminosäurereste noch besser definiert (Abb. 2.27).
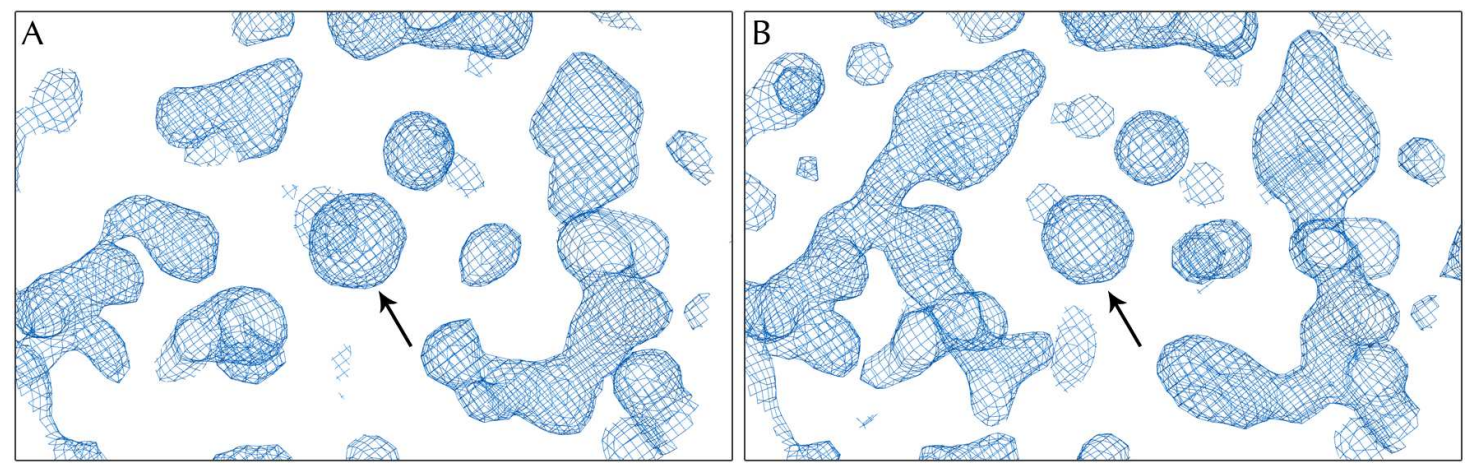

Abbildung 2.27: Vergleich der experimentellen Elekontronendichte nach Phasierung der Daten (A)

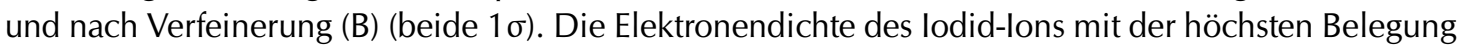
ist mit einen Pfeil markiert.

Das fertige Model enthält ein VosA190S-Molekül in der asymmetrischen Einheit. VosA190S besteht aus 200 Aminosäuren, zehn davon sind ein Teil der CStrep II-Affinitätssequenz (mit Linker). Von diesen 200 konnten die Aminosäuren 8-185 in der Elektronendichte lokalisiert werden. Die Elektronendichte für eine Schleife (Aminosäure 160 bis 167) konnte nicht eindeutig zugewiesen werden. Diese Reste liegen nah an einer kristallographischen Achse und sind nicht so gut definiert wie der Rest des Proteins. Die gleichen Reste des gegenüberliegenden Symmetriepartners befinden sich auch hier (Abb. 2.28).

Erschwerend kam hinzu, dass ein Großteil der Dichte hier nicht durch Proteinreste oder alternativen Konformation erklärt werden konnte. Während des Modellbaus und Verfeinerung wurde auch die Möglichkeit in Betracht gezogen das hier ein Austausch des C-Terminus (AS160-C) zwischen zwei Molekülen stattfindet (Abb. 2.29). Diese Idee wurde jedoch wieder verworfen, da ein geringerer R-Faktor erzielt werden konnte, wenn der C-Terminus in nicht-getauschter Form gebaut wurde. Nach Abschluss der Verfeinerung wurden noch Wassermoleküle in die Struktur platziert. An zwei Stellen konnten eine dreieckige planare Elektronendichtewolke beobachtet werden. Diese wurde als $\mathrm{NO}_{3}$-Molekül interpretiert (Abb. 2.28).

\footnotetext{
${ }^{1}$ engl. figure of merit
} 


\section{Kapitel 2 ERGEBNISSE}

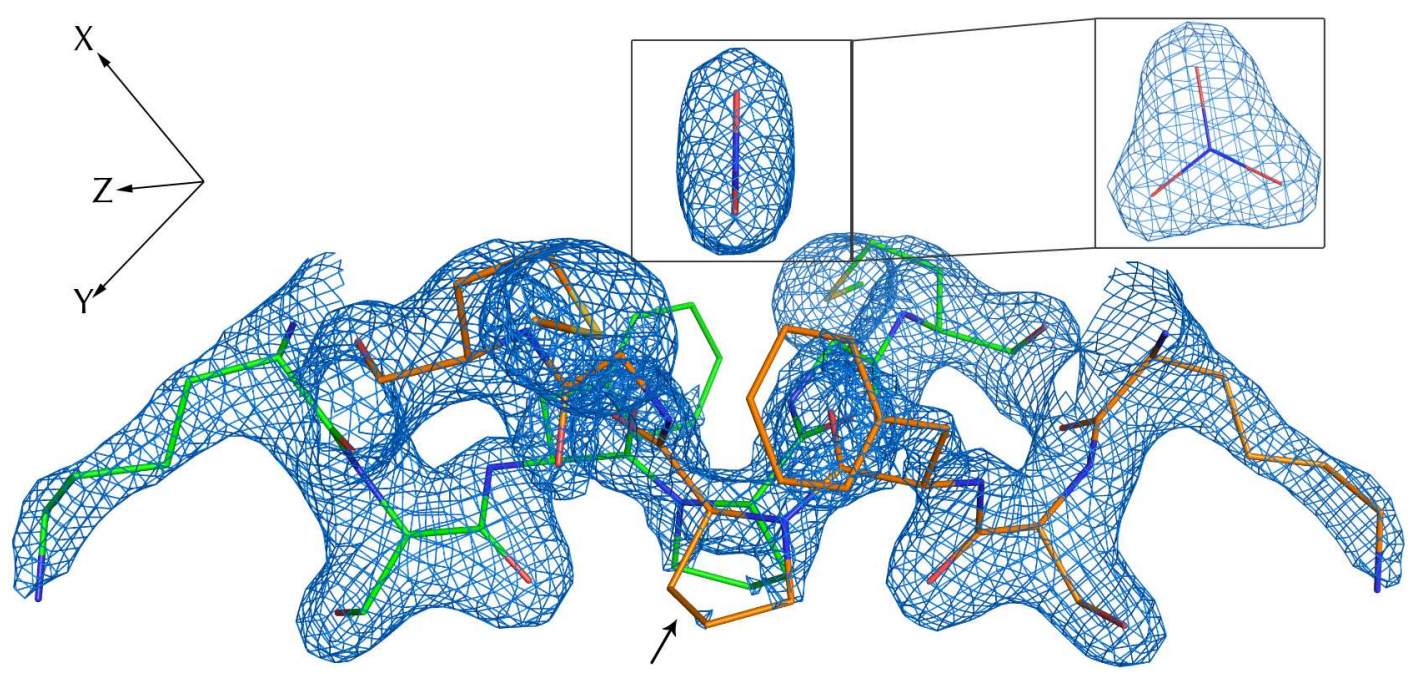

Abbildung 2.28: Verfeinerte Elekontronendichtekarte von VosA190S (1б). Die Ketten von zwei Molekülen entlang einer kristallographischen Achse sind farblich hervorgehoben (grün und orange), Prolin 163 beider Moleküle liegt parallel übereinander und ist mit einen Pfeil markiert. Vergrößerte Seitenansicht: Planare dreieckige Elektronendichte die genau auf der Achse liegt und als $\mathrm{NO}_{3}-\mathrm{Molekül}$ interpretiert wurde.

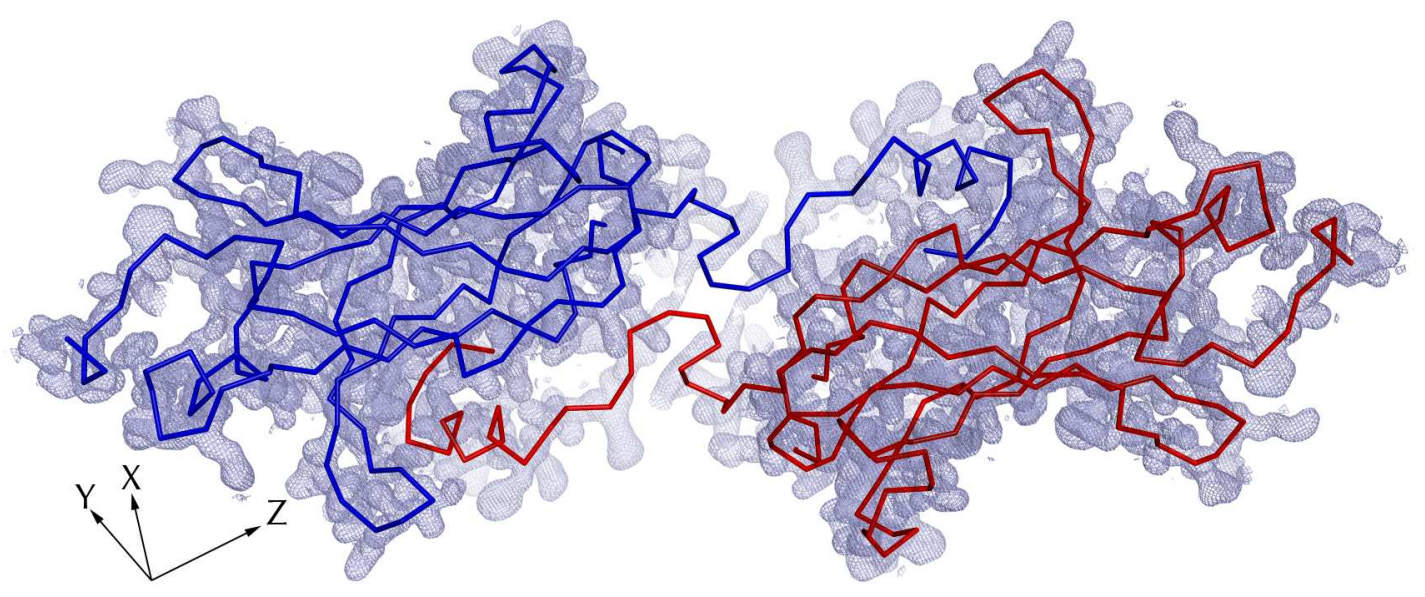

Abbildung 2.29: $\mathrm{C}_{\alpha}$-Rückgrat zweier VosA190S-Moleküle (rot und blau) die sich gegenseitig den C-Terminus (AS160-C) zur Verfügung stellen. Die Elekontronendichte $(1 \sigma)$ ist in grau dargestellt.

Die Verfeinerung wurde abgeschlossen als keine Verbesserung des R-Faktors durch Modifikation des Modelles mehr beobachtet wurde. Die Bindungswinkel $\psi$ und $\phi$ des $C_{\alpha}$-Rückgrats lagen innerhalb der erlaubten Werte, kein Rest lag in der nicht-erlaubten Region des Ramachandran-Diagramms (Abb. 2.30). Die Statistiken zur Verfeinerung sind in Tabelle 2.3 aufgeführt. 


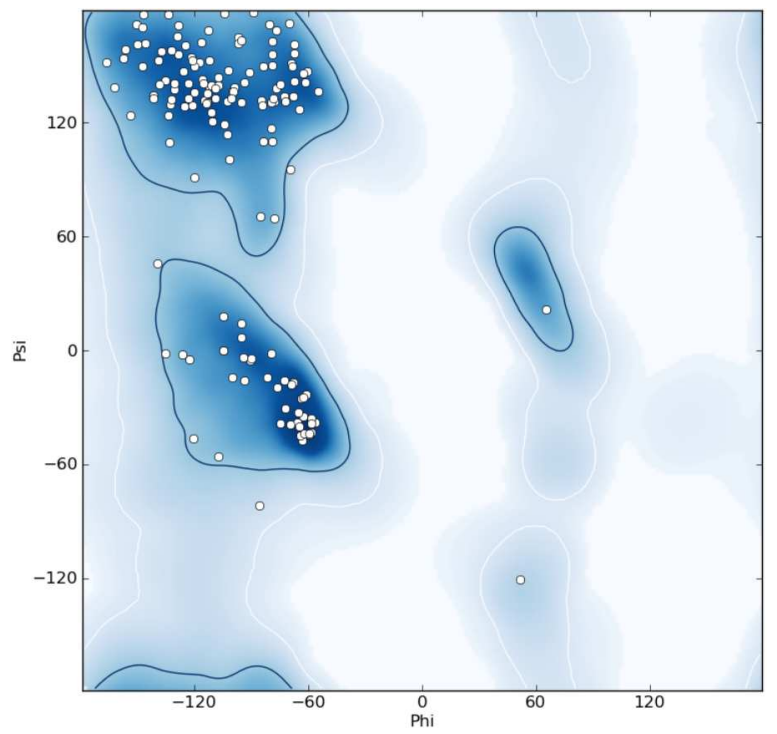

Abbildung 2.30: Ramachandran-Diagramm für alle Nicht-Glycin/Prolin-Reste von VosA190S, erstellt mit MOLPROBITY (Chen et al., 2010). Dargestellt ist die Verteilung der Bindungswinkel $\phi$ (XAchse) und $\psi$ (Y-Achse) der einzelnen Reste (weiße Punkte) innerhalb der bevorzugten (dunkelblau), erlaubten (blau), zusätzlich erlaubten (hellblau) und verbotenen (weiß) Region.

Tabelle 2.3: Statistiken zur Verfeinerung von VosA190S

\begin{tabular}{|c|c|}
\hline \multicolumn{2}{|c|}{ Verfeinerung von VosA190S } \\
\hline Auflösungsbereich [̊̊] & $47,35-1,79(1,90-1,79)^{*}$ \\
\hline Anzahl der gesamten Reflexe & $142606(19836)^{*}$ \\
\hline Einzigartige Reflexe & $35545(5553)^{*}$ \\
\hline $\mathrm{R}_{\text {cryst }}[\%]$ & $18,33(26,09)^{*}$ \\
\hline $\mathrm{R}_{\text {free }}[\%]$ & $22,03(34,18)^{*}$ \\
\hline Wilson B-Faktor $\left[\AA^{2}\right]$ & 28,7 \\
\hline \multicolumn{2}{|c|}{ Anzahl der Atome / Ø B-Faktor $\left[\AA^{2}\right]$} \\
\hline Protein & 1412 / 29,72 \\
\hline Wasser & 193 / 33,99 \\
\hline Ionen & $11 / 47,54$ \\
\hline \multicolumn{2}{|l|}{ Ramachandran-Statistiken } \\
\hline Bevorzugte Regionen [\%] & 97,7 \\
\hline Nicht-erlaubte Regionen [\%] & 0 \\
\hline \multicolumn{2}{|l|}{ Standardabweichungen } \\
\hline Bindungslängen [Å] & 0,0158 \\
\hline Winkel $\left[{ }^{\circ}\right]$ & 1,567 \\
\hline
\end{tabular}

* Werte in Klammern beziehen sich jeweils auf die höchstaufgelöste Schale. 


\section{Kapitel 2 | ERGEBNISSE}

\subsubsection{Struktur von VosA190S}

VosA190S bildet eine kompakte Domäne, die im folgenden als Velvet-Domäne bezeichnet wird. Diese besteht überwiegend aus $\beta$-Strängen, von denen drei auf der einen und vier auf der anderen Seite liegen. C-terminal sowie zwischen $\beta 2$ und -3 liegen kurze $\alpha$-Helices vor ( $\alpha 1$ und -2 ). Auf beiden Seiten des Proteins weisen je zwei verlängerte $\beta$-Stränge aus der insgesamt flachen Struktur heraus ( $\beta 4 / 5$ und $\beta 6 / 7, \mathrm{Abb} .2 .31$ ). Auch die C-terminalen Reste ab AS 160, die zu $\alpha 2$ führen, stehen etwas weiter ab. Die allgemeine Faltung erinnert an $\beta$-SandwichProteine, wie z.B. die Immunglobulinen (Poljak et al., 1973).

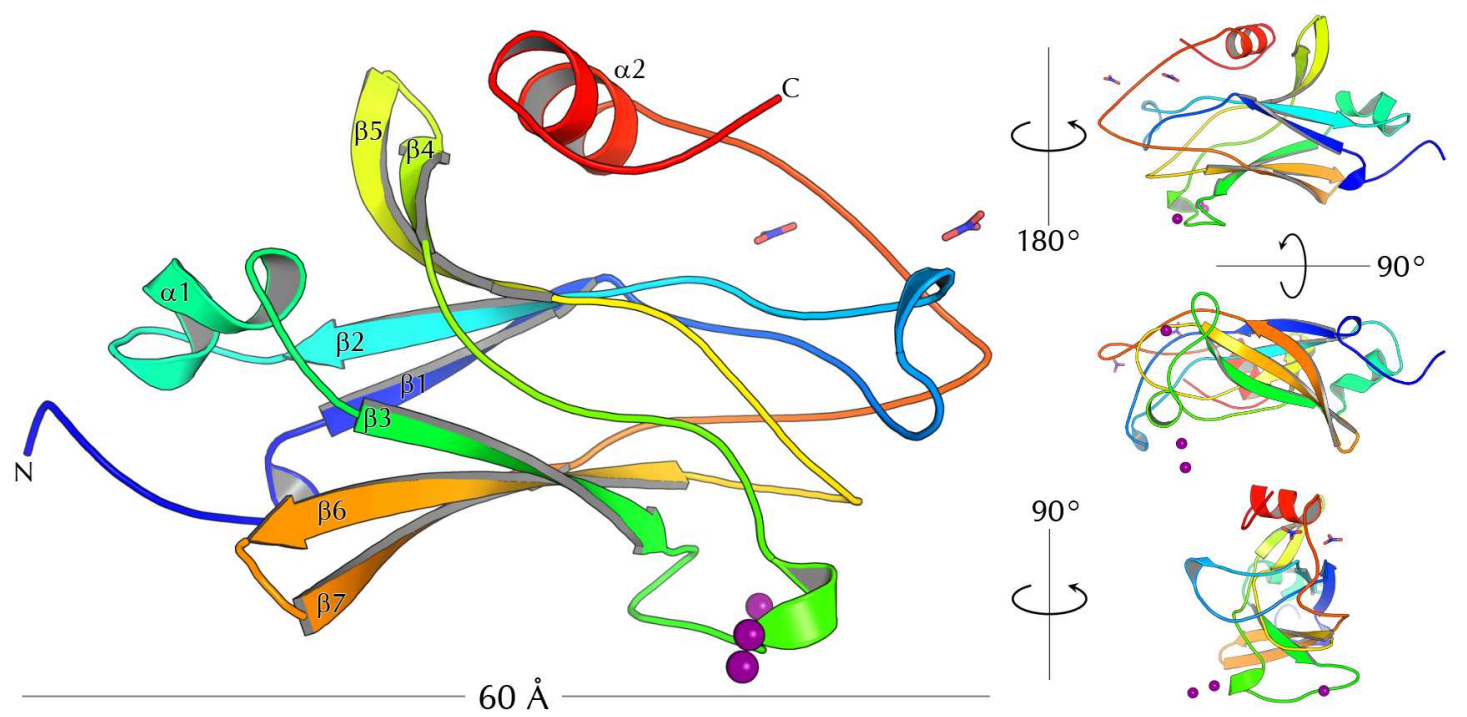

Abbildung 2.31: Kristallstruktur von VosA190S, die einzenen Sekundärstrukturelemente sind nummeriert ( $\alpha 1-2$ und $\beta 1-7$ ). Das Molekül ist entlang der Sequenz gefärbt ( $\mathrm{N}$-Terminus blau, C-Terminus rot). Rechts sind weitere Perspektiven mit jeweils gedrehter Achse gezeigt. Die $2 \mathrm{NO}_{3}-\mathrm{Moleküle}$ sind als Stabmodelle visualisiert (N, blau und $\mathrm{O}$, rot), die 3-lodid-Ionen sind als Kugeln dargestellt (violett).

Die asymmetrische Einheit enthielt nur ein Molekül, aber aus den Ergebnissen der Größenausschlusschromatograpie war bekannt das VosA190S ein Dimer ist. Das zweite Molekül wurde daher unter den Symmetriepartnern gesucht. Hierfür wurde, mit PISA (Krissinel und Henrick, 2007) aus dem CCP4-Paket (Winn et al., 2011), eine Suche nach Molekülen durchgeführt, die in der Kristallpackung große Oberflächen gegenseitig abdecken. Es wurden zahlreiche Molekülpaare gefunden, darunter zwei die jeweils eine Fläche von 1077,8 und 775,6 $\AA^{2}$ (M1 und -2 im folgenden) abdecken. Die weiteren Molekülpaare deckten weitaus weniger Fläche ab $\left(<400 \AA^{2}\right)$. M1 wurde von PISA als natives Molekülpaar vorgeschlagen. Eine Betrachtung der Kristallpackung zeigte das M2 sich nur in eine Raumrichtung wiederholte, während M1 durchgehend vorkam. Es wurde daher M1 als das native Dimer definiert (Abb. 2.32). 

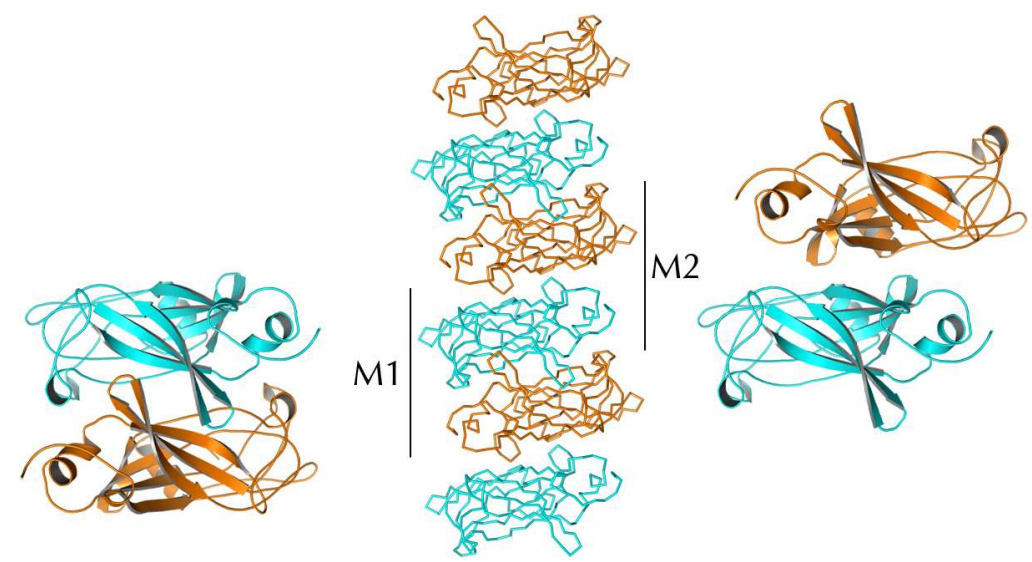

Abbildung 2.32: Ausschnitt aus der Kristallpackung von VosA190S. VosA190S-Moleküle (nur $\mathrm{C}_{\alpha^{-}}$ Rückgrat) sind abwechselnd cyan und orange eingefärbt. Beide von PISA vorgeschlagenen DimerKonformationen sind markiert und links bzw. rechts aus alternativer Perspektive gezeigt.

Die bereits erwähnten $\beta$-Stränge 6 und 7 beider Moleküle bilden durch diese Faltung eine Tasche, die durch die gleichen Stränge des jeweils anderen Moleküls vollständig besetzt wird (Abb. 2.33). Diese $\beta$-Stränge werden durch hydrophobe Interaktionen von Phe 72, Phe 136 und Val 143 beider Moleküle zusammengehalten (Abb. 2.34B). Auch die restlichen Interaktionen zwischen beiden Molekülen sind größtenteils hydrophober Natur (Abb. 2.34B). Weiterhin liegen sechs Wasserstoffbrückenbindungen jeweils zwischen Tyr 70/Pro 90 und Ser 91/Tyr 60 und Leu 94/Tyr 70 des ersten und zweiten Moleküls vor (Abb. 2.34A).

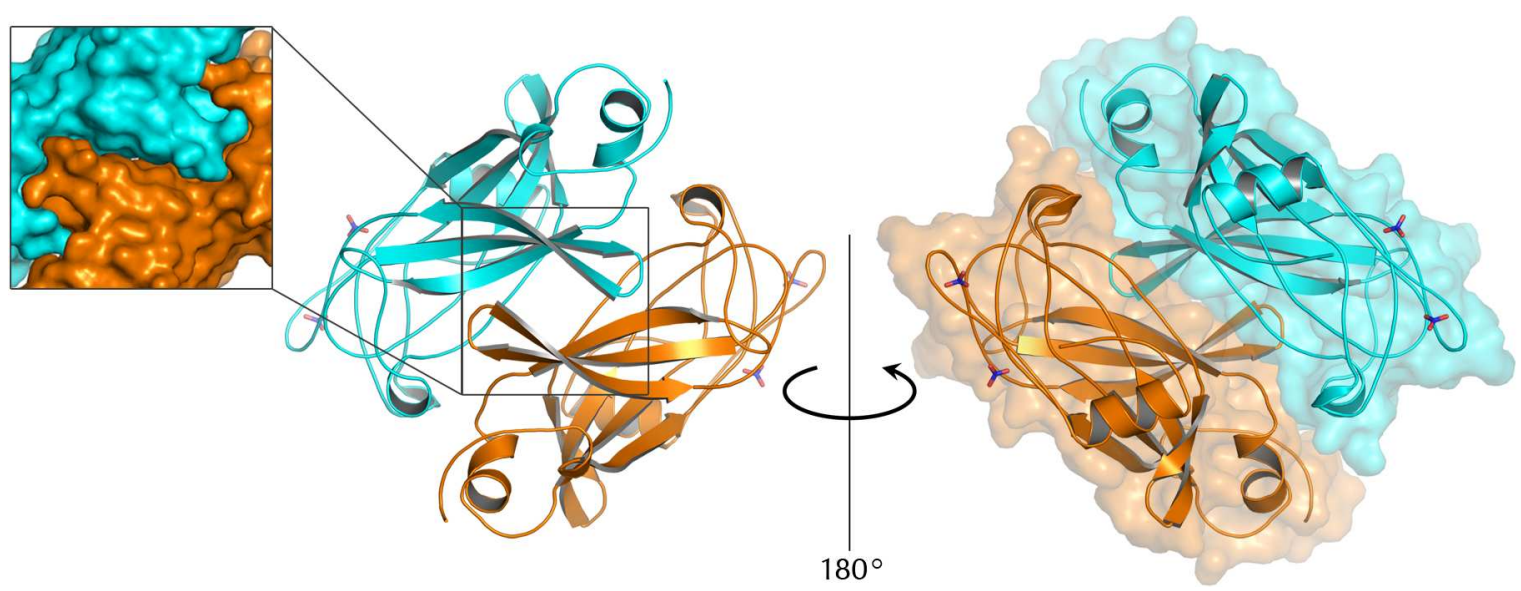

Abbildung 2.33: Modell des angenommenen VosA190S-Dimers. Links: Die einzelnen Moleküle (cyan und orange) weisen auf der einen Seite mit den $\beta$-Strängen 6 und 7 in das andere Molekül (Oberflächendarstellung in der Vergrößerung). Rechts: Rückseite des VosA190S-Dimer mit überlagerter Oberflächendarstellung. 


\section{Kapitel 2 | ERGEBNISSE}

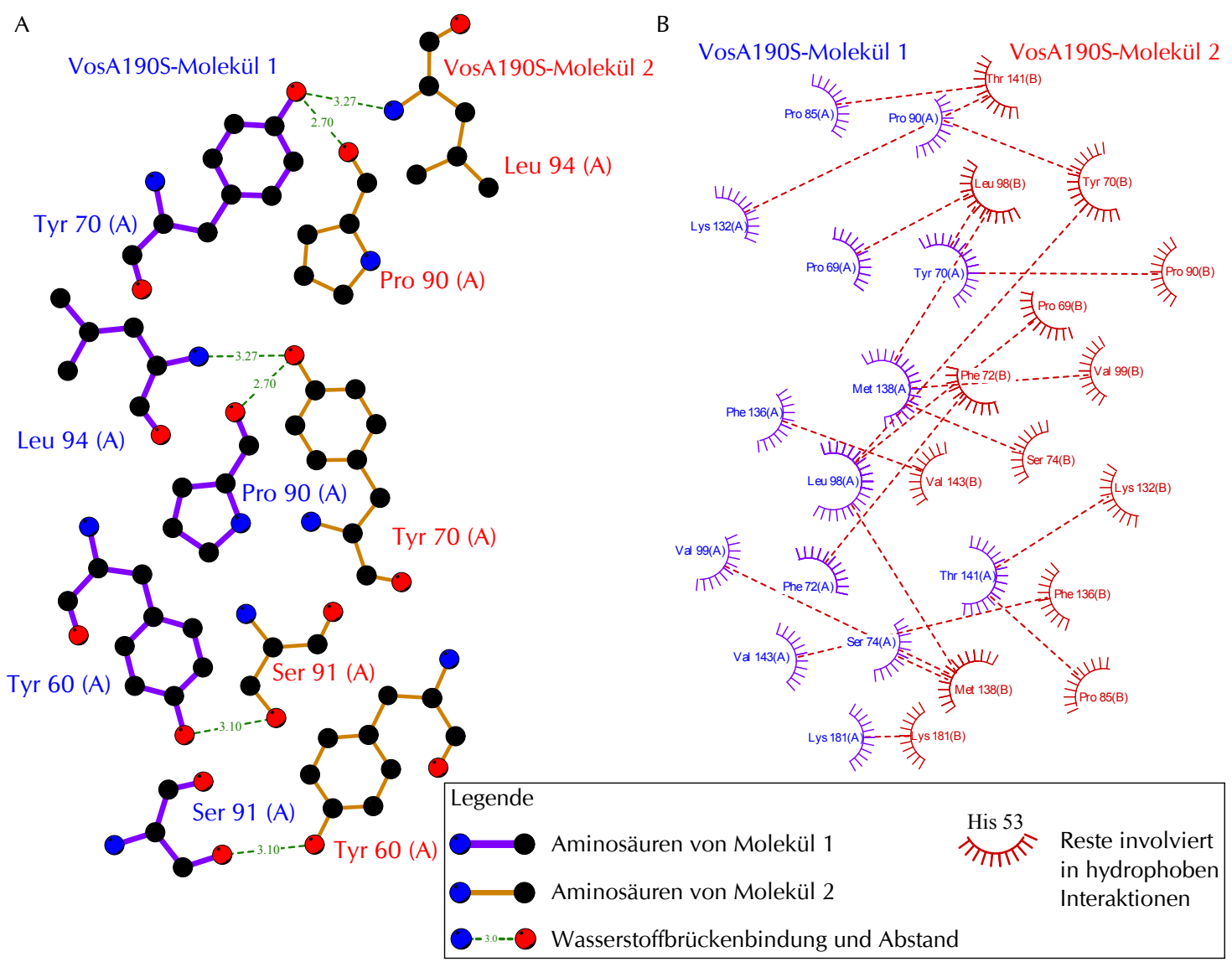

Abbildung 2.34: Schematische Darstellung der interagierenden Aminosäurereste beider VosA190SMoleküle. Dargestellt sind die Wasserstoffbrückenbindungen (A) und hydrophoben Interaktionen (B) zwischen den beiden Molekülen (Beschriftung in rot und blau). Sauerstoff, Stickstoff und Kohlenstoff sind jeweils rot, blau und schwarz dargestellt. Erstellt mit Dimplot/2D-GraLab (Wallace et al., 1995; Zhou et al., 2009).

A
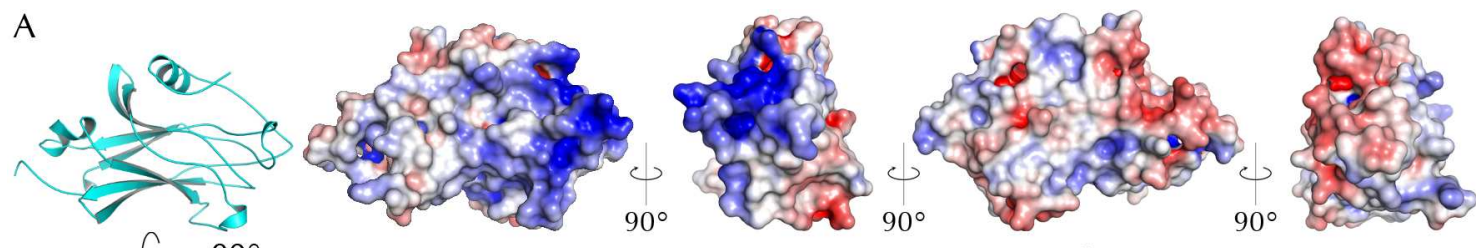

B
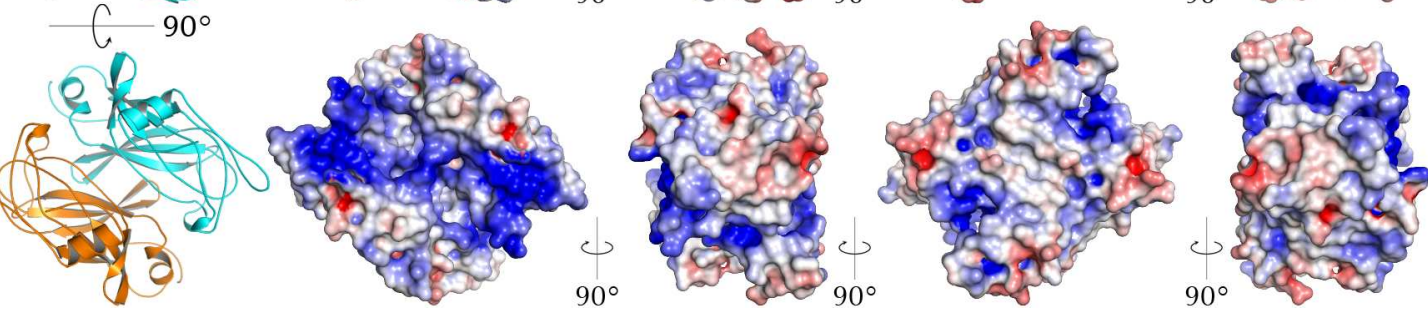

Abbildung 2.35: Verteilung der Oberflächenladung von VosA190S. Cartoondarstellung und Oberflächenladung des VosA190S-Monomers (A) und -Dimers (B). Positiv geladene Oberflächen sind blau und negativ geladene rot dargestellt. Oberflächenladungen wurden mit APBS berechnet und mit PyMOL visualisiert. 
Die Gesamtoberfläche eines VosA190S-Moleküls beträgt $8506 \AA^{2}$, von der $1120 \AA^{2}$ durch das zweite Molekül (13\%) abgedeckt werden. An einem Ende von VosA190 ist eine stark positiv geladene Oberfläche vorhanden. Diese Fläche liegt somit im Dimer jeweils am Ende des Gesamtmoleküls (Abb. 2.35).

\subsubsection{Strukturvergleich von VosA190S und NFkB-p50}

Eine Durchsuchung der Protein Data Bank (PDB) nach Proteinen mit ähnlicher Aminosäuresequenz ergab keine Treffer. Es wurde daher eine Suche nach ähnlichen Strukturen (unabhängig von der Sequenz) durchgeführt. Für den Vergleich von VosA190S mit dem Bestand der PDB wurde DALI (Holm und Rosenström, 2010) verwendet. Dabei wurden mehr als 1000 Treffer erhalten, von denen 59 ein Z-Wert $>8$ hatten. Höhere Z-Werte stehen dabei für strukturell ähnliche, geringe für strukturell unterschiedliche Proteine. Bei einem Z-Wert von über 20 gelten die Proteine definitiv als Homologe. Werte zwischen 8 und 20 werden für Proteine ausgegeben, die wahrscheinlich homolog sind (Holm et al., 2006). Das strukturell ähnlichste Protein in dieser List war das humane NFkB-p50² (PDB-Eintrag: 1SVC) mit einem Z-Wert von 11,3 und einer Standardabweichung von 2,8 $\AA$ für 118 $\mathrm{C}_{\alpha}$-Atome. Der Großteil der verbleibenden 59 Treffer sind vorwiegend NFKB-, Rel- oder allgemein $\beta$-Sandwich-Proteine.

Die strukturelle Ähnlichkeit beider Proteine liegt im N-terminalen Bereich der Rel-Homologie-Domäne (RHD) (Abb. 2.36). Alle $\beta$-Stränge von VosA190S weisen ein strukturelles Äquivalent in der RHD von NFkB-p50 auf, ausser $\beta 4$. In beiden Proteinen vorkommende $\alpha$-Helices liegen in vollkommen unterschiedlichen Positionen (Abb. 2.36). Insgesamt ist die strukturelle Ähnlichkeit auf den Kern der beiden Domänen, den $\beta$-Strängen, begrenzt.
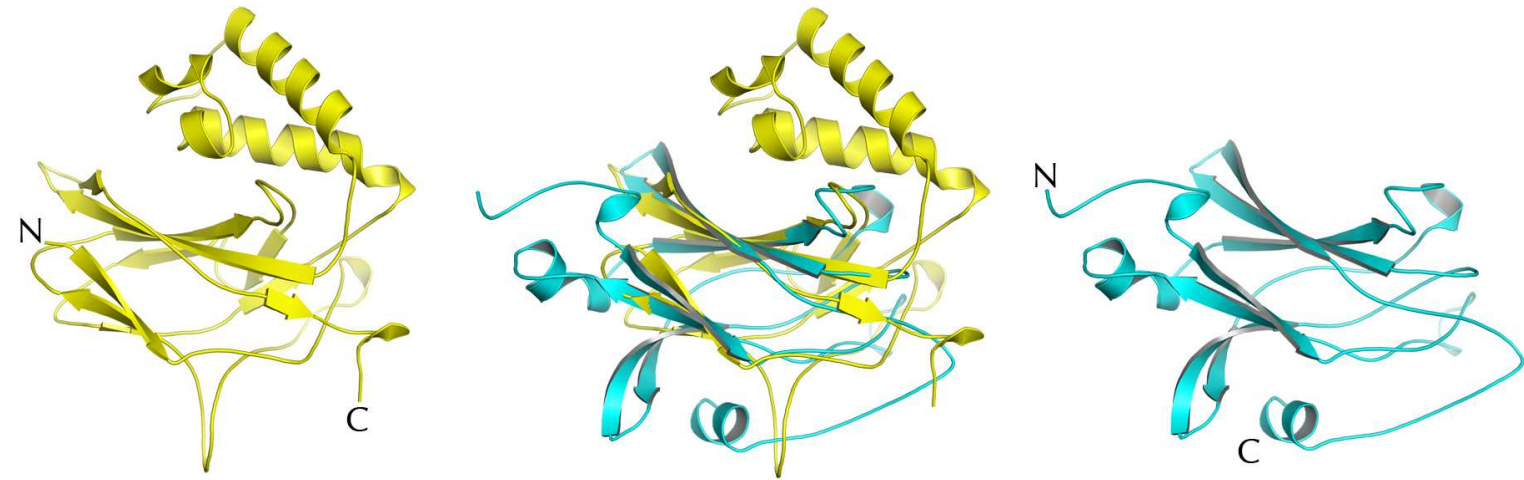

Abbildung 2.36: Strukturvergleich und -überlagerung der RHD von NFkB-p50 und VosA190S. Dargestellt sind die Einzelstrukturen der RHD von NFkB-p50 (gelb) und Velvet-Domäne von VosA (cyan) sowie Überlagerung beider Strukturen. In beiden Fällen ist nur ein Monomer gezeigt, die Nund C-Termini sind in den Einzelstrukturen markiert. NFkB-p50, PDB-Eintrag: 1SVC, Müller et al. (1995).

\footnotetext{
${ }^{2}$ engl. nuclear factor 'kappa-light-chain-enhancer' of activated B-cells
} 


\section{Kapitel 2 | ERGEBNISSE}

Bei der NFKB- und Rel-Protein-Familie handelt es sich um eine Reihe von Transkriptionsfaktoren, die direkt mit DNA interagieren und hierfür in den Zellkern transportiert werden müssen (Übersicht in Oeckinghaus und Ghosh, 2009). Die zweite Eigenschaft ist auch für Velvet-Proteine bekannt und in verschiedenen Arbeiten bereits näher untersucht worden. Die erste Eigenschaft wurde bisher nur vermutet, konnte aber im Verlauf dieser Arbeit auch für Velvet-Proteine beobachtet werden. Interessanterweise enthält die für den Vergleich verwendete Struktur von NFkB-p50 auch ein doppelsträngiges DNA-Fragment (19 bp) (Abb.2.37A).

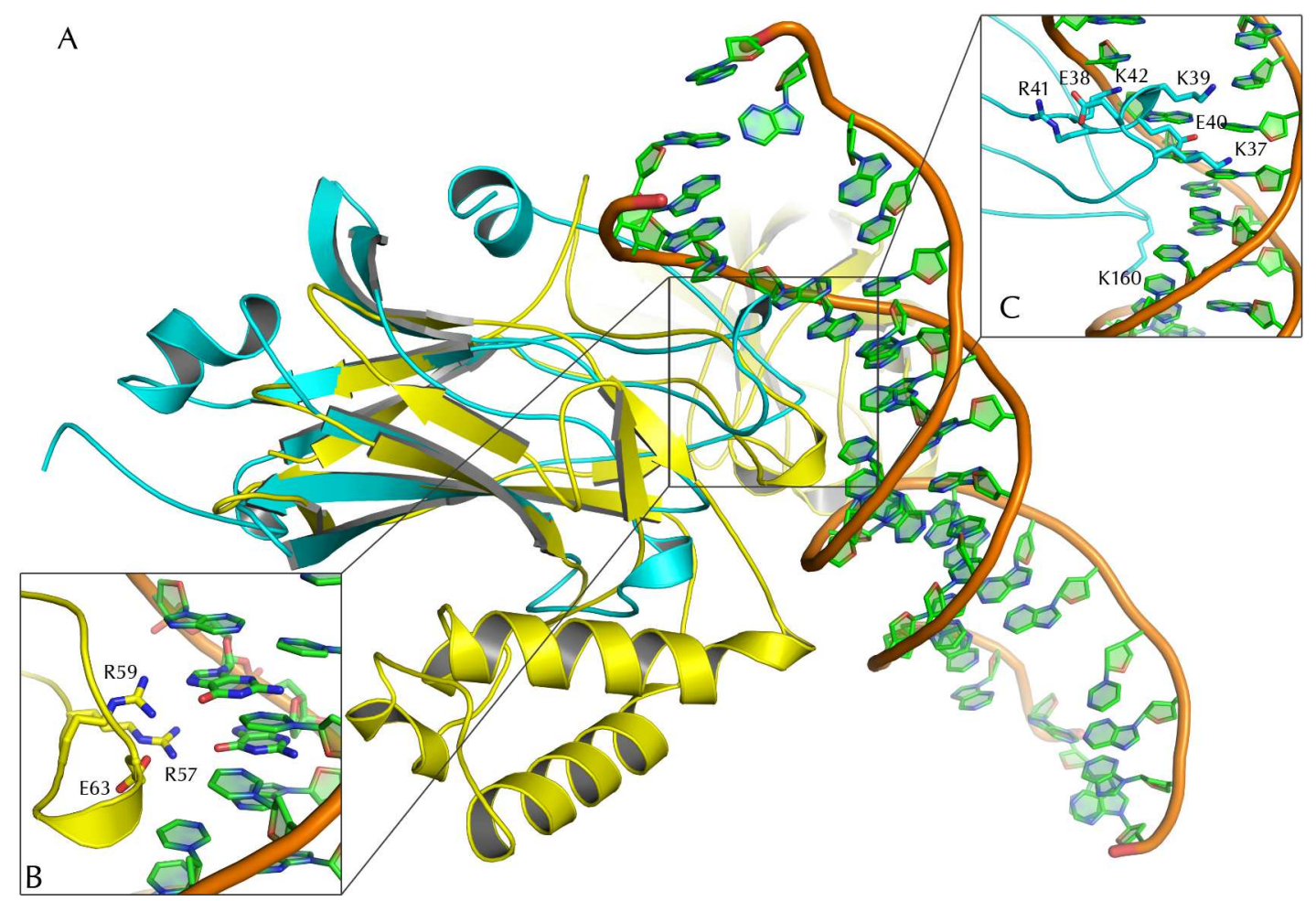

Abbildung 2.37: DNA-Bindung durch ein NFKB-p50-Molekül und überlagertes VosA190S. A: Überlagerte Monomere von VosA190S und NFkB-p50 gebunden an DNA. B: Die Erkennung von zwei aufeinander abfolgenden Guanin-Basen erfolgt durch R57/59 und E63 bei NFkB-p50 (gelb). C: Potenzielle Reste von VosA190S (cyan) die mit DNA (Basen grün, Rückgrat braun) interagieren könnten. Sauerstoff ist rot, Stickstoff blau, Kohlenstoff grün oder Farbe der Hauptkette. NFkB-p50, PDB-Eintrag: 1SVC, Müller et al. (1995).

Ausgehend von dieser Strukturüberlagerung wurde angenommen das VosA190S, oder allgemein Velvet-Proteine in einer ähnlichen Art und Weise DNA binden wie Proteine mit einer Rel-Homologie-Domäne. Der hierfür in Frage kommende Bereich von VosA190S weist im Vergleich zum restlichen Protein relativ starke positive Ladung auf (Abb. 2.35). An dieser Stelle befinden sich zwei Schleifen, die insgesamt vier Lysin- sowie ein Argininrest enthalten. Diese könnten potenziell mit einem DNA-Rückgrat oder direkt mit Basen interagieren (Abb. 2.37C). Die Rel-Proteine enthalten an dieser Stelle ein konserviertes Motiv 
bestehend aus zwei Argininen und einer Glutaminsäure (Müller et al., 1995). Dieses Motiv dient der Erkennung zweier aufeinander abfolgender Guanin-Basen (Abb. 2.37B).

Die NFKB- und Rel-proteine binden als Homo- oder Heterodimer an DNA (Abb. 2.38A). Da VosA190S auch ein dimeres Protein ist, wurde die Position des zweiten VosA190S-Moleküls ausgehend von der Überlagerung ermittelt. Die putativen Reste für die DNA-Bindung des zweiten Moleküls liegen jedoch in diesem Modell mindestens $13 \AA$ vom DNA-Rückgrat entfernt (Abb. 2.38B).
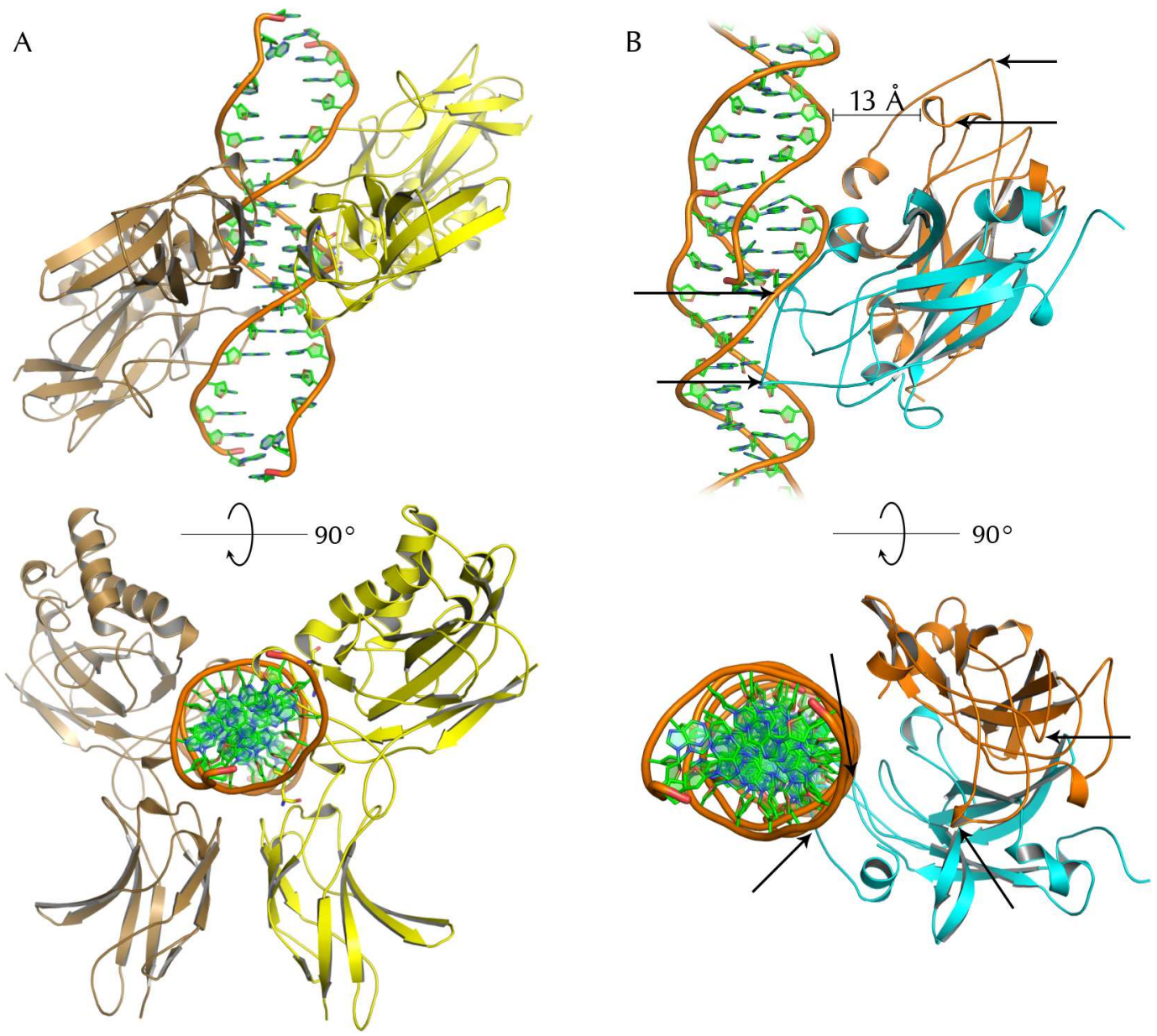

Abbildung 2.38: Vergleich von NFKB-p50-Homodimer gebunden an DNA und hypothetische DNABindung durch VosA190S-Homodimer. A: Zwei NFkB-p50-Moleküle (gelb und braun) umlagern die DNA und liegen etwas angewinkelt zu dieser. B: Hypothetisches Modell der DNA-Bindung durch zwei VosA190S-Moleküle, die putativen DNA-Bindestellen sind in beiden Perspektiven mit Pfeilen markiert. NFkB-p50, PDB-Eintrag: 1SVC, Müller et al. (1995). 


\title{
Kapitel 2 | ERGEBNISSE
}

\subsubsection{Essentielle Reste für die DNA-Bindung in VosA190S}

Es wurde versucht, das im Strukturvergleich mit NFKB-p50 erarbeitete Modell der DNA-Bindung durch VosA190S mittels Mutagenese zu verifizieren. Die von VosA gebundene Konsensussequenz wurde dabei freundlicherweise von Prof. Jae-Hyuk Yu (University of Wisconsin, Wisconsin, USA) zur Verfügung gestellt. Die erwähnten Aminosäuren von VosA190S wurden entweder einzeln oder in Kombination durch Alanin ersetzt, um so ihren Einfluss auf die DNA-Bindung zu testen. Die getesteten Mutanten enthielten folgende Mutationen: K37A, K39A, R41A, K42A, K160A, K37A/K39A (doppel) und K37A/K39A/R41A/K42A (tot). Alle Proteine wurden wie Wildtyp-VosA190S exprimiert und mit einer StrepTactin HP Säule gereinigt. Die Gelfiltration wurde ausgelassen, da nach Elution von der StrepTactin HP Säule bereits hochreines Protein vorlag.

\subsubsection{Bindungsstudien zu den VosA190S-Mutanten mit VelB-mini}

Um die korrekte Faltung der VosA190S-Mutanten zu überprüfen, wurde eine Bindungsstudie (6.2.3.5) mit der speziellen VelB-Mutante VelB-mini (2.2.2) durchgeführt. VosA190S-Mutanten (C-Strep II) wurden auf StrepTactin Sepharose immobilisiert und anschließend mit VelB-mini (C-His $\left.{ }_{6}\right)$ inkubiert. Alle VosA190SMutanten waren in der Lage VelB-mini zu binden und eluierten zusammen mit diesen. Eine Bindung von VelB-mini an die StrepTactin Sepharose konnte nicht beobachtet werden (Abb. 2.39, Spur VelB-mini/E). Sehr geringe Mengen von Strep Tactin waren auch im Eluat vorhanden (schwarzer Pfeil). Es wurde daher angenommen, das VosA190S korrekt gefaltet ist.

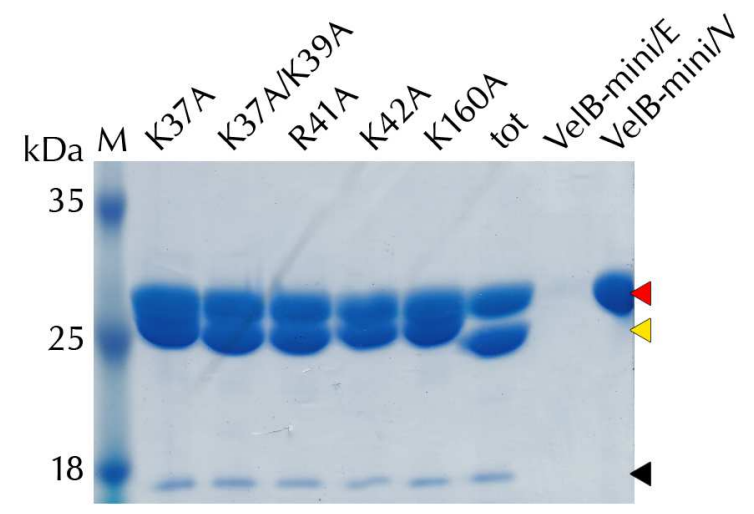

\begin{abstract}
Abbildung 2.39: SDS-PA-Gel von Bindestudie der VosA190S-Mutanten und VelB-mini mit StrepTactin Sepharose. Aufgetragen sind Proteingrößenstandard $(M)$ und Eluat der inkubierten Kombinationen von VosA190S-Mutanten und VelB-mini, VelB-mini auf StrepTactin Sepharose allein (VelB-mini/E) und verwendetes VelB-mini (VelB-mini/V). VosA190S-Mutanten sind mit einem gelben Pfeil, VelB-mini mit einen roten und StrepTactin mit einen schwarzen Pfeil markiert.
\end{abstract}




\subsubsection{DNA-Bindung der VosA190S-Mutanten}

Im Gelretardationsexperiment konnte in keiner der Proteinpräparationen DNA detektiert werden (Abb. 2.40, leere Spuren). Für dieses Experiment wurden jeweils 3,2 $\mu \mathrm{g}$ brlA10-DNA (44 bp) und $10 \mu \mathrm{g}$ Protein verwendet. Alle getesteten Mutanten wiesen verringerte DNA-Bindeaktivität auf. Der Einfluss von K37 und K39 war dabei am größten, und bei der Doppelmutanten K37A/K39A war nahezu keine DNA-Bindung mehr erkennbar. Auch das im Modell von der DNA wegweisende Arginin 41 wies geringere DNA-Bindung auf. Im Vergleich zu den anderen Mutanten weist K160A die stärkste Verschiebung im Gel auf (Abb. 2.40).

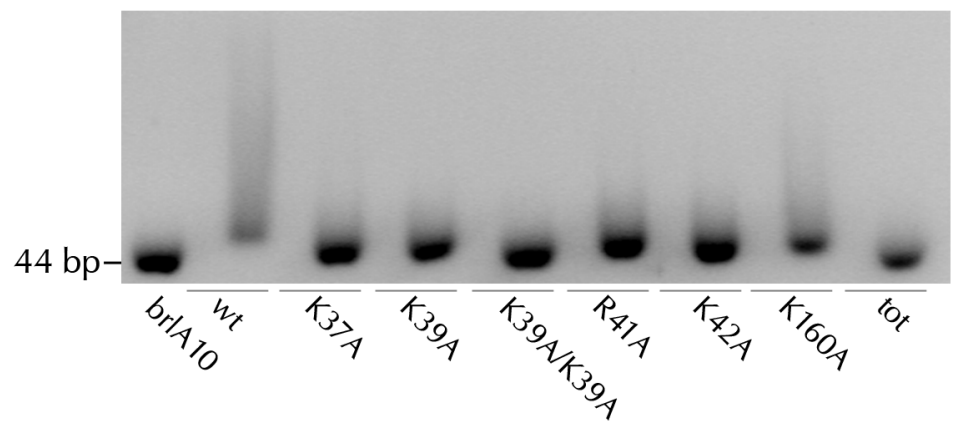

Abbildung 2.40: Agarosegel des Gelretardationsexperiments mit brlA10 DNA-Fragment (brlA10) und VosA190S-Mutanten. Eine größere Verschiebung weist auf eine stärkere Bindung durch das Protein hin. Alle Spuren, außer brlA10, enthalten das jeweilige Protein.

\subsection{VelB-VosA190S-Komplex}

Die erfolgreiche Kristallisation und Strukturbestimmung von VosA190S führte zu einem erneuten Versuch VelB zu kristallisieren, diesmal in Form eines VelBVosA190S-Komplexes. Dies war erfolgreich und die Struktur konnte bestimmt werden. Obwohl die ermittelte Struktur von VelB nicht enorm von VosA190S abweicht, ist sie sehr aufschlussreich hinsichtlich einer Besonderheit von VelB.

\subsubsection{Präparation des VelB-VosA190S-Komplex}

Dieser Komplex besteht aus VelB-C-His 6 (2.2) und VosA190S (2.7) und wurde wie in 6.2.5.12 beschrieben präpariert. Beide Proteine waren in der löslichen Fraktion (Abb. 2.41, Spur Ü). Im ersten Reinigungsschritt wurde eine HisTrap Säule verwendet, das Eluat (Spur EH) enthielt große Mengen VelB und relativ geringe Mengen an VosA190S. Auch waren zu diesen Zeitpunkt noch viele Verunreinigungen vorhanden. Die meisten dieser Verunreinigungen sowie auch überschüssiges VelB konnten durch den zweiten Reinigungsschritt (StrepTactin HP) entfernt werden (Spur U1-2). Das Eluat der StrepTactin HP Säule enthielt beide Proteine in relativ gleichen Mengen mit nur noch wenigen Verunreinigungen (Spur ES) und wurde direkt für die weitere Reinigung mit einer Superdex 200 26/60 Gelfiltrationssäule verwendet. 


\section{Kapitel 2 ERGEBNISSE}

Abbildung 2.41: SDS-PA-Gel der affinitätschromatographischen Reinigung des VelBVosA190S-Komplexes mit einer HisTrap und StrepTactin HP Säule. Aufgetragen sind Durchfluss (D1-2 und U1-2) und Eluat (EH und ES) beider Schritte sowie ein Proteingrößenstandard $(M)$. VelB ist mit einem $(\approx 41 \mathrm{kDa})$ roten und $\operatorname{VosA190S}(\approx 22,5 \mathrm{kDa})$ mit einen gelben Pfeil markiert.
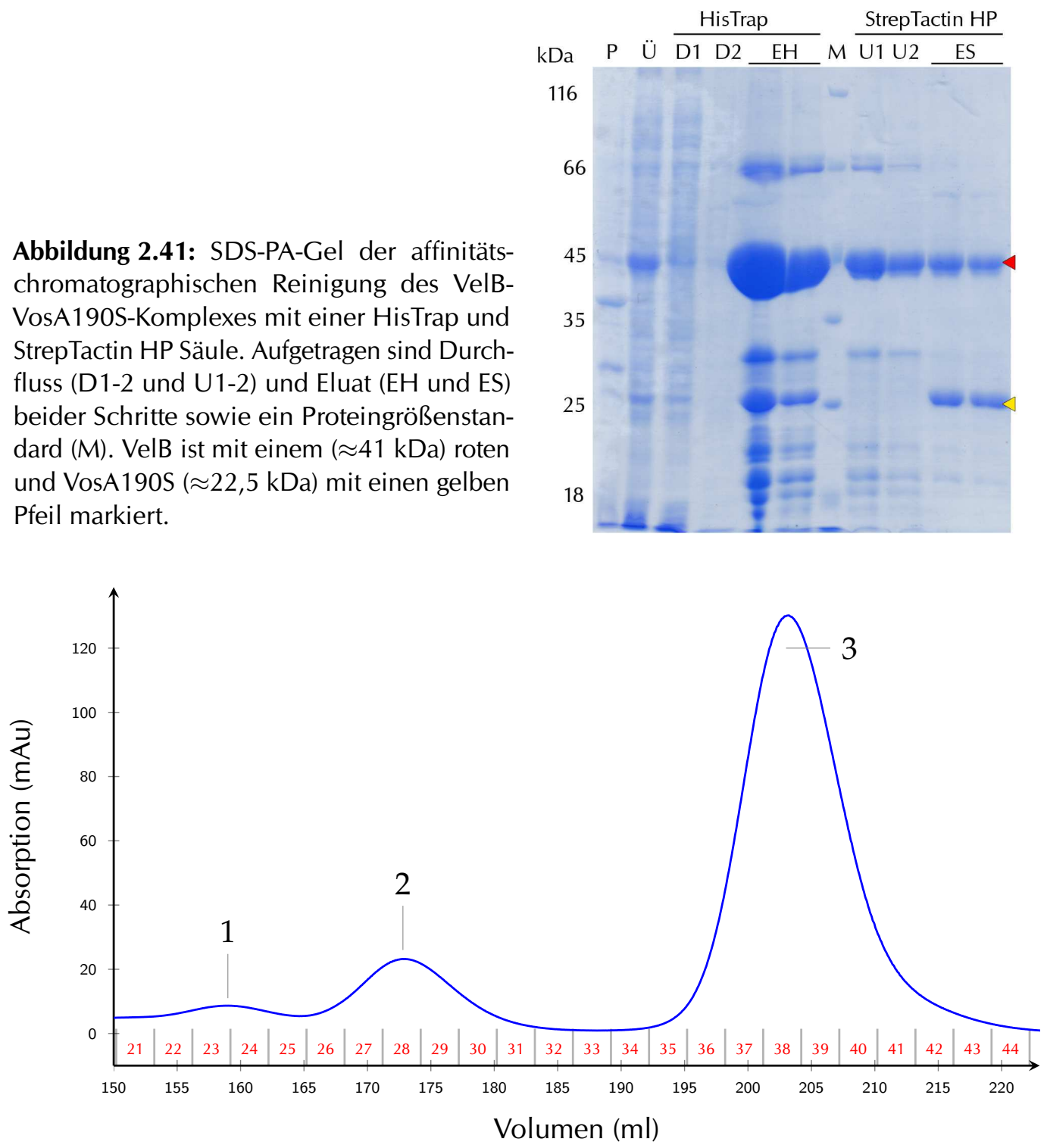

Abbildung 2.42: Chromatogramm der Größenausschlusschromatographie des VelB-VosA190SKomplexes über eine Superdex 200 16/60 Säule. Das erste UV-Maximum (1) entspricht dimeren VelB-VosA190S und das zweite (2) monomeren VelB-VosA190S. Blau: UV-Absorption bei $280 \mathrm{~nm}$ in gerätespezifischer Einheit (Y-Achse, $\mathrm{mAu}$ ) entlang des Elutionsvolumens (X-Achse, ml). Gesammelte Fraktionen sind entlang der X-Achse nummeriert.

In der Gelfiltration wurden drei lokale UV-Maxima beobachtet (Abb. 2.42), die alle VelB und VosA190S in unterschiedlichen Mengen enthielten. Protein aus UV-Maximum 3, enthielt auch noch einige Verunreinigungen. Es wurde für die Kristallisation verwendet, da es der Größe eines monomeren VelB-VosA190SKomplexes entsprach. 


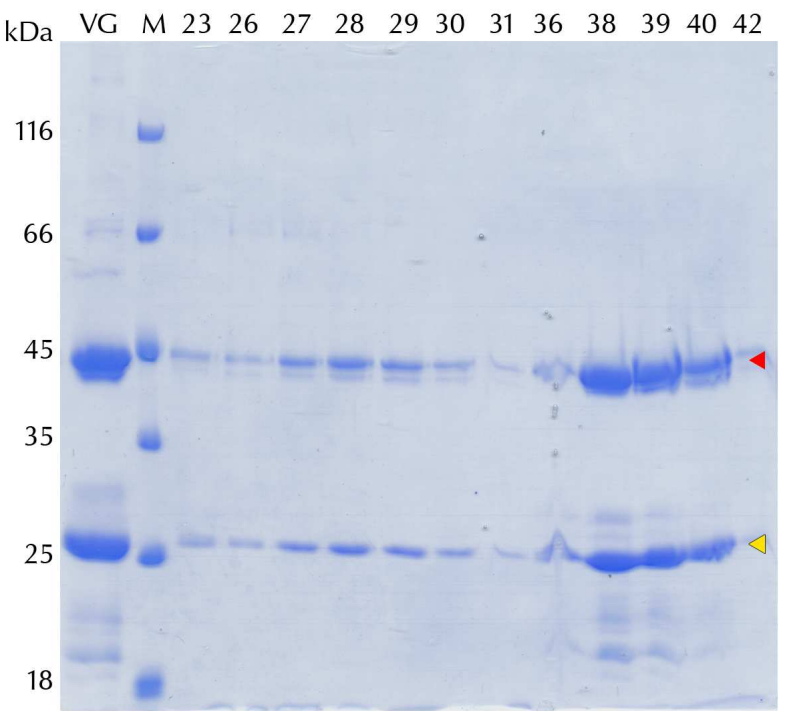

Abbildung 2.43: SDS-PA-Gel der Größenausschlusschromatographie des VelBVosA190S-Komplexes. Aufgetragen sind eine Probe vor der Gelfiltration (VG), Proteingrößenstandard $(M)$ und Fraktionen aus der Gelfiltration (23-42). Die Nummern beziehen sich auf die Fraktionen aus dem Chromatogramm in Abb. 2.42. VelB $(\approx 41 \mathrm{kDa})$ ist mit einem roten und $\mathrm{Vo}_{\mathrm{O}}$ sA190S $(\approx 22 \mathrm{kDa})$ mit einem gelben Pfeil markiert.

\subsubsection{Kristallisation des VelB-VosA190S-Komplex}

Die Sammlungen $\mathrm{AmSO}_{4}$ Suite, JB NucPro, JBScreens, JCSG, PGA und ProPlex wurden wie in 6.2.6.1 beschrieben bei $20^{\circ} \mathrm{C}$ pipettiert. Die Proteinkonzentration betrug 11,64 mg/ml. Nach 6 Tagen konnte in einer Bedingung plattenförmige ineinander gewachsene Kristalle beobachtet werden, die Bedingung enthielt $200 \mathrm{mM}$ Kalium-Formiat und 20\% PEG 3350. Die Kristalle konnten nicht reproduziert werden und wurden beim Versuch sie zu ernten zerstört (Abb. 2.44A). Nach 4 Wochen konnten in einigen weiteren Bedingungen ähnliche Kristalle beobachtet werden. Die Kristallisationsbedingungen enthielten:

- $25 \%$ PEG 4000, $150 \mathrm{mM}\left(\mathrm{NH}_{4}\right)_{2} \mathrm{SO}_{4}, 100 \mathrm{mM}$ MES pH 5,5 (Abb. 2.44B)

- 20\% PEG 10000, 100 mM HEPES pH 7,5 (Abb. 2.44C)

- $20 \%$ PEG 3350, $200 \mathrm{mM} \mathrm{NH}_{4} \mathrm{NO}_{3}$ (Abb. 2.44D)
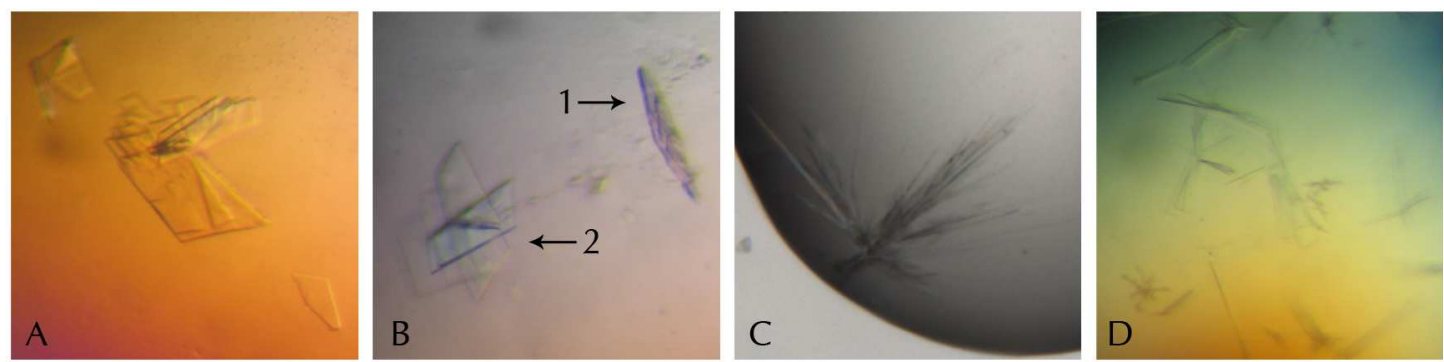

Abbildung 2.44: Kristalle vom VelB-VosA190S-Komplex. Erste Kristalle von VelB-VosA190S nach 6 Tagen (A), sowie weitere nach 28 und 34 Tagen (B-D). Initiale Beugungbilder (1) sowie ein Datensatz (2) wurde von den Kristallen aus Bedingung B aufgenommen. Die Kristallisationsbedingungen sind alle PEG-basierend (s. Text). Die Färbung ist durch Verwendung eines Polarisationsfilters entstanden. 


\section{Kapitel 2 | ERGEBNISSE}

\subsubsection{Strukturbestimmung des VelB-VosA190S-Komplex}

Es war möglich, einige Kristalle (Abb. 2.44B/1) zu ernten und initiale Beugungbilder, für die Bestimmung der Raumgruppe und der Zellkonstanten, aufzunehmen. An einer MicroMax 007 Drehanode (Rigaku, Japan) konnten mehrere Beugungbilder aufgenommen werden. Dabei konnte eine Streuung bis lediglich $\approx 6-7 \AA$ beobachtet werden. Die Raumgruppe sowie Zellkonstanten konnten mit MOSFLM/iMOSFLM bestimmt werden (Leslie, 2006; Battye et al., 2011). Die Kristalle gehörten der orthorombischen Raumgruppe P222 an, die Zellachsen wiesen folgende Länge auf, $a=52 \AA, b=56 \AA$ und $c=137 \AA$. Die Winkel $\alpha, \beta$ und $\gamma$ betrugen $90^{\circ}$. Mit diesen Daten wurde das Volumen der Einheitszelle berechnet, um die Anzahl der Moleküle in der asymmetrischen Einheit bei entsprechenden Lösungsmittelgehalt abzuschätzen. Die Berechnungen wurden mit dem CCP4-Paket durchgeführt und sind in Tabelle 2.4 zusammengefasst.

Tabelle 2.4: Matthews-Koeffizient und Lösungsmittelgehalt bei unterschiedlicher Zusammensetzung der asymmetrischen Einheit des VelB-VosA190S-Kristalls.

\begin{tabular}{lll}
\hline $\begin{array}{l}\text { Moleküle/ } \\
\text { asymmetrische Einheit }\end{array}$ & $\begin{array}{l}\text { Matthews- } \\
\text { Koeffizient }\end{array}$ & $\begin{array}{l}\text { Lösungsmittel- } \\
\text { gehalt [\%] }\end{array}$ \\
\hline $\begin{array}{l}\text { VelB (41 kDa) } \\
1\end{array}$ & 2,43 & 49,47 \\
\hline VosA190S (22,5 kDa) & & \\
1 & 4,43 & 72,27 \\
2 & 2,22 & 44,54 \\
3 & 1,48 & 16,81 \\
\hline VelB-VosA190S (63,5 kDa) & & \\
1 & 1,57 & 21,74 \\
\hline
\end{tabular}

Proteinkristalle weisen i.d.R. einen Lösungsgehalt von $\approx 50 \%$ und durchschnittlichem Matthews-Koeffizienten von 2,69 $\AA^{3}$ /Dalton auf (Matthews, 1968; Kantardjieff und Rupp, 2003). Es wurde daher angenommen, dass die asymmetrische Einheit der Kristalle entweder ein Molekül VelB oder zwei Moleküle VosA190S enthält. Da die Kristalle sehr zerbrechlich waren, was auf ein sehr hohen Lösungsmittelgehalt deutet, wurde ausgeschlossen, dass sowohl VelB als auch VosA190S in der asymmetrischen Einheit vorliegen können.

Die in Abbildung 2.44B (2) gezeigte Gruppe an Kristallen wurde beim Ernten vereinzelt und an der Messstation ID23-2 am ESRF (Grenoble, Frankreich) vermessen. Die Statistiken zur Datensammlung sind in Tabelle 2.5 zusammengefasst. 
Tabelle 2.5: Statistik zur Datensammlung eines VelB-VosA190S-Kristalls

\begin{tabular}{|c|c|}
\hline \multicolumn{2}{|c|}{ VelB-VosA190-Datensatz } \\
\hline Messstation & ID 23-2 (ESRF, Frankreich) \\
\hline 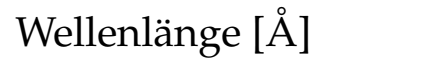 & 0,87260 \\
\hline Raumgruppe & $\mathrm{P} 2{ }_{1} 2_{1} 2_{1}$ \\
\hline Zellkonstanten $[\AA]$ & $a=52,03 ; b=56,75 ; c=138,17$ \\
\hline Winkel $\left[{ }^{\circ}\right]$ & $\mathrm{a}=\mathrm{b}=\mathrm{c}=90$ \\
\hline Auflösung [Å] & $36,95-2,20(2,31-2,20)$ \\
\hline $\mathrm{R}_{\text {merge }}[\%]$ & $12,6(48,3)^{*}$ \\
\hline Signal/Rauschen $(\mathrm{I} / \sigma)$ & $8,1(2,9)^{*}$ \\
\hline Vollständigkeit [\%] & $97,0(98,3)^{*}$ \\
\hline Redundanz & $4,5(4,5)^{*}$ \\
\hline
\end{tabular}

* Werte in Klammern beziehen sich jeweils auf die höchstaufgelöste Schale.

Der Datensatz wurde wie in 6.2.6.8 (S. 111) beschrieben prozessiert. Die gemessenen Kristalle waren isomorph zu den bereits getesteten Kristallen, daher wurde die Anwesenheit eines vollständigen VelB-VosA190S-Komplexes in der asymmetrischen Einheit ausgeschlossen (s. Tabelle 2.4). Zu diesen Zeitpunkt wurde die Annahme gemacht, dass zwei VosA190S-Moleküle vorliegen, da VelB bisher nicht kristallisiert werden konnte und andererseits VosA190S sehr gut kristallisierte. Für die Phasierung per molekularem Ersatz wurde das Programm Phaser (McCoy et al., 2007) verwendet, als Suchmodell kamen verschiedene VosA190S-Verkürzungen zum Einsatz. Erfolgreich war ein Modell, das lediglich die Reste Ser 17 bis Asp 79 und Ala 86 bis Met 165 enthielt. Es wurden zwei eindeutige Lösungen gefunden, mit einem gesamten LLG-Wert ${ }^{3}$ von 587. Das erste Molekül wies einen RFZ =10,4; TFZ $=20,4$ und LLG von 236 auf. Beim zweiten Molekül war RFZ=4,4; TFZ=16,5 und LLG lag bei 501. Der R-Faktor betrug 53,4\%. Die initiale Elektronendichtekarte war von geringer Qualität (gesamte FOM=0,41) und es war daher nicht möglich beide Moleküle eindeutig zu identifizieren. Die Struktur wurde daher in Coot per Hand gebaut und nach Verfeinerung konnte eines der beiden Moleküle als unvollständiges VelB identifiziert werden.

Für die Kristallisation des Komplexes wurde Volllängen-VelB (377 AS inkl. C-His 6 ) und VosA190S (200 AS inkl. C-Strep II) verwendet. Von VelB konnten 198, von VosA190S nur 149 Aminosäuren in der Elektronendichte lokalisiert werden. Unter der Annahme, dass sich lediglich die lokalisierten Reste in der asymmetrischen Einheit befinden, ergibt das einen $\approx 38,5 \mathrm{kDa}$ großen Komplex und einen Lösungsmittelgehalt von $\approx 52 \%$.

\footnotetext{
${ }^{3}$ engl. log likelihood gain, logarithmische Wahrscheinlichkeitssteigerung
} 


\section{Kapitel 2 | ERGEBNISSE}

Das fertig verfeinerte Modell enthält zwei Moleküle in der asymmetrischen Einheit sowie ein Sulfat-Ion zwischen beiden Molekülen. Die finalen Statistiken zur Verfeinerung sind in Tabelle 2.6 aufgeführt.

Tabelle 2.6: Statistiken zur Verfeinerung von VelB-VosA190S

\begin{tabular}{|c|c|}
\hline \multicolumn{2}{|c|}{ Verfeinerung von VelB-VosA190S } \\
\hline Auflösungsbereich [̊]] & $36,95-2,20(2,31-2,20)^{*}$ \\
\hline Anzahl der gesamten Reflexe & $99691(14610)^{*}$ \\
\hline Einzigartige Reflexe & $22156(3252)^{*}$ \\
\hline $\mathrm{R}_{\mathrm{work}}[\%]$ & $19,00(22,02)^{*}$ \\
\hline $\mathrm{R}_{\text {free }}[\%]$ & $24,56(28,44)^{*}$ \\
\hline Wilson B-Faktor $\left[\AA^{2}\right]$ & 24,5 \\
\hline \multicolumn{2}{|c|}{ Anzahl der Atome / Ø B-Faktor $[\AA ̊]^{2}$} \\
\hline Protein & $2782 / 25,36$ \\
\hline Wasser & $251 / 30,92$ \\
\hline Ionen & 5 / 20,30 \\
\hline \multicolumn{2}{|l|}{ Ramachandran-Statistiken } \\
\hline Bevorzugte Regionen [\%] & 96,2 \\
\hline Nicht-erlaubte Regionen [\%] & 0 \\
\hline \multicolumn{2}{|l|}{ Standardabweichungen } \\
\hline Bindungen $[\AA]$ & 0,0031 \\
\hline Winkel $\left[{ }^{\circ}\right]$ & 0,737 \\
\hline
\end{tabular}

* Werte in Klammern beziehen sich jeweils auf die höchstaufgelöste Schale.

\subsubsection{Struktur des VelB-VosA190S-Komplex}

Da die Struktur von VosA190S bereits in 2.7.4 detailliert beschrieben wurde und in dieser Struktur keine weiteren Reste zu sehen sind, soll hier der Schwerpunkt auf VelB und dem gesamten Komplex liegen. In beiden Proteinen sind Schleifen entweder proteolytisch entfernt worden oder unstrukturiert. Die Struktur ähnelt der des VosA190S-Homodimers, beide Proteine sind gegeneinander gestapelt. Von VosA190S weisen die $\beta$-Stränge $\beta 5$ und $\beta 6$ zu VelB, dessen entsprechende Schleife nicht vollständig definiert ist. Diese Schleife von VelB ist außerdem etwas länger und weist von VosA weg (Abb. 2.45). Beide Moleküle sind im Vergleich zum VosA-Homodimer um etwa $30^{\circ}$ rotiert (Abb. 2.46). 


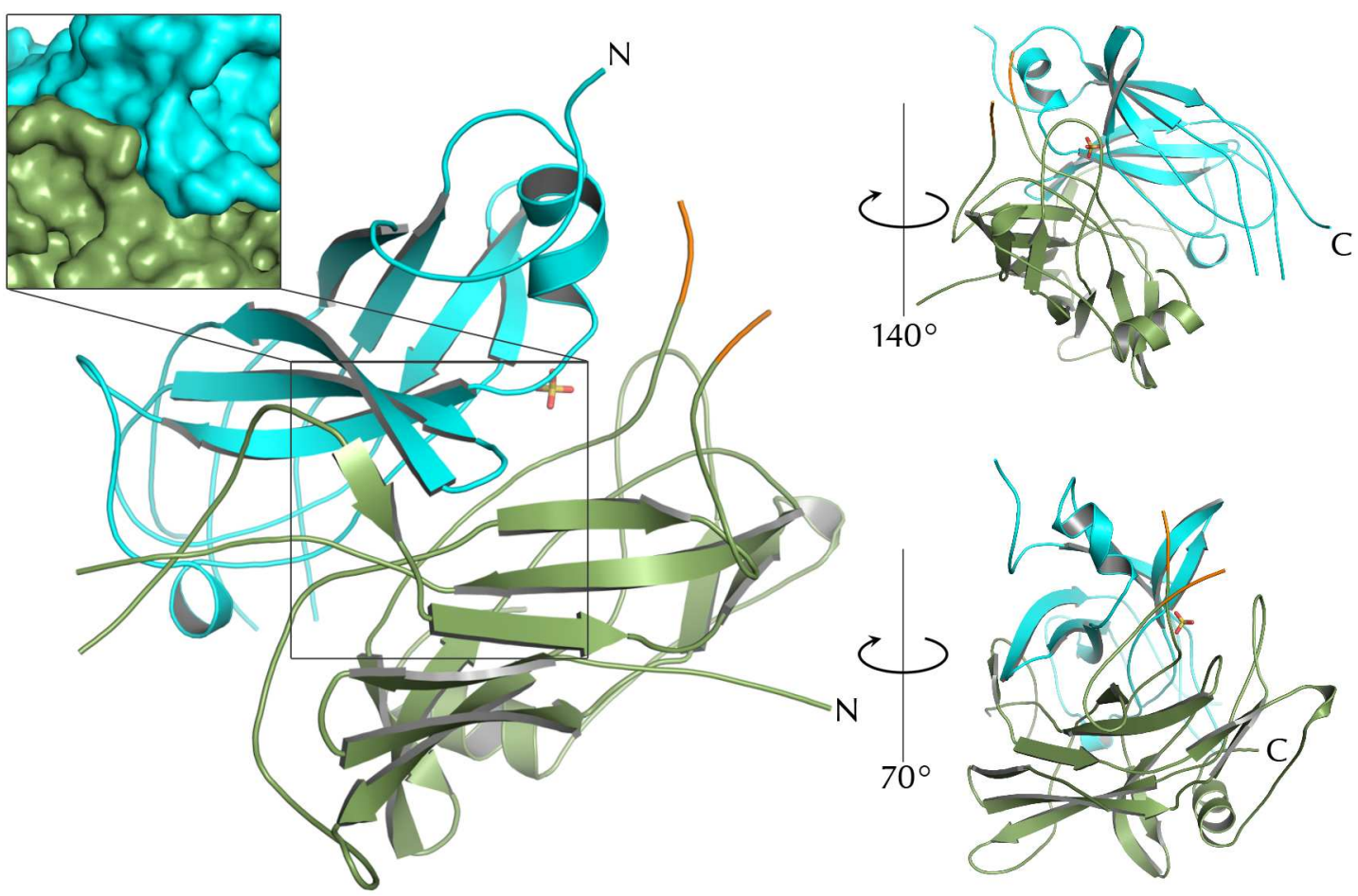

Abbildung 2.45: Kristallstruktur des VelB-VosA190S-Komplexes. Die Anordnung von VelB (grün) und VosA190S ist sehr ähnlich zu den der beiden VosA190S-Molekülen im VosA190S-Homodimer. Beide Proteine weisen mit $\beta$-Strängen zum anderen Protein (Oberflächendarstellung in der Vergrößerung). Die Reste Val 130 bis His 132 und Gly 232 bis Phe 234 von VelB sind orange hervorgehoben. Das $\mathrm{SO}_{4}{ }^{2-}$-Ion ist als Stabmodell (S, gelb und O, rot) dargestellt.
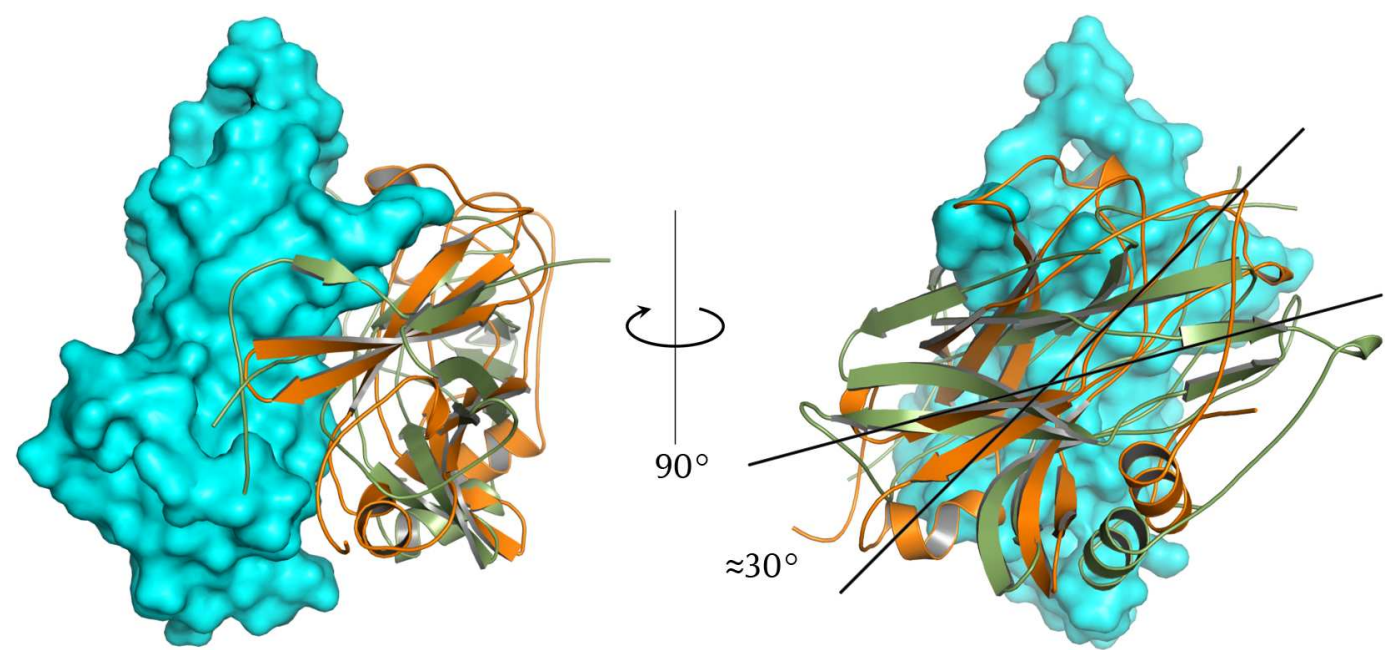

Abbildung 2.46: Unterschiedliche Orientierung der beiden Moleküle zueinander im Homo- und Heterodimer. VelB (grün) ist um etwa $30^{\circ}$ rotiert im Vergleich zu einem zweiten VosA190S-Molekül (orange). Für die Überlagerung wurde das erste VosA190S-Molekül aus dem VelB-VosA190SHeterodimer (cyan, Oberflächendarstellung) verwendet. 


\section{\begin{tabular}{l|l} 
Kapitel 2 & ERGEBNISSE
\end{tabular}}

Im Vergleich zum Homo-Dimer besteht ein weitaus größeres Netzwerk an Interaktionen zwischen beiden Molekülen. Zahlreiche polare Interaktionen, darunter 9 Wasserstoffbrückenbindungen, liegen zwischen den beiden Proteinen vor (Abb. 2.47A). Ein weiterer Unterschied ist, dass die Interaktionen bei VosA über die gesamte seitliche Oberfläche verteilt sind. Auch die Zahl an hydrophoben Interaktionen ist sehr viel höher (Abb. 2.47B).

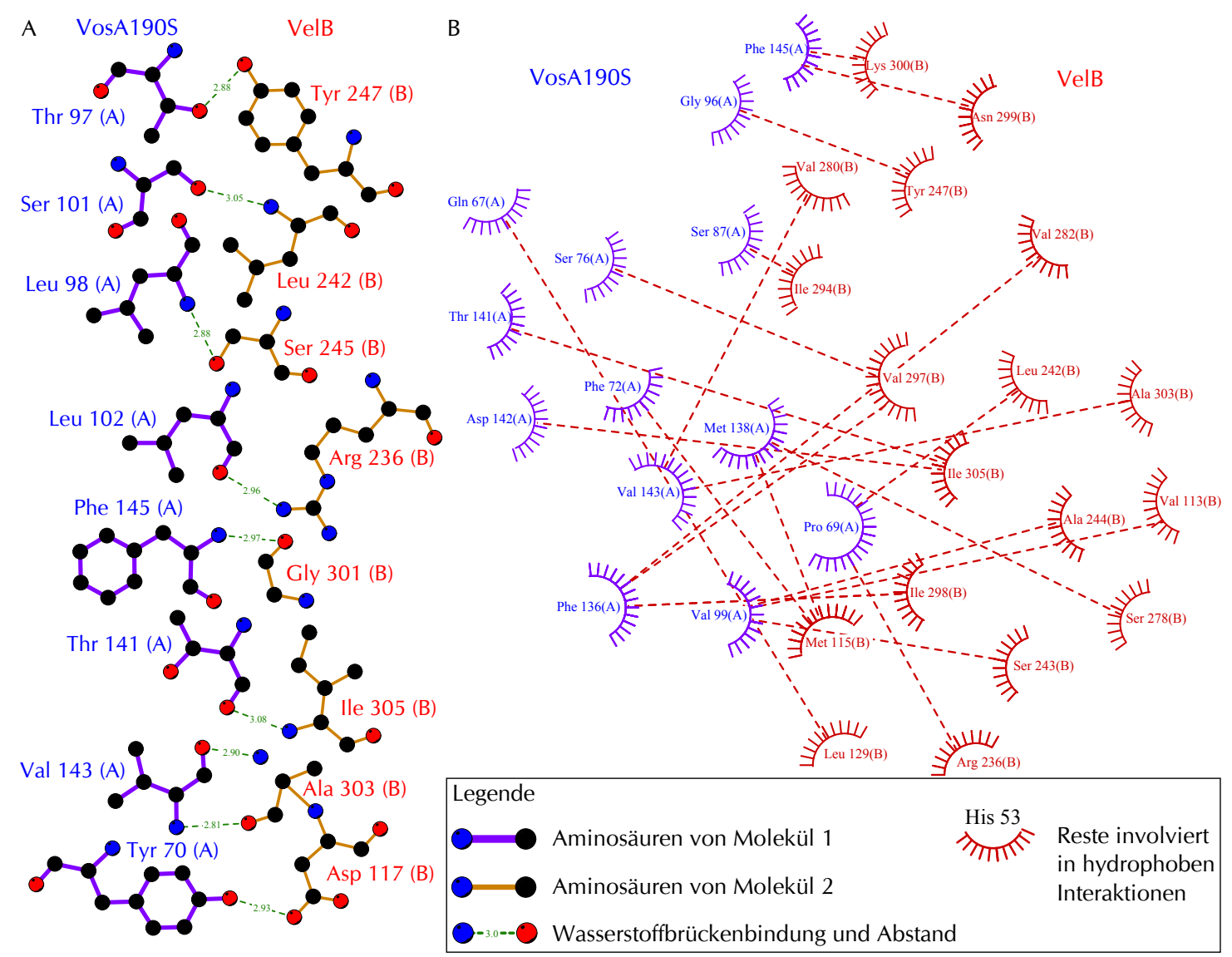

Abbildung 2.47: Aminosäuren von VelB und VosA190S die in die Bindung involviert sind. Dargestellt sind die Wasserstoffbrückenbindungen (A) und das Netzwerk an hydrophoben Interaktionen (B) zwischen den beiden Molekülen (rot und blau beschriftet). Sauerstoff ist rot, Stickstoff blau und Kohlenstoff schwarz dargestellt, erstellt mit Dimplot/2D-GraLab (Wallace et al., 1995; Zhou et al., 2009).

Die Ladungsverteilung ist ähnlich zum VosA190S-Homodimer, zwei positive Flächen, die jeweils am Ende des Komplexes zu liegen kommen (Abb. 2.48A), die aber aufgrund fehlender Reste in beiden Proteinen kleiner ausfallen. Dies führt dazu, dass auf der einen Seite des Gesamtmoleküls eine stark negative Ladung vorhanden ist (Abb. 2.48B). Durch die fehlenden Reste verringert sich die Oberfläche von VosA190S auf $7485 \AA^{2}$ (8506 $\AA^{2}$ im Homo-Dimer), von der $19 \%\left(1453 \AA^{2}\right)$ von VelB abgedeckt werden. VelB hat eine Oberfläche von $9855 \AA^{2}$ von der 14\% (1449 $\left.\AA^{2}\right)$ durch VosA190S abgedeckt werden. 


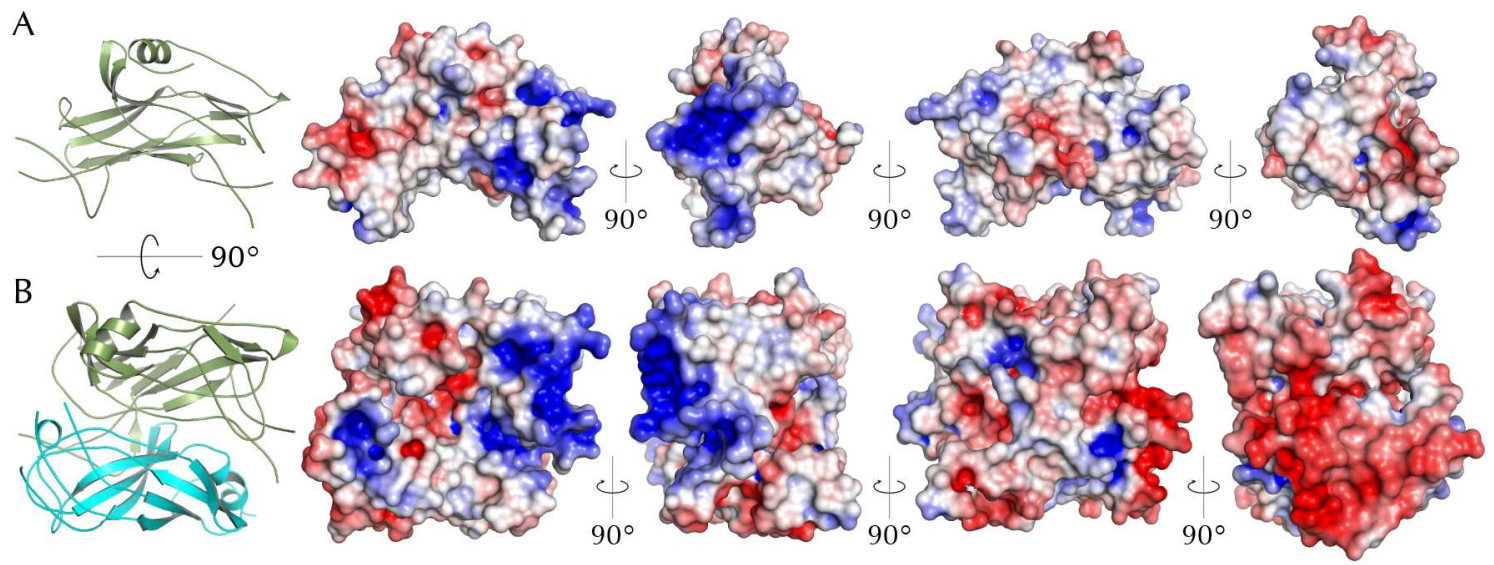

Abbildung 2.48: Verteilung der Oberflächenladung von VelB und dem VelB-VosA190S-Komplex. Cartoondarstellung und Oberflächenladung von VelB (A) und VelB-VosA190S-Komplex (B). Positiv geladene Oberflächen sind blau und negativ geladene rot dargestellt. Oberflächenladungen wurden mit APBS berechnet und mit PyMOL visualisiert.

Abgesehen von den $\mathrm{N}$ - und C-Termini sowie einiger Schleifen beider Proteine, konnten bei VelB die Reste 133-231 nicht in der Elektronendichtekarte lokalisiert werden. Die Reste, die zu His 132 hin- und von Gly 232 wegführen, sind in der Kristallpackung in einen Solvenskanal gerichtet (Abb. 2.49).

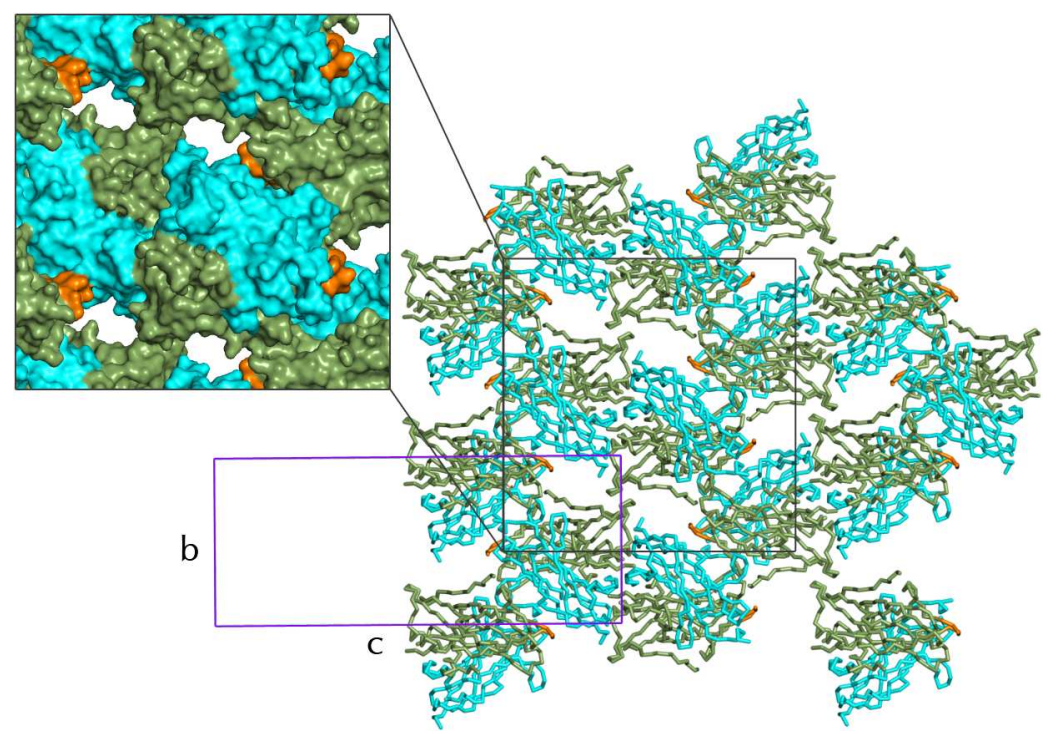

Abbildung 2.49: Ausschnitt aus der Kristallpackung von VelB-VosA190S. Gezeigt ist das $C_{\alpha}$-Rückgrat von VelB (grün) und VosA190S (cyan) und Einheitszelle (violett) entlang der a-Achse. Die Reste Val 130 bis His 138 und Gly 232 bis Phe 234 von VelB sind orange hervorgehoben und weisen in einen Solvenskanal (Oberflächendarstellung in der Vergrößerung).

VelB hat eine sehr ähnliche Faltung wie VosA190S, ein leicht deformiertes $\beta$-Sandwich. Im Vergleich zu VosA190S weist VelB insgesamt vier zusätzliche $\beta$-Stränge auf, enthält aber nur eine $\alpha$-Helix am C-Terminus. Zwischen $\beta 4$ und 


\section{Kapitel 2 | ERGEBNISSE}
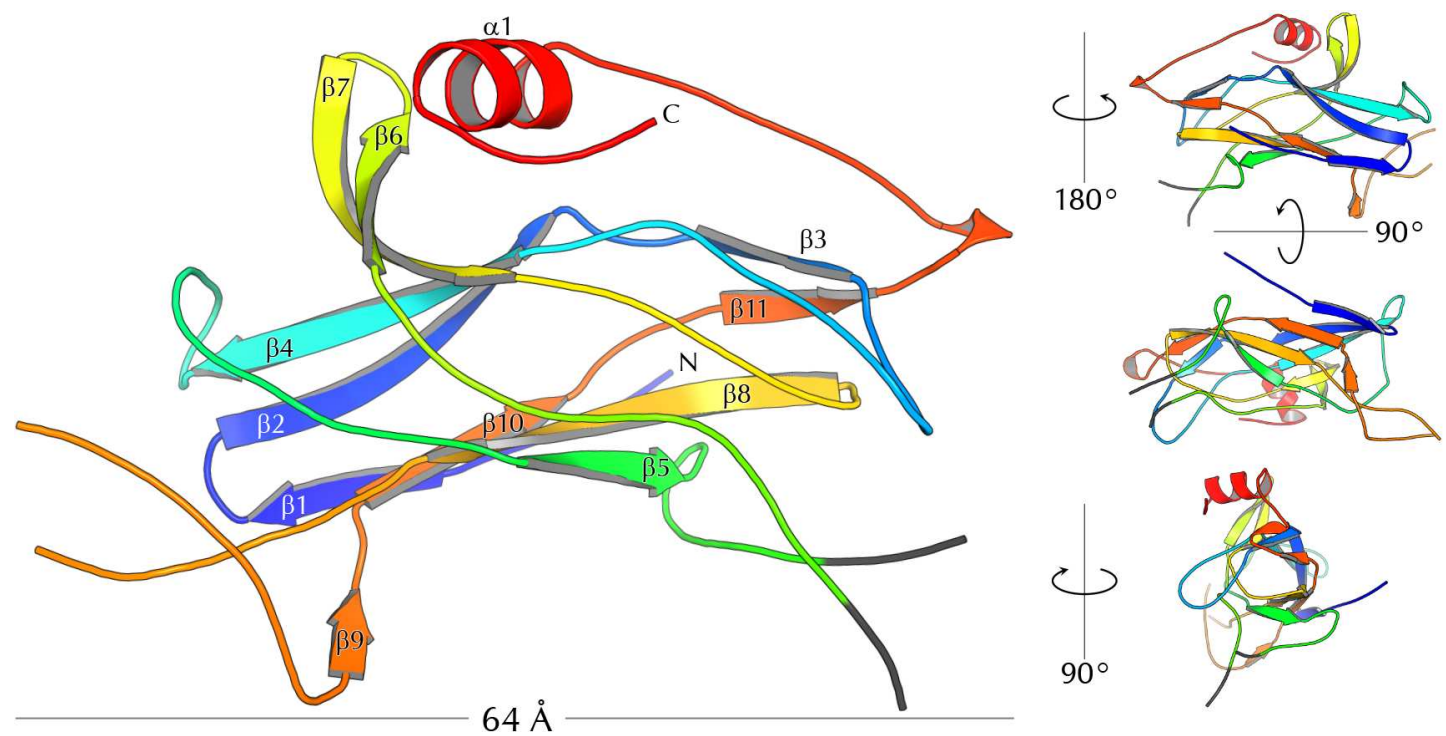

Abbildung 2.50: Kristallstruktur von VelB. Die einzenen Sekundärstrukturelemente sind durchnummeriert ( $\alpha 1$ und $\beta 1-11$ ). Das Molekül ist entlang der Sequenz gefärbt ( $\mathrm{N}$-Terminus blau, $\mathrm{C}$-Terminus rot). Die Reste Val 130 bis His 132 und Gly 232 bis Phe 234 sind dunkelgrau hervorgehoben. Rechts sind weitere Perspektiven gezeigt mit jeweils gedrehter Achse.

$\beta 5$ ( $\beta 2$ und $\beta 3$ bei VosA190S, Abb. 2.31, S. 48) befindet sich keine $\alpha$-Helix in VelB (Abb. 2.50). Die Standardabweichung zwischen dem $C_{\alpha}$-Rückgrat beider Proteine beträgt 0,915 (VosA190S aus VelB-VosA190S-Heterodimer) bzw. 0,775 (VosA190S aus VosA190S-Homodimer) (Abb. 2.51).
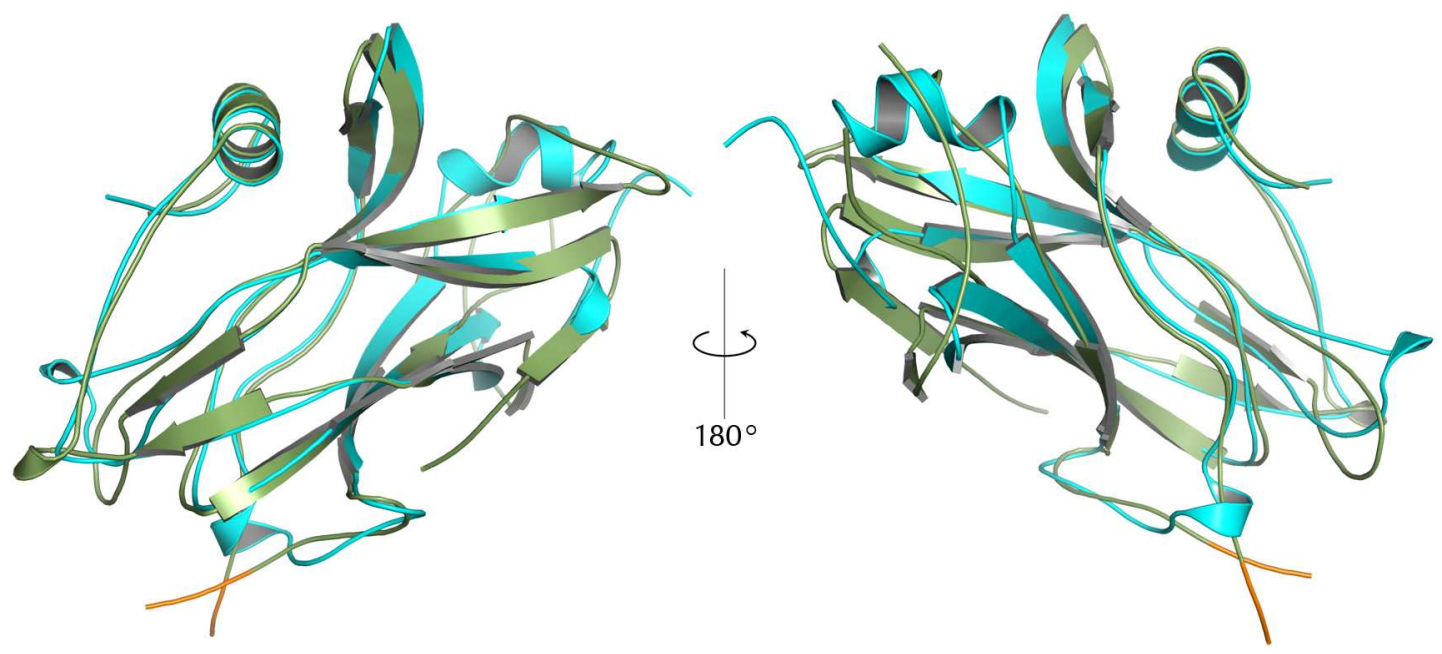

Abbildung 2.51: Überlagerung von VelB und VosA190S. Die Standardabweichung zwischen dem $C_{\alpha}$-Rückgrat von VelB (grün) und VosA190S (cyan, aus dem Homodimer) beträgt 0,775 $\AA$. Die Reste Val 130 bis His 138 und Gly 232 bis Phe 234 von VelB sind orange hervorgehoben. 


\subsubsection{Strukturvergleich mit NFKB-p50}

Auch die Struktur des VelB-VosA190S-Heterodimers wurde mit NFKB-p50 verglichen. Ein großer Unterschied zwischen dem VosA190S-Homodimer und dem VelB-VosA190S-Heterodimer ist die unterschiedliche Orientierung der beiden Moleküle ( $30^{\circ}$ Rotation). Bei Überlagerung des Heterodimers mit NFkB-p50 führt dies dazu, dass im Modell beide Moleküle mit ihren putativen DNAInteraktionsoberflächen sehr nah an das DNA-Rückgrat kommen (Abb. 2.52A). $\mathrm{Zu}$ den Resten von VelB, die mit der DNA interagieren könnten, zählen drei Lysine (K78, K320 und K321) und zwei Arginine (R80 und R81) (Abb. 2.52C). Des weiteren weist die unterbrochene Schleife von VelB in diesen Modellen von der DNA weg (Abb. 2.52A) und kommt in etwa dort zu liegen, wo sich bei NFkB-p50 die drei zusätzlichen $\alpha$-Helices befinden (Abb. 2.52B).

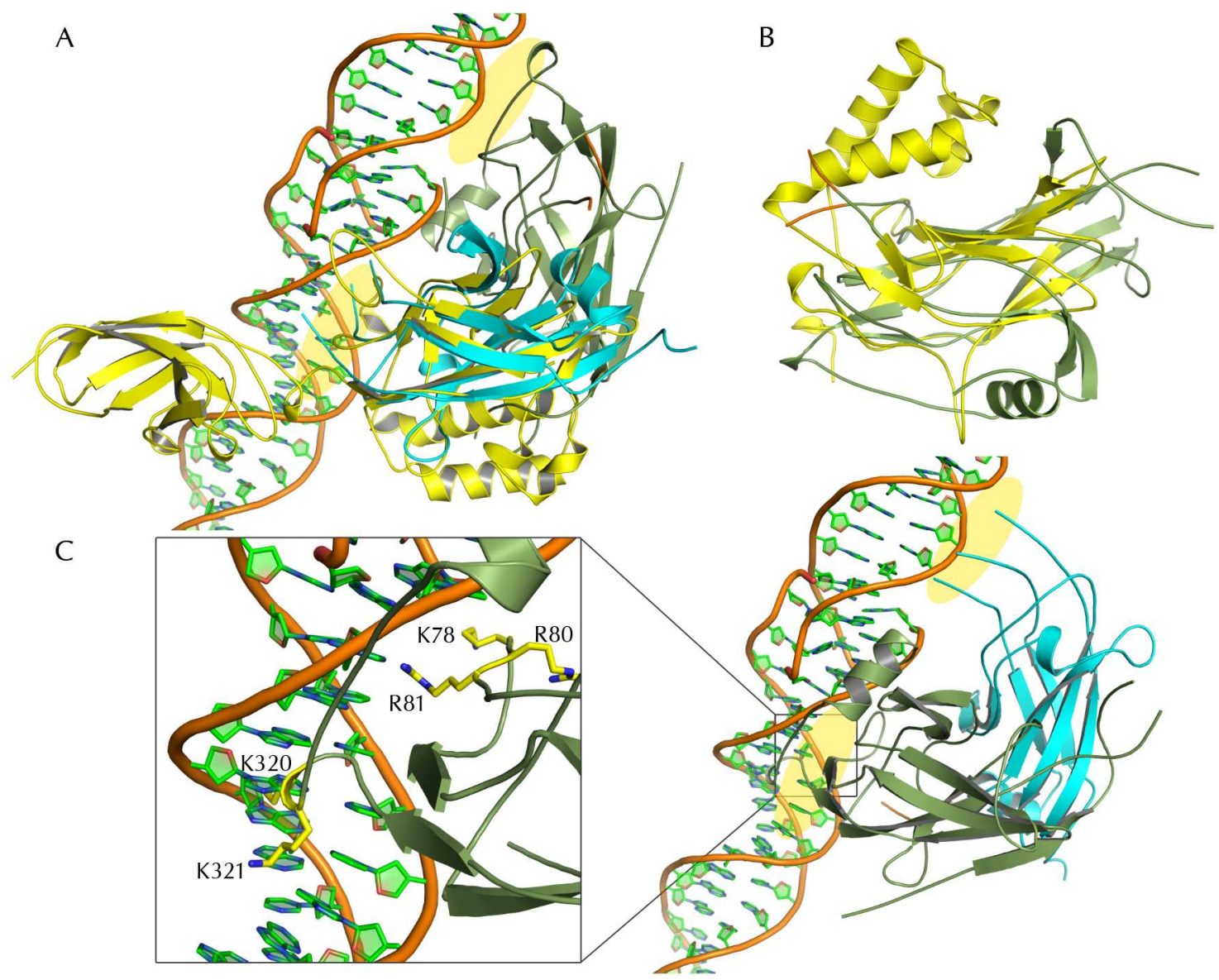

Abbildung 2.52: Überlagerung des VelB-VosA190S-Komplexes mit NFkB-p50. A: Überlagerung des VelB-VosA190S-Komplexes (grün/cyan) mit NFKB-p50 (gelb), VosA190S wurde für die Überlagerung verwendet. B: Überlagerung von VelB (grün) und der NFkB-p50-RHD (gelb). C: VelB (grün) an Stelle von NFkB-p50 (nicht gezeigt) bzw. VosA (cyan), die Reste R78, R80, R81, K320 und K321 sind als Stabmodell dargestellt (Vergrößerung). In beiden Darstellungen sind potenzielle Stellen für Interaktionen zwischen Protein und DNA eingekreist (gelb). Die Reste Val 130 bis His 132 und Gly 232 bis Phe 234 von VelB sind orange hervorgehoben. 


\section{Kapitel 2 | ERGEBNISSE}

\subsubsection{Minimal-VosA-VelB-Komplex}

In 2.6.2 konnte bereits gezeigt werden, das VelB-mini in der Lage ist, VeA224S zu binden. Dieser minimal-Komplex konnte jedoch nicht kristallisiert werden. Als einen weiteren Test für die korrekte Faltung von VelB-mini wurde die Bindung zu VosA190S geprüft. Hiermit sollte auch die Frage geklärt werden, ob die Reste 133-231 von VelB für die Interaktion mit VosA190S benötigt werden oder ob es sich hier möglicherweise um ein Kristallisationsartefakt handelt.

\subsubsection{Präparation des minimal-VelB-VosA190S-Komplex}

Der minimal-VelB-VosA190S-Komplex besteht aus VelB-mini $(2.2 .2$, S. 30) und VosA190S (2.7, S. 41). Beide Proteine lagen nach dem Zellaufschluss im Überstand vor (Abb. 2.53A, Spur Ü). Die Reinigung begann mit einer HisTrap Säule, nach der bereits fast alle Verunreinigungen entfernt werden konnten (Abb. 2.53A, Spur EH). Im Eluat lag ein Überschuß von mini-VelB vor, der durch Auftragen auf eine StrepTactin HP Säule entfernt werden konnte (Spur U1-2). Auch geringe Verunreinigungen im Bereich von 14 und $25 \mathrm{kDa}$ konnten so vollständig entfernt werden. Das Eluat der StrepTactin HP Säule enthielt in etwa gleichen Mengen VelB-mini und VosA190S (Spur ES). Der Komplex wurde abschließend über einer Superdex 200 16/60 Säule gereinigt.
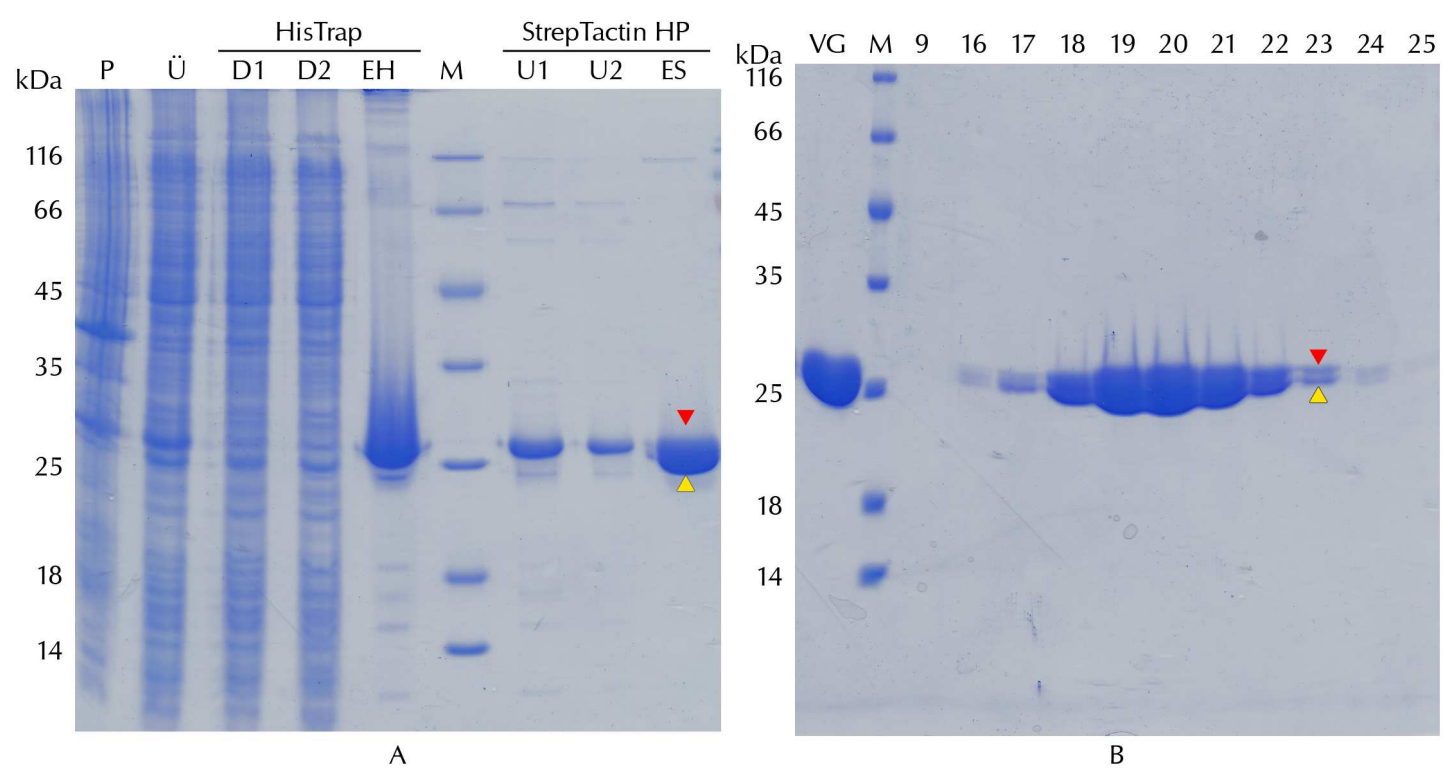

Abbildung 2.53: A: SDS-PA-Gel der affinitätschromatographischen Reinigung von des VelB-miniVosA190S-Komplex (mini-VelB-VosA190S) mit einer HisTrap und StrepTactin HP Säule. Aufgetragen sind Durchfluss (D1-2, U1-2) und Eluat (EH und ES) beider Schritte sowie ein Proteingrößenstandard (M). B: SDS-PA-Gel der Größenausschlusschromatographie des mini-VelB-VosA190S-Komplexes. Aufgetragen sind Probe vor der Gelfiltration (VG), Proteingrößenstandard (M) und Fraktionen aus der Gelfiltration (9-25). Die Nummern beziehen sich auf die Fraktionen aus der Gelfiltration (nicht gezeigt). Beide Proteine sind $\approx 22 \mathrm{kDa}$ groß, VelB-mini (roter Pfeil) wandert jedoch wie in vergangenen Experimenten (Abb. 2.39, S. 54) etwas höher als VosA190S (gelber Pfeil). 
Bei der Gelfiltration wurde nur ein UV-Maximum detektiert (nicht gezeigt), welches der Größe des Komplexes $(\approx 40-50$ kDa) entsprach. Der Komplex enthielt nach diesem Reinigungsschritt keine Verunreinigungen mehr (Abb. 2.53B). Die Ausbeute lag mit diesem Protokoll bei $\approx 20 \mathrm{mg}$ mini-VelB-VosA190S-Komplex aus $2 \times 500 \mathrm{ml} \mathrm{ZYM5052-Expressionskultur}$.

\subsubsection{Kristallisation des minimal-VosA-VelB-Komplex}

Da der Komplex in reiner Form gewonnen werden konnte, wurden alle in 6.1.10.1 aufgeführten Sammlungen mit einer Konzentrationen von 14,2 mg/ml und mit zwei Tropfenverhältnissen pipettiert (6.2.6.1). Es konnten bereits nach ein bis zwei Tagen Kristalle gefunden werden (Abb. 2.54). Die meisten Bedingungen enthielten Ammoniumsulfat als Präzipitantz und es war möglich, die Kristalle zu reproduzieren. Hierbei zeigte sich, dass durch die Änderung des Protein:Kristallisationslösungs-Verhältnis auf 3:1 die Anzahl der Kristalle sich verringerte, sich gleichzeitig aber ihre Größe steigern ließ.
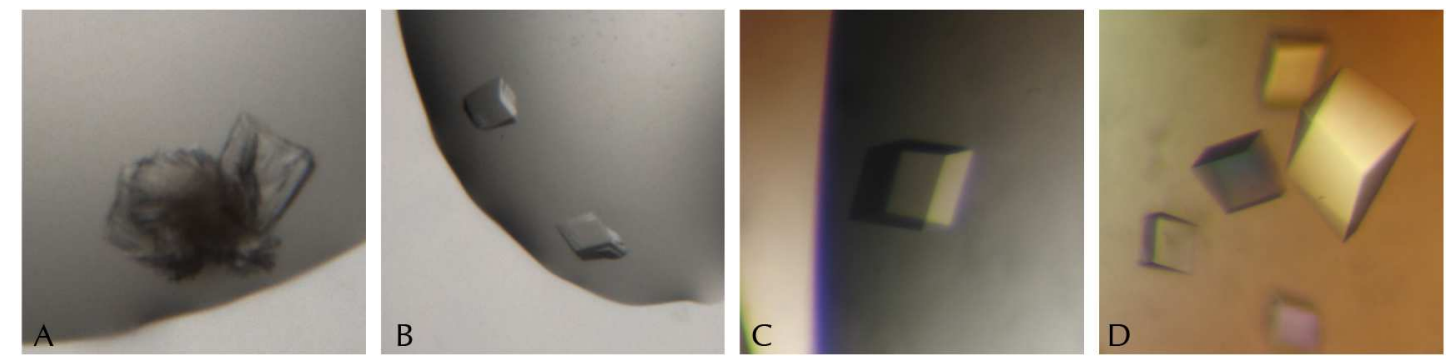

Abbildung 2.54: Kristalle von mini-VelB-VosA190S. Die Bedingungen enthalten A: $1,8 \mathrm{M}\left(\mathrm{NH}_{4}\right)_{2} \mathrm{SO}_{4}$, $50 \mathrm{mM}$ Tris/ $\mathrm{HCl} \mathrm{pH} 8,5$ und $25 \mathrm{mM} \mathrm{MgSO}{ }_{4}, \mathbf{B}: 2 \mathrm{M}\left(\mathrm{NH}_{4}\right)_{2} \mathrm{SO}_{4}$ und $100 \mathrm{mM}$ Tris/ $/ \mathrm{HCl} \mathrm{pH} \mathrm{8,5,} \mathrm{C:}$ 1,4 M Natriummalonat pH 7 und D: $2 \mathrm{M}\left(\mathrm{NH}_{4}\right)_{2} \mathrm{SO}_{4}$ und $100 \mathrm{mM}$ Tris/ $\mathrm{HCl} \mathrm{pH} \mathrm{8,5.} \mathrm{Das} \mathrm{Verhältnis}$ Protein:Kristallisationslösung ist 1:1 (A-C) bzw. 3:1 (D). Alle Kristalle sind nach etwa ein bis zwei Tagen entstanden. Die verwendete Proteinkonzentration ist in allen Bedingungen 14,2 mg/ml. Die Färbung ist durch die Verwendung eines Polarisationsfilter entstanden.

Um zu prüfen, ob es sich um Protein- oder Salzkristalle handelt, wurden mehrere Beugungsbilder aufgenommen. Bei den Kristallen (Abb. 2.54D) handelte es sich um Proteinkristalle mit entsprechend typischen Beugungsmuster. Es konnte eine Beugung bis 1,85 ̊̊ beobachtet werden (Abb. 2.55). Ersten Analysen zufolge gehören diese Kristalle der Raumgruppe P3 an. Die Zellachsen sind $a=b=82 \AA$ und $\mathrm{c}=131 \AA$ A. Die Winkel $\alpha$ und $\beta$ betragen $90^{\circ}, \gamma=120^{\circ}$. Damit ergeben sich für die asymmetrische Einheit mehrere Möglichkeiten der Zusammensetzung, die in Tabelle 2.7 zusammengefasst sind. Eine detaillierte Analyse dieser Kristalle steht noch aus. 


\section{Kapitel 2 | ERGEBNISSE}

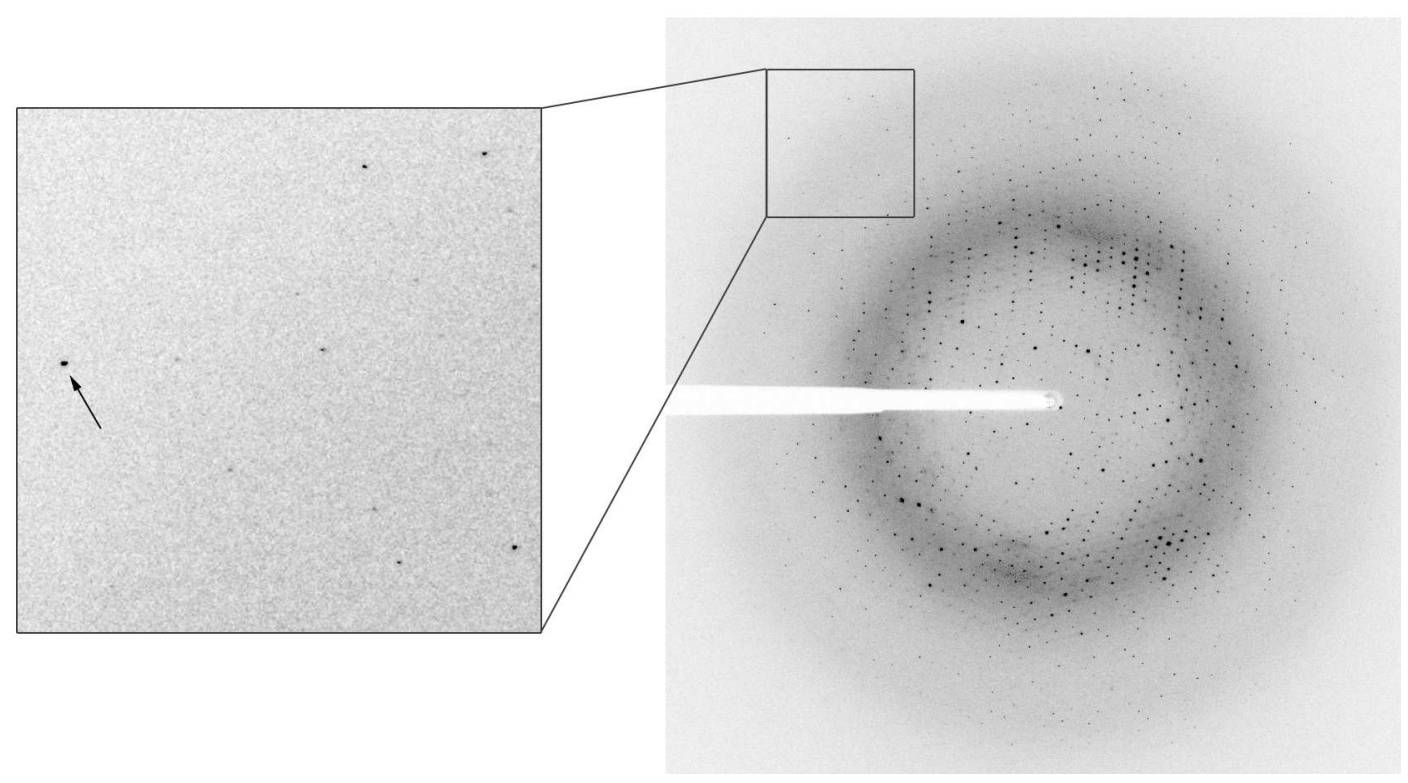

Abbildung 2.55: Beugunsbild eines mini-VelB-VosA190S-Kristalls. Eine Beugung bis $1,85 \AA$ (Vergrößerung) konnte beobachtet werden, das Bild wurde am ESRF (Grenoble, Frankreich) aufgenommen.

Tabelle 2.7: Matthews-Koeffizient und Lösungsmittelgehalt bei unterschiedlicher Zusammensetzung der asymmetrischen Einheit des mini-VelB-VosA190S-Kristalls (45 kDa Komplex).

\begin{tabular}{lll}
\hline $\begin{array}{l}\text { Moleküle/ } \\
\text { asymmetrische Einheit }\end{array}$ & $\begin{array}{l}\text { Matthews- } \\
\text { Koeffizient }\end{array}$ & $\begin{array}{l}\text { Lösungsmittel- } \\
\text { gehalt [\%] }\end{array}$ \\
\hline 1 & 5,65 & 78,25 \\
2 & 2,83 & 56,49 \\
3 & 1,88 & 34,74 \\
4 & 1,41 & 12,98 \\
\hline
\end{tabular}


KAPITEL 3

\section{Diskussion}

In dieser Arbeit wurde eine strukturelle Charakterisierung des trimeren VelvetKomplex bestehend aus den Proteinen LaeA, VeA und VelB aus Aspergillus nidulans durchgeführt. Ein weiteres Protein, das zur Familie der Velvet-Proteine gehört, VosA, wurde auch untersucht. Zu Beginn der Arbeit lagen weder über die putative Methyltransferase LaeA noch über die Velvet-Proteine strukturelle Daten vor. Die molekulare Funktionsweise der Velvet-Proteine war ebenso unklar. Im Verlauf dieser Arbeit wurde eine Funktion dieser Proteine identifiziert, die durch die Bestimmung von zwei Kristallstrukturen erklärt werden konnte. Diese Strukturen geben einen Einblick darüber wie Velvet-Proteine ihre regulatorische Funktion ausüben könnten. Die putative Methyltransferase konnte nicht kristallisiert werden, hier konnten jedoch Verkürzungen erstellt werden, die die Grundlage für zukünftige Untersuchungen bilden können.

\subsection{LaeA}

Volllängen-LaeA konnte mit verschiedenen Affinitätsmarkierungen (N/C-His 6 , N-GST, N-MBP) überexprimiert, jedoch nur mit MBP oder GST gereinigt werden. Die native Präparation von N- oder $\mathrm{C}_{-\mathrm{His}_{6}}$-LaeA war nicht möglich, da sich LaeA nach Zellaufschluss in der unlöslichen Fraktion befand. Bei der initialen Präparation von LaeA mit MBP wurde eine wichtige Beobachtung gemacht. Das Elutionsvolumen von LaeA entsprach etwa einem LaeA-Dimer ( $\approx 80 \mathrm{kDa})$. Das zwei LaeA-Moleküle miteinander interagieren können, wurde zuvor auch aus einen Yeast-2-Hybrid-Experiment abgeleitet (Bayram et al., 2008b). Das typische Verhalten von LaeA, nach Abspaltung der Affinitätssequenz auszufallen, lässt sich dadurch erklären, dass MBP auch vollkommen unlösliche Proteine in Lösung halten kann. Dies erfolgt vermutlich durch die Bildung von Mizellen, bei der das unlösliche Protein nach innen (abgeschirmt vom Lösungsmittel) und das hydrophile MBP nach außen gerichtet ist (Fox et al., 2001). Es wurde daher zunächst angenommen, dass lösliches LaeA korrekt gefaltet sein muss, um spe- 


\section{Kapitel 3 | DISKUSSION}

zifisch nur als Dimer zu eluieren, und unlösliches LaeA nicht korrekt gefaltet ist. Die darauf erfolgten Anstrengungen, um die Menge an korrekt gefalteten und somit löslichen LaeA zu erhöhen, führten zu keinem signifikanten Ergebnis (2.1.1, S. 21).

In späteren Experimenten wurde jedoch eine paradoxe Beobachtung gemacht. MBP-LaeA interagierte mit VeA und beide Proteine fielen nach Abspaltung von MBP aus, was dadurch zu erklären ist, dass beide Proteine weiterhin miteinander interagierten (2.5.1, S. 35). Auch blieb ein Teil von LaeA zusammen mit VeA in Lösung. Diese Interaktion war stabil genug, um an VeA über mehrere chromatographische Reinigungsschritte gebunden zu bleiben. Daraus kann geschlussfolgert werden, dass rekombinantes LaeA zumindest partiell korrekt gefaltet, gleichzeitig aber unlöslich ist. In der Literatur werden unlösliche Proteine, abgesehen von Membranproteinen, in der Regel mit nicht korrekt gefalteten Proteinen gleichgesetzt. Die Proteinmengen, die für eine systematische Kristallisation benötigt werden, konnten im Falle von Volllängen-LaeA nicht gewonnen werden. Die Ausbeute konnte weder durch Veränderung verschiedener Parameter während der Reinigung, noch durch Komplexierung mit VeA verbessert werden, und es wurde daher eine Verkürzung des Proteins ins Auge gefasst.

Die Verkürzungen LaeA91 und LaeA101 konnten erfolgreich überexprimiert und gereinigt werden. LaeA91 und -101 eluierten als Monomere in der Größenausschlusschromatographie. Es ist nicht klar, ob dies durch die Entfernung der N-terminalen Reste oder durch Erhöhung der Salzkonzentration verursacht wurde.

Um die Chancen für eine erfolgreiche Kristallisation von Aspergillus nidulans LaeA zu erhöhen, sind mehrere noch nicht ausgeschöpfte Möglichkeiten vorhanden. Limitierte Proteolyse könnte zur Identifizierung von stabilen Fragmenten oder direkt bei der Kristallisation verwendet werden. Auch die Komplexierung der bereits etablierten LaeA-Verkürzungen mit VosA ist denkbar, denn eine Bindung von LaeA91 mit Vollängen-VosA konnte im Rahmen dieser Arbeit beobachtet werden (nicht gezeigt). Dies ist ein Hinweis darauf, dass die entfernten Reste für die Interaktion mit VosA und wahrscheinlich auch VeA nicht notwendig sind. Bei VosA werden die ersten 239 Aminosäuren, also die gesamte Velvet-Domäne, für die Interaktion mit LaeA benötigt. Anders ist es bei VeA, wo die Velvet-Domäne nicht mit LaeA interagiert (Bayram et al., 2008b). Dieser Bereiche von VeA müsste jedoch weiter eingegrenzt werden, denn laut Vorhersage enthält er keine Sekundärstrukturelemente und ist möglicherweise unstrukturiert (nicht gezeigt). Es ist jedoch auch möglich, dass nach Bindung mit LaeA eine (geordnete) Faltung eingenommen wird. Eine weitere und sehr wichtige Option ist die Komplexierung mit dem Substrat von LaeA, welches jedoch zunächst identifiziert werden müsste. Sofern es sich bei dem Substrat von LaeA um ein Protein handelt, könnten Analysen des Gesamt-Proteoms von Wildtyp- und $\Delta$ LaeA-Aspergillus nidulans helfen dieses zu identifizieren. Nach 
erfolgreicher Identifizierung des Substrats, wäre es möglich präpariertes LaeA auf Funktionalität zu prüfen und biochemisch zu charakterisieren.

Wenn diese Versuche auch nicht zur erfolgreichen Kristallisation führen, besteht noch die Option, LaeA aus einen anderem Organimus zu analysieren. Abgesehen von den bereits teilweise analysierten LaeA-Orthologen aus Fusarium fujikuroi (Wiemann et al., 2010) und Aspergillus fumigatus (Bok et al., 2005), wäre der beste Kandidat das LaeA-Ortholog aus Chaetomium thermophilum. Dieser filamentöse Pilz besitzt die Eigenschaft bei Temperaturen von bis zu $55^{\circ} \mathrm{C} \mathrm{zu}$ wachsen. Das Genom wurde erst kürzlich veröffentlicht ${ }^{1}$, und erste Untersuchungen mit Proteinen aus diesen Pilz sind sehr erfolgversprechend (Amlacher et al., 2011). Ein Sequenzvergleich von Aspgerillus nidulans und putativen Chaetomium thermophilum LaeA ${ }^{2}$ ergibt eine Ähnlichkeit von $61 \%$ und Sequenzidentität von $44 \%$ (nicht gezeigt).

In Hinsicht auf LaeA muss jedoch auch gesagt werden, dass die reine Strukturbestimmung evtl. nicht ausreichen wird, um zu erklären, wie LaeA seine regulatorische Funktion ausübt. Ein bekanntes Beispiel ist die ungewöhnliche Methylierung einer $\alpha$-Aminogruppe, die seit mehr als 35 Jahren bekannt ist (Brosius und Chen, 1976; Wittmann-Liebold und Pannenbecker, 1976). Auch beim Ran Nukleotid-Austauschfaktor RCC1 kommt es zur $\alpha$-N-Methylierung (Chen et al., 2007). Diese Modifikation wird von einer Methyltransferase durchgeführt, die erst kürzlich identifiziert wurde (Tooley et al., 2010). Tooley und Mitarbeiter stellten fest, dass die Struktur dieses Enzyms hingegen bereits 2005 von einem Structural Genomics Konsortium veröffentlicht wurde (PDB-Eintrag: 2EX4).

\subsection{LaeA-VeA-VelB-Komplex}

Grundsätzlich war es möglich, den gesamten Velvet-Komplex nach der in Abschnitt 2.5.1 beschriebenen Strategie zu präparieren. Es gab aber mehrere Gründe, warum dieser Ansatz nicht weiterverfolgt wurde. Der Hauptgrund war die geringe Ausbeute, aus 51 ZYM5052-Expressionskultur $(\approx 100 \mathrm{~g}$ Zellmasse) konnten lediglich 200 bis $800 \mu \mathrm{g}$ Velvet-Komplex präpariert werden (2.5.1). Weiterhin dauerte es sehr lange den Komplex für die Gelfiltration einzuengen, hierbei gingen i.d.R. mehr als 50\% verloren. Letztlich war auch die Monodispersität des Komplexes nicht gegeben, in der Gelfiltration wurden zahlreiche überlappende lokale UV-Maxima detektiert (Abb. 2.18, S. 37). Die Ergebnisse dieser Experimente deuten aber darauf hin, dass alle Proteine eine korrekte Faltung einnehmen, da die bekannten Interaktionen vorliegen. In Anbetracht der möglichen Subkomplexe wurde, aufgrund der Löslichkeit, nur der VeA-VelB-Komplex als sinnvoll für eine weitere Untersuchung erachtet (3.3.2).

\footnotetext{
${ }^{1}$ GenBank-Eintrag: ADUW00000000.1

${ }^{2}$ UniProt-Eintrag: G0SCT5
} 


\section{Kapitel 3 | DISKUSSION}

\subsection{Velvet-Proteine}

Velvet-Proteine sind definiert durch drei konservierte Sequenzmotive (VelvetRegion), wobei Motiv 2 und 3 immer nah einander liegen. Bei VelB (Aspergillus nidulans) sind diese beiden Motive vom ersten Motiv durch etwa 100 Aminosäuren getrennt, bei VeA und VosA nicht (Webster und Sil, 2008). Obwohl diese Proteine in zahlreichen Pilzen eine wichtige regulatorische Funktion ausüben, war nur sehr wenig über ihre Struktur und molekulare Funktionsweise bekannt. Unklar war auch, ob die Verteilung der genannten Motive ein Indiz für mehrere Domänen ist oder ob die Velvet-Region eine Domäne bildet. Ein großes Problem zu Beginn der Arbeit war das Fehlen jeglicher biochemischer Daten zu diesen Proteinen. Es war daher zunächst nicht möglich, eine Aussage darüber zu machen, ob die rekombinant exprimierten Proteine eine korrekte Faltung aufweisen und für Kristallisation geeignet wären. Die festgestellte DNA-Bindung und später die Rekonstituierung aller bekannten Komplexe ist jedoch ein Indiz dafür, dass diese Proteine zumindest partiell korrekt gefaltet sind.

\subsubsection{VeA}

Volllängen-VeA konnte nicht zur Homogenität gereinigt werden, und die zahlreichen lokalen UV-Maxima in der Größenausschlusschromatographie (nicht gezeigt) deuteten zunächst auf ein entfaltetes Protein hin. Die nachfolgenden Experimenten unterstützen jedoch die Annahme, dass rekombinantes VeA eine korrekte Faltung aufweist. Volllängen-VeA interagierte spezifisch mit LaeA und VelB. Für die Interaktion mit LaeA werden laut Yeast-2-Hybrid-Experimenten die AS 276-573, für VelB die AS 1-300 von VeA benötigt (Bayram et al., 2008b). Da die Interaktionen auch gleichzeitig stattfanden (2.5.1), ist es eher unwahrscheinlich, dass das präparierte VeA entfaltet vorlag. Auch die beobachtete Interaktion mit humanen Importin $\alpha \triangle \mathrm{IBB}$ (KapA-Ortholog) spricht für ein korrekt gefaltetes Protein (2.4). Bei Volllängen-VeA war sowohl die Überexpression als auch die Reinigung ein Hindernis. Nur eine sehr geringe Überexpression konnte beobachtet werden (nicht gezeigt). Die Verkürzung VeA224S, die nur die Velvet-Domäne umfasst, konnte kristallisiert werden, eine genau Analyse steht noch aus. Dieser Bereich ist für die Interaktion mit VelB ausreichend (2.6.2, S. 40)

\subsubsection{VeA-VelB-Komplex}

Die Rekonstituierung des gesamten Velvet-Komplex war zwar erfolgreich, aber für kristallographische Zwecke nicht geeignet. Volllängen-VeA und VelB konnten einzeln nicht zur Homogenität gereinigt werden. Im Velvet-Komplex hingegen wurden nahezu keine Verunreinigungen beobachtet. Ähnlich verhielt es sich bei der Präparation des VeA-VelB-Komplexes. Durch die Ko-Expression beider Proteine und Verwendung von zwei verschiedenen Affinitätssequenzen konnte der Komplex auf sehr einfache Weise präpariert werden (2.6.1.1, S. 38). Womöglich stabilisieren sich beide Proteine gegenseitig. Geringe Mengen an E. coli Cha- 
peron DnaK waren auch in der Präparation vorhanden (Abb. 2.22, S. 39) und sind u.a. ein Hinweis darauf, dass eines der beiden Proteine nicht vollkommen korrekt gefaltet ist. DnaK wurde bei der Präparation des LaeA-VeA-VelB- und des minimalen-VeA-VelB-Komplexes nicht beobachtet. Möglicherweise interagiert VeA mit seinen freien C-terminalen Bereich mit DnaK, da die N-terminal liegende Velvet-Domäne bereits mit VelB interagiert. Die Kristallisation war nicht erfolgreich und zunächst fällt der Verdacht auf die noch vorhandene Insertion in VelB und den C-Terminus von VeA.

Entfernung all dieser Teile, wie im minimalen VeA-VelB-Komplex, führte zwar zu noch höherer Reinheit und Ausbeute, jedoch nicht zur erfolgreichen Kristallisation. Die Velvet-Domänen von VeA und VelB neigten nicht zur Präzipitation bei höheren Konzentrationen und Temperaturen. Auch waren keine Abbaufragmente von den beiden Proteinen in den Präparationen zu beobachten. Diese Ergebnisse decken sich mit den anderen Experimenten, aus denen hervorgeht, dass die Velvet-Domäne sehr stabil ist. Erweiterungen innerhalb oder C-terminal von der Velvet-Domäne führen hingegen zur Destabilisierung des jeweiligen Proteins, solange diese Regionen nicht von einen Bindungspartner besetzt werden.

\subsubsection{Velvet-Proteine interagieren mit DNA}

Sowohl die Arbeiten an VelB als auch später VeA und der VosA-Verkürzung VosA190S hatten gezeigt, dass Velvet-Proteine eine DNA-Bindung aufweisen (2.2, Abb. 2.9C, S. 29). Im Falle von VelB wurde DNA nur durch dimeres, nicht aber durch monomeres VelB gebunden. Unklar war, wie diese Proteine DNA binden können, da sie kein bekanntes DNA-Bindemotiv aufweisen. In weiteren Experimenten konnte diese DNA-Bindung auf die vollständige Velvet-Domäne von VosA (VosA190S) reduziert werden. In unabhängigen Arbeiten in der Gruppe von Prof. Jae-Hyuk Yu (University of Wisconsin, Wisconsin, USA) wurde mit einem ähnlichen Konstrukt (VosA AS 1-214) auch DNA-Bindung beobachtet (nicht-veröffentlichte Daten). Dieses Phänomen kann nach Bestimmung der Kristallstruktur von VosA190S (2.7.4) erklärt werden und gibt Hinweise über die Art und Weise, wie Velvet-Proteine ihre regulatorische Funktion ausüben könnten.

\subsubsection{VosA190S}

Bei der Kristallisation von VosA190S (C-Strep II) als auch VosA190H (C-His 6 ) konnte Kristallbildung in verschiedenen Bedingungen beobachtet werden. Eine der VosA190H-Bedingungen enthielt 150 mM Kaliumbromid, was für eine potenzielle Phasierung nach dem $\mathrm{MAD}^{3}$ oder auch $\mathrm{SAD}^{4}$-Verfahren in Frage gekommen wäre. Es wurde jedoch ein Austausch mit Kaliumiodid durchgeführt,

\footnotetext{
${ }^{3}$ engl. multi-wavelength anomalous dispersion

${ }^{4}$ engl. single wavelength anomalous dispersion
} 


\section{Kapitel 3 | DISKUSSION}

da dieses einige Vorteile mit sich bringt. Iodid-derivatisierte Kristalle müssen lediglich bei einer Wellenlänge ( $\mathrm{CuK} \alpha \lambda=1,5418 \AA$ oder $\operatorname{CrK} \alpha \lambda=2,2900 \AA)$ gemessen werden (SAD). Bei guter Datenqualität, d.h. hoher Auflösung, hoher Redundanz und sehr gutem Signal/Rauschen-Verhältnis ist es möglich, das Phasenproblem mit lediglich einen Datensatz zu lösen. Die Aufnahme mehrere Datensätze bei unterschiedlichen Wellenlängen (MAD) an einem Synchrotron wie bei Bromid- oder Selenium-derivatisierten Kristallen entfällt. Multiple Messungen am gleichen Kristall führen auch zu höheren Strahlenschäden, so das u.U. nicht alle Datensätze vollständig sind und die Strukturbestimmung erschwert wird. Es gibt jedoch auch einige Beispiele der erfolgreichen SAD-Phasierung von Bromid-derivatisierten Kristallen (Devedjiev et al., 2000; Hoover et al., 2001; Wlodawer et al., 2001). Ob das SAD-Verfahren erfolgreich sein wird, kann zum Zeitpunkt der Datensammlung nicht gesagt werden und ist besonders für Bromderivatisierte Kristalle nicht die bevorzugte Strategie. Die Struktur von VosA190S konnte aufgrund ko-kristallisierter Iodid-Ionen mit dem SAD-Verfahren gelöst werden.

VosA190S weist eine Immunoglobulin/Rel-N-ähnliche Domäne auf, die im folgenden als Velvet-Domäne bezeichnet wird. Bei Rel-N handelt es sich um die N-terminal gelegene Domäne in der Rel-Homologie-Region von NFkB- und Rel-Proteinen. Die Rel-Homologie-Region besteht aus zwei Immunglobulinähnlichen Domänen. Die C-terminal gelegene Domäne ist exklusiv für die Dimerisierung der Rel und NFKB-Proteine verantwortlich ist. Die Interaktionen mit der DNA finden über beide Domänen statt.

Eine Strukturüberlagerung von VosA190S und des strukturell ähnlichen NFkB-p50 (PDB-Eintrag: 1SVC, Müller et al., 1995) gab Hinweise auf die mögliche DNA-Bindung durch VosA190S. In dieser Überlagerung kommt das erste VosA190S-Molekül mit einer stark positiv geladenen Oberfläche zur DNA zu liegen. Die entsprechende Oberfläche des zweiten Moleküls hingegen ist mindestens $13 \AA ̊$ von der DNA entfernt (Abb. 2.38). Um beide putativen Bindungsstellen zu besetzen müsste die DNA gebogen oder die Orientierung der VosA190SMolekül zueinander verändert werden. Im VelB-VosA190S-Komplex sind beide Moleküle um etwa $30^{\circ}$ verschoben, wodurch dieser Abstand auf nur 3,8 $\AA$ verkürzt wird.

Die putativen Bindungsstellen in VosA190S werden von zwei Schleifen gebildet, die vier Lysine und ein Arginin enthalten. Positiv geladene Reste sind an dieser Stelle konserviert in Velvet-Proteinen. Die Bindung der DNA erfolgt wahrscheinlich über diese Reste, denn der Austausch dieser mit Alanin führt bei VosA190S zur verringerten DNA-Bindung (2.7.8, Abb. 2.40). Besonders der Einfluss von Arg 42 zur DNA-Bindung ist größer als angenommen, denn dieses weist im Modell von der DNA weg. Der Austausch von Lys 37 und Lys 39 gleichzeitig führt zum vollständigen Verlust der DNA-Bindung, was darauf hinweist, dass diese Reste den Großteil der Interaktionen mit der DNA vermitteln. Der Aus- 
tausch von Lys 160 führt auch zu einer verringerten DNA-Bindung und bestätigt damit die Annahmen, dass auch die zweite Schleife in der DNA-Bindung involviert ist. VosA190S liegt in Lösung als Dimer vor und bindet womöglich auch in dimerer Form an DNA (2.7.1). Der Austausch einer Aminosäure würde daher zum Verlust von zwei Interaktionspaaren führen und entsprechend die stark reduzierte DNA-Bindung erklären. Ein weiteres Indiz dafür, dass Velvet-Proteine nur als Homo- oder Heterodimer mit DNA interagieren, ist das Verhalten von VelB. VelB ist das einzige Velvet-Protein das sowohl als Monomer als auch Dimer in der Größenausschlusschromatographie eluierte. Lediglich dimeres VelB wies DNA-Bindung auf, monomeres hingegen nicht (Abb. 2.9, S. 29). Es ist jedoch an dieser Stelle auch anzuführen, dass VelB möglicherweise nicht representativ für die Velvet-Proteine ist (3.3.6).

Da die VosA190S-Mutanten weiterhin mit VelB-mini interagierten, ist davon auszugehen das der Austausch dieser Reste nicht die Faltung des Proteins kompromittierte (2.7.8, Abb. 2.40, S. 55).

Aus den vorliegenden Ergebnissen kann postuliert werden, dass es sich bei den Velvet-Proteinen um Transkriptionsfaktoren handelt, die direkt mit DNA interagieren. Diese Schlussfolgerung wird durch die Anwesenheit einer C-terminal gelegenen Transkriptions-aktivierenden Region in VosA unterstützt (Ni und $\mathrm{Yu}, 2007)$. Desweiteren konnte in der Arbeitsgruppe von Prof. Jae-Hyuk Yu (University of Wisconsin, Wisconsin, USA) die von VosA gebundene DNAKonsensussequenz bestimmt werden (nicht-veröffentlichte Daten). Mit diesen neuen und bereits vorhandenen Daten ergeben sich einige interessante Ähnlichkeiten zu den Rel/NFkB-Proteinen.

\subsubsection{VelB-VosA190S-Komplex}

Die Kristallisation von VelB gelang nur im Komplex mit VosA190S. Es ist davon auszugehen, dass die zahlreichen Reste in VelB und VosA, für die keine Elektronendichte ermittelt werden konnte, nicht unstrukturiert sind, sondern proteolytisch entfernt wurden. Es sprechen mehrere Gründe für diese Annahme. Bei VosA190S fehlen die Reste 37-39 sowie die Reste ab AS 159, welche in der Struktur des VosA190S-Homodimers klar geordnet und definiert sind. Es ist unwahrscheinlich, dass diese Reste in diesem Komplex ungeordnet sind. Bei VelB fehlt abgesehen von N- und C-terminal gelegenen Resten (AS N-43 und 344-C) auch der Bereich, der die Velvet-Domäne unterbricht (AS 133-231). Die Schleife, die zu diesen Resten führt, weist in einen Solvenskanal (Abb. 2.49, S. 63). Wenn angenommen wird, dass diese Reste zwar noch vorhanden aber ungeordnet sind, reduziert sich der Lösungsmittelgehalt von 52\% auf etwa 39\% (2.4, S. 2.4). Die Kristalle waren sehr fragil, was auf einen hohen Lösungsmittelgehalt hinweist. Es ist daher davon auszugehen, dass diese Reste tatsächlich proteolytisch entfernt wurden. Eine Proteasekontamination ist durchaus denkbar, da weder beim 


\section{Kapitel 3 | DISKUSSION}

Aufschluss der Zellen noch bei der späteren Präparation Proteaseinhibitoren verwendet wurden.

Zu den größten Unterschieden im Vergleich zum VosA190S-Homodimer zählt die veränderte Orientierung sowie die Anzahl der Interaktionen zwischen beiden Molekülen. Beide Moleküle sind im Vergleich zum VosA190S-Homodimer um etwa $30^{\circ}$ rotiert. Der Komplex wird durch weitaus mehr hydrophoben Interaktionen und Wasserstoffbrückenbindung zusammengehalten (Abb. 2.47, S. 62) als die beiden Moleküle im VosA190S-Homodimer (Abb. 2.34, S. 50). Weder für das VelB-Homodimer noch für das VosA-Homodimer ist eine in vivo Funktion bekannt. Beide Proteine allein sind nicht ausreichend für die Aktivierung der Biogenese von Trehalose sowie Sporogenese (Sarikaya Bayram et al., 2010). Es ist daher denkbar, dass die Homodimerisierung lediglich zur Stabilisierung der Proteine, z.B. durch Maskierung von hydrophoben Resten, dient.

\subsubsection{VelB - eine Ausnahme?}

Bisher war unklar, ob es sich beim Velvet-Bereich um eine Domäne handelt oder ob es zwei Domänen sind. Ausgehend von der VosA190S-Struktur, ist die Antwort auf diese Frage eindeutig, der Velvet-Bereich ist eine unabhängige Domäne (Velvet-Domäne).

Für VelB gilt es möglicherweise nicht, da nicht klar ist, wie die kristallisierte Velvet-Domäne von VelB entstanden ist. Es ist möglich, dass zwei VelB-Moleküle durch Austausch von Sekundärstrukturelementen die Domäne bilden, was auch die geringe Menge an dimeren VelB bei der rekombinanten Expression und Reinigung erklären würde. Die Dimerisierung von VelB ist wie der Aufbau von VelB eine Ausnahme unter den untersuchten Velvet-Proteinen. Die Velvet-Domänen von VosA und VeA (VosA190S und VeA224S) sind durchgehend und enthalten keine Unterbrechung. Ihr Elutionsvolumen in der Größenausschlusschromatographie entsprach jeweils einem Dimer. Bei VelB hingegen ist die Velvet-Domäne durch 99 Aminosäuren unterbrochen (Abb. 3.1), die als unstrukturiert (intrinsically disordered) vorhergesagt werden (DISOPRED, Bryson et al., 2005). Die spezielle Verkürzung VelB-mini eluierte als Monomer konnte aber weiterhin mit VeA224S (2.6.2) und VosA190S interagieren (2.8.6). Somit kann eine Dimerisierung der VelB-Velvet-Domäne wie bei VosA190S oder beim VelB-VosA190S-Komplex ausgeschlossen werden. Vielmehr ist anzunehmen, dass die Dimerisierung von VelB über die Insertion (AS 133-231), welche in VelB-mini fehlen, erfolgt. Die Zusammensetzung der Aminosäuren 133-231 wird dominiert von Prolin, Glutamin, Glycin, Tyrosin und Serin. Von Glutamin-reichen Polypeptiden ist bekannt, dass sie sehr stabile $\beta$-Faltblätter ausbilden können (Perutz et al., 1994). Eine weitere Möglichkeit einen Dimer auszubilden wäre der Austausch von Sekundärstrukturelementen zwischen zwei Molekülen, wie bei der Dimerisierungsdomäne (DD) des Rel-Proteins RelB. Huang und Mitarbeiter (2005) stellten fest, dass die RelHomologie-Region (RHR) von RelB im Vergleich zu anderen NFkB-Proteinen nur 
sehr schwer rekombinant exprimiert und gereinigt werden konnte. RelB-RHR wurde permanent degradiert, konnte aber durch Komplexierung mit einen Bindungspartner (NFk-p50/p52) stabilisiert werden (Huang et al., 2005). Ähnliches wurde in dieser Arbeit für VelB beobachtet (Komplexierung mit VeA). Auch nach Entfernung aller Reste die nicht zur Velvet-Domäne gehören (AS N-44, 126-240 und 343-C), konnte VelB nicht kristallisiert werden (2.2.2).

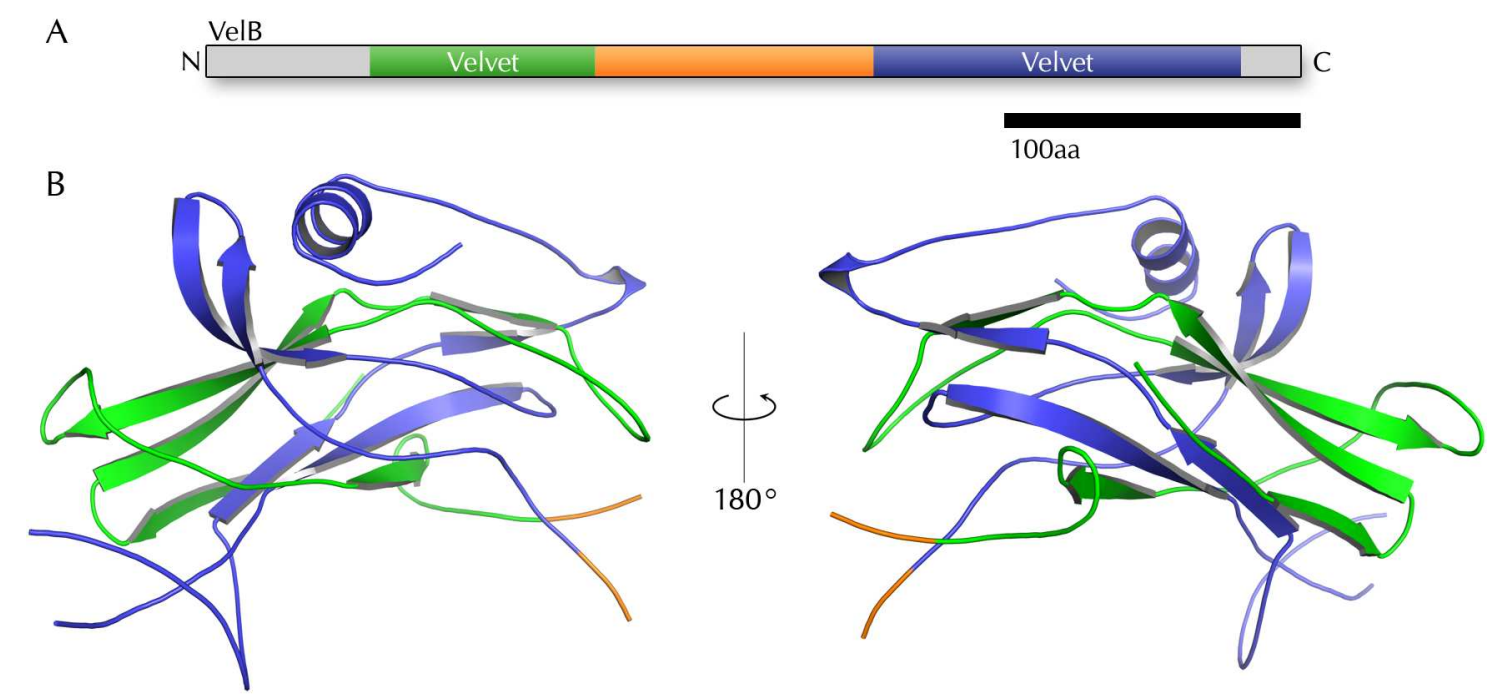

Abbildung 3.1: Domänenaufbau und Struktur von VelB. A: Die Velvet-Domäne (grün und blau) von VelB ist durch 99 Aminosäuren (orange) unterbrochen. B: Trotz der Insertion hat die Velvet-Domäne von VelB eine sehr ähnliche Faltung wie die von VosA (gleiche Farbgebung wie in A).

Ungeklärt bleibt der Ursprung und die Funktion der Insertion in VelB. Bei den meisten Proteinen mit wiederholenden Sequenzen wird angenommen, dass diese durch Fehl-Paarung während der Replikation der DNA entstehen (Levinson und Gutman, 1987). Die Insertion wird möglicherweise für die Interaktion mit anderen Proteinen wie z.B. weiteren Transkriptionsfaktoren oder RNA-Polymerase benötigt. Die Funktion der VeA-VelB- und VelB-VosA-Heterodimere in vivo ist gut untersucht, während die des VelB-Homodimer unbekannt ist. Eine in vivoAnalyse von VelB-mini könnte aufschlussreich sein, da es kein Homodimer ausbildet, aber noch mit VeA und VosA interagiert.

\subsubsection{Vergleich Velvet- und NFkB-Proteine}

Die Familie der NFкB- und Rel-Proteine wird definiert durch die konservierte Rel-Homologie-Region (RHR) bestehend aus zwei Immunglobulin-ähnlichen Domänen. Im Menschen gehören fünf Proteine, NFkB-1 und -2 sowie RelA, RelB und c-Rel, dieser Familie an. Sie können unterschiedliche Homo- und Heterodimere ausbilden, wobei nur die Rel-Proteine eine transkriptionsaktivierende Domäne (TAD) enthalten. Homo- oder Heterodimere von NFKB1 und 2 hingegen wirken repressiv (Übersicht in Huxford und Ghosh, 2009). Die Spezifität für eine bestimmte DNA-Sequenz und auch die regulierende Wirkung (Aktivierung 


\section{Kapitel 3 | DISKUSSION}

oder Reprimierung) wird durch die Zusammensetzung des Dimers festgelegt. Nicht alle Rel- und NFkB-Proteine können einander binden. Ein weiterer Unterschied zwischen den Rel und den NFkB-Proteinen ist das letztere zunächst in einer Vorläuferform synthetisiert werden. Sie enthalten C-terminal von der RHR Ankyrin-Wiederholungen, die proteolytische entfernt werden, um aktives NFKB zu generieren (Fan und Maniatis, 1991). Die Regulation von NFKB wird über eine Reihe von posttranslationalen Modifikationen sowie den Inhibitor IкB (engl. Inhibitor of $\kappa \boldsymbol{B}$ ) gesteuert. I $\kappa \mathrm{B}$ verhindert den Import von NFkB in den Zellkern durch Maskierung der Kernlokalisationssequenz (Ganchi et al., 1992; Latimer et al., 1998).

In Aspergillus nidulans sind vier Velvet-Proteine bekannt, VeA, VelB, VelC und VosA (Abb. 3.2). Die bereits bekannten Interaktionen unter den Velvet-Proteinen (S. 12, Abb. 1.7) konnten in dieser Arbeit mit rekombinant exprimierten Proteinen in vitro reproduziert werden. VosA ist der einzige Vertreter der Velvet-Familie, bei dem eine Transkriptions-stimulierende Aktivität gezeigt wurde (Ni und Yu, 2007). Diese Aktivität liegt in den AS 216-C vor, also außerhalb der Velvet-Domäne. Es ist denkbar, dass eine solche Aktivität auch im C-terminalen Bereich von VeA vorhanden ist, denn die C-terminalen Bereiche von VeA (AS 225-C) und VosA (AS 191-C) sind zu 26\% identisch und haben eine Ähnlichkeit von $47 \%$ (Überlappung von 215 AS, Abb. 3.3).

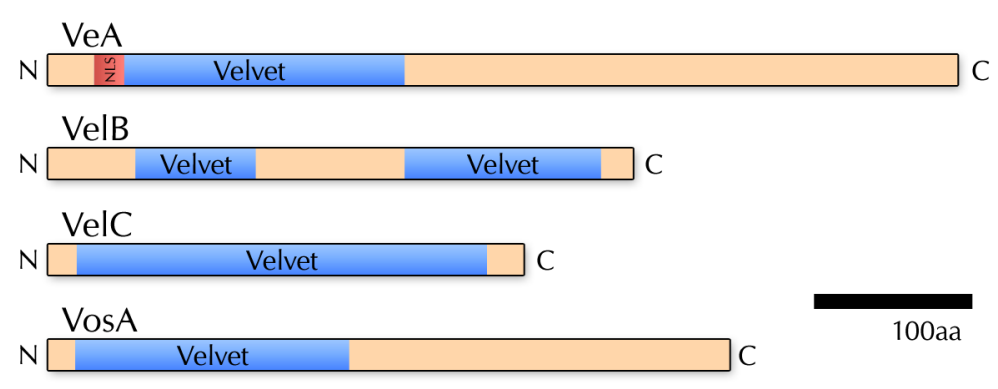

Abbildung 3.2: Domänenaufbau der Velvet-Protein in Aspergillus nidulans. Bei VeA und VosA liegt die Velvet-Domäne im N-terminalen Bereich, während bei VelB und VelC diese über das gesamte Protein verteilt ist. Bei VelB ist ausserdem die Velvet-Domäne unterbrochen. Basierend auf Domänenvorhersage mit CDD (Marchler-Bauer et al., 2011).

Die Velvet-Proteine bilden ähnlich wie die NFkB/Rel-Proteine Homo- und Heterodimere aus. Zu den Heterodimeren zählen VeA-VelB und VelB-VosA (Bayram et al., 2008b) und möglicherweise VelC-VosA (Ni et al., nicht-veröffentlichte Daten, Sarikaya Bayram et al., 2010). Diese verschiedenen Komplexe erfüllen unterschiedliche Funktionen (Abb. 1.7, S. 12). VeA-VelB werden für die Bildung von sexuellen Fruchtkörpern (Bayram et al., 2008b) und VelB-VosA für die Sporogenese und Biogenese von Trehalose (Ni und Yu, 2007; Sarikaya Bayram et al., 2010) benötigt. Womöglich werden durch diese Kombination verschiedene DNASequenzen erkannt. Abhängig davon, ob eines der beiden Proteine in diesen 


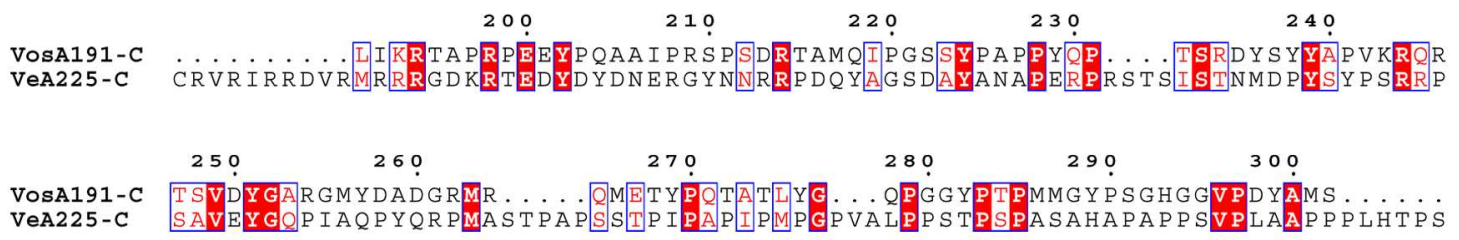

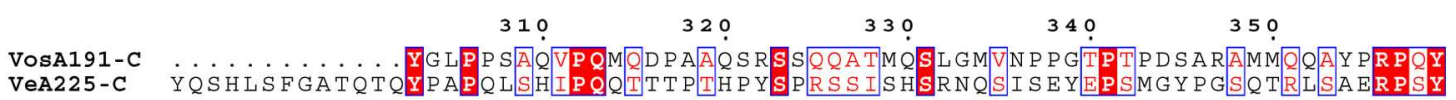

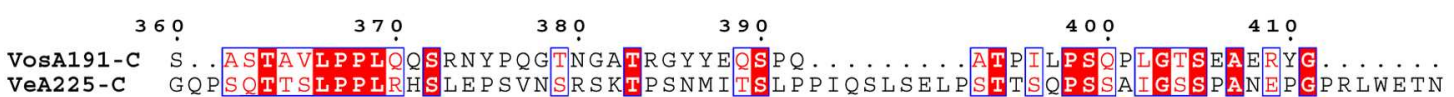

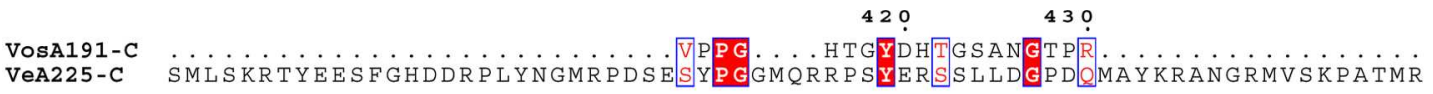

Abbildung 3.3: Sequenzvergleich der C-terminalen Regionen von VosA (AS 191-C) und VeA (AS 225-C) aus Aspergillus nidulans. Identische Reste sind rot unterlegt und ähnliche Bereiche blau umrahmt. Sequenzvergleich wurde mit ClustalW (Larkin et al., 2007) generiert und ESPript (Gouet et al., 1999) visualisiert.

Komplexen eine TAD enthält oder nicht, kommt es zur Aktivierung oder Repression des entsprechenden Gens.

VeA wird durch KapA, vorwiegend im Dunkeln, in den Zellkern transportiert (Stinnett et al., 2007). Es ist möglich, dass die Kernlokalisationssequenz von

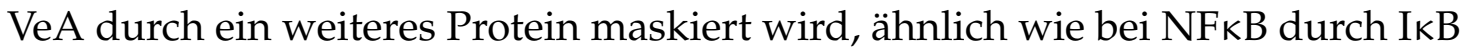
(Ganchi et al., 1992; Latimer et al., 1998). In bisherigen Reinigungen von TAPmarkierten VeA aus Aspergillus nidulans konnte jedoch nur LaeA, KapA und VelB isoliert werden (Bayram et al., 2008b). Ein solches Protein kann jedoch nicht ausgeschlossen werden, da ein kürzlich entdeckter Interaktionspartner von VeA, das Phytochrom FphA, auch nicht durch die TAP-Methode gefunden wurde (Purschwitz et al., 2008). Sollte ein solches Protein jedoch gefunden werden, bietet das rekombinant präparierte Volllängen-VeA eine gute Möglichkeit diese Interaktion in vitro zu charakterisieren. Die Kernlokalisationssequenz dieses Konstrukts war zugänglich und es wurde effizient von humanen Importin $\alpha$ $\triangle \mathrm{IBB}$ gebunden $(2.4$, S. 33).

\subsubsection{Ursprung der Velvet-Proteine}

$\mathrm{Zu}$ Beginn der Arbeit galten die Velvet-Proteine als eine Pilz-spezifische Proteinfamilie. Nach Bestimmung der Kristallstruktur der Velvet-Domäne von VosA und VelB wurde zunächst vermutet, dass die Velvet-Proteine möglicherweise mit den Immunglobulin-ähnlichen Rel/NFkB-Proteinen verwandt ist. VosA190S und NFкB-p50-Rel-N weisen jedoch nur eine Sequenzidentität von 13,7\% auf. Ein gemeinsame Vorläufer dieser beiden Proteine ist nicht bekannt. Neuere Studien geben jedoch Hinweise darauf, dass die Velvet- und auch die NFkB/Rel-Proteine 


\section{Kapitel 3 | DISKUSSION}

noch viel älter und nicht spezifisch für Pilze und Tiere sind (diese Arbeit und Sebé-Pedrós et al., 2011).

Vor kurzem wurde in der PFAM-Datenbank ein weiteres Velvet-Protein ${ }^{5}$ aufgenommen, dass nicht aus einem Pilz stammt. Dieses Velvet-Protein hat seinen Ursprung in dem Organimus Capsaspora owczarzaki (Stamm ATCC 30864), dessen Genom in einer ersten Version 2009 veröffentlicht ${ }^{6}$ wurde (Ruiz-Trillo et al., 2007). C. owczarzaki enthält, anders als Pilze, lediglich ein Velvet-Protein. Dieses besteht aus 826 Aminosäuren und enthält C-terminal von der Velvet-Domäne eine Glutamin-reiche Region (Abb. 3.6). Ob das C. owczarzaki-Velvet-Protein in vivo eine Funktion ausübt, ist unbekannt.

Bei Capsaspora owczarzaki handelt es sich um einen amöboiden Einzeller mit Scheinfüßchen (Abb. 3.4), der als Symbiont in der tropischen Schnecke Biomphalaria glabrata lebt (Hertel et al., 2002).

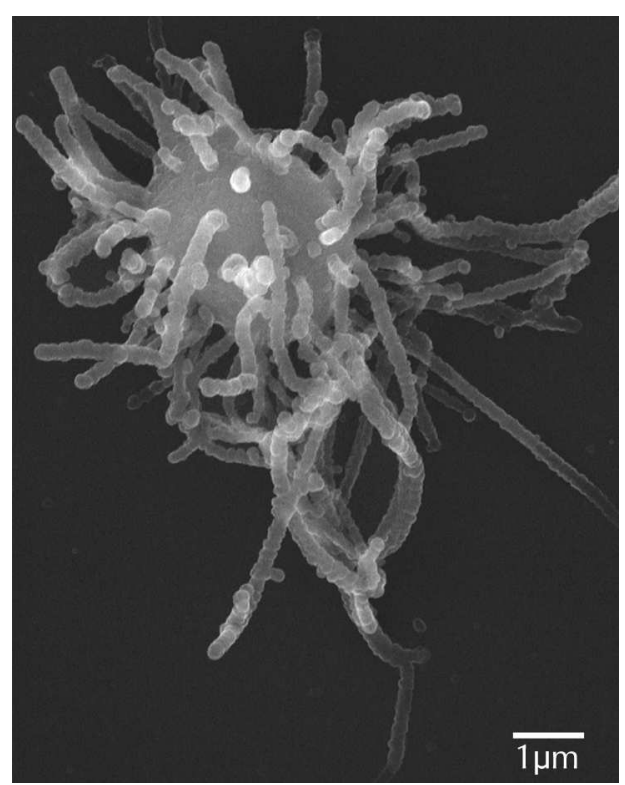

Abbildung 3.4: REM-Bild von Capsaspora owczarzaki, Bild freundlicherweise zur Verfügung gestellt von Arnau Sebé Pedrós (Barcelona).

C. owczarzaki zählt weder zu den Pilzen noch zu den Tieren (Metazoa). Die Zuordnung von diesen Organismus ist umstritten, er wird teilweise in eine eigene Gruppe (Ruiz-Trillo et al., 2004, 2008) oder zu den Choanozoa gezählt (ShalchianTabrizi et al., 2008). Diese unterschiedlichen Einordnungen entstehen durch die Verwendung unterschiedlicher Gene und Einbeziehung unterschiedlicher Taxa in der Analyse (Ruiz-Trillo et al., 2008). Somit liegt C. owczarzaki in der Systematik vorerst zwischen den Tieren und den Pilzen (Abb. 3.5).

Interessanterweise wurden in C. owczarzaki zahlreiche Transkriptionsfaktoren gefunden, die bisher als spezifisch für vielzellige Tiere galten (Sebé-Pedrós et al.,

\footnotetext{
${ }^{5}$ UniProt-Eintrag: E9CE84

${ }^{6}$ GenBank-Eintrag: ACFS01000000
} 


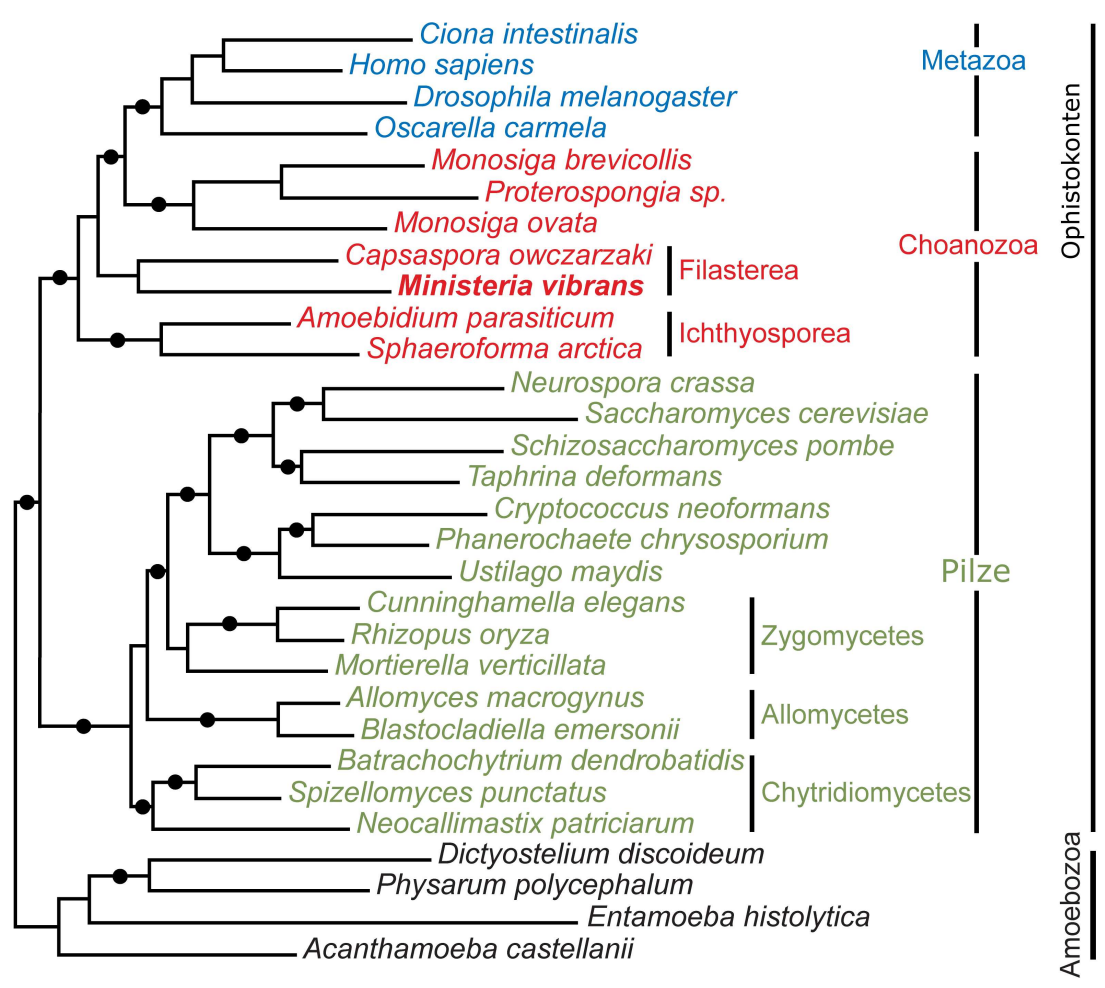

Abbildung 3.5: Phylogenie der Choanozoa und anderer Eukaryoten (rekonstruiert durch Sequenzanalysen), adaptiert aus Sebé-Pedrós et al., 2011.

2011). Dazu zählen Transkriptionsfaktoren der Runx- und NFkB/Rel-Familie, die in C. owczarzaki mit zwei bzw. einen Protein vertreten sind. Das NFkB-Protein ${ }^{7}$ aus C. owczarzaki enthält auch sechs Ankyrin-Wiederholungen und eine Kernlokalisationssequenz (Abb. 3.6). Unbekannt ist, ob C. owczarzaki die restlichen Komponenten der NFkB-Signalkaskade, wie der Inhibitor IкB und die entsprechenden IK-Kinasen, enthält.

C. owczarzaki Velvet

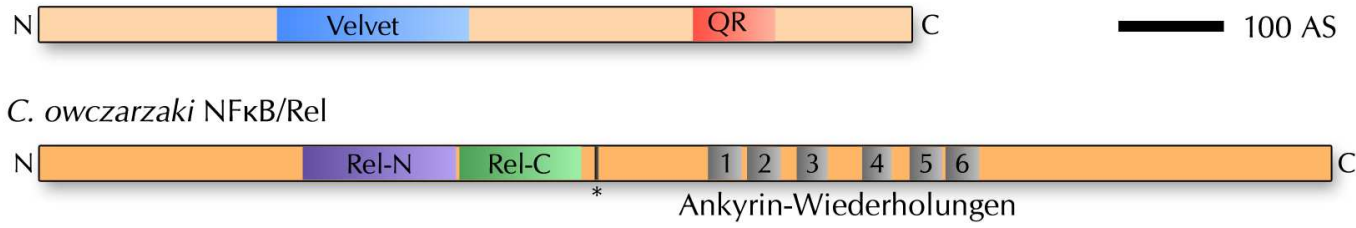

Abbildung 3.6: Domänenaufbau des Velvet- und NFkB/Rel-Proteins aus C. owczarzaki. Das VelvetProtein ist 826 AS groß und enthält C-terminal von der Velvet-Domäne (blau) eine Glutamin-reiche Region (rot). Beim 1223 AS großen NFkB/Rel-Protein liegen nach der Rel-N/C-Domäne (violett/grün) die Kernlokalisationssequenz $\left(^{*}\right)$ und sechs Ankyrin-Wiederholungen (grau) vor. Basierend auf Domänenvorhersage mit CDD (Marchler-Bauer et al., 2011) und Daten aus Sebé-Pedrós et al., 2011.

\footnotetext{
${ }^{7}$ Uniprot-Eintrag: E9C0J2
} 


\section{Kapitel 3 | DISKUSSION}

Beide Proteinfamilien haben also für eine gewisse Zeit koexistiert und sind daher keine Neuerungen die erst durch die Diversifizierung in Pilze und Tiere auftraten. Es ist gut möglich, dass die beiden Proteinfamilien einen gemeinsamen Ursprung haben. Abgesehen davon ist jedoch eine direkt Verwandtschaft unwahrscheinlich, da sich die Architektur beider Proteinfamilien doch stark unterscheidet. So haben alle Rel/NFkB-Proteine zwei Immunglobulin-ähnliche Domänen, während die Velvet-Proteine lediglich eine aufweisen. Auch existieren in den Velvet-Proteinen keine Ankyrin-Wiederholungen und folglich kommt es nicht zu einer proteolytischen Prozessierung von inaktiver zu aktiver Form. Die Velvet-Proteine sind somit die ersten Transkriptionsfaktoren in Pilzen die eine Immunglobulin-ähnliche Faltung haben. 


\section{KAPITEL 4}

\section{Zusammenfassung}

Die Regulation des sekundären Metabolismus und der Entwicklung in Aspergillus nidulans sind zwei miteinander verbundene Prozesse. Thre Regulation geschieht in Abhängigkeit von Licht. Die molekulare Grundlage dieser Verbindung ist ein Komplex bestehend aus den beiden Velvet-Proteinen VeA, VelB und der putativen Methyltransferase LaeA. Ein weiteres Protein der Velvet-Familie ist VosA, dass in Verbindung mit VelB eine essenzielle Rolle in der Sporogenese und Biosynthese von Trehalose spielt. Bisheriges Wissen über die generelle Funktion der einzelnen Proteine basiert überwiegend auf in vivo Analysen. Unbekannt hingegen ist die molekulare Funktionsweise sowie Struktur dieser Proteine. $\mathrm{Zu}$ diesem Zweck wurde in der vorliegenden Arbeit versucht dieses Defizit durch eine röntgenkristallographische Strukturanalyse der Proteine aufzuheben.

Grundlage für die Kristallisation von Proteinen sind große Mengen an hochreinen und homogenen Proteinpräparationen. Hierfür konnte in dieser Arbeit rekombinante Expression und Präparation aller Ziel-Proteine außer LaeA (nur verkürzte Form), etabliert werden. Die Kristallisation verkürzter LaeA-Varianten war nicht erfolgreich. Der Velvet-Komplex (LaeA-VeA-VelB) konnte zwar in vitro rekonstituiert werden, jedoch waren die Mengen nicht ausreichend für extensive Kristallisationsversuche. Die bisher durchgeführten Kristallisationsversuche waren erfolglos. Aufgrund großer Probleme mit LaeA wurde daher der VeAVelB-Komplex rekonstituiert. Dieser Komplex konnte weder bei Verwendung von Volllängen- noch verkürzten Formen beider Proteine kristallisiert werden.

Bei der Präparation von VelB wurde festgestellt das dieses oft mit DNA verunreinigt war. In einen einfachen Gelretardationsexperiment konnte die DNABindung durch VelB bestätigt werden. In weiteren Analysen wurde festgestellt das lediglich dimeres VelB diese DNA-Bindeaktivität aufwies, monomeres VelB hingegen nicht. Hieraus wurde geschlussfolgert, dass es sich bei den VelvetProteinen um DNA-bindende Proteine und möglicherweise Transkriptionsfaktoren handelt. Die Sequenz der Velvet-Proteine weist jedoch kein bekanntes DNA-Bindemotiv auf. 
Die Kristallisation der Velvet-Domäne von VosA (VosA190S) war erfolgreich. Die Struktur konnte aufgrund von co-kristallisierten Iodid-Ionen durch das SADVerfahren gelöst werden. Die Ergebnisse der Größenausschlusschromatographie deuteten auf ein dimeres Protein hin, welches durch die Struktur bestätigt werden konnte. Bei der Suche nach Proteinen mit ähnlicher Struktur wurde das humane NFkB-p50-Protein identifiziert, dessen N-terminale Rel-Homologie-Domäne (RHD) eine sehr große Ähnlichkeit zu VosA190S besitzt. Die NFkB-Proteine sind bekannte Transkriptionsfaktoren die DNA binden können. Die Strukturüberlagerung wurde genutzt, um potenziellen Aminosäurereste in VosA190S, die für die Bindung von DNA notwendig wären, zu identifizieren. Mutanten die auf dieser Basis generiert wurden, zeigten eine verringerte bis gar keine DNA-Bindung. Die Ergebnisse der Gelretardationsexperimente unterstützen die Hypothese das die mutierten Aminosäurereste in der DNA-Bindung verwickelt sind.

Der VelB-VosA190S-Komplex konnte auch kristallisiert und die Struktur durch molekularen Ersatz gelöst werden. Bei dieser Struktur zeigte sich, dass die Velvet-Domäne in VelB tatsächlich eine Domäne ist, die durch eine Insertion von 99 Aminosäuren unterbrochen ist. Für die Aminosäurereste der Insertion war jedoch keine Elektronendichte zu beobachten. Vermutlich wurden diese Reste, aufgrund einer Proteasekontamination während der Präparation oder Kristallisation, entfernt. Mit einer speziellen Verkürzung konnte gezeigt werden, dass diese Insertion für die Interaktion mit VeA (AS 1-224) oder VosA (AS 1-190) nicht benötigt wird. Ob diese Insertion in vivo eine Funktion erfüllt, ist nicht bekannt. VelB weist ein sehr ähnliche Struktur zu VosA190S auf. Im Vergleich zum VosA190S-Dimer liegen beide Proteine etwas verdreht und leicht versetzt zu einander. Die Erkenntnisse über die Strukturaufklärung der Velvet-Domänen von VosA und VelB wurden genutzt um ein verkürzte Form von VeA zu generieren (AS 1-224). Diese Form konnte kristallisiert werden und erste Einblicke deuten darauf hin, dass es sich bei VeA auch um ein Dimer handelt. Die einzelnen Moleküle liegen jedoch anders zueinander als beim VosA190S-Homo- oder VelB-VosA190S-Heterodimer.

Zusammenfassend lässt sich sagen, dass es sich bei den Velvet-Proteinen um die ersten Pilz-spezifischen Transkriptionsfaktoren handelt, die für die DNABindung eine RHD/Ig-ähnliche Struktur besitzen. Die für diese Proteine definierende Velvet-Domäne ist sowohl für die Interaktion mit DNA als auch für die Interaktion mit anderen Velvet-Proteinen verantwortlich. Die unerwartete strukturelle Ähnlichkeit mit der RH-Domäne der NFkB-Familie warf die Frage nach einen gemeinsamen Vorkommen auf. Durch Sequenzanalysen konnten im Genom des amöboiden Einzellers Capsaspora owczarzaki zwei Gene gefunden werden, die für ein ein Velvet- und ein NFkB/Rel-Protein kodieren. C. owczarzaki zählt weder zu den Tieren noch zu den Pilzen. Beide Proteinfamilien sind also älter als bisher erwartet und stellen nicht eine Innovation der Tiere oder Pilze dar. 


\section{KAPITEL 5}

\section{Summary}

The regulation of secondary metabolism and development in Aspergillus nidulans are two linked processes. Their regulation is dependent on light. The molecular basis for this connection is a complex composed of the two Velvet-proteins VeA, VelB and the putative methyltransferase LaeA (Velvet-complex). VelB together with VosA, which is another Velvet-protein, are essential for sporogenisis and biosynthesis of trehalose. Current knowledge about the general function of these proteins is based mostly on in vivo analysis. The molecular mode of function and structure of these proteins however is unknown. The current work aimed at resolving this by means of x-ray crystallographic structure analyis of these proteins.

Crystallization requires large amounts of highly pure and homogenous protein preparations. All proteins except LaeA (truncated form only) could be expressed and purified to homogeneity in sufficient amounts for crystallization. Truncated variants of LaeA could also be purified to high purity but could not be crystallized so far. The Velvet-complex (LaeA-VeA-VelB) could be reconstituted in vitro but the amounts were not sufficient for extensive crystallization trials. The crystallization trials that have been performed so far, were not successful. Due to severe problems with LaeA a complex comprising only VeA and VelB was reconstituted. Neither the use of full-length nor truncated proteins lead to crystallization of this complex.

During the preparation of VelB it was observed that it was regularly contaminated with DNA. A simple gel retardation assay confirmed that VelB binds to DNA. Further analysis of this phenomena led to the conclusion that only dimeric VelB bound to DNA, whilst monomeric VelB did not. At this point it was concluded that Velvet-proteins are DNA-binding proteins and potentially transcription factors. The sequence of the Velvet-proteins does not contain any known DNA-binding motif.

The crystallization of the Velvet-domain of VosA (VosA190S) was successful. The structure was solved using the SAD method, as the protein was co- 


\section{Kapitel 5 | SUMMARY}

crystallized with potassium-iodine. The dimeric state of protein that had been observed in gel-filtration could be confirmed with the structure. A search for structurally similar proteins identified the human NFkB-p50. The N-terminal Rel-Homology-domain (RHD) exhibits a high degree of similarity to the VelvetDomain of VosA. The NFkB-proteins are transcription factors that are known to bind to DNA. VosA190S residues that might be involved in DNA-binding were selected for mutagenesis based on a structure overlay of VosA190S and NFkB-p50 bound to DNA. The generated mutants all exhibited weaker or no DNA-binding at all. The results from this experiment support the hypothesis that the selected residues are involved in interaction with DNA.

The VelB-VosA190S-complex was also crystallized and the structure determined using molecular replacement. The structure revealed that the Velvet-domain of VelB is indeed only one domain which is interrupted by an insertion of 99 amino acids. However no electron density could be located for the residues of this insertion. It is assumed that this insertion was removed due to a protease contamination during purification or crystallization. Subsequently a truncation of VelB, lacking this insertion, was shown to still interact with truncated forms of VeA (aa 1-224) and VosA (aa 1-190). Whether this insertion has any function in vivo is currently not known. The overall fold of VelB is very similar to that of VosA190S. Compared to the VosA190S-homodimer both molecules are rotated slightly in respect to each other.

Based on the determined structures of the Velvet-domains of VosA and VelB a truncation of VeA was generated (aa 1-224) that could also be crystallized. Initial results indicate that VeA is also a dimer. Although a detailed analysis of the data is not complete at this point, the arrangement of both VeA-molecules might be different compared to those in the VosA190S-homo- or VelB-VosA190Sheterodimer.

To sum up, Velvet-proteins are the first fungi-specific transcription factors which have a RHD/Ig-like structure. The defining Velvet-domain of these proteins mediates interactions with DNA and other Velvet-proteins. The unexpected structural similarity to the Rel-homology-domain of NFkB/Rel-proteins led to the question whether there is a common precursor. Sequence-analysis revealed one gene in the amoeboid uni-cellular organism Capsaspora owczarzaki which encodes one Velvet-protein. The Capsaspora owczarzaki genome had previously been shown to contain one gene encoding one NFkB/Rel-protein. This organism does not belong to the fungi nor metazoa kingdom. Therefor both protein-families are much older than previously thought and not innovations of fungi or metazoa. 


\section{KAPITEL 6}

\section{Material und Methoden}

\subsection{Material}

\subsubsection{Chromatographiesysteme, -säulen und Zubehör}

In dieser Arbeit wurden die Chromatographiesysteme ÄKTA Prime und ÄKTAPurifier (Amersham Pharmacia Biotech, Freiburg) verwendet. Die Proben wurden entweder mit einen 5, 50 oder $150 \mathrm{ml}$ Superloop (GE Healthcare, München) aufgetragen. Folgende Säulen wurden mit diesen Systemen verwendet:

GSH-Sepharose $5 \mathrm{ml}$

GSH-Sepharose $15 \mathrm{ml}$

HisTrap 5ml Ni-NTA-Sepharose

HiPrep Desalting $5 \mathrm{ml}$

HiPrep Desalting 26/10

Superdex 75 (16/60 und 26/60)

Superdex 200 (16/60 und 26/600)

StrepTactin HP Sepharose $5 \mathrm{ml}$

StrepTactin HP Sepharose $15 \mathrm{ml}$

StrepTactin Sepharose
GE Healthcare, München

GE Healthcare, München

GE Healthcare, München

GE Healthcare, München

Amersham Pharmacia Biotech, Freiburg

Amersham Pharmacia Biotech, Freiburg

Amersham Pharmacia Biotech, Freiburg

GE Healthcare, München

GE Healthcare, München

IBA, Göttingen

\subsubsection{Computerprogramme und Datenbanken}

$\begin{array}{ll}\text { 2D-GraLab } & \text { Zhou et al., 2009 } \\ \text { ARP/wARP } & \text { Langer } \text { et al., 2008 } \\ \text { CCP4 } & \text { Winn } \text { et al., 2011 } \\ \text { CDD } & \text { Marchler-Bauer } \text { et al., 2011 } \\ \text { ClustalW } & \text { Larkin } \text { et al., 2007 } \\ \text { CNS } & \text { Brünger } \text { et al., 1998 } \\ \text { Coot } & \text { Emsley } \text { et al., 2010 } \\ \text { ESPript } & \text { Gouet } \text { et al., 1999 } \\ \text { HKL2MAP } & \text { Pape und Schneider, 2004 }\end{array}$




\section{Kapitel 6 | MATERIAL UND METHODEN}

Computerprogramme und Datenbanken (fortgesetzt)

$\begin{array}{ll}\text { LIGPLOT } & \text { Wallace } \text { et al., } 1995 \\ \text { Phaser } & \text { McCoy et al., 2007 } \\ \text { PHENIX } & \text { Adams } \text { et al., 2010 } \\ \text { PSIPRED } & \text { Bryson } \text { et al., 2005 } \\ \text { REFMAC5 } & \text { Murshudov et al., 2011 } \\ \text { SHELXC/D/E } & \text { Sheldrick, 2008 } \\ \text { XDS } & \text { Kabsch, 2010 }\end{array}$

\subsubsection{DNA-Oligonukleotide}

DNA-Oligonukleotide wurden von Sigma-Aldrich (Steinheim) bezogen und sind in Tabelle 6.1 aufgeführt.

Tabelle 6.1: Verwendete DNA-Oligonukleotide in dieser Arbeit. Die Sequenz ist immer in $5^{\prime}-3^{\prime}$ angegeben. Die Schmelztemperatur entspricht den Herstellerangaben.

\begin{tabular}{llr}
\hline Name & Sequenz & $\mathrm{T}_{\mathrm{M}}$ \\
\hline brlA_10F & ATTCGGCGACTAGGATCTTACTGGCCGCGGCCGAG & $85,9^{\circ} \mathrm{C}$ \\
brlA_10R & CTCGGCCGCGGCCAGTAAGATCCTAGTCGCCGAAT & $85,9^{\circ} \mathrm{C}$ \\
\hline
\end{tabular}

\subsubsection{Feinchemikalien}

Alle Feinchemikalien und organischen Substanzen wurden von den Firmen AppliChem (Darmstadt), Fluka (Buchs), BioRad (München), Merck (Darmstadt), Sigma-Aldrich (Steinheim), MWG Biotech (München), Oxoid (Basingstoke, England), IBA (Göttingen) und Roth (Karlsruhe) bezogen.

\subsubsection{Größenstandards für DNA und Proteine}

$\begin{array}{ll}\text { GeneRuler 1kb DNA Ladder } & \text { Fermentas, St. Leon-Rot } \\ \text { GeneRuler DNA Ladder Mix } & \text { Fermentas, St. Leon-Rot } \\ \text { Protein Molecular Weight Marker } & \text { Fermentas, St. Leon-Rot }\end{array}$




\subsubsection{Geräte}

AbiPrism 3100 DNA Sequencer

Alchemist HT-Roboter

Agarosegelelektrophorese-Kammer

Autoklav HST 4-5-8

Binokulare

Feinwaagen

GelDoc Geldokumentationsgerät

Gelschüttler Promax 1020

HLC Blockthermostat BT1302

Innova 4230 Schüttelinkubator

Inkubator Mytron

Magnetrührer IKAMAG REO

mar345dtb Detektorsystem

Microfluidizer $110 \mathrm{~S}$

PCR-Mastercycler gradient

PCR-Whatman Biometra T personal

pH-Meter Beckman

Photometer

Pipetten (verstellbar)

Pipettierhilfe Accu-Jet

Röntgendiffraktometer MicroMax 007

Rotor JA-20

Rotor JA-30.50 Ti

Rotor JLA-8.1000

Rotor S4180

SDS-PAGE-System Hoefer miniVE

Sonifier 250

Taumelrollenmischer RM5

Thermomixer comfort

Tischzentrifuge $5417 \mathrm{R}$

Tischzentrifuge Micro centrifuge II

Unitron Schüttelinkubatoren

Vakuumkonzentrator 5301

Vortexer

Zentrifuge Allegra 21R

Zentrifuge Avanti J-20 XPI

Zentrifuge Avanti J-30 I
Applied Biosystems, Darmstadt

Rigaku/MSC, Japan

Bio-Rad, München

Zirbus, Bad Grund

Carl Zeiss, Jena

Sartorius, Göttingen

Bio-Rad, München

Heidolph, Schwabach

Techne, Minneapolis, USA

New Brunswick Scientific, Nürtingen

Schütt, Göttingen

IKA, Staufen

mar Research, Norderstedt

Microfluidics, USA

Eppendorf, Hamburg

Biometra, Göttingen

Beckman Coulter, Krefeld

Eppendorf, Hamburg

Eppendorf, Hamburg

Brand, Wertheim

Rigaku/MSC, Japan

Beckman Coulter, Krefeld

Beckman Coulter, Krefeld

Beckman Coulter, Krefeld

Beckman Coulter, Krefeld

Amersham Pharmacia Biotech, Freiburg

Branson, USA

Schütt, Göttingen

Eppendorf, Hamburg

Eppendorf, Hamburg

Sylvania, Ohio, USA

Infors, Einsbach

Eppendorf, Hamburg

Schütt, Göttingen

Beckman Coulter, Krefeld

Beckman Coulter, Krefeld

Beckman Coulter, Krefeld 


\section{Kapitel 6 MATERIAL UND METHODEN}

\subsubsection{Organismen}

Alle verwendeten Organismen stammen aus der Stammsammlung der AG Ficner, Molekulare Strukturbiologie, Universität Göttingen.

E. coli BL21(DE3)

E. coli BL21 Star (DE3)

E. coli Rosetta 2 (DE3)

E. coli XL1-Blue

E. coli Arctic Express

E. coli SoluBL21 (DE3)

\subsubsection{Plasmide}

Alle Plasmide wurden von Dr. Özgür Bayram (OB), Jennifer Gerke (JG) und Dr. Achim Dickmanns (AD) (Universität Göttingen) bereitgestellt und sind in Tabelle 6.2 aufgeführt. Darauf kodierte Proteine enthalten teilweise eine Schnittstelle für die TEV- oder PreScission-Protease (PP).

\subsubsection{Proteasen und Inhibitoren}
AEBSF
Applichem, Darmstadt
ALP-Protease Inhibitor Mix APMSF
PreScission-Protease
MSB, Universität Göttingen
Applichem, Darmstadt
GE Healthcare, München
TEV Protease
MSB, Universität Göttingen

\subsubsection{Sammlungen von Kristallisationslösungen}

Die Kristallisationslösungen im $8 \times 12$-Format werden mit einen Alchemist HTRoboter zusammengemischt (Rigaku, Japan) und mit einen Phoenix / RE (Art Robbins, USA) Roboter pipettiert. Die Lösungen im $4 \times 6$-Format werden per Hand pipettiert.

6.1.10.1 Lösungen im $8 \times 12$-Format

$\begin{array}{ll}\mathrm{AmSO}_{3} \text { Suite } & \text { Qiagen, Hilden } \\ \text { JB NucPro } & \text { Jena BioScience, Jena } \\ \text { JBScreens }(1,2,4,5) & \text { Jena BioScience, Jena } \\ \text { JBScreens }(6,7,8,10) & \text { Jena BioScience, Jena } \\ \text { JCSG+ } & \text { Newman } \text { et al., 2005 } \\ \text { Morpheus } & \text { Molecular Dimensions, England } \\ \text { NatrixHT } & \text { Hampton Research, USA } \\ \text { PGA } & \text { Molecular Dimensions, England } \\ \text { ProPlex } & \text { Radaev } \text { et al., 2006 }\end{array}$


Tabelle 6.2: Verwendete Plasmide in dieser Arbeit. Die Plasmide vermitteln eine Resistenz gegen Ampicillin (Amp) oder Kanamycin (Kan).

\begin{tabular}{|c|c|c|c|c|c|}
\hline Plasmid & Aminosäuren & $\begin{array}{l}\text { Affinitäts- } \\
\text { sequenz }\end{array}$ & $\begin{array}{l}\text { Schnitt- } \\
\text { stelle }\end{array}$ & Resistenz & Quelle \\
\hline \multicolumn{6}{|l|}{ LaeA } \\
\hline pETM40-LaeA & Volllänge & N-MBP & TEV & Kan & OB \\
\hline pGEX6P1-LaeA91 & $91-\mathrm{C}$ & N-GST & PP & Amp & JG \\
\hline pGEX6P1-LaeA106 & $101-\mathrm{C}$ & N-GST & PP & Amp & JG \\
\hline \multicolumn{6}{|l|}{ VeA } \\
\hline pETM11-VeA & Volllänge & $\mathrm{N}-\mathrm{His}_{6}$ & TEV & Kan & OB \\
\hline pETM13-VeA & Volllänge & $\mathrm{C}-\mathrm{His}_{6}$ & - & Kan & JG \\
\hline pETM13-VeA224S & $\mathrm{N}-224$ & C-Strep II & - & Kan & JG \\
\hline \multicolumn{6}{|l|}{ VelB } \\
\hline pETM11-VelB & Volllänge & $\mathrm{N}-\mathrm{His}_{6}$ & TEV & Kan & OB \\
\hline pETM13-VelB & Volllänge & $\mathrm{C}-\mathrm{His}_{6}$ & - & Kan & JG \\
\hline pPR-IBA1-VelB & Volllänge & C-Strep II & - & Amp & JG \\
\hline pETM13-VelB-mini & $\begin{array}{l}44-126- \\
\text { ASIPPSTA- } \\
240-343\end{array}$ & $\mathrm{C}-\mathrm{His}_{6}$ & - & Kan & $\mathrm{JG}$ \\
\hline \multicolumn{6}{|l|}{ VosA } \\
\hline pETM13-VosA190S & N-190 & C-Strep II & - & Kan & OB \\
\hline pETM13-VosA190H & N-190 & $\mathrm{C}-\mathrm{His}_{6}$ & - & Kan & $\mathrm{OB}$ \\
\hline \multicolumn{6}{|c|}{ VosA-Mutanten (basieren auf pETM13-VosA190S) } \\
\hline K37A & N-190, K37A & C-Strep II & - & Kan & JG \\
\hline K39A & N-190, K39A & C-Strep II & - & Kan & JG \\
\hline R40A & $\mathrm{N}-190, \mathrm{R} 40 \mathrm{~A}$ & C-Strep II & - & Kan & $\mathrm{JG}$ \\
\hline K41A & N-190, K41A & C-Strep II & - & Kan & JG \\
\hline K160A & N-190, K160A & C-Strep II & - & Kan & JG \\
\hline Doppel & $\begin{array}{l}\text { N-190, } \\
\text { K37A/K39A }\end{array}$ & C-Strep II & - & Kan & JG \\
\hline Tot & $\begin{array}{l}\text { N-190, } \\
\text { K37A/K39A/R }\end{array}$ & $\begin{array}{c}\text { C-Strep II } \\
40 \mathrm{~A} / \mathrm{K} 41 \mathrm{~A}\end{array}$ & - & Kan & JG \\
\hline \multicolumn{6}{|c|}{ Importin $\alpha \Delta$ IBB (Homo sapiens) } \\
\hline pGEX6P1-Imp $\alpha-\Delta$ IBB & $55-C$ & N-GST & PP & Amp & $\mathrm{AD}$ \\
\hline
\end{tabular}




\section{Kapitel 6 | MATERIAL UND METHODEN}

\subsubsection{Lösungen im $4 \times 6$-Format}

$\begin{array}{ll}\text { Clear Strategy Screen } & \text { Molecular Dimensions, England } \\ \text { Crystal Screen 1\&2 } & \text { Hampton Research, USA } \\ \text { Crystal Screen Lite } & \text { Hampton Research, USA } \\ \text { Crystal Screen PEG/ION } & \text { Hampton Research, USA } \\ \text { Footprint Screens 1-3 } & \text { Stura et al., 1992 } \\ \text { JBScreen 1-9 } & \text { Jena BioScience, Jena } \\ \text { Magic Screen } & \text { Biogenova, Kanada } \\ \text { Structure Screen } & \text { Molecular Dimensions, England }\end{array}$

\subsubsection{Sonstige Materialien}

$\begin{array}{ll}\text { 24-Well Kristallisationsschalen } & \text { Hampton Research, USA } \\ \text { Amicon Ultra Konzentratoren } & \text { Millipore, Schwalbach/Ts } \\ \text { Bradfordreagenz }(5 \times) & \text { Bio-Rad, München } \\ \text { Crystal Clear Tape } & \text { Henkel, Aachen } \\ \text { Glasgeräte } & \text { Merck, Darmstadt } \\ \text { Nylonschleifen für Kristalle } & \text { Hampton Research, USA } \\ \text { Pipettenspitzen } & \text { Sarstedt, Nümbrecht } \\ \text { Reaktionsgefäße }(0.5-2 \mathrm{ml}) & \text { Sarstedt, Nümbrecht } \\ \text { Reaktionsgefäße }(15 \text { und 50ml) } & \text { Sarstedt, Nümbrecht } \\ \text { Sterilfilter } & \text { Millipore, USA } \\ \text { Vivaspin Konzentratoren } & \text { Vivascience, Hannover }\end{array}$

\subsection{Methoden}

\subsubsection{Molekularbiologische Methoden}

\subsubsection{Polymerase-Kettenreaktion}

Die Polymerase-Kettenreaktion (engl. polymerase chain reaction, PCR) erlaubt die selektive Amplifizierung von spezifischen DNA-Abschnitten (Mullis et al., 1986). Dabei wird von dem verwendeten Enzym, der DNA-Polymerase einer neuer Strang synthetisiert. Für die Synthese aus einer Matrize (engl. template-DNA) werden kurze DNA-Moleküle benötigt, die den Bereich der amplifiziert werden soll, flankieren. Diese so genannten Primer haben in der Regel eine Länge von 20-30 Bp und sind zum Anfang und Ende der zu amplifizierenden Region komplementär. An ihnen startet die DNA-Polymerase die Synthese eines Stranges, erweitert (engl. extension) also den Primer. Die in dieser Arbeit verwendeten DNA-Polymerasen sind in Tabelle 6.3 aufgeführt. Die PCR bildet die Grundlage für die gezielte Amplifizierung von Genen aus cDNA-Banken oder zur Überprüfung von DNA-Sequenzen in Vektoren. Ein Standard-PCR-Ansatz und -Programm ist aufgeführt. 
Tabelle 6.3: Verwendete thermostabile DNA-Polymerasen.

\begin{tabular}{llll}
\hline Name & Organimus & $\begin{array}{l}\text { Temperatur- } \\
\text { optimum }\left[{ }^{\circ} \mathrm{C}\right]\end{array}$ & $\begin{array}{l}\text { Elongations- } \\
\text { zeit/kbp [s] }\end{array}$ \\
\hline Pfu-Polymerase & Pyrococcus furiosus & 68 & $60-120$ \\
Taq-Polymerase & Thermus aquaticus & 72 & $30-60$ \\
Phusion & modifiziert, Pfu-ähnlich & 72 & $15-30$ \\
\hline
\end{tabular}

\begin{tabular}{ll}
\multicolumn{2}{l}{ Standard-PCR-Ansatz } \\
\hline $1 \times$ & PCR-Puffer \\
$10 \mathrm{mM}$ & je dATP, dCTP, dGTP und dTTP \\
$10 \mathrm{pmol}$ & je $5^{\prime}$ - und 3'-Primer \\
$10 \mathrm{bis} 100 \mathrm{ng}$ & template-DNA \\
$0,5-2 \mathrm{U}$ & DNA-Polymerase (s. Tabelle 6.3) \\
ad $50 \mu \mathrm{l}$ & $\mathrm{H}_{2} \mathrm{O}$ \\
\hline
\end{tabular}

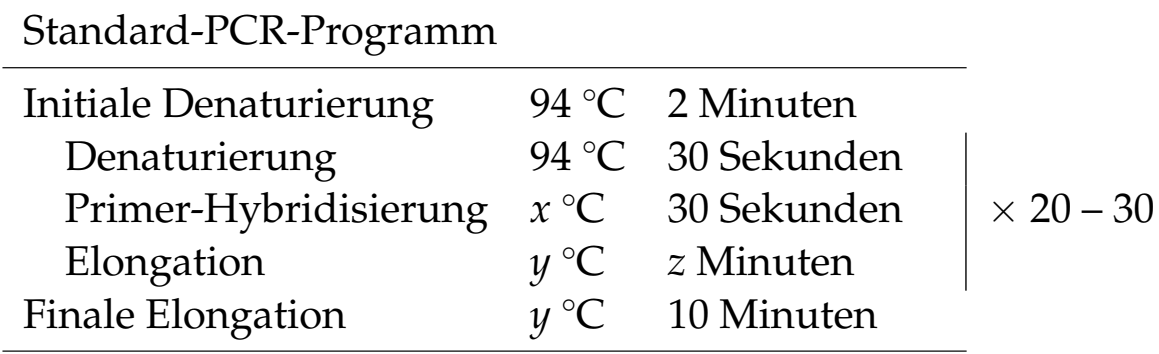

Für $x$ wird eine Temperatur 3 bis $5^{\circ} \mathrm{C}$ unter der Schmelztemperatur der beiden verwendeten Primer eingestellt. Die Temperatur als auch die Zeitdauer der Elongationsreaktion hängen von der verwendeten Polymerase ab, siehe dazu Tabelle 6.3.

\subsubsection{Konzentrationsbestimmung von DNA mit einen Photometer}

Wässrige Nukleinsäurelösungen weisen eine starke Absorption im UV-Licht auf, wobei das Absorptionsmaximum bei $260 \mathrm{~nm}$ liegt. Durch Bestimmung der Absorption bei $260 \mathrm{~nm}$ gegen einen Referenzwert kann die DNA-Konzentration quantitativ ermittelt werden. Hierzu werden folgende Umrechnungsfaktoren verwendet:

$$
\begin{array}{ll}
\text { Doppelsträngige DNA: } & 1 \mathrm{~A}_{260 \mathrm{~nm}}=50 \mu \mathrm{g} / \mathrm{ml} \\
\text { Einzelsträngige DNA: } & 1 \mathrm{~A}_{260 \mathrm{~nm}}=40 \mu \mathrm{g} / \mathrm{ml}
\end{array}
$$

Die Reinheit der Nukleinsäurelösung kann durch eine Messung der Absorption bei $280 \mathrm{~nm}$ bestimmt werden. Bei dieser Wellenlänge haben aromatische 


\section{Kapitel 6 | MATERIAL UND METHODEN}

Aminosäuren eine Absorptionsmaximum. Der Quotient von $A_{260 n m} / A_{280 n m}$ liegt bei reinen Nukleinsäurelösungen zwischen 1,8-2,0. Bei Verunreinigungen durch Proteine liegt der Quotient unter 1,8.

\subsubsection{Trennung von DNA-Fragmenten durch Agarosegelelektrophorese}

DNA-Fragmente können nach ihrer Größe in einen Agarosegel aufgetrennt werden. Aufgrund des negativ geladenen Phosphatrückgrats wandert DNA in einen angelegten elektrischen Feld zur Anode. In 1×TAE gelöste Agarose wird zum Kochen gebracht und anschließend in eine Gelkammer mit Kamm gegossen. Das erstarrte Gel wird mit $1 \times$ TAE überschüttet, die Proben werden mit Ladepuffer versetzt und dann auf dem Gel aufgetragen. An den Gel wird für 70 bis 90 Minuten eine Spannung von $80 \mathrm{~V}$ angelegt. Im Rahmen dieser Arbeit wurden 1 - 2\% Agarosegele verwendet.

\begin{tabular}{ll}
$6 \times$ Ladepuffer \\
\hline $10 \mathrm{mM}$ & Tris/HCl $\mathrm{pH} \mathrm{7,6}$ \\
$0,03 \%$ & Bromphenolblau \\
$0,03 \%$ & Xylen cyanol FF \\
$60 \%$ & Glyzerin \\
$60 \mathrm{mM}$ & EDTA \\
\hline
\end{tabular}

\begin{tabular}{ll}
\multicolumn{2}{l}{$50 \times \mathrm{TAE}$} \\
\hline $2 \mathrm{M}$ & Tris-Acetat, $\mathrm{pH} 8,0$ \\
$50 \mathrm{mM}$ & EDTA \\
$50 \mathrm{mM}$ & EDTA \\
\hline
\end{tabular}

\subsubsection{Gelretardation}

Für den Nachweis eine Protein-DNA-Interaktion kann die Gelretardation verwendet werden. Protein sowie DNA werden gemischt, inkubiert und auf einen Agarosegel (6.2.1.3) getrennt. Zusätzlich wird die DNA ohne Protein aufgetragen (Referenz). Ist das Laufverhalten des Protein-DNA-Gemischs anders als bei der Referenz-DNA dann ist eine Protein-DNA-Interaktion sehr wahrscheinlich. Für qualitative Zwecke werden in dieser Arbeit DNA-Fragmente zwischen 44-350 verwendet, die entweder durch die Anlagerung zweier Oligonukleotide oder mittels PCR (6.2.1.1) generiert werden. Bei der DNA1 handelt es sich um das ROSE1-Element aus Bradyrhizobium japonicum mit einen 5' T7-Promoter. Die DNA2 basiert auf der DNA1 und enthält 3' noch ein HDV-Ribozym sowie zwei MS2-Bindestellen. Das brlA-Fragment wurde von Jennifer Gerke (Universität Göttingen) zur Verfügung gestellt, es enthält 300 bp des brlA-Gens aus Aspergillus nidulans. 


\subsubsection{Visualisierung von Nukleinsäuren mit Ethidiumbromid oder GelRed}

Elektrophoretisch aufgetrennte Nukleinsäuren in einen Agarosegel können durch Inkubation in einen Ethidiumbromidbad $(1 \mu \mathrm{g} / \mathrm{ml})$ und anschließender Bestrahlung mit UV-Licht (254 bzw. $365 \mathrm{~nm}$ ) sichtbar gemacht werden. Einige Gele in der vorliegenden Arbeit sind nicht mit Ethidiumbromid sondern in einen TAE-Puffer mit $1 \times$ GelRed (Biotium, VWR, Darmstadt) gefärbt. GelRed kann alternativ auch $1 \times$ zum Gel zugegeben werden bevor es gegossen wird. Die Visualisierung geschieht bei beiden Färbungsmethoden durch Bestrahlung mit UV-Licht (254 nm bzw. 365 nm). Die Dokumentation der Gele erfolgt mit einen GelDoc EQ System (Bio-Rad, München) bei $254 \mathrm{~nm}$.

\subsubsection{Mikrobiologische Methoden}

\subsubsection{Herstellung von Flüssig- und Festmedien}

Für die Kultivierung von Bakterien werden Flüssig- und Festmedien verwendet. Sofern nicht anders vermerkt werden alle aufgeführten Medien nach Herstellung für 10 Minuten bei $121^{\circ} \mathrm{C}$ autoklaviert. Falls erforderlich werden sterilfiltrierte Antibiotika zugegeben, dies geschieht nach Abkühlen der Medien auf 40 bis $50{ }^{\circ} \mathrm{C}$. Die verwendeten Endkonzentrationen betragen $100 \mu \mathrm{g} / \mathrm{ml}$ Ampicillin, $34 \mu \mathrm{g} / \mathrm{ml}$ Chloramphenicol und $30 \mu \mathrm{g} / \mathrm{ml}$ Kanamycin.

\section{LB- und 2YT-Medium und -Agar}

\begin{tabular}{ll} 
LB-Medium & \\
\hline $1 \%(\mathrm{w} / \mathrm{v})$ & Trypton \\
$0,5 \%(\mathrm{w} / \mathrm{v})$ & Hefeextrakt \\
$0,5 \%(\mathrm{w} / \mathrm{v})$ & $\mathrm{NaCl}$ \\
\hline & \\
$2 Y \mathrm{Y}-\mathrm{Medium}$ \\
\hline $1 \%(\mathrm{w} / \mathrm{v})$ & Trypton \\
$1 \%(\mathrm{w} / \mathrm{v})$ & Hefeextrakt \\
$1 \%(\mathrm{w} / \mathrm{v})$ & $\mathrm{NaCl}$ \\
\hline
\end{tabular}

\begin{tabular}{ll} 
LB-Agar & \\
\hline $500 \mathrm{ml}$ & LB-Medium \\
$1,5 \%(\mathrm{w} / \mathrm{v})$ & Agar \\
\hline
\end{tabular}

\begin{tabular}{ll} 
2YT-Agar & \\
\hline $500 \mathrm{ml}$ & 2YT-Medium \\
$1,5 \%(\mathrm{w} / \mathrm{v})$ & Agar \\
\hline
\end{tabular}

\section{ZYM-5052 Autoinduktionsmedium}

Die einzelnen Komponenten des ZYM-5052 Autoinduktionsmedium (Studier, 2005) werden separat angesetzt, bis auf die Spurenelemente (sterilfiltriert) autoklaviert und dann zu jeweils $1 \times$ Endkonzentration zusammengemischt. Die Spurenelemente können bei Bedarf auch entfallen, sie sind für die Expression nicht essentiell. 


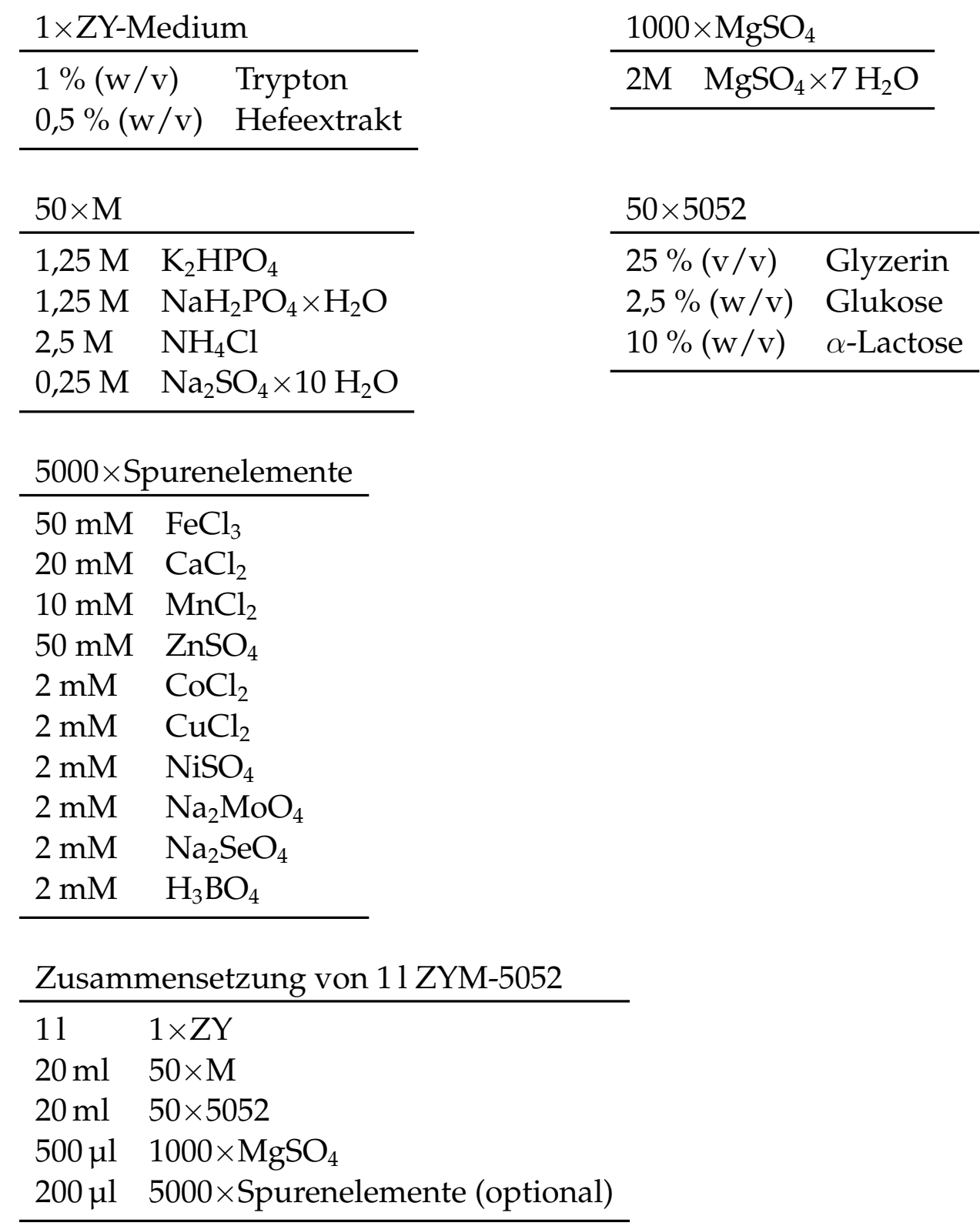

\subsubsection{Herstellung chemisch kompetenter Escherichia coli-Zellen}

Eine LB-Agarplatte wird mit dem gewünschten Zellstamm beimpft und über Nacht bei $37^{\circ} \mathrm{C}$ inkubiert. Eine einzelne Kolonie von dieser Agarplatte wird verwendet um $5 \mathrm{ml}$ LB-Medium anzuimpfen, die auch über Nacht bei $37^{\circ} \mathrm{C}$ inkubiert wird. Von dieser $5 \mathrm{ml}$ Vorkultur wird eine 1:500 Verdünnung in $500 \mathrm{ml}$ LB-Medium vorgenommen. Inkubiert wird diese bei $37^{\circ} \mathrm{C}$ bis zu einer $\mathrm{OD}_{600}$ von 0,6. Danach erfolgt die Zellernte durch Zentrifugation bei $3000 \times \mathrm{g}$ für 10 Minuten und $4{ }^{\circ} \mathrm{C}$. Das erhaltene Pellet wird in eiskaltem TFB1-Puffer resuspendiert und vor dem nächsten Schritt für 5 Minuten auf Eis gelassen. Die resuspendierten Zellen werden erneut für 10 Minuten bei $3000 \times \mathrm{g}$ und $4^{\circ} \mathrm{C}$ zentrifugiert. Das 
Zellpellet wird vorsichtig in $50 \mathrm{ml}$ eiskalten TFB2-Puffer resuspendiert und $\mathrm{zu}$ jeweils $50 \mu \mathrm{l}$ in $1,5 \mathrm{ml}$ Reaktionsgefäße aliquotiert. Diese Aliquote werden mit flüssigen Stickstoff gefroren und bei $-80^{\circ} \mathrm{C}$ gelagert.

\begin{tabular}{|c|c|}
\hline TFB1-Puffer & \\
\hline $30 \mathrm{mM}$ & Kaliumacetat $\mathrm{pH} 7,0$ \\
\hline $50 \mathrm{mM}$ & $\mathrm{MnCl}_{2}$ \\
\hline $10 \mathrm{mM}$ & $\mathrm{CaCl}_{2}$ \\
\hline 100 mM & $\mathrm{RbCl}_{2}$ \\
\hline $15 \%(\mathrm{v} / \mathrm{v})$ & Glyzerin \\
\hline
\end{tabular}

TFB2-Puffer

TFB1 wird mit 0,2 M Essigsäure auf einen $\mathrm{pH}$ von 5,8 eingestellt, TFB2 mit 1 $\mathrm{M} \mathrm{NaOH}$ auf $\mathrm{pH} 6,5$.

\subsubsection{Transformation chemisch kompetenter E. coli-Zellen}

Chemisch kompetente Escherichia coli-Zellen werden zunächst auf Eis aufgetaut. Die Transformation erfolgt durch Zugabe von 10 bis $100 \mu \mathrm{g}$ Plasmid-DNA zu $50 \mu$ l chemisch kompetenten Escherichia coli-Zellen. Die Zellen werden für 30 Minuten auf Eis inkubiert, dann für 1 Minute einem Hitzeschock bei $42{ }^{\circ} \mathrm{C}$ unterzogen und anschließend für 5 Minuten auf Eis gekühlt. Die abgekühlten Zellen werden nach Zugabe von $800 \mu$ LB-Medium 45 Minuten bei $37^{\circ} \mathrm{C}$ und 650 Upm inkubiert. Für die Ausplattierung und Selektion auf einer LB-Agar Platte mit Antibiotikum werden die Zellen für 1 Minuten bei $5000 \times \mathrm{g}$ und $4{ }^{\circ} \mathrm{C}$ zentrifugiert. Das Pellet wird in $100 \mu \mathrm{L}$ LB-Medium resuspendiert und auf der LB-Agar Platte ausplattiert. Die Platte wird über Nacht bei $37{ }^{\circ} \mathrm{C}$ inkubiert. Das eingeführte Plasmid enthält ein Gen mit einer Antibiotikaresistenz, die eine Selektion von transformierten und nicht-transformierten Zellen durch die Zugabe von Antibiotika ins Medium erlaubt.

\subsubsection{Herstellung von Glyzerin-Dauerkulturen}

Für die dauerhafte Lagerung von E. coli-Zellen werden $5 \mathrm{ml}$ LB-Medium mit dem zu lagernden Stamm angeimpft und über Nacht bei $37^{\circ} \mathrm{C}$ inkubiert. Aus dieser Kultur werden $400 \mu \mathrm{l}$ Zellsuspension mit $400 \mu 180$ \% (v/v) Glyzerin gemischt und mit flüssigen Stickstoff schockgefroren. Die Lagerung von GlyzerinDauerkulturen erfolgt bei $-80^{\circ} \mathrm{C}$. 


\section{Kapitel 6 | MATERIAL UND METHODEN}

\subsubsection{Präparation von Plasmid-DNA}

Für die Amplifikation von Plasmid-DNA wird diese in E. coli-XL1 Blue Zellen transformiert und die Zellen über Nacht bei $37^{\circ} \mathrm{C}$ angezogen. Die Präparation von Plasmid-DNA aus E. coli-Zellen erfolgt mit den QIAGEN Plasmid Mini Kit-System. Ausgangsmaterial für die Präparation sind $5 \mathrm{ml}$ Übernachtkultur des plasmidtragenden E. coli-Stamms. Es wird nach den Angaben des Herstellers vorgegangen. Die Vorgehensweise bei der Präparation von Plasmid-DNA ist hier kurz zusammengefasst. Die Zellen werden durch Zentrifugation geerntet und durch alkalische Lyse aufgeschlossen. Die Entfernung der Zelltrümmer geschieht durch Zentrifugation. Die Trennung von Plasmid-DNA von genomischer DNA erfolgt über eine Einwegsäule mit Silikamembran.

\subsubsection{Expression rekombinanter Proteine in E. coli}

Für die Expression von rekombinanten Proteinen in Escherichia coli wird zunächst das Gen in ein geeignetes Plasmid eingeführt. Dabei wird es so in das Plasmid integriert, dass es hinter einen Promoter liegt und der korrekte Leserahmen erhalten bleibt. Der Promoter steht unter der Kontrolle des lac-Operons womit die Expression des dahinterliegenden Gens über die Zugabe von Lactose oder einen künstlichen Induktor wie Isopropyl- $\beta$-D-thiogalactopyranosid (IPTG) steuerbar ist. In der vorliegenden Arbeit wird zusätlich zu der klassischen Induktion mit IPTG auch ein modifiziertes Autoinduktionssystem (Studier, 2005) verwendet.

\section{Expression in 2YT-Medium}

2YT-Medium wird 1:100 mit Übernacht-Kulturen angeimpft, bei $37^{\circ} \mathrm{C}$ und $220 \mathrm{Upm}$ bis zu einer $\mathrm{OD}_{600}$ von 0,5 - 1,0 inkubiert. Induktion der Proteinexpression geschieht durch Zugabe von 0,5-1 mM IPTG, danach wird auf eine Temperatur von $18^{\circ} \mathrm{C}$ runtergekühlt. Die Expression wird für 16-18 Stunden durchgeführt.

\section{Exression in ZYM5052-Medium (Variante 1)}

ZYM5052-Medium wird 1:100 mit Übernacht-Kulturen angeimpft, bei $37^{\circ} \mathrm{C}$ und $220 \mathrm{Upm}$ bis zu einer $\mathrm{OD}_{600}$ von $0,5-1,0$. Die Inkubation wird bei $18^{\circ} \mathrm{C}$ und 220 Upm für 48 Stunden fortgesetzt.

\section{Exression in ZYM5052-Medium (Variante 2)}

ZYM5052-Medium wird 1:100 mit Übernacht-Kulturen angeimpft und für 72 Stunden bei $16^{\circ} \mathrm{C}$ und 220 Upm inkubiert. 


\subsubsection{Zellernte und Aufschluss}

Zellen werden durch Zentrifugation für 20 Minuten bei $5000 \times \mathrm{g}$ und $4{ }^{\circ} \mathrm{C}$ geerntet. Das Pellet wird mit flüssigem Stickstoff eingefroren und bei $-80^{\circ} \mathrm{C}$ gelagert. Für den Aufschluss werden i.d.R. $1 \mathrm{~g}$ Pellet in $5 \mathrm{ml}$ Lysispuffer resuspendiert. Die Zusammensetzung des Lysispuffers hängt von dem zu isolierenden Protein ab und muss experimentell ermittelt werden. Der Zellaufschluss geschieht im Fluidizer (Microfluidics, Newton, USA) der eisgekühlt wird und vor dem Aufschluss mit dem verwendeten Lysispuffer äquilibriert wird. Bei einem Druck von 0,55 MPa werden die Zellen in 5-6 Zyklen aufgeschlossen. Das erhaltene Lysat wird in JA-20 Zentrifugenröhrchen überführt und für 30 Minuten bei $30000 \times \mathrm{g}$ und $4{ }^{\circ} \mathrm{C}$ zentrifugiert. Zur Analyse der Löslichkeit des Proteins im verwendeten Puffer, werden $50 \mu \mathrm{l}$ vom Überstand und resuspendierten Pellet mit $50 \mu \mathrm{l} 2 \times$ Laemmli-Puffer versetzt und nach 5 Minuten kochen bei $95^{\circ} \mathrm{C}$ auf einen SDS-PAGel analysiert (6.2.3.2). Sollen aus den Überstand löslichen Proteinen präpariert werden, so wird dieser noch mit einen $0,45 \mu \mathrm{m}$ Filter filtriert.

\subsubsection{Proteinbiochemische Methoden}

\subsubsection{Konzentrationsbestimmung von Proteinlösungen}

Für die Bestimmung der Proteinkonzentration in einer Lösung werden $20 \mu l$ dieser Lösung mit $980 \mu 1$ eines 1:5 verdünnten Bradfordreagenz (Bio-Rad, München) gemischt und 5 Minuten bei Raumtemperatur inkubiert. Für den Leerwert werden $20 \mu \mathrm{l}$ des Puffers in der das Protein gelöst ist mit $980 \mu \mathrm{l}$ eines 1:5 verdünnten Bradfordreagenz gemischt und auch für 5 Minuten bei Raumtemperatur inkubiert. Anschließend wird die $\mathrm{OD}_{595}$ der Probe gegen den Leerwert gemessen. Das Photometer wurde so kalibriert, das im Bereich von $\mathrm{OD}_{595}$ 0,1 - 0,9 die Absorption der Proteinkonzentration in $\mathrm{mg} / \mathrm{ml}$ entspricht.

\subsubsection{SDS-Polyacrylamidgelelektrophorese}

Für die analytische Größentrennung von Proteinen wird die diskontinuierliche SDS-Polyacrylamidgelelektrophorese (Laemmli, 1970) verwendet. Für die Durchführung einer SDS-PAGE wird pro Gel eine Glasplatte und eine Keramikplatte mit Ethanol gewaschen und staubfrei getrocknet. Auf die Keramikplatte wird jeweils am rechten und linken Rand ein Abstandshalter aufgelegt. Auf den Abstandshalter wird die Glasplatte aufgesetzt. Dieser Aufbau wird in eine Gießkammer für 4 Gele eingesetzt. Die Kammer wird bis $2 \mathrm{~cm}$ unterhalb des oberen Randes mit Trenngellösung aufgefüllt und mit Isopropanol überschichtet. Nach Polymerisierung des Trenngels wird das Isopropanol entfernt. Die Kammer wird bis zur oberen Kante mit Sammelgellösung gefüllt und pro Gel wird ein Kamm eingesetzt, der nach Polymerisierung entfernt wird.

Für die Elektrophorese wird ein Gel in eine Gelhalterung eingespannt und in die Laufkammer gesetzt. Das Reservoir der Laufkammer und der Gelhalterung werden mit Laufpuffer gefüllt. Zu analysierende Proben werden 1:1 (v/v) mit 
$2 \times$ Laemmli-Probenpuffer gemischt, für 5 Minuten bei $95^{\circ} \mathrm{C}$ gekocht und in die Geltaschen geladen.

\begin{tabular}{ll}
\multicolumn{2}{l}{ Trenngel 12,5\% } \\
\hline $12,5 \%(\mathrm{w} / \mathrm{v})$ & Acrylamid \\
$0,33 \%(\mathrm{w} / \mathrm{v})$ & Bisacrylamid \\
$0,375 \mathrm{M}$ & Tris $/ \mathrm{HCl} \mathrm{pH} \mathrm{8,8}$ \\
$0,1 \%(\mathrm{w} / \mathrm{v})$ & $\mathrm{SDS}$ \\
$0,1 \%(\mathrm{v} / \mathrm{v})$ & TEMED \\
$0,05 \%(\mathrm{w} / \mathrm{v})$ & $\left(\mathrm{NH}_{4}\right)_{2} \mathrm{~S}_{2} \mathrm{O}_{8}$ \\
\hline
\end{tabular}

\begin{tabular}{ll} 
Sammelgel & \\
\hline $5 \%(\mathrm{w} / \mathrm{v})$ & Acrylamid \\
$0,13 \%(\mathrm{w} / \mathrm{v})$ & Bisacrylamid \\
$0,125 \mathrm{M}$ & Tris/ $\mathrm{HCl} \mathrm{pH} 6,8$ \\
$0,1 \%(\mathrm{w} / \mathrm{v})$ & SDS \\
$0,1 \%(\mathrm{v} / \mathrm{v})$ & TEMED \\
$0,05 \%(\mathrm{w} / \mathrm{v})$ & $\left(\mathrm{NH}_{4}\right)_{2} \mathrm{~S}_{2} \mathrm{O}_{8}$ \\
\hline
\end{tabular}

\begin{tabular}{ll} 
Laufpuffer & \\
\hline $25 \mathrm{mM}$ & Tris/HCl \\
$192 \mathrm{mM}$ & Glycin \\
$0,1 \%(\mathrm{w} / \mathrm{v})$ & SDS \\
$0,1 \%(\mathrm{w} / \mathrm{v})$ & Bromphenolblau \\
$5 \%(\mathrm{v} / \mathrm{v})$ & 2-Mercaptoethanol \\
\hline
\end{tabular}

\begin{tabular}{ll}
$2 \times$ Laemmli-Probenpuffer \\
\hline $62,5 \mathrm{mM}$ & Tris $/ \mathrm{HCl}$ \\
$70 \mathrm{mM}$ & SDS \\
$50 \%(\mathrm{v} / \mathrm{v})$ & Glyzerin \\
\hline
\end{tabular}

Zum Anfärben von Proteinen in Polyacrylamidgelen wird Coomassie Brilliant Blue verwendet. Die untere Nachweisgrenze liegt bei 0,6 $\mu \mathrm{g} / \mathrm{cm}$ Gel. Nach der Elektrophorese wird das Polyacrylamidgel für eine Stunde in einem Färbebad geschwenkt. Entfärbt wird das Gel für 4-5 Stunden in Wasser.

\begin{tabular}{ll} 
Färbelösung & \\
\hline $10 \%(\mathrm{v} / \mathrm{v})$ & Ethanol \\
$5 \%(\mathrm{v} / \mathrm{v})$ & Essigsäure \\
$0,002 \%(\mathrm{w} / \mathrm{v})$ & Coomassie Brilliant Blue G/R 250
\end{tabular}

Zur Dokumentation werden entfärbte Gele in einem Scanner (AGFA Snapscan 50 oder Canon CanoScan 5600F) digitalisiert und im Dateiformat TIFF gespeichert.

\subsubsection{Einengen von Proteinlösung durch Zentrifugation}

Um Proteinlösungen zu konzentrieren werden diese in ein Gefäße überführt, dessen Boden eine Membran mit definierter Porengröße hat (Konzentrator). Durch Zentrifugation werden Proteine entsprechend ihrer Größe durch die Membran durchgelassen oder zurückgehalten. Kleinere Moleküle wie Wasser und gelöste Ionen werden auch durchgelassen. Durch die Wahl der Porengröße kann das Protein oberhalb der Membran eingeengt werden. Zentrifugiert wird je nach Art und Hersteller des Konzentrators bei $3000-4000 \times \mathrm{g}$ und $4^{\circ} \mathrm{C}$. Die Konzentration der Proteinlösung wird jeweils vor und nach dem Einengen bestimmt (6.2.3.1). 


\subsubsection{Spaltung von Proteinen durch Proteasen}

Die Verwendung von Proteasen in dieser Arbeit dient der Entfernung der GSToder MBP-Affinitätssequenz, die mit den Zielproteinen rekombinant fusioniert ist um sie über Affinitätschromatographie reinigen zu können (6.2.4). Zwischen dem Zielprotein und der Affinitätssequenz liegt eine Schnittstelle für die zu verwendende Protease. Zur Abtrennung der Affinitätssequenz werden 0,01 mg Protease pro $1 \mathrm{mg}$ Fusionsprotein zugegeben und für 16 Stunden bei $4{ }^{\circ} \mathrm{C}$ auf einem Taumelrollenmischer inkubiert. Die Effektivität der Spaltungsreaktion wird durch SDS-PAGE analysiert (6.2.3.2).

\subsubsection{Nachweis von Protein-Protein-Interaktionen}

Für den qualitativen Nachweis einer Bindung zwischen zwei Proteinen wird eines der beiden Proteine mit einer Affinitätssequenz versehen sein um es zu immobilisieren. In dieser Arbeit wird für diese Methode die Strep II-Markierung und entsprechend StrepTactin Sepharose (IBA, Göttingen) gewählt. Alle Schritte werden bei $20^{\circ} \mathrm{C}$ durchgeführt. $500 \mu \mathrm{g}$ Strep II-markiertes Protein wird zu $100 \mu \mathrm{l}$ StrepTactin Sepharose (äquilibriert mit Puffer-S: 10 mM HEPES pH 7,4 und 150 $\mathrm{mM} \mathrm{NaCl}$ ) gegeben und für 5 Minuten bei 400 Upm inkubiert. Nach Inkubation wird die Sepharose abzentrifugiert (2 Minuten, $400 \times \mathrm{g}$ ) und der Überstand entfernt. Es werden $200 \mu \mathrm{l}$ Puffer-S werden zugegeben und wieder für 5 Minuten bei 400 Upm inkubiert. Der Überstand wird wieder durch Zentrifugation (2 Minuten, $400 \times \mathrm{g}$ ) entfernt und die Sepharose so dreimal mit je $200 \mu \mathrm{l}$ Puffer-S gewaschen. $500 \mu \mathrm{g}$ des zweiten Proteins werden zur Sepharose gegeben und für 5 Minuten bei 400 Upm inkubiert. Es wird wie oben beschrieben dreimal mit je $200 \mu \mathrm{l}$ Puffer-S gewaschen und abschließend mit $100 \mu$ Puffer-E (Puffer-S mit 2,5 mM Desthiobiotin) eluiert. In einen weiteren Ansatz wird nur das zweite Protein zur StrepTactin Sepharose gegeben (Negativkontrolle). Es wird wie oben gewaschen und eluiert. Die Analyse der Eluate erfolgt mit SDS-PAGE (6.2.3.2).

\subsubsection{Chromatographische Methoden}

Alle chromatographischen Reingungen erfolgen an einem ÄKTA Prime oder ÄKTA Purifier System mit Fraktionssammler (Amersham Pharmacia Biotech, Freiburg). Chromatographiesystem und angeschlossene Säulen werden vor Verwendung in Wasser und dann in Puffer überführt. Zum Ende des Experiments werden beide Komponenten mit Wasser gespült und $20 \%$ Ethanol gelagert. Für die affinitätschromatographische Präparation von rekombinanten Proteinen aus E. coli, wird das in 6.2.2.7 beschriebene Lysat verwendet. Die Analyse der jeweiligen chromatographischen Methoden (ausser Umpufferung) erfolgt per SDS-PAGE (6.2.3.2). 


\section{Kapitel 6 MATERIAL UND METHODEN}

\subsubsection{Präparation von GST-Fusionsproteinen}

Die Isolierung von GST-Fusionsproteinen aus Lysat erfolgt durch immobilisiertes Glutathion an einer Säulenmatrix, der Glutathion-Sepharose 4B (GSH-Sepharose). An dieser Matrix wird das Fusionsprotein immobilisiert, während andere Proteine nicht an die Säulenmatrix binden bzw. durch Waschschritte entfernt werden. Die Elution des Fusionsproteins erfolgt durch Zugabe eines Puffers der 30 mM reduziertes Glutathion enthält.

\subsubsection{Präparation von $\mathrm{His}_{6}$-Fusionsproteinen}

Für die Reinigung von Proteinen mit einer N- oder C-terminalen $6 \times$ His-Sequenz wird eine Affinitätsmethode mit immobilisierten Metallchelatkomplexen (engl. immobilized metal ion affinity chromatography, IMAC) verwendet. Nach Auftragen der Probe und einen Waschschritt werden gebundene Proteine durch einen Imidazolgradienten eluiert. Alternativ kann auch ohne einen Gradienten direkt mit einen Puffer der 300-400 mM Imidazol enthält eluiert werden.

Die verwendeten Puffer dürfen kein EDTA enthalten, da EDTA ein Komplexbildner ist, der besonders stabile 1:1 Komplexe mit zweifach positiv geladenen Ionen (z.B. Ni ${ }^{2+}$ ) bildet. Diese werden dadurch wieder in die mobile Phase überführt und die Säule bindet keine Proteine mehr. Für die Reinigung von Proteinen mit Hexa-Histidin Sequenz wird in dieser Arbeit eine $5 \mathrm{ml}$ HisTrap Ni-NTA Sepharose-Säule (GE Healthcare, München) verwendet.

\subsubsection{Präparation von MBP-Fusionsproteinen}

Proteine die $\mathrm{N}$ - oder C-terminal mit dem Maltosebindeprotein (MBP) fusioniert sind, können mit einer Amylose-Matrix (NEB, Frankfurt am Main) präpariert werden. Zelllysat (6.2.2.7) wird auf das Material aufgetragen und mit 3-5 Säulenvolumen mit Puffer gewaschen. Das Amylose-Material wird entweder in einen XK 26/60-Gehäuse zusammen mit einen ÄKTA-Prime System oder in einer Econo-Pac Gravitationsflusssäule (Bio-Rad, München) verwendet. Geklärtes Zelllysat (6.2.2.7) wird aufgetragen und die Säule anschließend mit vier bis fünf Säulenvolumen Puffer gewaschen. Die Elution des Zielproteins erfolgt mit der Zugabe eines Puffers, der 10 mM Maltose enthält. Die Analyse aller Fraktionen erfolgt per SDS-PAGE (6.2.3.2).

\subsubsection{Präparation von Strep II-markierten Proteinen}

Proteine die mit der Strep II-Markierung (Aminosäureabfolge WSHPQFEK) versehen sind, können über eine mutierte Variante von Streptavidin (StrepTactin) aus Zelllysaten präpariert werden (Voss und Skerra, 1997). Für die Reinigung von Strep II-markierten Proteinen wird eine StrepTactin HP $5 \mathrm{ml}$ Säule verwendet. Nach Auftrag der Probe und Waschschritt wird das Ziel Protein durch einen Puffer, der 2,5 mM Desthiobiotin enthält, eluiert. Die Säule wird mit 2 Säulenvolumen $0.5 \mathrm{M} \mathrm{NaOH}$ regeneriert und anschliessend mit Wasser gespült. Die Lagerung der Säule erfolgt in $20 \%$ Ethanol bei $4{ }^{\circ} \mathrm{C}$. 


\subsubsection{Größenausschlusschromatographie}

Die Möglichkeit Proteine nativ und im präparativen Maßstab ihrer Größe nach aufzutrennen wird durch die Größenausschlusschromatographie realisiert. Dabei eluieren größe Moleküle früher und kleine Moleküle später von der Säule. In dieser Arbeit wird das Superdex 75 und Superdex 200-Material (Amersham Pharmacia Biotech) in XK 16/60- oder XK 26/60-Gehäusen verwendet. Das Probenvolummen wird vor dem Auftragen auf $\approx 5 \mathrm{ml}$ durch Einengen (6.2.3.3) reduziert.

\subsubsection{Umpuffern von Proteinlösungen}

Für die Entsalzung von Proteinlösungen werden in dieser Arbeit die Säulen HiPrep Desalting 26/10 und HiPrep Desalting $5 \mathrm{ml}$ (GE Healthcare, München) verwendet. Die Proteinkonzentration der zu entsalzenden Probe darf nicht höher als $70 \mathrm{mg} / \mathrm{ml}$ sein und das Volumen nicht $10 \mathrm{ml}$ überschreiten. Die Säule wird zur Verwendung mit dem Puffer äquilibriert in dem das Protein überführt werden soll. Danach wird die Proteinlösung aufgetragen und mit dem Äquilibrierungspuffer eluiert und fraktioniert.

\subsubsection{Expressions- und Reinigungsprotokolle}

Alle gereinigten Proteine, ausser dimeres VelB, werden im Puffer des letzten Reinigungsschrittes (i.d.R. Gelfiltration) bei $-80^{\circ} \mathrm{C}$ gelagert. Falls nicht anders angegeben erfolgt die Reinigung bei $20^{\circ} \mathrm{C}$.

\subsubsection{MBP-LaeA}

Für die Expression von MBP-LaeA wird Rosetta 2 (DE3) oder BL21 Star (DE3) mit den Plasmid pETM40-LaeA transformiert (6.2.2.3). Die Expression erfolgt wie in 6.2.2.6 beschrieben, mit 11 2YT-Medium. Die Reinigung erfolgt bei 4 oder $20^{\circ} \mathrm{C}$. Der Puffer für den Zellaufschluss enthält $10 \mathrm{mM}$ Tris $/ \mathrm{HCl}$ pH 8, $350 \mathrm{mM}$ $\mathrm{NaCl}$ und $1 \mathrm{mM}$ EDTA. Im ersten Schritt wird eine Amylose-Säule (6.2.4.3) verwendet. Das Eluat wird mit TEV-Protease behandelt (6.2.3.4), für 10 Minuten bei 4800 Upm zentrifugiert und der Überstand ankonzentriert (Endvolumen $\approx 5 \mathrm{ml}$ ). Die Reinigung wird abgeschlossen mit einer Superdex 75 26/60-Säule, äquilibriert mit $10 \mathrm{mM}$ Tris/ $\mathrm{HCl} \mathrm{pH} 8$ und $150 \mathrm{mM} \mathrm{NaCl}$.

\subsubsection{GST-LaeA91 und -101}

Für die Expression von GST-LaeA91 und -101 wird Rosetta 2 (DE3) mit den Plasmid pGEX6P1-LaeA91 bzw pGEX6P1-LaeA101 transformiert (6.2.2.3). Die Reinigung von GST-LaeA91 und -101 sind identisch, es wird daher nur die von GST-LaeA91 beschrieben. Die Zellen werden aufgeschlossen in $300 \mathrm{mM} \mathrm{NaCl}$, $1 \mathrm{mM}$ DTT und $30 \mathrm{mM}$ HEPES pH 7,4. Das Eluat des ersten Reinigungsschrittes, eine GSH-Sepharose (6.2.4.1), wird mit PreScission-Protease behandelt (6.2.3.4) und mit einer Superdex 75 16/60 Säule weitergereinigt. Diese Säule ist äquilibriert mit $400 \mathrm{mM} \mathrm{NaCl}, 1 \mathrm{mM}$ DTT und 10 mM HEPES pH 7,4. Fraktionen, 


\section{Kapitel 6 MATERIAL UND METHODEN}

die LaeA91 und teilweise noch GST enthalten, werden erneut auf eine GSHSepharose (400 mM NaCl, 1 mM DTT und 10 mM HEPES pH 7,4) aufgetragen. Der Durchfluss enthält reines LaeA91 und wird weiterverwendet.

\subsubsection{VelB}

Die Expression von VelB erfolgt in Rosetta 2 (DE3), transformiert mit pETM13VelB in 2YT-Medium nach 6.2.2.6. Für den Zellaufschluss und die weitere Reinigung wird ein Puffer mit mit $20 \mathrm{mM}$ Tris/ $\mathrm{HCl} \mathrm{pH} \mathrm{8,} 30 \mathrm{mM}$ Imidazol und $500 \mathrm{mM} \mathrm{NaCl}$ verwendet. Optional kann der Aufschlusspuffer noch $2 \mathrm{M} \mathrm{LiCl}$ enthalten. C-His ${ }_{6}$-VelB wird mit einer HisTrap $5 \mathrm{ml}$ Säule gereinigt (6.2.4.2). Das Eluat wird auf eine Superdex 200 16/60-Säule (6.2.4.5) aufgetragen, äquilibriert mit $10 \mathrm{mM}$ Tris/ $\mathrm{HCl} \mathrm{pH} 8$ und $150 \mathrm{mM} \mathrm{NaCl}$. Gereinigtes monomeres VelB wird bei $-80^{\circ} \mathrm{C}$ gelagert, dimeres nicht.

\subsubsection{VelB-mini}

VelB-mini wird in Rosetta 2 (DE3), transformiert mit pETM13-VelB-mini, in ZYM5052-Medium bei $16^{\circ} \mathrm{C}$ exprimiert (6.2.2.6, Variante 2). Die Zellen werden aufgeschlossen mit $35 \mathrm{mM}$ Imidazol, $400 \mathrm{mM} \mathrm{NaCl}$ und $35 \mathrm{mM}$ HEPES pH 7,5. Die Reinigung verläuft wie bei Volllängen-VelB (6.2.5.3). Der Puffer für die Gelfiltration enthält $10 \mathrm{mM}$ HEPES pH 7,5 und $150 \mathrm{mM} \mathrm{NaCl}$.

\subsubsection{VeA224S}

Die Expression erfolgt in Rosetta 2 (DE3), transformiert mit pETM13-VeA224S, in $500 \mathrm{ml}$ ZYM5052-Medium (6.2.2.6, Variante 2) bei $16^{\circ} \mathrm{C}$. Der Puffer für den Aufschluss und ersten Reinigungsschritt enthält 40 mM HEPES pH 7,4, 40 mM Imidazol und $400 \mathrm{mM} \mathrm{NaCl}$. Die Reinigung erfolgt über eine StrepTrap HP $5 \mathrm{ml}$ Säule (6.2.4.4). Das Eluat kann direkt für die Kristallisation verwendet werden, optional kann eine Gelfiltration (Superdex 200 16/60, 6.2.4.5) mit 10 mM HEPES $\mathrm{pH}$ 7,4 und $400 \mathrm{mM} \mathrm{NaCl}$ durchgeführt werden.

\subsubsection{Importin $\alpha \Delta \mathrm{IBB}-\mathrm{VeA}-K o m p l e x$}

VeA wird mit einer C-His ${ }_{6}$ - und Importin $\alpha \Delta \mathrm{IBB}$ mit einen N-GST-Affinitätssequenz in Rosetta 2 (DE3) exprimiert. Die Expressionen werden separat in 2YT (VeA) und ZYM5052-Medium (Importin $\alpha \Delta \mathrm{IBB}$ ) bei $16{ }^{\circ} \mathrm{C}$ durchgeführt (6.2.2.6). Die Zellpellets werden zusammen in $30 \mathrm{mM}$ Imidazol, $400 \mathrm{mM} \mathrm{NaCl}$ und $30 \mathrm{mM}$ HEPES pH 7,4 aufgeschlossen. Dieser Puffer wird für die ersten zwei Reinigungsschritte verwendet. Die Reinigung wird bei $4{ }^{\circ} \mathrm{C}$ durchgeführt. Als erster Reinigungsschritt wird ein HisTrap Säule verwendet (6.2.4.2). Das Eluat wird mit einer GSH-Sepharose weitergereinigt (6.2.4.1). Das Eluat der GSH-Sepharose wird mit PreScission-Protease (6.2.3.4) behandelt und auf eine Superdex 200 16/60-Säule aufgetragen (6.2.4.5). Diese Säule ist mit 10 mM HEPES $\mathrm{pH}$ 7,4 und $100 \mathrm{mM} \mathrm{NaCl}$ äquilibriert. 


\subsubsection{LaeA-VeA-VelB-Komplex}

Für die Rekonstituierung des Velvet-Komplex werden die Proteine separat wie bisher beschrieben in Rosetta 2 (DE3) exprimiert. Im Falle von LaeA wird MBPLaeA (pETM40-LaeA) verwendet. VelB enthält N-terminal eine $\mathrm{His}_{6}$-Sequenz (pETM11-VelB) die durch TEV-Protease entfernt werden kann. VeA enthält eine C-terminale $\mathrm{His}_{6}$-Sequenz ohne Proteaseschnittstelle (pETM13-VeA). Da zu diesem Zeitpunkt noch kein VelB-C-Strep II-Konstrukt vorlag, wurde diese Strategie gewählt. Volllängen-VeA wird wie VelB (6.2.5.3) exprimiert. Die Zellpellets werden vor den Aufschluss gemischt und zusammen in $30 \mathrm{mM}$ Imidazol, $300 \mathrm{mM}$ $\mathrm{NaCl}$ und $30 \mathrm{mM}$ Tris/ $\mathrm{HCl} \mathrm{pH}$ 7,5 aufgeschlossen. Dieser Puffer wird für die ersten zwei Reinigungsschritte verwendet. Die Reinigung wird bei $4{ }^{\circ} \mathrm{C}$ durchgeführt. Im ersten Schritt wird eine Amylose-Matrix verwendet (6.2.4.3). Das Eluat wird mit TEV-Protease behandelt (6.2.3.4) und der Überstand auf eine HisTrap $5 \mathrm{ml}$ Säule aufgetragen und eluiert (6.2.4.2). Das Eluat der HisTrap Säule wird per Gelfiltration (Superdex 200 26/60) weitergereinigt. Der Puffer enthält 300 mM $\mathrm{NaCl}$ und $20 \mathrm{mM}$ Tris/ $\mathrm{HCl} \mathrm{pH} 7,4$.

\subsubsection{VeA-VelB-Komplex}

VeA-VelB werden in Rosetta 2 (DE3), nach Transformation mit den Plasmiden pETM13-VeA und pPR-IBA1-VelB, ko-epxrimiert. Die Expression erfolgt in 2YTMedium bei $16^{\circ} \mathrm{C}$ (6.2.2.6). Für den Zellaufschluss, sowie die ersten zwei Reinigungsschritte, wird ein Puffer mit 30 mM Imidazol, $400 \mathrm{mM} \mathrm{NaCl}$ und $30 \mathrm{mM}$ HEPES pH 7,4 verwendet. Der erste Reinigungsschritt besteht aus einer HisTrap $5 \mathrm{ml}$ Säule (6.2.4.2). Das HisTrap-Eluat wird mit einer StrepTrap HP $5 \mathrm{ml}$ Säule weitergereinigt (6.2.4.4). Das Eluat der StrepTrap-Säule wird abschließend mit einer Superdex 200 16/60-Säule (6.2.4.5), äquilibriert mit 10 mM HEPES pH 7,4 und $300 \mathrm{mM} \mathrm{NaCl}$, gereinigt.

\subsubsection{VeA224S-VelB-mini-Komplex}

VeA224S und VelB-mini werden separat in Rosetta 2 (DE3), transformiert mit pETM13-VeA224S bzw. pETM13-VelB-mini, in ZYM5052-Autoinduktionsmedium (6.2.2.6, Variante 2) bei $16^{\circ} \mathrm{C}$ exprimiert. Zellpellets werden in $300 \mathrm{mM} \mathrm{NaCl}$, $35 \mathrm{mM}$ Imidazol und $35 \mathrm{mM}$ HEPES pH 7,4 gemischt und aufgeschlossen. Dieser Puffer wird auch für die ersten zwei Reinigungsschritte verwendet. Die Reinigung verläuft im weiteren wie beim Volllängen-VeA-VelB-Komplex (6.2.5.8). 


\section{Kapitel 6 MATERIAL UND METHODEN}

\subsubsection{VosA190S}

VosA190S wird in Rosetta 2 (DE3), transformiert mit pETM13-VosA190S, in ZYM5052-Medium (6.2.2.6, Variante 2) bei $16^{\circ} \mathrm{C}$ exprimiert. Für den Zellaufschluss und ersten Reinigungsschritt wird ein Puffer mit $30 \mathrm{mM}$ Imidazol, $400 \mathrm{mM} \mathrm{NaCl}$ und $30 \mathrm{mM}$ HEPES pH 7,4 verwendet. Das Eluat des ersten Reinigungsschrittes, eine StrepTrap HP $5 \mathrm{ml}$ Säule (6.2.4.4), wird für die weitere Reinigung auf eine Superdex 200 16/60-Säule aufgetragen. Diese ist äquilibriert mit $10 \mathrm{mM}$ HEPES pH 7,4 und $400 \mathrm{mM} \mathrm{NaCl}$.

\subsubsection{VosA190H}

Für die Expression von VosA190H wird Rosetta 2 (DE3) mit den Plasmid pETM13VosA190H transformiert. Die Expression ist identisch zu VosA190S (6.2.5.10). Für den Zellaufschluss und ersten Reinigungsschritt wird ein Puffer mit $30 \mathrm{mM}$ Imidazol, $400 \mathrm{mM} \mathrm{NaCl}$ und $30 \mathrm{mM}$ HEPES pH 7,4 verwendet. VosA190H wird zunächst mit einer HisTrap $5 \mathrm{ml}$ Säule (6.2.4.2) gereinigt. Das Eluat dieses Schrittes wird auf eine Superdex 200 16/60-Säule, äquilibriert mit 10 mM HEPES $\mathrm{pH} 7,4$ und $400 \mathrm{mM} \mathrm{NaCl}$, aufgetragen.

\subsubsection{VelB-VosA190S-Komplex}

VelB und VosA190S werden separat in Rosetta 2 (DE3), transformiert mit pETM13VelB bzw. pETM13-VosA190S, in ZYM5052-Medium bei $16^{\circ} \mathrm{C}$ exprimiert (6.2.2.6, Variante 2). Beim Zellaufschluss werden die beiden Pellets gemischt und in $30 \mathrm{mM}$ Imidazol, $400 \mathrm{mM} \mathrm{NaCl}$ und $30 \mathrm{mM}$ HEPES pH 7,4 aufgeschlossen. Die Reinigung erfolgt bei $4{ }^{\circ} \mathrm{C}$. Zunächst wird das Lysat mit einer HisTrap $5 \mathrm{ml}$ Säule gereinigt (6.2.4.2). Das erhaltene Eluat wird auf eine StrepTrap HP $5 \mathrm{ml}$ Säule aufgetragen (6.2.4.4). Das Eluat aus diesen Schritt wird abschließend mit einer Superdex 200 26/60-Säule gereinigt. Der verwendete Puffer enthält $10 \mathrm{mM}$ HEPES pH 7,4 und $400 \mathrm{mM} \mathrm{NaCl}$.

\subsubsection{VelB-mini-VosA190S-Komplex}

Beide Proteine werden separat in Rosetta 2 (DE3) exprimiert. Diese werden hierfür mit den Plasmiden pETM13-VelB-mini und pETM13-VosA190S transformiert. Die Expression wird in ZYM5052-Medium bei $16^{\circ} \mathrm{C}$ (6.2.2.6, Variante 2) durchgeführt. Zellpellets aus beiden Expressionen werden in $400 \mathrm{mM} \mathrm{NaCl}, 35 \mathrm{mM}$ Imidazol und $35 \mathrm{mM}$ HEPES pH 7,4 gemischt und aufgeschlossen. Die weitere Reinigung erfolgt wie beim Volllängen-VelB-VosA190S-Komplex (6.2.5.12). 


\subsubsection{Kristallographische Methoden}

\subsubsection{Hochdurchsatzkristallisation}

Für die Hochdurchsatzkristallisation wird ein Phoenix / RE - Pipettierroboter (Art Robbins, USA) verwendet. Dabei werden in MRC-96-3well-Platten zu 0,25 $\mu 1$ Proteinlösung 0,25 $\mu 1$ Kristallisationslösung gegeben. Das Reservoir enthält $40 \mu 1$ Kristallisationslösung. Es werden zwei Verhältnisse an Protein : Kristallisationslösung (1:1 und 2:1) und eine Kontrolle (Puffer : Kristallisationslösung 1:1) pipettiert. Die Platten werden bei 4 oder $20^{\circ} \mathrm{C}$ inkubiert und in zeitlichen Abständen automatisch vom Minstrel System (Rigaku, Japan) fotografiert.

\subsubsection{Optimierung von Kristallen}

Für die Optimierung von Kristallen werden die einzelnen Komponenten einer Kristallisationsbedingung variert, dafür werden Kristallisationsplatten mit $6 \times 4$ Kammern (Hampton Research, USA) verwendet. In jeder dieser Kammern ist zentral eine Säule mit einer kleinen Vertiefungen angebracht. Um die Säule herum liegt das Reservoir, welches mit jeweils $500 \mu$ l der Kristallisationsbedingungen gefüllt wird. In die Vertiefung der Säule wird $1 \mu l$ der Proteinlösung und $1 \mu l$ aus dem Reservoir (1:1 Mischung) pipettiert und leicht gemischt, d.h. der Tropfen sitzt über der Kristallisationsbedingung (engl. sitting drop). Abschliessend wird die Platte mit Klarsichtklebeband verschlossen, bei 4 oder $20^{\circ} \mathrm{C}$ inkubiert und regelmäßig auf Kristallbildung im Binokular untersucht.

\subsubsection{Kryo-Kristallographie}

Geeignete Proteinkristalle werden vor Vermessung durch Röntgenstrahlen mit einer Nylonschleife (engl. loop) geerntet, für wenige Sekunden in einen Kryopuffer getaucht und dann in flüssigen Stickstoff eingefroren. Der Kryopuffer besteht in der Regel aus der Kristallisationslösung und weiteren Reagenzien. In dieser Arbeit werden für PEG-basierte Kristallisationsbedingungen 12 \% (v/v) 1-4-Butandiol und für andere 20-30 \% Glyzerin verwendet. Durch diese Prozedur werden Eisbildung beim Einfrieren der Kristalle minimiert, die eine spätere Auswertung der Daten erschweren können. Auch kann sich Zusammensetzung des Kryopuffers auf das Beugungsverhalten von Röntgenstrahlen der Kristalle auswirken und ist daher von großer Bedeutung. 


\section{Kapitel 6 | MATERIAL UND METHODEN}

\subsubsection{Datensammlung}

In Nylonschleifen immobilisierte Proteinkristalle werden auf einen Goniometerkopf angebracht und mit Röntgenstrahlen vermessen. Es wird in der Regel bei 100 bis $110 \mathrm{~K}$ gemessen um Schäden am Kristall durch Strahlung zu minimieren. Der Datensatz von einen VosA190S-Kristallen wurde an einer Rigaku MicroMax 007-Anlage in der Abteilung Molekularen Strukturbiologie (Universität Göttingen, Göttingen) gemessen (MM007). Der Datensatz des VelB/VosA190SKomplexekristalls wurde am ESRF (Grenoble, Frankreich) an der Messstation ID23-2 gemessen (ID23-2). Die VeA224S Kristalle wurden am SLS (Villigen, Schweiz) an der Messstation X06SA gemessen. Die Details der Messungen sind in Tabelle 6.4 zusammengefasst.

Tabelle 6.4: Parameter bei der Datensammlung der VosA190S-, VelB-VosA190S und VeA224SKristalle

\begin{tabular}{|c|c|c|c|}
\hline & VosA190S & VelB/VosA190S & VeA224S \\
\hline Messstation & MM007 & ID23-2 & X06SA \\
\hline Wellenlänge [Å] & 1,5418 & 0.8726 & 0.8000 \\
\hline Temperatur [K] & 110 & 100 & 100 \\
\hline Detektor & mardtb 345 & $\operatorname{mar} M X-225$ & Pilatus 6M \\
\hline Detektorabstand [mm] & 140 & 120 & 600 \\
\hline Winkel $\left[{ }^{\circ}\right]$ & 103,7 & 100 & 125 \\
\hline Oszillation $\left[{ }^{\circ}\right]$ & 0,1 & 0,25 & 0,25 \\
\hline Belichtungszeit [s] & 240 & 1,5 & 0,2 \\
\hline
\end{tabular}

\subsubsection{Phasenbestimmung und Berechnung der Elektronendichtekarte}

Bei den im Beugungsexperiment gemessenen Intensitäten handelt es sich um die Miller Indizes hkl. Vom Kristall ausgehende Reflexe können mit den Strukturfaktor $\mathrm{F}(\mathrm{hkl})$ beschrieben werden, dessen Amplitude $|\mathrm{F}(\mathrm{hkl})|$ als Intensität gemessen wurde. Für die Berechnung der Elektronendichte $\rho$ gilt:

$$
\rho(x y z)=1 / V \sum_{h k l}\left|F_{h k l}\right| e^{-2 \pi i(h x+k y+l z)+i \alpha(h k l)}
$$

Da die Phasendifferenz $\alpha(h k l)$ nicht direkt gemessen werden kann, ist ein Strukturbestimmung lediglich mit den gemessenen Intensitäten nicht möglich. Dies ist das Phasenproblem der Kristallographie. Für die Lösung dieses Phasenproblems gibt es verschiedene Methoden. In dieser Arbeit werden die Methoden molekularer Ersatz (MR, engl. molecular replacement) und anomale Dispersion bei einer Wellenlänge (SAD, engl single wavelength anomalous dispersion) verwendet. Beim molekularer Ersatz wird die Struktur eines Proteins benötigt das mindestens eine Sequenzidentität von etwa 30 \% zum gesuchten Protein aufweist. Bei 
SAD werden Proteinkristalle generiert die ein geeignetes Schwermetall enthalten, wie z.B. Brom oder Iod. Das Absorptionsmaximum dieser Elemente liegt im Bereich der Röntgenstrahlen die in der Proteinkristallographie verwendet werden (0,8-2 §). Diese Eigenschaft führt dazu das bestimmte Symmetrieäquivalente Reflexe (Friedelpaare) im Beugungsmuster nicht die gleiche Intensität haben und somit nicht den Friedel Gesetz folgen. Durch diese unterschiedlichen Intensitäten lässt sich die Position der Schweratome in der Einheitszelle bestimmen und erste Abschätzungen zu den Phasen zu berechnen. Bei einer Wellenlänge von 1,5418 $\AA$ (Cu-Drehanode) hat das in dieser Arbeit verwendete Iodid einen imaginären Anteil am Streufaktor f"von 6,8 Elektronen (Dauter und Dauter, 2001). Grundsätzlich ist auch eine anderes Halogen, Schwermetall oder Element mit anomaler Streuung für die SAD/MAD-Phasierung denkbar. Der Vorteil bei Iodid liegt jedoch in der Möglichkeit die Phasen durch einen Datensatz an einer Drehanode zu erhalten. Brom-derivatisierte Kristalle können unter Anwendung von Synchrotronstrahlung (0,8-1 ̊) mit den MAD-Verfahren zur erfolgreichen Phasierung führen. In der Literatur gibt es auch einige Beispiele für die Phasierung nach dem SAD-Verfahren mit Bromid-Ionen (Devedjiev et al., 2000; Hoover et al., 2001; Wlodawer et al., 2001). Ob jedoch das SAD-Verfahren angewendet werden kann, ist zum Zeitpunkt der Datensammlung nicht klar und ist daher besonders für Brom-derivatisierte Kristalle nicht die bevorzugte Methode.

\subsubsection{Modellbau und Verfeinerung}

Für den automatischen Modellbau wird das ARP/wARP-Paket (Langer et al., 2008) verwendet. Der manuelle Modellbau erfolgt mit Coot (Emsley et al., 2010). Die Verfeinerung wird mit REFMAC5 (Murshudov et al., 2011) aus CCP4 (Winn et al., 2011), PHENIX (Adams et al., 2010) und CNS (Brünger et al., 1998) durchgeführt. Manueller Modellbau und Verfeinerung werden zyklisch durchgeführt mit den Ziel die errechneten Amplituden $\left(\left|F_{c}\right|\right)$ der Strukturfaktoren denen der beobachteten Amplituden $\left(\left|F_{o}\right|\right)$ so gut wie möglich anzunähern. Dabei dienen zwei Faktoren als Qualitätsindikatoren für die Übereinstimmung von Beobachtung und Interpretation, der kristallographische R-Faktor $\left(\mathrm{R}_{\text {cryst }}\right)$ und der freie R-Faktor $\left(R_{\text {free }}\right)$ (Brünger, 1992). Die Formel für die Berechnug der beiden R-Faktoren lautet:

$$
R=\frac{\sum|| F_{o}|-| F_{c}||}{\sum\left|F_{o}\right|}
$$

Beim kristallographischen R-Faktor werden sämtliche Reflexe in der Berechnung verwendet. Dahingegen werden beim freien R-Faktor nur ein Teil der Reflexe (5 $\%)$ verwendet die nicht in die Verfeinerung mit einbezogen wurden. Dieser Teil dient lediglich der Bewertung des Modells. Im Idealfall liegen beide Werte unter $20 \%$ und i.d.R. nicht mehr als 5\% voneinander weg.

Desweiteren wird beim Modellbau darauf geachtet, dass das Modell nicht gegen bekannte Werte für Bindungslängen und -winkel verstößt. Die Verwen- 


\section{Kapitel 6 | MATERIAL UND METHODEN}

dung von $\mathrm{F}_{\mathrm{o}}-\mathrm{F}_{\mathrm{c}}$ - und $2 \mathrm{~F}_{\mathrm{o}}-\mathrm{F}_{\mathrm{c}}$-Elektronendichtekarten erlaubt es grobe Fehler bei der Interpretation der Elektronendichte auszumachen.

\subsubsection{Strukturaufklärung von VosA190S}

Die Indizierung, Integration und Datenreduktion des VosA190S-Datensatzes erfolgt mit dem XDS-Paket (Kabsch, 2010), dabei wurden Friedel-Paare nicht gemittelt (Option: FRIEDEL' S_LAW=FALSE). Die Lokalisierung der Iodid-Ionen und Phasierung der Daten erfolgte mit SHELXC/D/E (Sheldrick, 2008), gesteuert über HKL2MAP (Pape und Schneider, 2004). Die relativ hohe Auflösung des VosA190S-Datensatzes erlaubte es den Großteil des Proteins automatisch durch ARP/wARP (Langer et al., 2008) bauen zu lassen. Fehlende bzw. falsch eingebaute Aminosäuren wurde manuell in Coot (Emsley et al., 2010) korrigiert bzw. ergänzt.

\subsubsection{Strukturaufklärung des VelB-VosA-Komplex}

Die Indizierung, Integration und Datenreduktion der gemessenen Daten vom VelB/VosA-Komplex wurde mit MOSFLM (Leslie, 2006) und SCALA aus dem CCP4-Paket (Winn et al., 2011) durchgeführt. Die Struktur des VelB-VosA-Komplexes wurde durch molekularen Ersatz mit Phaser (McCoy et al., 2007) von Dr. Piotr Neumann (Universität Göttingen) gelöst. Als Suchmodell wurde ein verkürztes VosA-Modell verwendet, das die Aminosäuren Ser 17 bis Asp 79 und Ala 86 bis Met 165 enthält. Es wurden zwei Moleküle in der assymetrischen Einheit gefunden. Die Struktur wurde per Hand mit Coot gebaut, mit CNS und PHENIX verfeinert und erlaubte schließlich die Identifizierung der beiden Proteine.

\subsubsection{Visualisierung und Oberflächenberechnungen}

Die Visualisierung der Modelle erfolgt mit Coot oder PyMOL. Oberflächenladungen werden mit PDB2PQR (Dolinsky et al., 2007) und APBS (Baker et al., 2001) berechnet und mit PyMOL dargestellt. Berechnung von Oberflächen erfolgt mit AreaImol und PISA aus dem CCP4-Paket (Winn et al., 2011). Interaktionen zwischen zwei Molekülen werden mit DIMPLOT aus dem LIGPLOT-Paket (Wallace et al., 1995), gesteuert mit 2D-GraLab (Zhou et al., 2009) ermittelt und dargestellt. 


\section{Literaturverzeichnis}

Adams, P. D., P. V. Afonine, G. Bunkóczi, V. B. Chen, I. W. Davis, N. Echols, J. J. Headd, L.W. Hung, G. J. Kapral, R. W. Grosse-Kunstleve, A. J. McCoy, N. W. Moriarty, R. Oeffner, R. J. Read, D. C. Richardson, J. S. Richardson, T. C. Terwilliger, und P. H. Zwart 2010. PHENIX: a comprehensive Python-based system for macromolecular structure solution. Acta crystallographica. Section D, Biological crystallography, 66(Pt 2):213-21.

Amlacher, S., P. Sarges, D. Flemming, V. van Noort, R. Kunze, D. P. Devos, M. Arumugam, P. Bork, und E. Hurt

2011. Insight into structure and assembly of the nuclear pore complex by utilizing the genome of a eukaryotic thermophile. Cell, 146(2):277-89.

Araújo-Bazán, L., S. Dhingra, J. Chu, J. Fernández-Martínez, A. M. Calvo, und E. a. Espeso

2009. Importin alpha is an essential nuclear import carrier adaptor required for proper sexual and asexual development and secondary metabolism in Aspergillus nidulans. Fungal genetics and biology : FG \& B, 46(6-7):506-15.

Archer, D. B., I. F. Connerton, und D. A. MacKenzie 2008. Filamentous fungi for production of food additives and processing aids. Advances in biochemical engineering/biotechnology, 111(February):99-147.

Axelrod, D. E., M. Gealt, und M. Pastushok 1973. Gene control of developmental competence in Aspergillus nidulans. Developmental biology, 34(1):9-15.

Baker, N. a., D. Sept, S. Joseph, M. J. Holst, und J. a. McCammon 2001. Electrostatics of nanosystems: application to microtubules and the ribosome. Proceedings of the National Academy of Sciences of the United States of America, 98(18):1003741.

Ballario, P., P. Vittorioso, a. Magrelli, C. Talora, a. Cabibbo, und G. Macino 1996. White collar-1, a central regulator of blue light responses in Neurospora, is a zinc finger protein. The EMBO journal, 15(7):1650-7.

Battye, T. G. G., L. Kontogiannis, O. Johnson, H. R. Powell, und A. G. W. Leslie 2011. iMOSFLM: a new graphical interface for diffraction-image processing with MOSFLM. Acta crystallographica. Section D, Biological crystallography, 67(Pt 4):271-81.

Bayram, O., C. Biesemann, S. Krappmann, P. Galland, und G. H. Braus 2008a. More than a repair enzyme: Aspergillus nidulans photolyase-like CryA is a 


\section{\begin{tabular}{l|l} 
Anhang & LITERATURVERZEICHNIS
\end{tabular}}

regulator of sexual development. Molecular biology of the cell, 19(8):3254-62.

Bayram, O. und G. H. Braus

2011. Coordination of secondary metabolism and development in fungi: the velvet family of regulatory proteins. FEMS microbiology reviews.

Bayram, O., S. Krappmann, M. Ni, J. W. Bok, K. Helmstaedt, O. Valerius, S. BrausStromeyer, N.-J. Kwon, N. P. Keller, J.-H. Yu, und G. H. Braus 2008b. VelB/VeA/LaeA complex coordinates light signal with fungal development and secondary metabolism. Science (New York, N.Y.), 320(5882):1504-6.

Bayram, O., S. Krappmann, S. Seiler, N. Vogt, und G. H. Braus 2008c. Neurospora crassa ve-1 affects asexual conidiation. Fungal genetics and biology: $F G \mathcal{E} B, 45(2): 127-38$.

Bhatnagar, D., J. Yu, und K. C. Ehrlich 2002. Toxins of filamentous fungi. Chemical immunology, 81:167-206.

Blumenstein, A., K. Vienken, R. Tasler, J. Purschwitz, D. Veith, N. Frankenberg-Dinkel, und R. Fischer 2005. The Aspergillus nidulans phytochrome FphA represses sexual development in red light. Current biology : $C B, 15(20): 1833-8$.

Bok, J. W., S. A. Balajee, K. A. Marr, D. Andes, K. F. Nielsen, J. C. Frisvad, und N. P. Keller 2005. LaeA, a regulator of morphogenetic fungal virulence factors. Eukaryotic cell, 4(9):1574-82.

Bok, J. W. und N. P. Keller 2004. LaeA, a regulator of secondary metabolism in Aspergillus spp. Eukaryotic cell, 3(2):527-35.

Bok, J. W., D. Noordermeer, S. P. Kale, und N. P. Keller 2006. Secondary metabolic gene cluster silencing in Aspergillus nidulans. Molecular microbiology, 61(6):1636-45.

Bonfante, P.

2003. Plants, mycorrhizal fungi and endobacteria: a dialog among cells and genomes. The Biological bulletin, 204(2):215-20.

Borel, J. F., C. Feurer, H. U. Gubler, und H. Stähelin 1976. Biological effects of cyclosporin A: a new antilymphocytic agent. Agents and actions, 6(4):468-75.

Bramley, P. M. und B. H. Davies

1975. Carotene biosynthesis by cell extracts of mutants of Phycomyces blakesleeanus. Phytochemistry, 14(2):463-469.

Brandt, W. H.

1953. Zonation in a prolineless strain of Neurospora. Mycoligia, 45(2):194-208.

Braus, G. H., S. Krappmann, und S. E. Eckert

2002. Molecular Biology of Fungal Development. New York: Marcel Dekker Inc. 
Brosius, J. und R. Chen

1976. The primary structure of protein L16 located at the peptidyltransferase center of Escherichia coli ribosomes. FEBS letters, 68(1):105-9.

Brünger, A. T.

1992. Free R value: a novel statistical quantity for assessing the accuracy of crystal structures. Nature, 355(6359):472-5.

Brünger, A. T., P. D. Adams, G. M. Clore, W. L. DeLano, P. Gros, R. W. Grosse-Kunstleve, J. S. Jiang, J. Kuszewski, M. Nilges, N. S. Pannu, R. J. Read, L. M. Rice, T. Simonson, und G. L. Warren

1998. Crystallography \& NMR system: A new software suite for macromolecular structure determination. Acta crystallographica. Section D, Biological crystallography, 54(Pt 5):905-21.

Bryson, K., L. J. McGuffin, R. L. Marsden, J. J. Ward, J. S. Sodhi, und D. T. Jones 2005. Protein structure prediction servers at University College London. Nucleic acids research, 33(Web Server issue):W36-8.

Casselton, L. und M. Zolan

2002. The art and design of genetic screens: filamentous fungi. Nature reviews. Genetics, 3(9):683-97.

Cerdá-Olmedo, E.

2001. Phycomyces and the biology of light and color. FEMS microbiology reviews, 25(5):503-12.

Champe, S. P. und A. A. El-Zayat

1989. Isolation of a sexual sporulation hormone from Aspergillus nidulans. Journal of bacteriology, 171(7):3982-8.

Champe, S. P., P. Rao, und A. Chang

1987. An endogenous inducer of sexual development in Aspergillus nidulans. Journal of general microbiology, 133(5):1383-7.

Chen, T., T. L. Muratore, C. E. Schaner-Tooley, J. Shabanowitz, D. F. Hunt, und I. G. Macara

2007. N-terminal alpha-methylation of RCC1 is necessary for stable chromatin association and normal mitosis. Nature cell biology, 9(5):596-603.

Chen, V. B., W. B. Arendall, J. J. Headd, D. A. Keedy, R. M. Immormino, G. J. Kapral, L. W. Murray, J. S. Richardson, und D. C. Richardson

2010. MolProbity: all-atom structure validation for macromolecular crystallography. Acta crystallographica. Section D, Biological crystallography, 66(Pt 1):12-21.

Cheng, X., R. E. Collins, und X. Zhang

2005. Structural and sequence motifs of protein (histone) methylation enzymes. Annual review of biophysics and biomolecular structure, 34:267-94.

Crosthwaite, S. K., J. J. Loros, und J. C. Dunlap

1995. Light-induced resetting of a circadian clock is mediated by a rapid increase in frequency transcript. Cell, 81(7):1003-12. 


\section{\begin{tabular}{l|l} 
Anhang & LITERATURVERZEICHNIS
\end{tabular}}

Dauter, Z. und M. Dauter

2001. Entering a new phase: using solvent halide ions in protein structure determination. Structure (London, England : 1993), 9(2):R21-6.

De Lucca, A. J.

2007. Harmful fungi in both agriculture and medicine. Revista iberoamericana de micología : órgano de la Asociación Española de Especialistas en Micología, 24(1):3-13.

Devedjiev, Y., Z. Dauter, S. R. Kuznetsov, T. L. Jones, und Z. S. Derewenda 2000. Crystal structure of the human acyl protein thioesterase I from a single X-ray data set to 1.5 A. Structure (London, England : 1993), 8(11):1137-46.

Dolinsky, T. J., P. Czodrowski, H. Li, J. E. Nielsen, J. H. Jensen, G. Klebe, und N. a. Baker 2007. PDB2PQR: expanding and upgrading automated preparation of biomolecular structures for molecular simulations. Nucleic acids research, 35(Web Server issue):W5225.

Dong, A., X. Xu, A. M. Edwards, C. Chang, M. Chruszcz, M. Cuff, M. Cymborowski, R. Di Leo, O. Egorova, E. Evdokimova, E. Filippova, J. Gu, J. Guthrie, A. Ignatchenko, A. Joachimiak, N. Klostermann, Y. Kim, Y. Korniyenko, W. Minor, Q. Que, A. Savchenko, T. Skarina, K. Tan, A. Yakunin, A. Yee, V. Yim, R. Zhang, H. Zheng, M. Akutsu, C. Arrowsmith, G. V. Avvakumov, A. Bochkarev, L.-G. Dahlgren, S. Dhe-Paganon, S. Dimov, L. Dombrovski, P. Finerty, S. Flodin, A. Flores, S. Gräslund, M. Hammerström, M. D. Herman, B.-S. Hong, R. Hui, I. Johansson, Y. Liu, M. Nilsson, L. Nedyalkova, P. Nordlund, T. Nyman, J. Min, H. Ouyang, H.-w. Park, C. Qi, W. Rabeh, L. Shen, Y. Shen, D. Sukumard, W. Tempel, Y. Tong, L. Tresagues, M. Vedadi, J. R. Walker, J. Weigelt, M. Welin, H. Wu, T. Xiao, H. Zeng, und H. Zhu

2007. In situ proteolysis for protein crystallization and structure determination. Nature methods, 4(12):1019-21.

Emsley, P., B. Lohkamp, W. G. Scott, und K. Cowtan 2010. Features and development of Coot. Acta crystallographica. Section D, Biological crystallography, 66(Pt 4):486-501.

Etxebeste, O., A. Garzia, E. a. Espeso, und U. Ugalde 2010. Aspergillus nidulans asexual development: making the most of cellular modules. Trends in microbiology, 18(12):569-76.

Fan, C. M. und T. Maniatis 1991. Generation of p50 subunit of NF-kappa B by processing of p105 through an ATP-dependent pathway. Nature, 354(6352):395-8.

Fox, J. D., R. B. Kapust, und D. S. Waugh

2001. Single amino acid substitutions on the surface of Escherichia coli maltose-binding protein can have a profound impact on the solubility of fusion proteins. Protein science : a publication of the Protein Society, 10(3):622-30.

Froehlich, A. C., Y. Liu, J. J. Loros, und J. C. Dunlap 2002. White Collar-1, a circadian blue light photoreceptor, binding to the frequency promoter. Science (New York, N.Y.), 297(5582):815-9. 
Galagan, J. E., S. E. Calvo, C. Cuomo, L.-J. Ma, J. R. Wortman, S. Batzoglou, S.-I. Lee, M. Baştürkmen, C. C. Spevak, J. Clutterbuck, V. Kapitonov, J. Jurka, C. Scazzocchio, M. Farman, J. Butler, S. Purcell, S. Harris, G. H. Braus, O. Draht, S. Busch, C. D'Enfert, C. Bouchier, G. H. Goldman, D. Bell-Pedersen, S. Griffiths-Jones, J. H. Doonan, J. Yu, K. Vienken, A. Pain, M. Freitag, E. U. Selker, D. B. Archer, M. a. Peñalva, B. R. Oakley, M. Momany, T. Tanaka, T. Kumagai, K. Asai, M. Machida, W. C. Nierman, D. W. Denning, M. Caddick, M. Hynes, M. Paoletti, R. Fischer, B. Miller, P. Dyer, M. S. Sachs, S. a. Osmani, und B. W. Birren

2005. Sequencing of Aspergillus nidulans and comparative analysis with A. fumigatus and A. oryzae. Nature, 438(7071):1105-15.

Ganchi, P. A., S. C. Sun, W. C. Greene, und D. W. Ballard 1992. I kappa B/MAD-3 masks the nuclear localization signal of NF-kappa B p65 and requires the transactivation domain to inhibit NF-kappa B p65 DNA binding. Molecular biology of the cell, 3(12):1339-52.

Gouet, P., E. Courcelle, D. I. Stuart, und F. Métoz

1999. ESPript: analysis of multiple sequence alignments in PostScript. Bioinformatics (Oxford, England), 15(4):305-8.

Hamahata, A., Y. Takata, T. Gomi, und M. Fujioka 1996. Probing the S-adenosylmethionine-binding site of rat guanidinoacetate methyltransferase. Effect of site-directed mutagenesis of residues that are conserved across mammalian non-nucleic acid methyltransferases. The Biochemical journal, 317 ( Pt 1:141-5.

Han, K., D. Lee, J. Kim, M. Kim, K. Han, W. Kim, Y. Park, H. Kim, und D. Han 2003. Environmental factors affecting development of Aspergillus nidulans. JOURNAL OF MICROBIOLOGY-SEOUL-, 41(1):34-40.

Hawksworth, D.

1991. The fungal dimension of biodiversity: magnitude, significance, and conservation. Mycological Research, 95(6):641-655.

He, Q., P. Cheng, Y. Yang, L. Wang, K. H. Gardner, und Y. Liu 2002. White collar-1, a DNA binding transcription factor and a light sensor. Science (New York, N.Y.), 297(5582):840-3.

Hertel, L. a., C. J. Bayne, und E. S. Loker 2002. The symbiont Capsaspora owczarzaki, nov. gen. nov. sp., isolated from three strains of the pulmonate snail Biomphalaria glabrata is related to members of the Mesomycetozoea. International journal for parasitology, 32(9):1183-91.

Hogenesch, J. B. und H. R. Ueda 2011. Understanding systems-level properties: timely stories from the study of clocks. Nature reviews. Genetics, 12(6):407-16.

Holm, L., S. Kääriäinen, C. Wilton, und D. Plewczynski 2006. Using Dali for structural comparison of proteins. Current protocols in bioinformatics / editoral board, Andreas D. Baxevanis ... [et al.], Chapter 5:Unit 5.5. 


\section{\begin{tabular}{l|l} 
Anhang & LITERATURVERZEICHNIS
\end{tabular}}

Holm, L. und P. Rosenström

2010. Dali server: conservation mapping in 3D. Nucleic acids research, 38(Web Server issue):W545-9.

Hoover, D. M., O. Chertov, und J. Lubkowski

2001. The structure of human beta-defensin-1: new insights into structural properties of beta-defensins. The Journal of biological chemistry, 276(42):39021-6.

Huang, D.-B., D. Vu, und G. Ghosh

2005. NF-kappaB RelB forms an intertwined homodimer. Structure (London, England: 1993), 13(9):1365-73.

Huxford, T. und G. Ghosh

2009. A structural guide to proteins of the NF-kappaB signaling module. Cold Spring Harbor perspectives in biology, 1(3):a000075.

Idnurm, A., J. Rodríguez-Romero, L. M. Corrochano, C. Sanz, E. a. Iturriaga, A. P. Eslava, und J. Heitman

2006. The Phycomyces madA gene encodes a blue-light photoreceptor for phototropism and other light responses. Proceedings of the National Academy of Sciences of the United States of America, 103(12):4546-51.

Kabsch, W.

2010. XDS. Acta crystallographica. Section D, Biological crystallography, 66(Pt 2):125-32.

Käfer, E.

1965. Origins of translocations in Aspergillus nidulans. Genetics, 52(1):217-32.

Kantardjieff, K. A. und B. Rupp

2003. Matthews coefficient probabilities: Improved estimates for unit cell contents of proteins, DNA, and protein-nucleic acid complex crystals. Protein science : a publication of the Protein Society, 12(9):1865-71.

Kato, N., W. Brooks, und A. M. Calvo

2003. The expression of sterigmatocystin and penicillin genes in Aspergillus nidulans is controlled by veA, a gene required for sexual development. Eukaryotic cell, 2(6):117886.

Keller, N. P., G. Turner, und J. W. Bennett

2005. Fungal secondary metabolism - from biochemistry to genomics. Nature reviews. Microbiology, 3(12):937-47.

Kim, H.-S., K.-Y. Han, K.-J. Kim, D.-M. Han, K.-Y. Jahng, und K.-S. Chae 2002. The veA gene activates sexual development in Aspergillus nidulans. Fungal Genetics and Biology, 37(1):72-80.

Krissinel, E. und K. Henrick 2007. Inference of macromolecular assemblies from crystalline state. Journal of molecular biology, 372(3):774-97.

Laemmli, U. K.

1970. Cleavage of Structural Proteins during the Assembly of the Head of Bacteriophage T4. Nature, 227(5259):680-685. 
Langer, G., S. X. Cohen, V. S. Lamzin, und A. Perrakis

2008. Automated macromolecular model building for X-ray crystallography using ARP/wARP version 7. Nature protocols, 3(7):1171-9.

Larkin, M. a., G. Blackshields, N. P. Brown, R. Chenna, P. a. McGettigan, H. McWilliam, F. Valentin, I. M. Wallace, A. Wilm, R. Lopez, J. D. Thompson, T. J. Gibson, und D. G. Higgins

2007. Clustal W and Clustal X version 2.0. Bioinformatics (Oxford, England), 23(21):29478.

Latimer, M., M. K. Ernst, L. L. Dunn, M. Drutskaya, und N. R. Rice 1998. The N-terminal domain of IkappaB alpha masks the nuclear localization signal(s) of p50 and c-Rel homodimers. Molecular and cellular biology, 18(5):2640-9.

Leslie, A. G. W.

2006. The integration of macromolecular diffraction data. Acta crystallographica. Section D, Biological crystallography, 62(Pt 1):48-57.

Levinson, G. und G. A. Gutman 1987. Slipped-strand mispairing: a major mechanism for DNA sequence evolution. Molecular biology and evolution, 4(3):203-21.

Liu, Y. und D. Bell-Pedersen

2006. Circadian rhythms in Neurospora crassa and other filamentous fungi. Eukaryotic cell, 5(8):1184-93.

Marchler-Bauer, A., S. Lu, J. B. Anderson, F. Chitsaz, M. K. Derbyshire, C. DeWeese-Scott, J. H. Fong, L. Y. Geer, R. C. Geer, N. R. Gonzales, M. Gwadz, D. I. Hurwitz, J. D. Jackson, Z. Ke, C. J. Lanczycki, F. Lu, G. H. Marchler, M. Mullokandov, M. V. Omelchenko, C. L. Robertson, J. S. Song, N. Thanki, R. a. Yamashita, D. Zhang, N. Zhang, C. Zheng, und S. H. Bryant

2011. CDD: a Conserved Domain Database for the functional annotation of proteins. Nucleic acids research, 39(Database issue):D225-9.

Matthews, B. W.

1968. Solvent content of protein crystals. Journal of molecular biology, 33(2):491-7.

McCoy, A. J., R. W. Grosse-Kunstleve, P. D. Adams, M. D. Winn, L. C. Storoni, und R. J. Read

2007. Phaser crystallographic software. Journal of applied crystallography, 40(Pt 4):658674.

Mooney, J. L. und L. N. Yager

1990. Light is required for conidiation in Aspergillus nidulans. Genes $\mathcal{E}$ Development, 4(9):1473-1482.

Müller, C. W., F. A. Rey, M. Sodeoka, G. L. Verdine, und S. C. Harrison 1995. Structure of the NF-kappa B p50 homodimer bound to DNA. Nature, 373(6512):311-7.

Mullis, K., F. Faloona, S. Scharf, R. Saiki, G. Horn, und H. Erlich 1986. Specific enzymatic amplification of DNA in vitro: the polymerase chain reaction. 


\section{\begin{tabular}{l|l} 
Anhang & LITERATURVERZEICHNIS
\end{tabular}}

Cold Spring Harbor symposia on quantitative biology, $51 \mathrm{Pt}$ 1:263-73.

Murshudov, G. N., P. Skubák, A. a. Lebedev, N. S. Pannu, R. a. Steiner, R. a. Nicholls, M. D. Winn, F. Long, und A. a. Vagin

2011. REFMAC5 for the refinement of macromolecular crystal structures. Acta crystallographica. Section D, Biological crystallography, 67(Pt 4):355-67.

Newman, J., D. Egan, T. S. Walter, R. Meged, I. Berry, M. Ben Jelloul, J. L. Sussman, D. I. Stuart, und A. Perrakis

2005. Towards rationalization of crystallization screening for small- to medium-sized academic laboratories: the PACT/JCSG+ strategy. Acta crystallographica. Section D, Biological crystallography, 61(Pt 10):1426-31.

$\mathrm{Ni}, \mathrm{M}$. und J.-H. Yu

2007. A novel regulator couples sporogenesis and trehalose biogenesis in Aspergillus nidulans. PloS one, 2(10):e970.

Nützmann, H.-W., Y. Reyes-Dominguez, K. Scherlach, V. Schroeckh, F. Horn, A. Gacek, J. Schümann, C. Hertweck, J. Strauss, und A. a. Brakhage

2011. Bacteria-induced natural product formation in the fungus Aspergillus nidulans requires Saga/Ada-mediated histone acetylation. Proceedings of the National Academy of Sciences of the United States of America, Pp. 1-6.

Oeckinghaus, A. und S. Ghosh

2009. The NF-kappaB family of transcription factors and its regulation. Cold Spring Harbor perspectives in biology, 1(4):a000034.

Pape, T. und T. R. Schneider

2004. HKL2MAP : a graphical user interface for macromolecular phasing with SHELX programs. Journal of Applied Crystallography, 37(5):843-844.

Perutz, M. F., T. Johnson, M. Suzuki, und J. T. Finch

1994. Glutamine repeats as polar zippers: their possible role in inherited neurodegenerative diseases. Proceedings of the National Academy of Sciences of the United States of America, 91(12):5355-8.

Pittendrigh, C. S., V. G. Bruce, N. S. Rosenweig, und M. L. Rubin 1959. Growth Patterns in Neurospora: A Biological Clock in Neurospora. Nature, 184(4681):169-170.

Poljak, R. J., L. M. Amzel, H. P. Avey, B. L. Chen, R. P. Phizackerley, und F. Saul 1973. Three-dimensional structure of the Fab' fragment of a human immunoglobulin at 2,8-A resolution. Proceedings of the National Academy of Sciences of the United States of America, 70(12):3305-10.

Price-Lloyd, N., M. Elvin, und C. Heintzen 2005. Synchronizing the Neurospora crassa circadian clock with the rhythmic environment. Biochemical Society transactions, 33(Pt 5):949-52.

Purschwitz, J., S. Müller, und R. Fischer 2009. Mapping the interaction sites of Aspergillus nidulans phytochrome FphA with the global regulator VeA and the White Collar protein LreB. Molecular genetics and 
genomics : $M G G, 281(1): 35-42$.

Purschwitz, J., S. Müller, C. Kastner, M. Schöser, H. Haas, E. a. Espeso, A. Atoui, A. M. Calvo, und R. Fischer

2008. Functional and physical interaction of blue- and red-light sensors in Aspergillus nidulans. Current biology : $C B, 18(4): 255-9$.

Qian, C. und M.-M. Zhou

2006. SET domain protein lysine methyltransferases: Structure, specificity and catalysis. Cellular and molecular life sciences : CMLS, 63(23):2755-63.

Radaev, S., S. Li, und P. D. Sun 2006. A survey of protein-protein complex crystallizations. Acta crystallographica. Section D, Biological crystallography, 62(Pt 6):605-12.

Reedy, J. L., R. J. Bastidas, und J. Heitman 2007. The virulence of human pathogenic fungi: notes from the South of France. Cell host $\mathcal{E}$ microbe, 2(2):77-83.

Richarme, G. 1982. Associative properties of the galactose binding protein and maltose binding protein. Biochemical and Biophysical Research Communications, 105(2):476-481.

Rockwell, N. C., Y.-S. Su, und J. C. Lagarias 2006. Phytochrome structure and signaling mechanisms. Annual review of plant biology, 57(January):837-58.

Rodriguez-Romero, J., M. Hedtke, C. Kastner, S. Müller, und R. Fischer 2010. Fungi, hidden in soil or up in the air: light makes a difference. Annual review of microbiology, 64:585-610.

Rogers, S., R. Wells, und M. Rechsteiner 1986. Amino acid sequences common to rapidly degraded proteins: the PEST hypothesis. Science (New York, N.Y.), 234(4774):364-8.

Ruiz-Trillo, I. n., G. Burger, P. W. H. Holland, N. King, B. F. Lang, A. J. Roger, und M. W. Gray

2007. The origins of multicellularity: a multi-taxon genome initiative. Trends in genetics : TIG, 23(3):113-8.

Ruiz-Trillo, I. n., Y. Inagaki, L. A. Davis, S. Sperstad, B. Landfald, und A. J. Roger 2004. Capsaspora owczarzaki is an independent opisthokont lineage. Current biology: CB, 14(22):R946-7.

Ruiz-Trillo, I. n., A. J. Roger, G. Burger, M. W. Gray, und B. F. Lang 2008. A phylogenomic investigation into the origin of metazoa. Molecular biology and evolution, 25(4):664-72.

Sancar, A.

2003. Structure and function of DNA photolyase and cryptochrome blue-light photoreceptors. Chemical reviews, 103(6):2203-37. 


\section{\begin{tabular}{l|l} 
Anhang & LITERATURVERZEICHNIS
\end{tabular}}

Sanchez, J. F., Y.-M. Chiang, und C. C. C. Wang 2008. Diversity of polyketide synthases found in the Aspergillus and Streptomyces genomes. Molecular pharmaceutics, 5(2):226-33.

Sarikaya Bayram, O., O. Bayram, O. Valerius, H. S. Park, S. Irniger, J. Gerke, M. Ni, K.-H. Han, J.-H. Yu, und G. H. Braus

2010. LaeA control of velvet family regulatory proteins for light-dependent development and fungal cell-type specificity. PLoS genetics, 6(12):e1001226.

Scamardella, J. M.

1999. Not plants or animals: a brief history of the origin of Kingdoms Protozoa, Protista and Protoctista. International microbiology : the official journal of the Spanish Society for Microbiology, 2(4):207-16.

Sebé-Pedrós, A., A. de Mendoza, B. F. Lang, B. M. Degnan, und I. n. Ruiz-Trillo 2011. Unexpected repertoire of metazoan transcription factors in the unicellular holozoan Capsaspora owczarzaki. Molecular biology and evolution, 28(3):1241-54.

Selby, C. P. und A. Sancar

2006. A cryptochrome/photolyase class of enzymes with single-stranded DNAspecific photolyase activity. Proceedings of the National Academy of Sciences of the United States of America, 103(47):17696-700.

Shaaban, M. I., J. W. Bok, C. Lauer, und N. P. Keller 2010. Suppressor mutagenesis identifies a velvet complex remediator of Aspergillus nidulans secondary metabolism. Eukaryotic cell, 9(12):1816-24.

Shalchian-Tabrizi, K., M. a. Minge, M. Espelund, R. Orr, T. Ruden, K. S. Jakobsen, und T. Cavalier-Smith

2008. Multigene phylogeny of choanozoa and the origin of animals. PloS one, 3(5):e2098.

Sheldrick, G. M.

2008. A short history of SHELX. Acta crystallographica. Section A, Foundations of crystallography, 64(Pt 1):112-22.

Skromne, I., O. Sánchez, und J. Aguirre

1995. Starvation stress modulates the expression of the Aspergillus nidulans brlA regulatory gene. Microbiology (Reading, England), 141 ( Pt 1:21-8.

Stinnett, S. M., E. a. Espeso, L. Cobeño, L. Araújo-Bazán, und A. M. Calvo 2007. Aspergillus nidulans VeA subcellular localization is dependent on the importin alpha carrier and on light. Molecular microbiology, 63(1):242-55.

Studier, F. W.

2005. Protein production by auto-induction in high-density shaking cultures. Protein Expression and Purification, 41(1):207-234.

Stura, E. A., G. Nemerow, und I. Wilson

1992. Strategies in the crystallization of glycoproteins and protein complexes. Journal of Crystal Growth, 122(1-4):273-285. 
Tooley, C. E. S., J. J. Petkowski, T. L. Muratore-Schroeder, J. L. Balsbaugh, J. Shabanowitz, M. Sabat, W. Minor, D. F. Hunt, und I. G. Macara

2010. NRMT is an alpha-N-methyltransferase that methylates RCC1 and retinoblastoma protein. Nature, 466(7310):1125-8.

Tsitsigiannis, D. I. und N. P. Keller

2006. Oxylipins act as determinants of natural product biosynthesis and seed colonization in Aspergillus nidulans. Molecular microbiology, 59(3):882-92.

Vaidya, A. T., C.-H. Chen, J. C. Dunlap, J. J. Loros, und B. R. Crane

2011. Structure of a Light-Activated LOV Protein Dimer That Regulates Transcription. Science signaling, 4(184):ra50.

Vienken, K., M. Scherer, und R. Fischer

2005. The $\mathrm{Zn}(\mathrm{II}) 2 \mathrm{Cys} 6$ putative Aspergillus nidulans transcription factor repressor of sexual development inhibits sexual development under low-carbon conditions and in submersed culture. Genetics, 169(2):619-30.

Voss, S. und A. Skerra

1997. Mutagenesis of a flexible loop in streptavidin leads to higher affinity for the Strep-tag II peptide and improved performance in recombinant protein purification. Protein engineering, 10(8):975-82.

Wallace, A. C., R. A. Laskowski, und J. M. Thornton

1995. LIGPLOT: a program to generate schematic diagrams of protein-ligand interactions. Protein engineering, 8(2):127-34.

Webster, R. H. und A. Sil

2008. Conserved factors Ryp2 and Ryp3 control cell morphology and infectious spore formation in the fungal pathogen Histoplasma capsulatum. Proceedings of the National Academy of Sciences of the United States of America, 105(38):14573-8.

Wiemann, P., D. W. Brown, K. Kleigrewe, J. W. Bok, N. P. Keller, H.-U. Humpf, und B. Tudzynski

2010. FfVel1 and FfLae1, components of a velvet-like complex in Fusarium fujikuroi, affect differentiation, secondary metabolism and virulence. Molecular microbiology, 77(July):972-994.

Winn, M. D., C. C. Ballard, K. D. Cowtan, E. J. Dodson, P. Emsley, P. R. Evans, R. M. Keegan, E. B. Krissinel, A. G. W. Leslie, A. McCoy, S. McNicholas, G. N. Murshudov, N. S. Pannu, E. a. Potterton, H. R. Powell, R. J. Read, A. Vagin, und K. S. Wilson 2011. Overview of the CCP4 suite and current developments. Acta crystallographica. Section D, Biological crystallography, 67(Pt 4):235-42.

Wittmann-Liebold, B. und R. Pannenbecker 1976. Primary structure of protein L33 from the large subunit of the Escherichia coli ribosome. FEBS letters, 68(1):115-8.

Wlodawer, A., M. Li, Z. Dauter, A. Gustchina, K. Uchida, H. Oyama, B. M. Dunn, und K. Oda

2001. Carboxyl proteinase from Pseudomonas defines a novel family of subtilisin-like 


\section{\begin{tabular}{l|l} 
Anhang & LITERATURVERZEICHNIS
\end{tabular}}

enzymes. Nature structural biology, 8(5):442-6.

Zhang, X., Z. Yang, S. I. Khan, J. R. Horton, H. Tamaru, E. U. Selker, und X. Cheng 2003. Structural basis for the product specificity of histone lysine methyltransferases. Molecular cell, 12(1):177-85.

Zhou, P., F. Tian, und Z. Shang 2009. 2D depiction of nonbonding interactions for protein complexes. Journal of computational chemistry, 30(6):940-51.

Zoltowski, B. D., C. Schwerdtfeger, J. Widom, J. J. Loros, A. M. Bilwes, J. C. Dunlap, und B. R. Crane

2007. Conformational switching in the fungal light sensor Vivid. Science (New York, N.Y.), 316(5827):1054-7. 


\section{Abkürzungsverzeichnis}

\begin{tabular}{|c|c|}
\hline${ }^{\circ} \mathrm{C}$ & Grad Celsius \\
\hline$\times g$ & Vielfaches der Erdbeschleunigung \\
\hline$\alpha$ & Alpha \\
\hline$\beta$ & Beta \\
\hline$\gamma$ & Gamma \\
\hline$\mu$ & Präfix, mikro \\
\hline $\mathrm{Abb}$ & Abbildung \\
\hline AflR & Aflatoxin regulator \\
\hline$\AA$ & Ångström $(0,1 \mathrm{~nm})$ \\
\hline Arnt & aromatic hydrocarbon receptor nuclear translocator \\
\hline AS & Aminosäure \\
\hline Bp & Basenpaar \\
\hline brlA & bristle A \\
\hline bzw. & beziehungsweise \\
\hline ccgs & circadian controlled genes \\
\hline Cry-DASH & Cryptochrome-Drosophila, Arabidopsis, Synechocystis, Human \\
\hline CryA & Cryptochrome A \\
\hline $\mathrm{Da}$ & Dalton \\
\hline $\mathrm{ddH}_{2} \mathrm{O}$ & bidestilliertes Wasser \\
\hline DNA & Desoxyribonukleinsäure \\
\hline dNTP & Desoxyribonukleosidtriphosphat \\
\hline EDTA & Ethylendiamintetraessigsäure \\
\hline FAD & Flavin-Adenin-Dinukleotid \\
\hline FOM & Figure of merit \\
\hline FphA & Fungal phytochrom $A$ \\
\hline FRQ & frequency \\
\hline g & Gramm \\
\hline GST & Glutathion-S-Transferase \\
\hline HEPES & 2-(4-(2-Hydroxyethyl)- 1-piperazinyl)-ethansulfonsäure \\
\hline HKRD & histidine kinase related domain \\
\hline HMG & high-mobility group \\
\hline i.d.R. & in der Regel \\
\hline
\end{tabular}




$\begin{array}{ll}\text { IMAC } & \text { immobilized metal ion affinity chromatography } \\ \text { IPTG } & \text { Isopropyl- } \beta \text {-D-isothiogalactosid } \\ \text { k } & \text { Präfix, kilo } \\ \text { KapA } & \text { Karyopherin } A \\ \text { 1 } & \text { Liter } \\ \text { LaeA } & \text { Loss of AflR expression } A \\ \text { LB } & \text { Lysogeny Broth } \\ \text { LOV } & \text { light, oxygen, voltage } \\ \text { LreA/B } & \text { Light response A/B } \\ \text { M } & \text { Molarität } \\ \text { m } & \text { Meter } \\ \text { m } & \text { Präfix, milli } \\ \text { mAu } & \text { Milliabsorptionseinheit } \\ \text { MBP } & \text { Maltosebindeprotein } \\ \text { n } & \text { Präfix, nano } \\ \text { NFkB } & \text { nuclear factor, kappa-light-chain-enhancer, of activated B-cells } \\ \text { nm } & \text { Nanometer } \\ \text { NRPS } & \text { Nicht-ribosomale Proteinsynthese } \\ \text { Nt } & \text { Nukleotide } \\ \text { NTA } & \text { Nitrilotriessigsäure } \\ \text { OD } & \text { Optische Dichte } \\ \text { orlA } & \text { osmotic-remedial lysis A } \\ \text { PAGE } & \text { Polyacrylamid-Gelelektrophorese } \\ \text { PAS } & \text { Per-Arnt-Sim } \\ \text { PCR } & \text { Polymerasekettenreaktion } \\ \text { Per } & \text { period } \\ \text { PEST } & \text { Prolin, Glutaminsäure, Serin, Threonin } \\ \text { Pfr } & \text { Phytochrome far red } \\ \text { Pfu } & \text { Pyrococcus furiosus } \\ \text { PK } & \text { Polyketid } \\ \text { Pr } & \text { Phytochrome red } \\ \text { PRMT } & \text { protein arginine methyltransferase } \\ \text { psiA/B/C } & \text { precocious sex inducer A/B/C } \\ \text { REM } & \text { Raster-Elektronen-Mikroskop } \\ \text { RHD } & \text { Rel-Homologie-Domäne } \\ \text { RNA } & \text { Ribonukleinsäure } \\ \text { RosA } & \text { repressor of sexual development A } \\ \text { rsmA } & \text { remediator of secondary metabolism A } \\ \text { SAM } & \text { S-Adenosyl-Methionin } \\ \text { SDS } & \text { Sodium-dodecylsulfat } \\ & \end{array}$




$\begin{array}{ll}\text { SET } & \text { Su(var)3-9, enhancer of zeste, trithorax } \\ \text { Sim } & \text { single minded } \\ \text { ST } & \text { Sterigmatocystin } \\ \text { TAP } & \text { tandem affinity purification } \\ \text { Taq } & \text { Thermus aquaticus } \\ \text { TEM } & \text { Transmissionselektronenmikroskop } \\ \text { TEMED } & \text { N, N, } \mathrm{N}^{\prime}, \mathrm{N}^{\prime} \text { Tetramethylethylendiamin } \\ \mathrm{T}_{\mathrm{M}} & \text { Schmelztemperatur } \\ \text { tpsA/C } & \text { alpha-trehalose-phosphate synthase A/C } \\ \text { Tris } & \text { Tris(hydroxymethyl)-aminoethan } \\ \mathrm{U} & \text { Unit, Enzymaktivitätseinheit } \\ \text { u.a. } & \text { unter anderen } \\ \mathrm{Upm} & \text { Umdrehungen pro Minute } \\ \mathrm{UV} & \text { Ultraviolett } \\ \text { V } & \text { Volumen } \\ \text { v/v } & \text { Volumenprozent } \\ \text { VeA } & \text { Velvet } A \\ \text { VelB } & \text { Velvet-like protein } B \\ \text { vgl. } & \text { vergleiche } \\ \text { VosA } & \text { Viability of spores } A \\ \text { VVD } & \text { vivid } \\ \text { w/v } & \text { Gewichtsprozent } \\ \text { WC-1/2 } & \text { White collar } 1 / 2 \\ \text { WCC } & \text { White collar complex } \\ \text { WT } & \text { Wildtyp } \\ \text { z.B. } & \text { zum Beispiel } \\ & \end{array}$




\section{Danksagung}

An dieser Stelle sei allen gedankt die zur Erstellung dieser Doktorarbeit im Zeitraum von 2007-2011 in irgendeiner Weise behilflich waren.

Prof. Dr. Ralf Ficner danke ich ganz besonders für die Möglichkeit an (u.a.) diesen überaus spannenden Projekt zu arbeiten, sein großes Interesse hieran sowie Unterstützung. Prof. Dr. Gerhard Braus (und Prof. Dr. Oliver Einsle) danke ich für die Übernahme des Koreferats.

Dr. Achim Dickmanns und Annette Berndt danke ich für einige wichtige Vorabeiten an diesen Projekt. Bei Özgür Bayram und Jennifer Gerke bedanke ich mich für die exzellente Kollaboration an diesen Projekt - ohne die vielen Klone und Insiderinfos wäre es sehr schwer gewesen. An dieser Stelle sei auch Dr. Oliver Valerius und Dr. Bernhard Schmidt für die zahlreichen MS-Analysen gedankt.

Ein riesiges Dankeschön an Piotr Neumann, der mindestens 1001 Fragen zu kristallographischen Problemen beantwortet hat und ebenso viele Jobs für einige MR-Probleme laufen lies.

Bei Stephanie Schell, Andreas Schmitt und Eike Schulz bedanke ich mich für die Aufnahme eines sehr wichtigen Datensatzes, nachdem ich länger als ne' Stunde brauchte.

Bei den Mitgliedern des Helikase/RNA-Labor's Andreas Schmitt sowie Henning Christian bedanke ich mich für die sehr freundliche Arbeitsatmosphäre, viele geteilte Gele und den zahlreichen durchaus wissenschaftlichen Diskussionen. Thomas Monecke, Piotr Neumann und Henning Christian danke ich für die kritische Durchsicht der Arbeit. Akkusativ, Dativ, Komma hin oder her - wenn's das bringt... anscheinend schon.

Kristina Lakomek danke ich für die Hilfe bei der anfänglichen Arbeit mit RNA und beim Design der DNA-Oligos für die Ko-Kristallisation.

Zum Abschluss danke ich ganz herzlich meiner Familie, insbesondere meiner Schwester, die mich in schweren Zeiten begleitet und wesentlich zu meinen Studium beigetragen haben. 